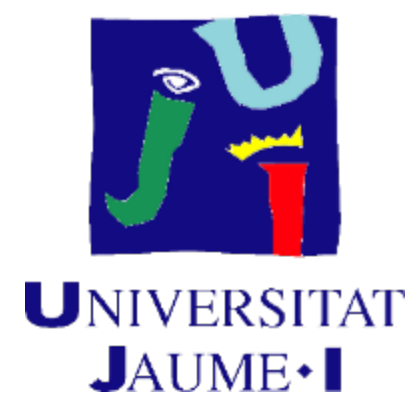

Programa de Doctorado en Estudios Internacionales de Paz Conflicto y Desarrollo

Escuela de Doctorado de la Universitat Jaume I

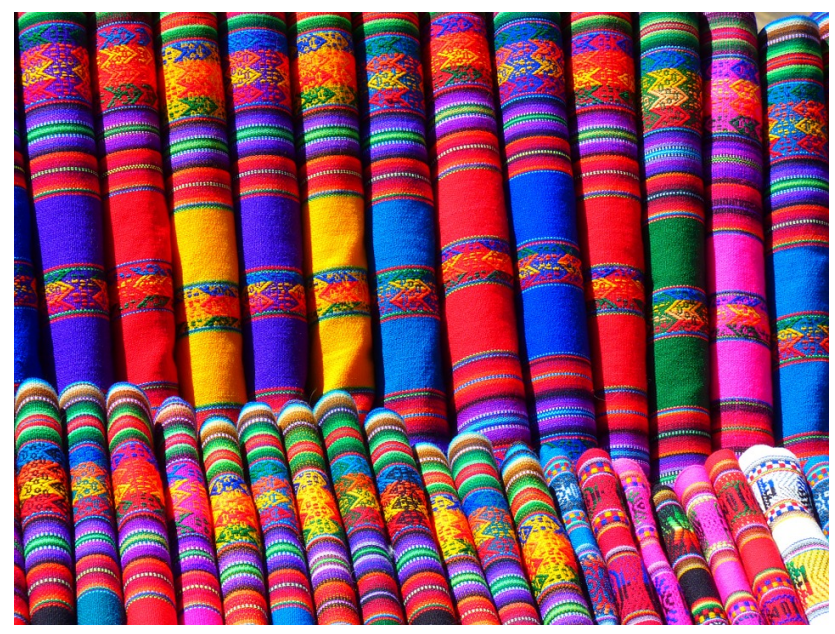

\title{
Una propuesta de construcción de paz desde las resistencias indígenas del sureste mexicano
}

\author{
Autor: \\ Miriam Arely Vázquez Vidal \\ Supervisores: \\ Sidi Omar \\ Sonia Reverter-Bañón
}

Abril 2019 



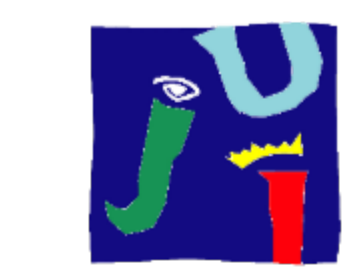

UNIVERSITAT

JAUME•I

Programa de Doctorado en Estudios Internacionales de Paz Conflicto y Desarrollo

Escuela de Doctorado de la Universitat Jaume I

\section{Una propuesta de construcción de paz desde las resistencias indígenas del sureste mexicano}

Memoria presentada por Miriam Arely Vázquez Vidal para optar al grado de doctora por la Universitat Jaume I

Miriam Arely

Vázquez Vidal

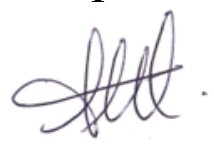

Sidi Omar

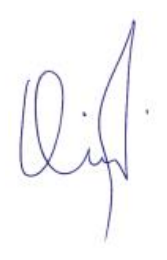

Sonia Reverter-Bañón

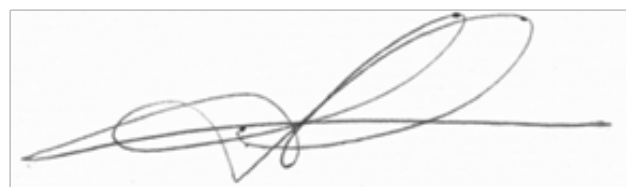

Castellón de la Plana, abril 2019 


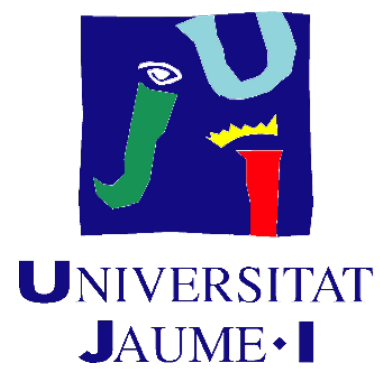

La realización de esta investigación se ha logrado gracias al apoyo del Consejo Nacional de Ciencia y Tecnología del Gobierno de México. 
Todos los seres humanos son mortales, pero para todos los seres humanos la muerte es un accidente y, aun si la conoce y acepta, es una violencia indebida.

Simone de Beauvoir

A Luca, porque vivo con la esperanza de encontrarme contigo algún día. 

Agradecimientos

El desarrollo de esta investigación ha sido posible gracias al apoyo y la confianza de muchas personas que en estas breves palabras quiero agradecer.

En primer lugar, agradezco el apoyo de mis directores Dr. Sidi Omar y Dra. Sonia Reverter-Bañón, muchas gracias por la confianza y libertad que me permitieron encontrar mi camino para escribir esta tesis.

En segundo lugar, a mi compañero de vida Anthony Marc, gracias por ser mi amigo, mi colega, mi revisor y mi mayor crítico, no imagino mi vida sin ti, nada funcionaría, las palabras son insuficientes para agradecer todo lo que significas para mi. A mis hijos, Mateo y Thiago, por retarme cada día a vivir las paces.

A mi madre, Areli Vidal, gracias por confiar siempre en mí, eres el mayor ejemplo de fuerza y bondad, sólo espero algún día regresarte un poco de todo lo que me has dado, este logro es para y por ti.

A mis hermanas: Lisselle, tu fortaleza y claridad han sido mis pilares para alcanzar mis metas, gracias por siempre estar ahí. Carlota, por tu tenacidad para lograr todo lo que te propones, que ha sido mi referente para terminar esta etapa. A Juan Karlos, por no dudar nunca de mí, por apoyarme y entenderme siempre, tu confianza y apoyo son base en mi vida.

A Roberto y Deli, ustedes fueron el mejor regalo de mis pasos por Chiapas, gracias por abrime las puertas de su vida. Estaré eternamente agradecida por todo lo que hicieron por nosotros.

Al Dr. Raymundo de CIDECI-UNITierra, gracias por la confianza, la paciencia, por entenderme y guiarme, gracias a usted esta tesis es posible. Su congruencia, fuerza y entrega son mi modelo como trabajadora para la paz.

A la Cátedra UNESCO de Filosofía para la Paz, especialmente a Adela y Sofía, ustedes son el motor y corazón del Máster y el Doctorado, gracias por todo el esfuerzo que ponen cada día para que nuestros sueños de paz puedan realizarse.

Por último, quiero agradecer a la familia que mi vida en Castellón me ha regalado. Gracias Natacha por nuestras eternas charlas, te admiro y agradezco tenerte en mi vida, gracias Guillaume por el todo el apoyo, gracias Esther por esa paz que me has enseñado, gracias Jordi Prieto por tu alegría, gracias Kavita por tu fuerza para enfrentar la vida, gracias Blandine por tu capacidad de sobreponerte a las dificultades, gracias Jordi Renau por todos tus consejos y gracias Francis por tu entereza.

A mis mexicanos Eva, Haydee y Abraham, gracias por enseñarme que los necesitaba en mi vida para terminar esta etapa y construir la siguiente con ustedes.

Y gracias a todas y todos con los que durante estos años coincidimos y cuyas experiencias dotaron de sentido esta investigación. Mi sueño es que algún día quien abra este trabajo pueda encontrar en mis palabras fuerza para seguir trabajando por un mundo donde las paces sean infinitas y las violencias innecesarias. 

Índice

\section{Resumen / Abstract}

$>$ Introducción general: Repensando la historia, construyendo la paz .......... 1

$>$ Capítulo I: Comprendiendo México .................................. 9

○ México en Cifras ............................................... 12

- Agustina Joaquín Toribio ..................................... 19

- Antonio López Velasco ........................................ 25

○ Repensando la historia de México ................................... 30

- La Conquista ............................................ 31

- Colonialismo interno: independencia y revolución ................ 35

- El nacionalismo de independencia y la creación del Estado Soberano ........................................... 36

- El nacionalismo posrevolucionario, la construcción de la nación por el Estado ................................ 46

- El nacionalismo en la era del multiculturalismo y el reconocimiento de la diversidad .....................6 61

○ Conclusiones ...................................................... 65

Capítulo II: Panorama general entorno a la paz ....................... 69

○ Aproximaciones a la paz ......................................... 70

○ Aproximaciones a la violencia ..................................... 82

- El concepto de política en Hannah Arendt ............................... 90

○ Conclusiones ................................................... 94

Capitulo III: De marcos teóricos a puentes de entendimiento ................ 97

- De la Filosofía Clásica occidental a la Filosofía para la Paz............... 98

- Del asombro de la realidad a la construcción de una episteme dominante ................................................... 101

- La teoría de la esclavitud aristotélica: justificando la Conquista de América ................................................ 107

- Una perspectiva diferente: la Filosofía para hacer las paces ...... 115

- Aportes para seguir dialogando entorno a la Filosofía para hacer las Paces ......................................... 124

○ Pensamiento decolonial ........................................ 129

- Diferencias con el pensamiento postcolonial .................. 130

- La decolonialidad: un pensamiento en resistencia .............. 134

- Giro epistemológico decolonial ................................. 148

- Filosofía de la liberación ........................................ 162 
- Construyendo puentes: de regreso a la filosofía occidental con lentes de pensamiento decolonial ......................................... 169

○ Conclusiones................................................... 181

Capítulo IV: Análisis filosófico de la historia del EZLN ................... 184

○ La vida en Chiapas ............................................... 186

○ ¿Quiénes son los zapatistas? ..................................... 197

○ Conclusiones ..................................................... 218

Capítulo V: Una propuesta de construcción de paz desde las resistencias indígenas: una mirada al pluriverso y la comunalidad ..................... 221

- El universo más allá de la modernidad ............................. 222

- La filosofía para la paz desde la ontología relacional .................. 236

- La comunalidad una propuesta de construcción de paz vivencial ........ 244

○ Conclusiones .................................................. 249

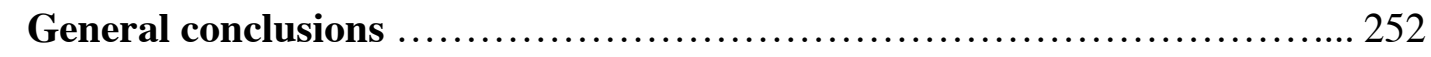

Bibliografía ....................................................... 264 


\section{Resumen}

Esta tesis doctoral presenta una propuesta de construcción de paz en términos filosóficos, basada en un análisis historiográfico de México que identifica los paradigmas de la violencia en los que está fincada la sociedad mexicana, así como un análisis de los marcos interpretativos sobre paz y violencia que existen en el país. Todo esto con la mirada puesta en desarrollar una base filosófica para construir la paz, entendiéndola como un proceso de construcción comunal fincado en la ontología pluriversal que demanda la construcción de un puente de entendimiento entre la filosofía para hacer las paces y el pensamiento decolonial. De igual manera, se presenta la resistencia indígena más importante del país, el zapatismo, como ejemplo de ese proceso de paz que busca la creación de un mundo donde quepan muchos mundos.

Palabras clave: pensamiento decolonial, zapatismo, filosofía para hacer las paces, pluriverso, México, violencia. 


\begin{abstract}
This doctoral thesis presents a proposal for the construction of peace in philosophical terms, based on a historiographical analysis of Mexico that identifies the paradigms of violence on which the Mexican society is based, as well as an analysis of the interpretative frameworks on peace and violence that exist in the country. All this with the aim of developing a philosophical basis to build peace, understanding it as a communal construction process rooted in the pluriversal ontology that demands the construction of a bridge of understanding between philosophy for peace and decolonial thought. In the same way, the most important indigenous resistance in the country is presented, the Zapatist movement, as an example of that peace process that seeks the creation of a world where many worlds can fit.
\end{abstract}

Key words: decolonial thought, Zapatist movement, philosophy for peace, pluriverse, Mexico, violence. 


\section{Introducción general: Repensando la historia, construyendo la paz}

Comenzar toda investigación académica suele ser bastante complicado y más aún cuando el objeto de estudio es complejo, dinámico y no responde a una sola visión de la realidad; ese es el caso del presente trabajo.

El objeto de estudio es México, un país con una historia rica, pero muy compleja, una sociedad alegre y amigable, pero con índices de violencia alarmantes que lo sitúan en el lugar $142^{\circ}$ de $163^{\circ}$ de países en el Índice Global de Paz ${ }^{1}$. Tiene un esquema de desigualdad muy grave $^{2}$, y si no fuera poco, en 2017 se han cumplido de 11 años de "guerra ${ }^{3}$ contra el narcotráfico" que ha dejado aproximadamente 175000 muertos $^{4}$ y más de 30000 desaparecidos 5

Además del objeto de estudio, tengo un objetivo, y este es saber si existe alguna propuesta política de construcción de paz en el país que sea capaz de dotar a nuestra sociedad de los vínculos necesarios para juntos construir una vida más armónica. Y fue así como hace unos años me encontré con el zapatismo y su propuesta política de autonomía y resistencia, que sin lugar a dudas ha marcado todo mi actuar.

\footnotetext{
${ }^{1}$ El Índice de Paz Global (Global Peace Index) es un indicador que mide el nivel de paz y la ausencia de violencia de un país o región. Lo elaboran y publican desde el año 2007 el Institute for Economics and Peace junto a varios expertos de institutos para la paz y think tanks y el Centre for Peace and Conflict Studies, de la Universidad de Sydney, con datos procesados por la Unidad de Inteligencia del semanario británico The Economist. Para esta investigación se ha utiilizado la versión en línea: https://www.datosmacro.com/demografia/indice-paz-global (31 de diciembre de 2017).

${ }^{2}$ Basta mencionar que el salario medio en México es el más bajo en todo el mundo acorde al Global Peace Index también: https://www.datosmacro.com/paises/mexico (31 de diciembre de 2017).

${ }^{3}$ Recomiendo el especial informativo del periódico español El País sobre 11 años de la guerra, pues de manera simple muestra en cifras el gran fracaso de la de Guerra iniciada por Felipe Calderón y perpetuada por el gobierno de Enrique Peña Nieto (https:/elpais.com/especiales/2016/guerranarcotrafico-mexico/\#0)

${ }^{4}$ Fuente: Secretariado Ejecutivo del Sistema Nacional de Seguridad Pública.

${ }^{5}$ Comisión Nacional de Derechos Humanos http://informe.cndh.org.mx/menu.aspx?id=10036 (31 de diciembre de 2017)
} 
El enfoque de la investigación no pretende dar una visión exhaustiva de la realidad del país, sino una imagen que pueda hacer ver a lectores y lectoras que la violencia actual tiene una razón histórica y epistémica, además de ser el resultado de años de crecimiento de la pobreza y la desigualdad.

Ahora, la metodología empleada es el análisis filosófico pues concibo la filosofía del mismo modo que el gran pensador mexicano Don Luis Villoro que en su discurso de ingreso al Colegio Nacional en 1978 afirma:

(...) la filosofía ha sido vista a menudo como un ejercicio corrosivo del poder. Desde Grecia, el filósofo genuino aparece como un personaje inconforme, cínico o extravagante, o bien desdeñoso de la cosa pública, distante y distinto, "escondido en un rincón murmurando con tres o cuatro jovenzuelos" (Gorgias, 485d). Con frecuencia es tildado de corruptor, de disolvente, de introductor de peligrosas novedades. A lo largo de la historia, casi todo filósofo renovador ha merecido, en algún momento, alguno de estos epítetos: disidente, negador de lo establecido, perturbador de las conciencias, sacrílego o hereje, anárquico o libertino, reacio e independiente, cuando no francamente revolucionario. En efecto, la actividad filosófica auténtica, la que no se limita a reiterar pensamientos establecidos, no puede menos de ejercerse en libertad de toda sujeción a las creencias aceptadas por la comunidad: es un pensamiento de liberación. (... $)^{6}$

En estas palabras no sólo encuentro la motivación necesaria para hacer filosofía, sino también la fuerza para hablar de paz. Me niego, tal y como nos invita Villoro, a comprender la historia de México como violenta.

Ciertamente, no cierro los ojos ante lo hechos de violencia que acontecen en el país todos los días y que motivaron en gran medida esta investigación, pero me niego a creer que ese es el camino y que no hay nada que hacer más que aceptarlo. Desde mi posición como ciudadana y filósofa para la paz me niego a normalizar la violencia, me niego a sólo decir "espero que no me pase a mi".

\footnotetext{
${ }^{6}$ Discurso de ingreso al Colegio Nacional en 1978 en la Ciudad de México
} 
Cada día de los últimos años he dedicado mis investigaciones a entender qué pasó. ¿Cómo llegamos aquí? ¿Es nuestra historia una historia de violencia? ¿Estamos destinados a vivir así? ¿Podemos vivir en paz? ¿Conocemos siquiera el significado de la paz? ¿Somos capaces de consensuar una definición? Y si lo logramos podemos preguntar, ¿es posible la paz en México?

Las respuestas requieren necesariamente de un nuevo análisis de la historia del país y la construcción de un puente de entendimiento de las distintas corrientes de pensamiento que fundaron el país. Es momento de desarrollar una perspectiva distinta de lo que hasta ahora han contado que hemos sido y somos. ¿Por qué? Utilizo nuevamente palabras de Villoro:

[...] la filosofía satisface una necesidad de autenticidad y libertad. (Y) ¿No está ahora más viva que nunca esa necesidad? ¿No requerimos con urgencia aprender a asombrarnos de nuevo ante las opiniones que por "obvias", se nos quieren inculcar, aprender a poner en cuestión de nuevo todos los mitos con que nos han adormecido, recuperar la presión y veracidad de los conceptos bajo los disfraces gastados de los discursos en uso? (Villoro, 1978)

Así, esta tesis tiene como objetivo principal el desarrollo de una propuesta de construcción de paz en términos filosóficos, basada en un análisis historiográfico de México que permita identificar los paradigmas de la violencia en los que está fincada la sociedad mexicana ${ }^{7}$, así como un análisis de los marcos interpretativos sobre paz y violencia que existen en México, todo esto con la mirada puesta en desarrollar una base filosófica para construir la paz en el país que supere esos principios de violencia y que no es otra cosa más que mostrar como la comprensión de la paz como un proceso de construcción comunal fincado en la ontología pluriversal, puede acercarnos a una realidad más armónica y justa.

\footnotetext{
${ }^{7}$ No exclusivamente, incluso puede considerarse un análisis de los países colonizados. Sin embargo, para los objetivos de esta investigación sólo se hablará de México.
} 
En el camino, esta investigación tiene dos metas muy claras: la primera pretende relevar y analizar el pensamiento decolonial y sus posibles diálogos con la Filosofía para la paz tomando como eje el movimiento zapatista como experiencia de transformación pacífica de conflictos. Cabe aclarar que respecto del movimiento zapatista no busca aportar nuevos conocimientos, sino más bien ofrecer una nueva perspectiva para entender el pensamiento de resistencia y algunos antecedentes y condiciones contemporáneas del conflicto.

El pensamiento decolonial, la filosofía de la liberación y la filosofía para la paz son el marco teórico de esta tesis pues mediante su denuncia al pensamiento único de la modernidad, la marginación y el empobrecimiento de algunas regiones del continente, se unen en la comprensión de la violencia como herramienta y vía de acción frente a un conflicto. En resumen, reconocen la violencia como herramienta de dominación y ya no como elemento natural, y es así cómo se comprenderá a lo largo de esta investigación.

La pertinencia y relevancia de la tesis se basa en considerar que desde la Filosofía para la paz se ha propuesto como línea de trabajo la integración de los estudios decoloniales. El peso de la argumentación en los distintos capítulos trabaja en la dirección de establecer una conexión entre el pensamiento filosófico europeo y las concepciones de ontologías latinoamericanas, además de mostrar una conexión entre el pensamiento decolonial y las experiencias como los zapatistas.

La segunda meta es ofrecer una perspectiva nueva de la resistencia zapatista que supera el uso de la violencia directa, para posicionarse como paradigma de la lucha noviolenta en la actualidad gracias a la reivindicación de su concepción de paz $^{8}$ y desarrollo.

\footnotetext{
${ }^{8}$ La palabra paz dentro de la resistencia zapatista se entiende como libertad, justicia y dignidad. Cabe mencionar que esta concepción emerge de la necesidad de liberación frente al horror colonial, como se detalló en el análisis historiográfico, pero no limitan el concepto pues ellos no buscan hacerlo
} 
Ahora, en el primer capítulo se ofrece una mirada de lo que significa vivir en México desde las cifras hasta las experiencias cotidianas con la violencia directa, estructural y cultural. Además, y como aporte central en la investigación, en este capítulo se identifican los seis principios de la violencia a través de un análisis de la historia de México ${ }^{9}$.

En el segundo capítulo se hace un breve análisis de los tres conceptos fundamentales para la investigación: paz, violencia y política. A través de un análisis teórico sobre ellos se propone comprender, por un lado, el marco que sustenta la visión de paz de esta tesis y por otro las afirmaciones sobre la violencia estructural y los paradigmas en los que está cimentada la sociedad mexicana.

El tercer capítulo carga con gran parte del peso teórico de esta investigación pues es aquí donde se tiene como objetivo la creación de un puente de entendimiento entre las diversas corrientes de pensamiento. Es justamente aquí donde se sientan las bases de esa propuesta de construcción de paz, objetivo principal de esta investigación.

El cuarto capítulo se centra en la realidad zapatista pues como se ha mencionado en las primeras líneas, ésta nos sirve como ejemplo de una lucha noviolenta decolonial pero que está en constante diálogo con el pensamiento europeo. Como se analiza, su propuesta ética y

universal. Ellos entienden la paz de esta forma para ellos, pero comprenden que hay otros mundos y otros escenarios en los que no es así, incluso su propia definición está en constante movimiento, pues la libertad, la justicia y la dignidad no son metas que se alcanzan sino ideales que regulan la acción.

${ }^{9}$ Los -cidios o paradigmas de la violencia son el resultado de un análisis que comenzó en Encuentro Latinoamericano: Con la Encíclica "Laudato Si" defendemos los derechos de la tierra, el territorio y los bosques el 13 y 14 de febrero de 2016 en San Cristóbal de las Casas, Chiapas durante la ponencia "El aporte de los pueblos indígenas para la conservación de la creación de Dios y los retos futuro" del Dr. Juan José Tamayo, teólogo de la Universidad Alfonso III, donde identificó los 6 -cidios que se presentan en esta investigación. Sin embargo, estos -cidios los he tomado como referentes para analizar la historia de México, además de principios de la violencia cultural profundizando así el estudio de los mismos y llevándolos más allá de la propuesta oral del Dr. Tamayo. 
ontológica no responde a la lógica ni al mercado, ni a los valores europeos, aunque no los deja de lado, los tiene enfrente y dialoga constantemente con ellos. Además, son un ejemplo de construcción de paz pues han logrado la consolidación de una forma de ser y existir que para muchos en el mundo es imposible.

Este capítulo analiza brevemente su historia que no ha sido sencilla y está plagada de violencias, pero lo hace desde la filosofía para la paz (buscando los elementos que permitan superar la violencia) de su historia.

También en este capítulo se alcanza una de las metas planteadas, y es dar una visión distinta del movimiento zapatista, desde una lente de paz y noviolencia.

Finalmente, el quinto capítulo pretender recoger la fundamentación ontológica de las resistencias indígenas y presentarla como una propuesta de construcción de paz que transforma por completo la cosmovisión bajo la cual el pensamiento europeo está fincado. Este es quizá uno de los capítulos más complejos pues se construye una conexión entre la propuesta pluriversal de Arturo Escobar y Mario Blaser y el pensamiento europeo de Hannah Arendt y la filosofía para la paz de Vicent Martínez Guzmán.

También se presenta una breve mención al concepto de comunalidad desde el pensamiento de Gustavo Esteva, Arturo Guerrero Osorio y Jaime Martínez Luna, asumiendo el reto académico que dicho concepto presenta.

Para terminar, debe quedar claro que la presente investigación es la tercera parte de un proyecto académico, intelectual y activista que vengo realizando desde hace 12 años (2007).

En la primera investigación El origen del mal: un estudio sobre los gobiernos totalitarios (2011), se hizo un análisis sobre el mal de acuerdo a la obra Eichmann en Jerusalén: un estudio sobre la banalidad del mal (1963) y La vida del espiritu (1978), de Hannah Arendt, ambas obras cruciales y fundamentales de la filósofa alemana. En esta 
investigación se concluyó que el mal es la violencia y la injusticia y su causa es la incapacidad de pensar (reflexionar) (Vázquez, 2011), es así que se puede afirmar que para erradicar el mal de las sociedades es necesario el diálogo y la búsqueda del sentido de la vida en comunidad. Sin embargo, esta investigación estaba bastante limitada a la teoría y a los discursos filosóficos en los que muchas veces la realidad queda en segundo plano.

Esta fue la razón principal por la que en la segunda investigación: El origen de la violencia: un estudio sobre el poder como dominación al poder como consenso (2013), se hizo un análisis sobre la violencia y más específicamente sobre su causa originaria y las formas en que aparece en el mundo (directa, estructural y cultural), de tal suerte que se pueda comprender cómo eliminarla o inutilizarla en el mundo. Para no caer en el mismo error que la investigación pasada y hablar sólo en términos teóricos, se hizo un análisis de la resistencia indígena más emblemática y fuerte de las últimas décadas en México, el zapatismo, pero desde un repaso de parte de la literatura sobre ellos.

A través de ella y un estudio sobre los conceptos de poder y violencia en Arendt, se concluyó que el origen de la violencia descansa en el poder como dominación ya que permite dotar a la violencia de toda su potencialidad como herramienta. Pero también se ha comprendido que, si hay una transformación del concepto de poder en el que se añadan las características encontradas en la eliminación del mal, es decir, diálogo y consenso en comunidad, se puede erradicar la violencia, simplemente porque ya no es necesaria.

Otros elementos se presentaron como fundamentales de la resistencia zapatista: la búsqueda de la libertad, la construcción de justicia y la experiencia de la dignidad. Fue especialmente el concepto de dignidad que transformó por completo la comprensión del uso de la violencia, y la justicia fue la que otorgó los requisitos mínimos para la lucha noviolenta, pues dejó de entenderse como una vía de venganza o dominación para comprenderse como 
un elemento básico de la reconciliación. Como ejemplo de esto se mencionó la lucha de las mujeres zapatistas.

Y finalmente llegamos a esta investigación donde se analiza la violencia desde la realidad mexicana, tratando de comprender a través de las estadísticas y la historia, los principios que comprenden la violencia cultural del país, así como la necesidad de construir un puente de entendimiento que nos permita superar la dominación ontológica y epistémica y de tal suerte establecer las bases para una propuesta de construcción de paz, entendiendo ésta siempre como un proceso real, existencial y por lo tanto relacional.

Por último, a partir de ahora, utilizaré tanto la primera persona del singular, como la primera persona del plural para escribir este texto, el primer caso para mostrar propuestas originales y la segunda para propuestas que creo comparten los autores que estaré trabajando. 


\section{Capítulo I: Comprendiendo México}

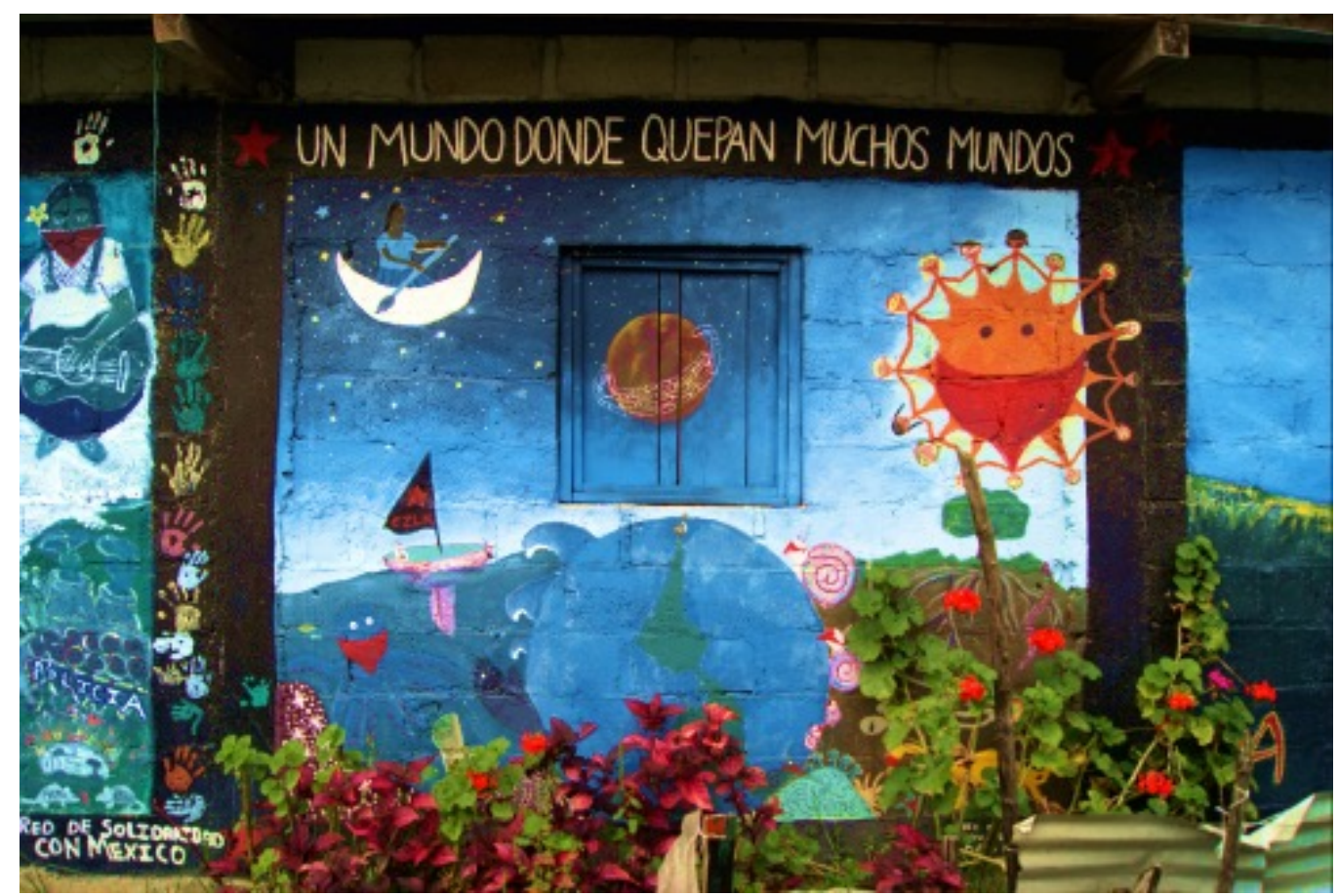

Quizá no hay nada más sorprendente en este mundo nuestro que la casi infinita diversidad de sus apariencias, el enorme valor como espectáculo de sus vistas, sonidos y olores, algo a lo que casi nunca se refieren los filósofos. -Hannah Arendt

Vivir en México significa comprender la realidad en opuestos, a primera vista no hay espacio para puntos medios, eres rico o pobre, eres fresa o naco ${ }^{10}$, indio o mestizo, culto o ignorante, activista o indiferente, víctima o victimario. Según mi experiencia, las relaciones sociales están marcadas por estereotipos que han sido alimentados por un aparato gubernamental y mediático para olvidarnos de nuestro pasado comunitario.

\footnotetext{
${ }^{10}$ En términos coloquiales, naco se define como una persona sin educación, que pertenece a una clase socioeconómica baja y generalmente está vinculado al tono de la piel, entre más moreno más naco. Incluso la Real Academia de la Lengua Española lo utiliza como sinónimo de indio/indígena. Por otro lado, fresa, hace referencia a una persona de clase social alta, que tiene una particular forma de vestir, hablar y actuar. Su equivalente en España sería pijo.
} 
Como intentaré mostrar a lo largo de este capítulo, seguimos siendo fieles a la victoria colonial-capitalista del individualismo ilustrado que ha tenido como consecuencia la descomposición del tejido social desde la raíz, haciendo casi imposible el resurgimiento de una sociedad unida para luchar juntos contra la violencia directa, cultural y estructural que afecta el país.

Pero, ¿qué es eso del individualismo ilustrado? Según la definición de la Real Academia de la Lengua, individualismo es: «tendencia filosófica que defiende la autonomía y supremacía de los derechos del individuo frente a los de la sociedad y el Estado» (Real Academia de la Lengua; 2014; 88) otra acepción dice que «es la tendencia a pensar y obrar con independencia de los demás, sin sujetarse a la normas generales» (Real Academia de la Lengua; 2014:89) En resumen, es posible decir que el individualismo es pensar en el yo sin el tú y mucho menos sin el nosotros y nosotras.

No es difícil ver en la era de la modernización y el auge del consumo, frases como: "ámate a ti mismo para poder amar a los demás", "porque tú lo vales”, etc. Por más triviales que parezcan estas frases, son parte del aparato donde lo importante es tener individuos y no personas, individuos y no comunidad, pues sólo a través de ellos es posible vivir en los opuestos y legitimar las desigualdades, tal y como se verá desde la perspectiva de los estudios pluriversales.

Es muy fácil comprender la riqueza y pobreza extrema desde estos puntos, sobre todo en la realidad latinoamericana: si mi educación se basa en tratar de mejorar MI situación, si me tengo que preocupar por estar bien YO, no importa que el de abajo no tenga nada para que lo pueda tener yo. El sistema nos ha enseñado que mientras nosotros tengamos nuestras necesidades básicas (y especialmente las que no son básicas) cubiertas, lo que pase a nuestro alrededor no nos afecta. Es la ley del más fuerte racionalizada y, más aún, politizada al estilo 
del Príncipe de Maquiavelo, es decir, la política de dominación descansa sobre la legitimación del individualismo frente a la comunidad (Escobar; 2015:113).

Durante muchos años, acorde con la educación que he recibido, pensaba que la raíz de esta violencia como dominación era la escisión filosófica provocada por el yo cartesiano, y a pesar de que aún creo que podemos encontrar ciertas raíces ahí, la esencia de esta violencia es la supremacía de la sustancia sobre la relación dentro de la filosofía aristotélica y llevada hasta sus últimas consecuencias dentro del pensamiento kantiano especialmente en sus aportes a la Ilustración.

Para Kant ${ }^{11}$, alcanzar la mayoría de edad y la autonomía, es posible si aprendes a pensar por ti mismo, es decir, si aprendes a salirte de los esquemas planteados por los demás, y aunque esto es necesario en el quehacer filosófico y el desarrollo del pensamiento crítico, el problema radica en que se fundamenta en el desarrollo de una razón solitaria que parece dotar de sentido a la realidad, elimina del razonamiento el diálogo con los demás, base del tejido social. Es así que se podría decir que el individualismo ilustrado es aquella legitimación filosófica, política y social de la eliminación de la colectividad, el diálogo y la reflexión provocada por los Otros (Escobar, 2015; Blaser, 2015).

Bajo esta mirada, México (y muchos otros países colonizados también) es la gran victoria del pensamiento ilustrado, pero con la carga de la victimización y la desigualdad colonial; es decir, somos lo suficientemente individualistas para negar el diálogo, pero estamos lo suficientemente humillados como para no confiar siquiera en nuestros

\footnotetext{
${ }^{11}$ En el segundo capítulo de esta investigación ahondaremos en la crítica a la modernidad desde el pensamiento decolonial y la filosofía para la paz, por ahora sólo me he limitado a dar una visión general de tal suerte que podamos inciar el proceso de decolonización de la historia y las cifras del México.
} 
pensamientos, es así que, los discursos bien estudiados y estructurados de los medios masivos de comunicación a favor de la maquinaria del sistema, entran sin ningún filtro. Somos el receptor perfecto de las narrativas coloniales y neocoloniales, pues no confiamos ni en los demás ni en nosotros mismos.

Estas afirmaciones son parte del resultado del viaje que he emprendido desde hace más de 5 años para comprender la situación de mi país, este análisis me ha llevado a repasar la historia, las cifras oficiales en cuanto a economía, marginación y seguridad, además de revisar las propuestas de conocimiento que a mi juicio más han condicionado al país.

En este primer capítulo haré un recorrido histórico, no de modo exhaustivo, sino desde una reflexión filosófica, sobre los momentos más importantes, a mi juicio, de la historia del país: la conquista, la época colonial, la formación de una nación con la independencia, la revolución mexicana y los movimientos antisistema del siglo $\mathrm{XX}$, y en cada uno de estos, la participación activa y pasiva de las comunidades indígenas o pueblos originarios. Es verdad que la limitación a estas épocas históricas puede estar a debate, aunque espero que a lo largo de este capítulo se entienda la razón de la elección de hechos históricos.

Antes de abordar la historia haré un breve análisis de algunas de las cifras que muestran la realidad de México: los índices de pobreza, desigualdad, marginación y violencia. El objetivo será mostrar la pertinencia y más aún, la urgencia de investigaciones que estén comprometidas con la transformación de la realidad actual de México.

\section{México en cifras}

México es un país con 119530753 habitantes según cifras oficiales (Instituto Nacional de Estadística y Geografía INEGI) en un territorio de 1964375 kilómetros cuadrados. Limita al norte con Estados Unidos de América y al Sur con Guatemala y Belice. Sus fronteras, son 
un reflejo claro de sus anhelos y contradicciones, por un lado, la colonial necesidad de pertenecer al "mundo desarrollado" y por el otro su ya pertenencia a un mundo indígena y latinoamericano; un mestizo deseando ser criollo en una familia indígena.

En México se hablan (oficialmente) 67 lenguas, incluido el español que es la lengua común de comunicación en prácticamente todo el territorio. Es además una república federal dividida en 32 entidades.

Es muy interesante ver cómo la distribución de la riqueza en el país responde igual a los patrones marcados por el sistema internacional, un norte más rico que el sur en cuanto a desarrollo industrial se refiere, mientras que el sur es muy rico en cuanto a recursos naturales se refiere, pero con una población con alarmantes índices de pobreza.

En $2016^{12}$ el número de personas en situación de pobreza era de 53.4 millones, que representan el 43\% de la población y las personas en situación de pobreza extrema eran 9.4 millones, un 7,6\% de la población. Bajos los fríos números, se empieza a vislumbrar la grave realidad que muchos enfrentan, pero considero que se debe ahondar un poco más en cuanto a pobreza se refiere, ya que es quizá una de las causas más visibles que tenemos de la violencia directa que se ha desatado en el país en las últimas décadas.

Acorde a la investigación realizada por Miguel del Castillo Negrete Rovira, de la Comisión Económica para América Latina y el Caribe (CEPAL), La distribución y desigualdad de los activos financieros y no financieros en México, el país ocupa el número 15 en función de su Producto Interno Bruto, ubicándolo como una de las economías más

\footnotetext{
${ }^{12}$ Toda la información sobre estadística ha sido tomada del estudio presentado por Consejo Nacional de la Política de Desarrollo Social (CONEVAL con base en la información proporcionada por el Instituto Nacional de Estadística y Geografía sobre la evolución de la pobreza de 2010 - 2016 el 30 de agosto de 2017 en la Ciudad de México. Para más información confrontar con el Comunicado de prensa del CONEVAL número 09.
} 
fuertes en el mundo (incluso en cuanto a paridad de poder de compra, México se ubica en el 11 lugar, cuatro lugares por encima de España, por ejemplo), sin embargo cuando confrontamos con la cifras de pobreza en el país, la realidad es muy distinta y esto es gracias al gran lastre de la desigualdad. Según Negrete Rovira:

En 2014, la riqueza total del país ascendió a 76,7 billones de pesos, es decir, cada habitante tendría en promedio 640000 pesos en bienes y activos financieros. Aunque, ciertamente, no toda la riqueza pertenece a las familias. El gobierno administra el 23\% de los activos, las empresas privadas el 19\%, las empresas públicas el 9\%, el resto del mundo posee $7 \%$ y las instituciones financieras el 5\%. No obstante, las familias se llevan la mayor proporción: $37 \%$, es decir, 28 billones de pesos. En promedio cada hogar tendría, si se distribuyera este monto de manera equitativa, 900000 pesos en activos físicos (casas, terrenos, automóviles y diversos bienes del hogar), y financieros (dinero e inversiones financieras), monto que sería más que suficiente para que las personas tuvieran una vida holgada: cerca de 400000 pesos por adulto, en promedio ${ }^{13}$. (2017:46)

El problema, tal y como ya se mencionó, no es la riqueza que tiene el país sino la distribución, de acuerdo a este mismo estudio: «dos terceras partes de la riqueza están en manos del 10\% más rico del país y el $1 \%$ de los muy ricos acaparan más de un tercio. Por ello, el coeficiente de Gini es de $0,79^{14}$. La repartición es todavía más desigual en los activos financieros: el $80 \%$ es propiedad del 10\% más rico.» (Negrete Rovira, 2017:46)

${ }^{13}$ Énfasis mío, para mostrar que por lo menos 9.4 millones de personas en el país viven con menos de un dólar al día.

${ }^{14}$ Acorde al CONEVAL, uno de los indicadores de cohesión social es el coeficiente de Gini que mide la desigualdad de los ingresos de la población. Este indicador se estima a partir del ingreso corriente total per cápita de los hogares. Según el estudio presentado por CONEVAL en agosto de 2017, el Gini para México en 2016 fue de 0,498 (entre más cercano es a uno mayor es la desigualdad en la distribución del ingreso), pero el estudio de Negrete Rovira casi duplica situándolo en 0,79 . A este respecto se debe mencionar que INEGI en los últimos años (durante el sexenio de Enrique Peña Nieto) ha sido duramente criticado por manipular las cifras de la pobreza y desarrollo, al cambiar su metodología para medir históricamente la pobreza del país, provocando incluso en 2016 que el CONEVAL no publicará su estudio este año. Las cifras que se utilizan en esta investigación son las presentadas en 2017. 
La desigualdad está marcada también por las carencias que la población tiene en los servicios de salud, vivienda o educación, así el 72\% de la población (86 millones de personas) carecen de algunas de estos, mientras que el 22\% (23 millones) carecen de las tres. Además, el $17 \%$ de la población tiene un ingreso inferior a la línea de bienestar mínimo ${ }^{15}$, y el 50\% (62 millones) tiene un ingreso inferior a la línea de bienestar.

Un dato que refleja una de las causas de la pobreza y la desigualdad es el salario interprofesional mínimo en contraste con el precio del valor de la canasta alimentaria y no alimentaria en México, tanto en las zonas urbanas como rurales.

En México la canasta alimentaria cuenta con aproximadamente 82 productos y cuesta en zonas urbanas 1475 pesos (63 euros aproximadamente) y zonas rurales 1052 pesos (45 euros), cuando unimos las dos canastas (la canasta no alimentaria incluye transporte, higiene personal, vivienda, menaje, salud, comunicación, vestimenta y entretenimiento) que son el límite de bienestar, los costos quedan 2959,88 pesos (126 euros) para zonas urbanas y 1 914,76 pesos (81 euros) para zonas rurales. El salario mínimo interprofesional en México es de 2080 pesos mensuales por ocho horas de trabajo (89 euros) que lo ubican en el lugar número 78 de 96 países en el mundo acorde al índice de Paz Global.

Así, podemos concluir que la pobreza en México es un problema estructural, un problema de las políticas públicas y la actuación gubernamental, además de una consecuencia real del sistema capitalista como se analizará en el segundo capítulo. Si un sueldo no garantiza por lo menos la línea de bienestar, parece que la pobreza y la desigualdad no son un problema

\footnotetext{
${ }^{15}$ El Bienestar mínimo equivale al valor de la canasta alimentaria por persona por mes y la línea de bienestar equivale a la canasta alimentaria más la no alimentaria por persona por mes.
} 
que le interese al estado resolver. Además, ratifica la postura que establece que los pobres son necesarios para que existan ese $1 \%$ que tiene dos terceras partes de la riqueza del país.

Con estas cifras en la mente, me pregunto si realmente podemos hablar de paz en México, si podemos transformar la realidad del país cuando las estructuras de opresión, dominación están tan arraigadas. México es un mundo clasista y racista que cada día se olvida de sus orígenes comunales para adoptar los ideales neoliberales, de tal suerte que la pobreza aparezca como algo irremediable, o mejor aún, como algo "normal" para los "morenitos", para los "indios", así lo muestran una vez más las cifras: la población hablante de lengua indígena en situación de pobreza es del 77,6\%, mientras que la población no hablante de lengua indígena es del 41\% entre 2014 y 2016. Más de tres cuartas partes de la población indígena del país vive en pobreza, y de ahí casi la mitad en pobreza extrema (34,8\%).

Las cifras son desoladoras, pero cuando les ponemos rostros, se vuelven intolerables, así sucede con un libro devastador publicado en 2016 por Salvador Frausto, Los doce mexicanos más pobres, en la que un grupo de artistas y periodistas recorrieron el territorio mexicano para hacerle frente a la famosa lista Forbes de las personas más ricas del mundo y presentar la vida de algunas de las personas más pobres de México.

El resultado es un libro excepcional que ha servido como campaña de concientización sobre la desigualdad y la pobreza, apoyada por OXFAM México, que muestra la vida de algunas de las personas que «viven en las comunidades más pobres, de los municipios más pobres, de los estados más pobres. Son los olvidados de los olvidados» (Frausto: 2016:3).

Mencionaré dos historias que contribuyen a seguir comprendiendo México, la primera será la historia de Agustina Joaquín Toribio de la Ciudad de México y la segunda la 
de Antonio López Velasco de Chiapas. He elegido estas historias pues están en los dos lugares de acción en los que he desarrollado mi investigación y donde he tenido experiencias que han marcado fuertemente mi vida personal y profesional.

A pesar, de que dentro de la academia occidental suele no ser relevante la historia personal de los intelectuales y mucho menos de las personas de a pie, en este trabajo he decido contar la historia de Antonio y Agustina, pues a través del reconocimiento de las historias de vida es que he podido dilucidar ciertos paradigmas de la violencia estructural del país, y más aún de la violencia cultural en la que estamos sumidos como sociedad en México.

Es también gracias a las experiencias durante los cinco años que llevo realizando esta investigación que he podido ver como mi cultura, por más occidentalizada que pretenda ser, responde a otra cosmología que me reta e intimida, y que he podido reivindicar una vez que la he comenzado a comprender y que me une de manera profunda con ese mundo de los olvidados.

Es verdad que la cultura mexicana es difícil de comprender, pues es una mezcla de sabores, olores y colores que escapan a cualquier descripción literaria; es compleja, rica y muchas veces irracional. Los mexicanos conocemos la pobreza, la violencia, la desigualdad, la humillación, el hambre, el frío, la muerte... y lo más irracional de todo es que seguimos viviendo y la mayoría del tiempo sonriendo, somos una sociedad que afronta la muerte con una fiesta, afronta la corrupción con chistes, y afronta la pobreza compartiendo.

Como ya mencioné, dentro de la academia filosófica, es difícil encontrar relatos de vida que nos ayuden a profundizar en nuestras investigaciones, los análisis cualitativos carecen de la bien valorada objetividad científica y a pesar de que la antropología o la sociología nos han otorgado herramientas interesantes para medir las experiencias subjetivas, 
es difícil encontrar experiencias personales que nos ayuden a comprender mejor las propuestas teóricas en términos filosóficos.

Es verdad que dentro de los estudios de Paz y específicamente dentro de la Filosofía para la Paz de Vicent Martínez Guzmán, la intersubjetividad se prioriza y por lo tanto la experiencia dota de sentido a la teoría ${ }^{16}$. Esta constante lucha entre la experiencia personal, la investigación académica y el activismo político, se palpa en los diferentes movimientos que llevan siglos en el Sur $^{17}$, y no es posible compartir las conclusiones teóricas que emergen de ahí sin contar estas tres historias.

Por muchos años, en busca de esa objetividad y neutralidad científica, me mantuve al margen de mis propias investigaciones, en términos personales, pero mi breve paso por los Altos de Chiapas me enseñó por las buenas y por las malas, la necesidad de involucrarse personal y políticamente, aunque los precios que se paguen sean muy altos. Ahora comienzo con la historia de Antonio y Agustina, que nos ayudan a comprender mejor la vida en México.

\footnotetext{
${ }^{16}$ Esta afirmación se desarrollará en detalle en el segundo capítulo de la presente investigación.

${ }^{17}$ Boaventura Dos Santos con su epistemología del sur entiende el sur como una metáfora del sufrimiento humano causada por el capitalismo, creado por la expansión colonial de Europa (Boaventura Do Santos, 2006:45)
} 
Agustina Joaquín Toribio ${ }^{18}$

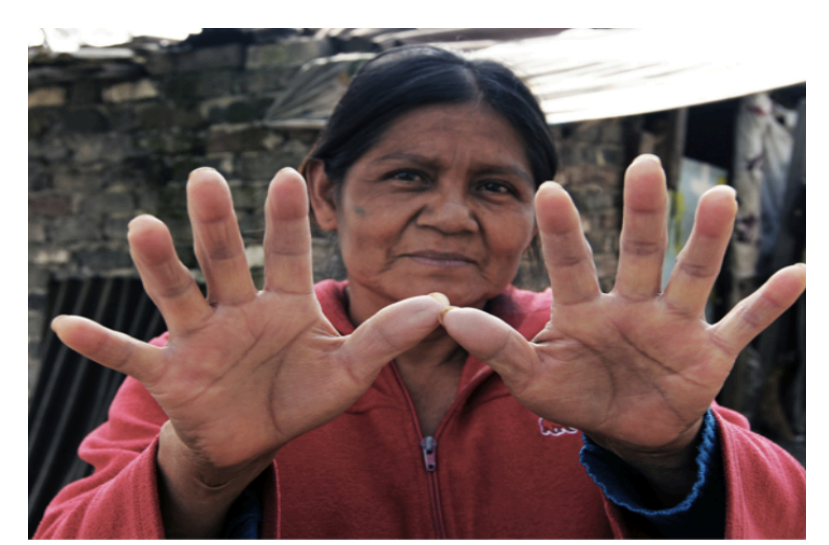

Foto: Luis Alberto Castillo, Los doce mexicanos más pobres

Vive en Tempiluli, un pueblo en la Delegación Tláhuac, en las faldas de la Sierra de Santa Catarina, en la periferia de la Ciudad de México. En el pueblo las casas son en su mayoría de troncos, láminas, cartones, asbesto, costales y cualquier cosa que se puede acarrear. Hay algunas casas de concreto con garaje y cisternas que las hacen ver como mansiones opulentas.

El pueblo está rodeado por canales que antaño hacían necesaria la transportación en barca, pero ahora esos canales son más pequeños, inexistentes y otros contaminados, ya que en 1980 el gobierno del Distrito Federal decidió desviar el agua de dos manantiales que dotaban de agua a los canales, para surtir las necesidades de los nuevos barrios de la Ciudad de México.

La calle principal del pueblo está pavimentada, pero llena de topes que dificultan mucho el pasar de los coches, cosa que no es un problema ya que la mayoría de los habitantes se mueve en bicicletas y bici-taxis o simplemente caminando.

Agustina es una mujer mixe originaria de Palomares, Oaxaca, tiene 55 años. En su pueblo natal quedó viuda con tres hijos, al morir su marido en una riña callejera, y para

\footnotetext{
${ }^{18}$ Ambas historias son un resumen de las entrevistas y relatos que se presentan en el libro Los doce mexicanos más pobres.
} 
mantenerse vendía totopos (tortillas cortadas en triangulo y fritas) en la plaza del pueblo. Sacaba 10 pesos diarios. Ahí conoció a Fidencio, un campesino oriundo de Tláhuac que la convenció para irse con él a la Ciudad de México y criar a sus tres hijos: «Tráemelos, yo los voy a sacar adelante. Voy a ser su papá y los voy a enseñar a trabajar».

Así fue como llegaron a vivir a Tempiluli, hace más de 20 años cuando aún podían vivir de la agricultura, hoy los tiempos y las circunstancias han cambiado y ahora Fidencio, de 66 años es ayudante de albañil; trabaja a dos horas de su casa y gana 80 pesos (3,40 euros) al día sin seguridad social.

Dejaron de poder dedicarse a la agricultura debido a la falta de riego y el cambio en la tierra; «Para él la tierra se volvió salitrosa y está cansada. “Todavía alcanzamos a sembrar aquí maíz; pero cuando la gente llegó a vivir se empezó a ensuciar más, hasta muertos nos echaban al agua. Se fue terminando todo porque ya cambió todo, el clima. En este tiempo (noviembre) se daban las milpas. Ahora no se da nada".»

Cuando se quedaron sin el campo, Fidencio tuvo que salir a buscar empleo. «Pasó de la pobreza rural, que se caracteriza por una población con mayores posibilidades de obtener alimentos, a una urbana, en que se tiene que competir por un trabajo para ganar dinero y así comprar comida. Por eso la canasta básica se cotiza en menor costo.»

Agustina también salió a trabajar como empleada doméstica en distintos barrios de la ciudad de México, pero ahora con su diabetes es más difícil. Además, ayuda a cuidar a sus nietos. Tiene 10.

El sueldo de Fidencio se reparte entre 6: él, Agustina, Viridiana de 21 años hija de ambos (madre soltera) y sus dos nietos. El sexto con quien reparte su dinero es el transporte público, pues tiene que pagar los pasajes para llegar a su lugar de trabajo. Quiere regresar al campo, pero no hay trabajo. 
El hijo mayor de Agustina, Guillermo Lucas, tiene 34 años y hace 16 se casó con Catalina, tienen 5 hijos: Eduardo (16), Évelin (14), José María (8), Ángel Guillermo (6) y María Fernanda (dos años y medio). Ambos viven en una casa que se construyeron detrás de la de Agustina, y a pesar de los esfuerzos, no han podido poner suelo en estos 16 años, sigue siendo tierra. Fidencio y Agustina tardaron 15 años en poner el suyo.

La joven pareja se gana la vida vendiendo esquites (sopa de granos de maíz), patas de pollo, elotes y café afuera de una escuela cercana. Ganan 100 pesos diarios (4 euros) por 12 horas de trabajo, y eso se reparte entre los 7 miembros de la familia, «equivalen a 14,28 pesos por persona. Menos de un dólar al día, menos de 1,25 dólares que la ONU establece como línea de bienestar mínimo y de los 1.90 que sugiere el Banco Mundial». Incluso la canasta básica, acorde a las cifras de CONEVAL establece como línea de bienestar mínima, 30,60 pesos diarios por persona.

¿Qué hacen para comer si no les alcanza con el dinero que ganan? Catalina: "Comemos a veces frijoles, arroz, sopa, lentejas, todo lo que es semilla. Cuando voy a la Central de Abastos (el mercado de alimentos más grande de la Ciudad de México) por mi mercancía, traigo coliflor, brócoli, verdura. Gracias a Dios comemos tres veces al día”.

La segunda hija de Guillermo y Catalina, Evelin, con 14 años no pudo seguir estudiando porque sus padres olvidaron el día de inscripción y al siguiente que fueron les dijeron que la plaza de su hija ya la habían ocupado. Así, se ha quedado sin estudiar este año. Mientras tanto se dedica a ayudar en casa con los quehaceres domésticos y cuidando a sus hermanos. Sus padres dicen que el siguiente año volverá a la escuela, $3^{\circ}$ de secundaria. Si no regresa, quedará por debajo del nivel educativo de su padre y con retos muchos más grandes, ya que perteneciendo a la Generación $Z$ (nacida en la era digital) no tiene computadora, teléfono fijo, ni internet. 
Su vulnerabilidad es muy alta: «está en riesgo de caer en la pobreza laboral, en ser la tercera generación que no pueda dejar la pobreza extrema por más que, como sus abuelos y padres, trabaje y esté dispuesta a insertarse en el mercado laboral, es una economía que prefiere a los más capacitados y por ende a los más favorecidos»

En la segunda entrevista de Salvador a Agustina, pregunta:

- ¿Su familia es pobre?

- Sí, porque no tenemos y no comemos lo que la gente rica, que come su guisado y su ensalada, con su postre...

- ¿Ha visto de cerca de la gente rica?

- Sí, cuando trabajé.

- ¿Qué veía?

- Pues comían bien, se vestían bien se calzaban, tenían dinero...

Agustina se lleva las manos a la cara y se cubre el rostro. Rompe en llanto.

- Ya no me pregunte más - respira hondo y mantiene el rostro cubierto con las manos arrugadas, de uñas cortas y amarillas.

Agustina da por terminada la entrevista. Con su mirada perdida, clavada en el piso, agrega:

- $\quad$ Sí es triste ser pobre. Lo que más duele de ser pobre es el maltrato. ${ }^{19}$

La historia que nos presenta el autor considero que es tremenda, no sólo por la gravedad de la situación, sino por lo conocido que me parece el relato. Hay que recordar que más de nueve millones de mexicano viven así y 45 millones sólo un poco mejor.

Mencionaré algunos de los aspectos de esta historia que considero más relevantes para seguir construyendo la imagen que nos permita comprender México.

1. Modelo extractivista de desarrollo que tiene como consecuencia el olvido de campo y el paso de la pobreza rural a la pobreza urbana: es muy interesante ver como las fechas que menciona Fidencio se relacionan directamente con el tiempo en el que

19 Además de la publicación del libro, las entrevistas se grabaron y forman parte de una campaña de concientización y sensibilización de la pobreza de OXFAM. Aquí la liga para el video de Agustina: https://youtu.be/oPWZRJvKtYQ (última visita 8 de enero de 2018). 
México entra al salón de los países desarrollados con el Tratado de Libre Comercio con Estados Unidos de América y Canadá en 1994. La vida de las ciudades está por encima de la vida en el campo, haciendo una diferencia terrible y muchas veces irremediable, entre el valor de la vida de las personas. Sólo me queda una pregunta ¿Desarrollarnos y evolucionar es comprar en lugar de sembrar?

2. La triple discriminación que viven las mujeres en pobreza: la realidad de las mujeres en México es simplemente inefable, las discriminaciones que sufren cada día y la violencia a la que están expuestas son enormes. Se les trata mal por ser pobres, indígenas y mujeres.

3. La salud como lujo: aunque no se menciona en el resumen que he puesto en este apartado, Agustina tiene diabetes y cuenta con un seguro popular al que ha accedido mintiendo sobre su domicilio, pues logró tenerlo en un lugar a hora y media de su casa. Ahí va a recibir su insulina. El problema es que no siempre tiene dinero para el transporte para ir por ella y tiene que salir a las seis de la mañana para llegar a tiempo y recibir la medicación. Además, tiene que ir sola porque los demás trabajan y eso significa una vulnerabilidad aún mayor, ya que en los últimos años la violencia machista y los feminicidios ${ }^{20}$ han aumentado significativamente. Va cuando puede permitírselo. Su salud no puede ser la prioridad en un mundo lleno de carencias.

4. Las posibilidades de salir de la pobreza con un modelo de mercado laboral que toma en cuenta solo a los más favorecidos: ¿qué futuro tienen Agustina y su familia? «En

\footnotetext{
${ }^{20}$ En el estudio presentado por Inmujeres México de la Secretaría de Gobernación y ONU Mujeres México en diciembre de 2017, se hace un balance histórico de los feminicidios en el país. Desde 1985 hasta 2016 en el país han existido 52,210 feminicidios, sólo en 2016 2,746, sólo en la Ciudad de México 144 (Violencia Feminicida en México. Aproximaciones y Tendencias 1985-2016: 2017:1822),
} 
general, la violencia y la discriminación contra la población más pobre y vulnerable es cosa de todos los días y está institucionalizada» (Fraustro, 2015: 147).

La vida de Agustina no nos deja indiferentes, pero si impotentes en cuanto se comprende que su situación no es un problema individual, sino un problema estructural del país. La pobreza en México, y en muchas partes del mundo, es causada por la desigualdad ya que, para tener riqueza extrema, se necesita pobreza extrema (Negrete Rovira 2016; Salvador Fraustro 2017; Esquivel Hernández, 2015).

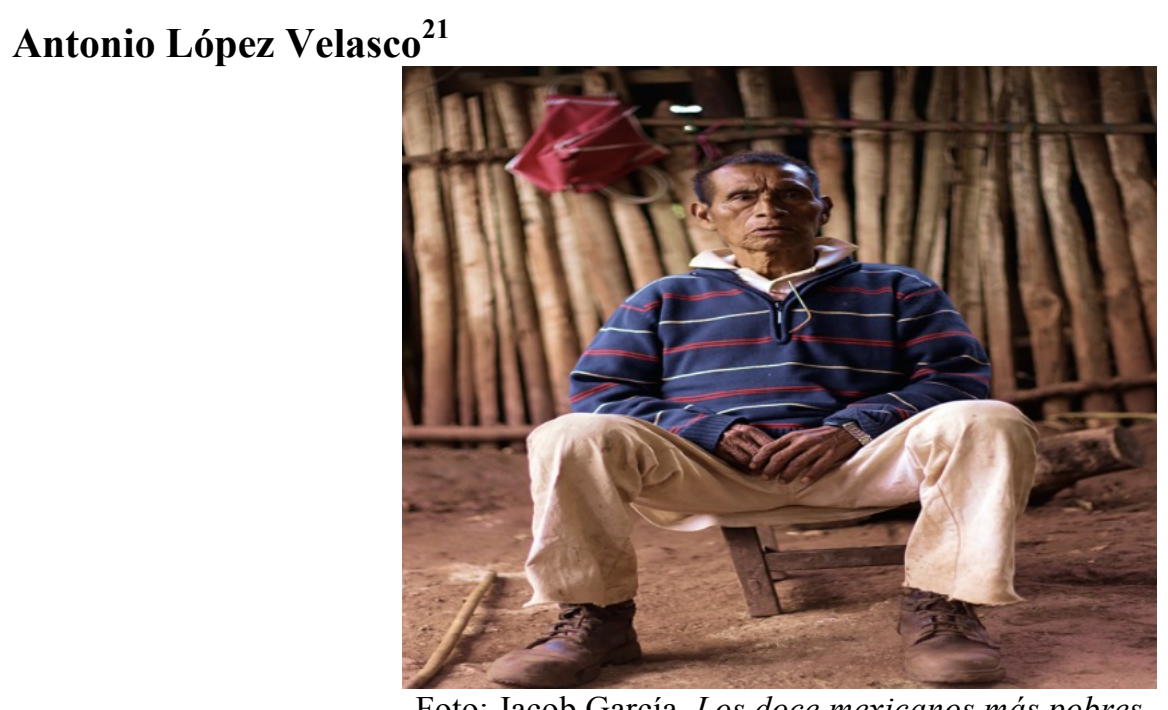

Foto: Jacob García, Los doce mexicanos más pobres

La vida en los Altos de Chiapas es quizá una de las más complejas en el territorio mexicano, no sólo por la pobreza que hay en el estado (es el estado más pobre del país), sino por la visibilidad que las últimas décadas ha tenido gracias al levantamiento del Ejercito Zapatista de Liberación Nacional en 1994, esto ha provocado que exista un foco de atención permanente en la región, pero desde una banalización de los problemas. Hay un turismo zapatista que de manera compleja invisibiliza visibilizando.

\footnotetext{
${ }^{21}$ Video de OXFAM: https://youtu.be/YVqROWdsONg?list=PLzZWPZeeuEw7HD97S HRQOUXWvkH fq
} 
A tan sólo hora y media de la mítica y enigmática ciudad de San Cristóbal de las Casas se encuentra un pequeño municipio llamado San Juan Cancuc, tiene aproximadamente 30000 habitantes (y sólo 40 profesores bilingües tseltal-castellano y una docena de médicos). El $80 \%$ de la población vive en pobreza extrema, el 16,8 \% en pobreza moderada y sólo el 3\% vive por encima de la línea de bienestar. Cuatro de cada diez cancuquenses son analfabetas, seis de cada diez mujeres no saben leer ni escribir. Aquellos hombres que estudian llegan en promedio a quinto de primaria, y ellas a segundo. E1 99\% de las viviendas no están conectadas al drenaje, el 55\% tiene piso de tierra y nadie, ni una persona tiene refrigerador o lavadora. $^{22}$

Como casi toda la región, San Juan Cancuc está rodeado por montañas y bosques llenos de pinos, prácticamente todo el año hace frío y más cuando "cae la neblina", los caminos son peligrosos pues algunas veces no logras ver ni a un metro de distancia. Las casas en su mayoría son de palos de madera con techos de lámina y suelo de tierra.

Antonio es un indígena tseltal de 78 años que no habla español. Es famoso en la región, pues se le conoce como el hombre más fértil. Ha tenido 29 hijos. Con su primera mujer, tuvo diez, con la segunda diez y la tercera, que es la única que aún vive, ha tenido nueve.

En su casa viven 13, los demás hijos han hecho su vida en otro lugar y, según recuerda, ocho han muerto. Desde hace dos años (2014) que llegó la plaga de la roya a los cafetales de la zona, los habitantes sólo consiguen con la venta de su café 3500 pesos anuales (150 euros), y si no fuera por la ayuda del gobierno con el programa PROSPERA que otorga dinero en efectivo a las familias con mayores carencias no tendrían dinero para sobrevivir.

22 Nuevamente todos los datos mencionados, son parte de los relatos presentados en el libro Los doce mexicanos más pobres 
Ese es el caso de Antonio, que con los 1160 pesos bimestrales que recibe debe dividirlo entre las 13 personas de su familia, eso significa que cada mes reciben 580 para los trece, que se traduce en 19 pesos diarios para los trece. 1,4 pesos por persona al día. La línea de bienestar mínima es de un dólar, 19 pesos aproximadamente, ellos tienen 1,4, son los pobres de los pobres.

No se menciona de qué murieron las mujeres, los hijos que Antonio perdió dicen que fueron por "pura tos. A veces calentura, fiebre. Así se morían. A veces en un instante se morían. A veces en la noche ya estaba amamantando y al otro día ya estaba llorando y se moría. En un rato se morían.” La tasa de mortalidad en este municipio es de 40 niños por cada 1000 habitantes, que es muy superior a la del estado que es de 23 por cada 1000.

Es interesante ver como siempre se regresa a las demandas más básicas cuando a Chiapas se refiere, demandas que en su momento hizo en EZLN y que el autor de esta lista recuerda al inicio del relato:

la población indígena chiapaneca padece 15000 muertos al año. Eso es tanto como lo de la guerra de El Salvador, cada año. Nada más que los muertos de un solo lado, y con la gran vergüenza de que la mayoría son por diarreas, enfermedades digestivas. Que las soluciones de los principales problemas de nuestro país atraviesan necesariamente por los problemas de libertad y democracia. Esa es la principal demanda. (Fraustro, 2016:10)

Tal como cuenta el autor, y el mundo desde entonces lo ha constatado, los pueblos indígenas mexicanos sobreviven en condiciones profundas de precariedad.

Igual que con el anterior relato, quiero destacar algunas cuestiones:

1. 29 hijos y 3 mujeres, nos refleja varias cuestiones: la primera que la muerte está siempre presente en Chiapas, la precariedad y vulnerabilidad de sus habitantes es 
atroz. En 2014 la razón de mortalidad materna (RMM) ${ }^{23}$ en Chiapas fue de 68.1, mientras que a nivel nacional fue de 38.1, la ubica en el segundo estado con más muertes en el país por esta razón. La segunda, el machismo que sumerge a las mujeres en una situación escalofriante; pariendo y muriendo, y si mueres eres reemplazada. Y tercero, la vida tiene un valor completamente distinto, la muerte de un hijo jamás se olvida, pero la muerte de ocho parece que sí, porque si no se olvidara, ¿podría soportarse sin perder la razón?

2. El olvido del campo y afectaciones del medio ambiente ponen en una situación de verdadera vulnerabilidad a las personas ya de por sí vulnerables. Una plaga llevó a la ruina un poblado, imaginemos catástrofes peores como auguran los científicos con el cambio climático. La discriminación ahora los atraviesa también por su geografía.

Mirar las cifras desde la vida de las personas, mirar la pobreza con nombre y apellido nos otorga una posibilidad única, ya que nos compromete y responsabiliza. Es imposible no pensar en nuestro día a día, en la manera en que nosotros vivimos, en las necesidades que creemos que tenemos y los problemas que tenemos. En una primera mirada, nos atraviesa la culpabilidad que bien llevada puede hacernos modificar ciertas acciones de nuestra vida diaria, pero en muchos otros casos, creo que también ayuda a construir un discurso apologético de la pobreza sin realmente entender la crudeza de la situación.

\footnotetext{
${ }^{23}$ La Razón de Mortalidad Materna (RMM) se define como el número de defunciones de la población femenina, mientras se encuentren embarazadas o dentro de los 42 días siguientes a la terminación del embarazo, debida a cualquier causa relacionada con o agravada por el embarazo mismo o su atención (con exclusión de las muertes accidentales o incidentales), en un determinado año, por cada 100 mil nacidos vivos en ese mismo año. Indicadores 2014, Observatorio de Mortalidad Materna en México.
} 
Analicemos pues esta afirmación, cuando vemos la vida de los pobres, solemos terminar las conversaciones diciendo que son más felices que nosotros porque necesitan menos, nosotros estamos llenos de cosas que no necesitamos pero que deseamos, estamos desconectados de la naturaleza y de nuestro propio entorno gracias a la tecnología y gracias a la sociedad de consumo (Bauman 2001, Alonso 2005, Esteva 2016). Y a pesar de lo cierto de estas cuestiones, como se verá en este trabajo, es necesario caminar despacio y con precaución para no afirmar que sólo a través de la pobreza se llega a la felicidad, tal y como lo hace el catolicismo: «Bienaventurados los pobres porque de ellos será el reino de los cielos».

La ontología de los pueblos originarios, tal y como se comprenderá al final de todo este trabajo, está encaminada a comprender que los actuales términos de riqueza llevan en su esencia el empobrecimiento de los demás, y ese empobrecimiento causa dolor y muerte, y por lo tanto, debe denunciarse siempre y erradicarse. Se debe comprender que la felicidad que podemos ver en la pobreza responde a esa otra cosmología que se ha mantenido viva en resistencia, esa cosmología es la vida comunitaria, que como veremos se comprende viviéndola y para vivir hay que renunciar a la individualidad, el pilar del pensamiento occidental.

Estas afirmaciones se comprenderán una vez presentada la propuesta del pensamiento zapatista y la ontología en la que descansa, por ahora es importante sólo mencionarlo para que la comprensión de México, sus cifras y los relatos sea decolonial ${ }^{24}$.

${ }^{24}$ Cómo se analizará en el capítulo III, el pensamiento decolonial tiene como propuesta central repensar el mundo y las relaciones de sus entidades desde la colonización en siglo XVI, pero no solamente en términos históricos sino en términos epistémologicos con el afán de liberarse (descolonizarse) en el ser, hacer y pensar. 


\section{Repensando la historia de México}

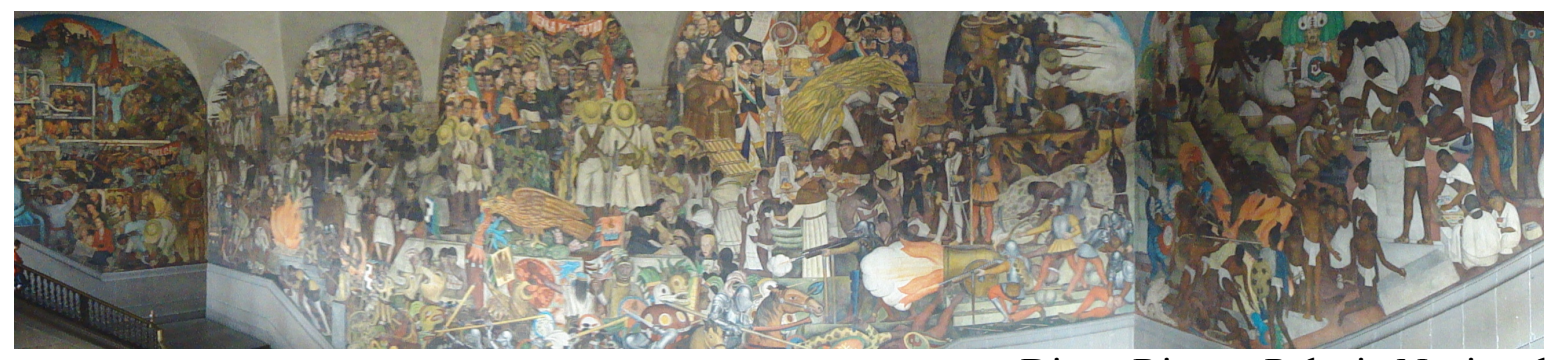

Diego Rivera, Palacio Nacional

Toca el momento de analizar la historia oficial del país, aquélla que nos han contado, que aparece en los libros oficiales y ha construido la imagen que tenemos de nosotros como país y sociedad.

He elegido cinco momentos que a su vez nos otorgan cinco principios en los que se justifica, a mi juicio, la violencia: la conquista, la independencia, la revolución, socialismo en movimiento (años cuarenta a ochenta) y resistencia (movimientos antisistema; mediados noventa hasta nuestros días).

Fue bastante complejo llegar a estos momentos cuando tenemos una historia que data desde el 33000 A.C. con la Etapa Lítica (Velázquez García, 2014:17) y que es rica tanto en cultura, ciencia y filosofía. Para contextualizar un poco se debe mencionar que el primer siglo de nuestra era es aceptado por muchos historiadores como un tiempo de florecimiento cultural (que tiene antecedentes bien marcados siglos antes de Cristo) (Nalda, 2014:75). En ese tiempo aparecen los grandes centros de población como Monte Albán en Oaxaca o Teotihuacán en el Estado de México. Comprender la riqueza de la historia del país merecería por lo menos una vida dedicada a hacerlo, pero los objetivos y limitaciones de espacio nos obligan a delimitar la investigación a ciertos momentos.

Han sido tres los criterios para elegir los momentos históricos. El primero, la relación con la historia universal, principalmente los puntos de encuentro con las sociedades europeas. 
Segundo, los momentos que fundaron la idea de un país y una sola cultura mexicana. Tercero, los momentos que reflejan un descontento social que provoca levantamientos armados y a la par movimientos no-violentos. Así llegamos a las cinco etapas ya mencionadas. Analicemos cada una:

\section{La Conquista}

El periodo que comprende este hecho histórico que se defino como «no sólo el sometimiento de una ciudad sino las muchas manifestaciones de la llegada de los españoles, la respuesta a ello, los enfrentamientos, los acomodos, y las consecuencias inmediatas del proceso que abarco desde 1529 o antes, hasta alrededor de 1560» (García Martínez, 2014: 169). Fueron años en el que se instauró un nuevo orden a nivel mundial.

El proceso colonial, consecuencia ideológica, práctica y política de la conquista del Nuevo Mundo se originó gracias a la expansión de la economía y cultura europea durante el siglo XV, primero los castellanos llegaron a las islas Canarias (2014:170) que ocuparon violentamente, extrajeron sus riquezas (en este caso con la producción de azúcar) colapsaron a la población nativa e introdujeron a los esclavos africanos. Ahí definieron su patrón de acción para las próximas décadas. Sin embargo, en el Nuevo Mundo, como en ese momento le llamaban, perfeccionaron sus modelos de colonización.

Después de un ataque armado en el Nuevo Mundo se formaron asentamientos fijos con un gobierno formal, crearon un orden jurídico y una vida cultural muy parecida a la de Castilla para mantener sus lazos (García Martínez, 2014:170).

La ocupación española en el continente americano se dio primero en Cuba, Jamaica, Santo Domingo y Puerto Rico, fue hasta 1517 que Francisco Hernández de Córdoba llegó a «la costa de Yucatán y se dio el primer contacto entre el mundo europeo y el 
mesoamericano.» (García Martínez, 2014:171). En la tercera expedición (1519), comandada por Hernando Cortés que desembarcó en Zempoala, cerca del actual puerto de Veracruz, se inició lo que para muchos es el derrocamiento del mundo mesoamericano (García Martínez, 2014:172).

En 1521 se da la caída de Tenochtitlán, el señorío más importante de Mesoamérica en ese momento, sin lugar a dudas, la alianza con el señorío de Tlaxcala le dio a Cortés una ventaja cuantiosa y que determinó el resultado final. Sin embargo, Tenochtitlán no cae por una estrategia de guerra deficiente, sino porque a través del sitio de la ciudad y la contaminación de sus canales, miles de mexicas murieron:

De julio de 1520 a agosto de 1521 la guerra de conquista de México consistió básicamente en el sitio, acoso y destrucción de la ciudad hasta que se rindió por hambre y por la viruela que, introducida por los conquistadores, mató a muchos de sus defensores incluido el propio hueytlahtoani Cuitláhuac, sucesor de Moctezuma. [...] Fue en una canoa, el 13 de agosto de 1521, donde se hizo la captura de Cuauhtémoc, jefe de la primera resistencia y último hueytlahtoani. (García Martínez, 2014: 177)

A partir de ese momento, la conquista y colonización de todo el territorio mesoamericano se dio rápidamente, aunque no sin intensas batallas y grandes dificultades (García Martínez, 2014: 178). Pero faltaron muchas décadas para poder instaurar todo el poder colonial que aún se sigue arrastrando.

El poder de dominación desde la conquista hasta nuestros días se enseña como algo normal y natural, tanto en las culturas originarias como en la española. Uno de los aspectos más interesantes del proceso de colonización es el uso de la plataforma política que ya tenían instaurados los señoríos indígenas, que funcionaban casi como principados, y de los cuales se sirvieron los españoles para instaurar el poder, tal y como lo tenían en España.

Es pertinente apuntar que las diferencias o mejor dicho las licencias que los señores tenían en el Nuevo Mundo tenían una escala de valores diferentes, pues en el Nuevo Mundo se daba 
prioridad a la ganancia de territorios, esclavos y riquezas antes que la legalidad o la ética, que ya estaba contenida en el estandarte de la religión.

La conquista se presenta como un hecho que gracias a la necesidad de un intercambio comercial más favorable y a la dominación bajo la que vivían los pueblos alrededor de los aztecas, los españoles vencieron.

Desde ese momento nos enseñaron que perdimos, nos enseñaron que nos desarrollaron, que nos alejaron de salvajismo y la idolatría. En palabras de Galeano, nos enseñaron que los indios:

... no son, aunque sean. Que no hablan idiomas, sino dialectos. Que no profesan religiones, sino supersticiones. Que no hacen arte, sino artesanía. Que no practican cultura, sino folklore. Que no son seres humanos, sino recursos humanos. Que no tienen cara, sino brazos. Que no tienen nombre, sino número. Que no figuran en la historia universal, sino en la crónica roja de la prensa local. Los nadies, que cuestan menos que la bala que los mata. (Galeano, 1989:59)

Nos descubrieron y nos conquistaron. Con la conquista el poder de dominación se instauró en el mundo como el medio para vivir.

Nuestra vida y la del enemigo perdieron valor pues ahora morir será consecuencia directa de la dominación. Si muere uno o mueren veinte es lo mismo, la vida ya no importa y mucho menos la de ese indio que no es, aunque sea. El genocidio se hizo presente en el mundo porque la vida humana era más barata que el oro. El genocidio se hizo forma de vida y cultura, algunos le llaman colonialidad del poder, el saber y el ser. Otros le llaman construcción de discursos dominantes y hegemónicos, pero la realidad fue que el mundo a partir de ese momento se comprendió bajo un lema de violencia, poder y dominación ${ }^{25}$.

\footnotetext{
${ }^{25}$ Esto no minimiza en ningún sentido las atrocidades cometidas siglos atrás y en diversas culturas, pero la presente investigación defiende que es a través de la conquista de América que se instaura un nuevo modo de dominación global jamás visto.
} 
Siguiendo la propuesta del grupo Modernidad/Colonialidad/Decolonialidad ${ }^{26}$ que se $^{2}$ abordará detalladamente en el tercer capítulo, es interesante pensar y analizar las cosas que se fueron gestando en el pensamiento de resistencia. A mi juicio hay dos grandes aportaciones al conocimiento mundial, el primero, el reconocimiento de la dignidad de las personas como algo inherente a la existencia humana con Fray Bartolomé de las Casas y; segundo, el uso de una lengua común, que, aunque colonial dominante y a través de la cual muchas lenguas quedaron sometidas, hoy nos permite comunicarnos en todo el territorio Mesoamericano, el español $^{27}$.

En conclusión, podemos decir que la Conquista, aquél encuentro violento entre dos mundos, dejó el que puede ser quizá el primer genocidio de la historia del mundo, en tanto que era una población específica con la que se quería acabar, construyendo así el primer paradigma de la violencia en nuestro país, la vida que vale es la que tiene riqueza material.

\footnotetext{
${ }^{26}$ Es un nuevo marco interpretativo asociado principalmente con los nombres de Aníbal Quijano, Walter Mignolo, Enrique Dussel, Catherine Walsh y Edgardo Lange, entre otros, todos autores contemporáneos. Más adelante se analizará en detalle su propuesta.

${ }^{27}$ En la propuesta política actual del zapatismo que se analiza en el 5to capítulo de esta investigación, ser verá la importancia de una lengua común, pues a través de ella la organización nacional en pequeñas comunidades es posible.
} 


\section{Colonialismo interno: independencia y revolución}

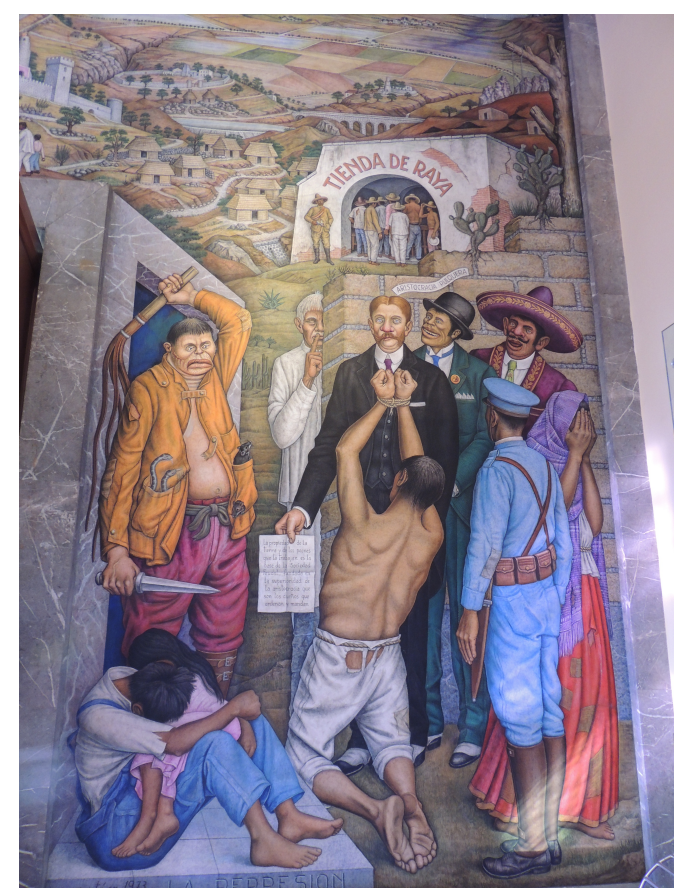

La caridad es humillante porque se ejerce verticalmente y desde arriba; la solidaridad es horizontal e implica respeto mutuo.

Eduardo Galeano

La Independencia y la Revolución representan quizá los años más importantes del país en cuanto a consolidación nacional se refiere, es por esto que para analizarlo será necesario recurrir al concepto de colonialismo interno de Pablo González Casanova (2003), pues a través de él es que se podrán comprender los fundamentos de dominación que siguen presentes en la sociedad actual.

El colonialismo interno tal y como propone Natividad Gutiérrez Chong «aún tiene vigencia como categoría de análisis para explicar la marginación estructura, la exclusión social y la ausencia de representación de los pueblos amerindios» (Gutiérrez Chong: 2010: 118). De tal suerte, esta categoría sirve para reconocer tres herramientas de análisis de la historia de la sociedad mexicana: primero el problema de desarrollo, segundo la creación de un movimiento social de liberación y tercero la creación de un proyecto ideológico y político 
liderado por indígenas a nivel mundial. Por otro lado, el colonialismo interno es imposible comprenderlo sin hacer un análisis sobre el concepto de nacionalismo, que a su vez se instaura y modifica en la sociedad mexicana en tres momentos históricos: independencia, revolución y el levantamiento zapatista. (Gutiérrez Chong: 2010: 119).

En este apartado de la investigación se analizará el concepto de nacionalismo en sus tres etapas. Sin embargo, las herramientas de análisis de colonialismo interno se mencionarán de manera parcial en este capítulo ya que forman parte del grueso de la investigación; el problema de desarrollo se analiza fundamentalmente en el tercer capítulo, el surgimiento de un movimiento de liberación nacional en el cuarto y la propuesta ideológica y política en el quinto. Aquí simplemente se abordará en su vertiente histórica y para identificar así los paradigmas de violencia que emergen de estas etapas, así como los momentos de paz ${ }^{28}$.

\section{Nacionalismos: el camino del colonialismo interno}

El mundo moderno, tal y como afirma Schöpflin descansa sobre «la proposición de que el mundo está dividido en naciones y sólo en naciones, que cada nación posee un pasado compartido y un futuro, y posiblemente que cada nación está conectada a un territorio particular, el cual puede ser también simbólico" (Schöpflin, 2001:225). Sin embargo, cada nación ha recorrido su propia historia, haciendo muy difícil acuñar un perfil específico o, mejor dicho, un modelo claro de construcción nacional. Para la presente investigación ahondaremos en el perfil que propone Natividad Gutiérrez Chong en su texto Los pueblos

\footnotetext{
28 Es muy importante reconocer cómo el giro decolonial, como se analizará en el siguiente capítulo, permite comprender como todo momento histórico de dominación produce necesariamente un movimiento de resistencia. Esto tiene repercusiones ontológicas muy interesantes, por ejemplo, que no es posible comprender el ser sin el no-ser y más aún el yo sin el tú. La afirmación será más clara después de leer el segundo capítulo.
} 
indigenas y los nacionalismos, escrito con motivo del bicentenario de la Independencia y Centenario de la Revolución en México.

En este texto se contrapone la creencia en el pensamiento occidental de que Europa es la cuna de la doctrina del nacionalismo con la Revolución Francesa y que su influencia llega a América para provocar los movimientos de independencia. No obstante, los hechos históricos y las circunstancias de la época muestran que es la declaración de Thomas Jefferson el 4 de julio de 1776 (13 años antes de la toma de La Bastilla) la que «contribuye a crear el ambiente político para desmantelar, de 1810 a 1821, el largo tutelaje colonial con la desintegración de los virreinatos y las capitanías de las Américas, y a construir la capacidad de autogobierno» (Gutiérrez Chong, 2010:120). Sin embargo, y como se verá en la siguiente explicación, la carga ideológica determinará no sólo el tipo de rebelión, sino los actores protagónicos y los olvidados, hecho que evidentemente determinó el modelo de nación mexicana.

Existen pues tres momentos históricos fundantes del nacionalismo mexicano, el primero la autodeterminación del pueblo con el surgimiento y consolidación del Estado a partir de las luchas libertarias o mejor conocido como el movimiento de Independencia. El segundo momento, la consolidación del Estado-Nación y, por ende, del colonialismo interno, este momento será de 1910 con la Revolución pasando por lo que se ha denominado en esta investigación como socialismo en movimiento (1938 expropiación petrolera a la matanza estudiantil del 2 de octubre 1968). El tercer momento, se califica como la redefinición de la 
nación como una nación multicultural, que tiene como momento clave el levantamiento armado del Ejército Zapatista de Liberación Nacional el 1 de enero de $1994^{29}$.

Estos tres momentos tienen actores y líderes fundamentales, que a su vez reflejan las circunstancias sociales de la época, es así que se reconoce en la Independencia la participación protagónica de los criollos y mestizos olvidando las demandas de los pueblos originarios. En el segundo momento, se encuentra que son los mestizos, campesinos e intelectuales de la época los que marcan el rumbo. En el tercero, por primera vez se encuentra el liderazgo político de los pueblos originarios. El siguiente cuadro ayudará a comprender estas etapas que se analizarán en detalle.

\section{l. El nacionalismo de independencia y la creación del Estado soberano}

Las guerras de independencia y el fin del gobierno colonial Las disputas territoriales y la marcación de un territorio soberano La formación del Estado y la elección de gobiernos popularmente electos La defensa de la nación y el territorio contra la invasión y la agresión extranjeras

\section{E l nacionalismo posrevolucionario, la construcción de la nación por el Estado}

La nacionalización de la economía

La homogeneización de la cultura y la unificación lingüística

La socialización y la estandarización por vía de la cultura cívica

La infraestructura y la comunicación

La asimilación de los indígenas y de otras minorías

La construcción e inculcación de la identidad nacional (mestizaje e indigenismo)

\section{E l nacionalismo en la era del multiculturalismo y el reconocimiento a la diversidad}

El neoliberalismo económico

Los levantamientos indígenas y los resurgimientos étnicos

El activismo político en torno a la conciencia de identidad y diversidad

étnica, de género y de protección al medio ambiente

La democratización del Estado

La cultura de los derechos humanos

La legislación del derecho a la libre determinación y a la autonomía de los pueblos indios

Fuente: Natividad Guitierrez Chong, 2010:121

29 Las décadas (1970-1990) que separa los momentos históricos que se han determinado, no se analizarán en detalle, ya que como se muestra en el segundo capítulo, estos años en la región estarán marcados por liberalismo económico y las políticas públicas de desarrollo. 


\section{El nacionalismo de independencia y la creación del Estado soberano}

El periodo de independencia es un momento histórico bastante complejo, se conoce como la etapa entre 1810, estallido de la revuelta armada, hasta 1821, año en el que a través del Plan de Igual se proclama la Independencia. Las circunstancias políticas europeas marcaron la fecha en la que da inicio la guerra, pero, como analizaremos brevemente, la independencia es el resultado de siglos de formación de una nueva identidad nacional, diferente a la de los españoles peninsulares y diferente a la de los pueblos originarios, tal y como apuntan algunos autores, «desde el siglo XVI se fue configurando un sentimiento de diferencia de los españoles americanos frente a los peninsulares, llamado después “patriotismo criollo", esto no excluía otras identidades» (Ávila y Jáuregui, 2014)

Uno de los aspectos más interesantes de los estudios históricos de los últimos años es la versión oficial del grito de independencia de Miguel Hidalgo que se presentaba como la gesta de un pueblo por alcanzar su independencia, sin embargo, como han demostrado varios autores (Jauregui 2014, Ávila 2014, Aspe, 2016) el levantamiento fue consecuencia directa de la inestabilidad de la Corona Española en Europa en aquel momento más que los deseos de emancipación de un pueblo. Como los hechos los muestran, en 1808 Napoleón se apoderó del trono español y se lo entregó a su hermano José Bonaparte lo que provocó una insurrección en todo el reino y la Nueva España no fue la excepción (Ávila y Jauregui, 2014: $359)$.

El discurso del cura Hidalgo, refleja lo que antes se ha denominado como patriotismo criollo; personas de padres españoles nacidos en territorio americano que se miraban así mismos como una especie de sociedad nueva mejorada, pero tradicional y fiel a las costumbres españolas. Cuando Miguel Hidalgo dice, «Viva Fernando VII» intenta mostrar 
cómo la Nueva España debería ser ahora el centro del reino, el lugar donde se debería proteger al Rey de la invasión francesa.

Virginia Aspe, filósofa mexicana, va más allá y propone que Hidalgo gracias a sus estudios de Teología y Filosofía, va moldeando la idea de que la Nueva España debería ser un país en el que cupieran los pueblos originarios, los criollos y mestizos en condiciones de paz, de acuerdo a sus usos y costumbres, unidos en el cristianismo. La autora se basa en dos textos fundamentales del pensamiento del padre de la patria, por un lado, su disertación para poder ganar la cátedra de Teología en la Universidad de San Nicolás en 1784 y la carta que escribe en prisión antes de ser fusilado en $1813^{30}$. De este último, cita:

Aunque el pueblo se valió de todos los medios para lograr su libertad, inicuos y torpes, con tal de que lo condujeran a sostener su defensa contra el despotismo y la opresión de quienes su único interés es ganar el poder y el dinero, buscamos establecer un gobierno que se componga por todas las ciudades del reino y mantenga la religión y leyes benéficas que gobiernen con dulzura a mis hermanos, que se destierre la pobreza para animar a la individualidad y el uso libre de la riqueza que Dios derramó en este continente. (Hidalgo, 1813 en Aspe, 2017)

La cita es riquísima pues establece los tres conceptos bajo los que se construirá la nueva sociedad mexicana (las bases del nacionalismo de la primera etapa): el primero, el

\footnotetext{
${ }^{30}$ Ambos textos se encuentran en la obra Miguel Hidalgo y Costilla. Documentos de su vida: 17501813, de Felipe I. Echenique March y Alberto Cué García. Sin embargo, esta investigación se basa en la ponencia de la Dra. Aspe en la Universidad de San Nicolás, en el marco de las conferencias "Pensadores y Humanistas de la Universidad Michoacana” en junio de 2017 en Morelia, Michoacán.
} 
cristianismo $^{31}$; segundo, la lucha armada como medio para alcanzar la libertad $d^{32}$ y el tercero; el racismo ${ }^{33}$ enmascarado en el clasismo típico de la sociedad española de ese momento.

Es interesante ver que en esta propuesta los criollos, en especial los clérigos como Miguel Hidalgo, tendrán en mente la inclusión de la sociedad indígena en este camino para fortalecer la Nueva España, para ellos las discusiones sobre razas eran cuestionamientos de una mente europea cansada, tal y como lo muestran los discursos del jesuita Francisco Javier Clavijero: «Sus almas son en lo radical como las de los demás hombres, y están dotados de las mismas facultades. Jamás han hecho menor honor a su razón los europeos, que cuando dudaron de la racionalidad de los americanos» (Clavijero, 2014:63).

Sin embargo, es muy importante ver aquí, que el racismo no aparente de los clérigos estaba cubierto por un clasismo evidente. Un indio, si era parte de la nobleza prehispánica, era racional, era igual que los españoles (desde la perspectiva de los criollos); pero un indio pobre, sin sangre real, era uno más para el servicio y claramente al servicio de la iglesia. No es menor el hecho de que la ruptura del cristianismo con el pensamiento de Lutero encontrará consuelo en la población de América, tal y como lo muestran las cifras actuales.

La forma en la que se instauró la colonia en el territorio mesoamericano fue a través de los señoríos prehispánicos (García Martínez, 2014:173), y después de siglos de

31 México en la actualidad es el segundo país con más católicos acorde al Anuario Pontificio de 2017 con 110 millones de católicos bautizados de 119 millones de habitantes.

${ }^{32}$ En poco más de 200 años hemos tenido una guerra de independencia que duró 11 años, una revolución que duró entre 7 y 14 años, según el lente con que se miré como se analizará en el siguiente apartado, una guerra cristera que duró 3 años, dos levantamientos armados importantes, el del Ejército Popular Revolucionario y el del Ejército Zapatista de Liberación Nacional, y una "guerra contra el narcotráfico" que lleva poco más de 10 años, sólo por mencionar algunos de los conflictos armados más icónicos, sin mencionar los casos de represión estatal.

${ }^{33}$ El concepto de racismo se analizará en detalle en el siguiente capítulo, ya que por su importancia teórica dentro pensamiento colonial merece un estudio más profundo. 
dominación, este hecho caracterizó y fundamentó el clasismo de la época, pero como se verá más adelante, es la estratificación racial determinada la que consolida la estratificación social o de clase.

En la lucha de independencia, como era ya tradición después de tres siglos de colonización, los pueblos originarios no se tomaron en cuenta como interlocutores válidos en el proceso, sino como brazos, monedas de cambio, objetos de estudio, justificación de guerras y cuerpos de combate. Gutiérrez Chong acierta con su pregunta: «¿Había indígenas participando en las gestas libertarias que buscaban abolir el colonialismo y, por tanto, alcanzar el ideal de independencia?» (Chong, 2010: 122). ¿De qué modo participaban? Es más, ¿de dónde sacaron las poblaciones amerindias las aspiraciones de independencia? ¿Obtuvieron esta información a través de una "doctrina europea" o de una teoría protonacionalista (sentimientos de pertenencia colectiva a nivel macro político) o de sentimientos de exclusión racial o cultural)? Si se asume, tal y como proponen los escritos de Clavijero, que los pueblos originarios eran parte del proyecto nacional como actores libres, sería posible rastrear la fundamentación teórica que recibieron, tal como es posible hacerlo con los clérigos que lideraron el movimiento.

Los procesos históricos permiten afirmar que la organización nacionalista, capaz de movilizar a un pueblo entero, es necesariamente trasmitida no sólo de manera oral, sino que tienen sus bases en una fundamentación escrita, es decir que hay un proceso de educación (lectura-diálogo-reflexión). Aceptando esto, se puede afirmar entonces que hay efectivamente una influencia clara y necesaria del pensamiento europeo, revitalizado por la experiencia próxima de las 13 colonias americanas, que provocan el estallido. Incluso, la historia oficial, en México por lo menos, afirma que es gracias a la lectura de los grandes 
autores del siglo de las luces como Voltaire o Montesquieu que surgen los deseos nacionalistas en México.

Aunque la influencia de los autores es clara en grandes personajes como Miguel Hidalgo, tal y como Aspe defiende, la influencia no es así para toda la población; «varios estudios (Lavrin, 1976, y Arrom, 1985) han demostrado el alto analfabetismo de las mujeres, incluso de las pertenecientes a la élite. La lectura y escritura, en español y en latín hacían posible el acceso a las ideas y a la discusión, pero ésta estaba determinada por el género y por la estratificación etno-racial» (Gutiérrez Chong; 2010: 122).

Este hecho, sin lugar a dudas, determinó el tipo nación que se pretendía construir; en sus raíces queda sin cambio la desigualdad y relaciones de dominación. Si a esto se suman la inexistencia de revueltas indígenas exitosas o mejor dicho, verdaderamente organizadas, ni grandes líderes como Hidalgo o Morelos ${ }^{34}$, se puede comprender cómo la Independencia no fue para todos.

Además de lo inverosímil que resulta la propuesta de una nación multicultural en el incipiente proyecto de nación mexicana a principios del siglo XIX, se suma el hecho de la que la maquinaría colonial no se trastocó durante los años posteriores a la Independencia, no sólo por la compleja red colonial que se había trazado, sino porque desde esa misma fundamentación teórica, la «Ilustración fue vista como un mecanismo idóneo para eliminar las muchas formas de conocer vigentes en las poblaciones nativas y sustituirlas por una sola

\footnotetext{
${ }^{34}$ Quizá una de las rebeliones indígenas más famosas es la Jacinto Canek en Yucatán en 1761, que tuvo un contenido altamente anticolonialista, aunque con una organización deficiente que condujeron a la derrota y asesinato de su líder Canek. Sin embargo, es interesante analizar la perspectiva que Robert W. Patch presenta en su texto La rebelión de Jacinto Canek en Yucatán: una nueva interpretación que toma la insurrección como un movimiento de revitalización cultural muy importante para la época.
} 
forma única y verdadera de conocer el mundo: la suministrada por la racionalidad científicotécnica de la modernidad» (Castro Gómez; 2008: 14).

Tal y como defiende Castro Gómez, la Ilustración y la forma en que fue leída por los criollos de la época, se fundamenta en la creencia de una superioridad étnica de estos (enraizada en la sociedad después de siglos de colonización) desde donde América Latina fue construida. Este autor defiende su hipótesis siguiendo el mismo camino que en su momento hizo Edward Said sobre Oriente, mostrando que «América fue leída y traducida desde la hegemonía geopolítica y cultural adquirida por Francia, Holanda, Inglaterra y Prusia, que en ese momento fungía como centro productores e irradiadores de pensamiento» (Castro Gómez, 2008:11) $)^{35}$.

Si a la fuerza teórica de la Ilustración y su propagación a través de poderosos actores como los criollos, le sumamos los sentimientos de rabia acumulados por siglos de injusticias y humillaciones de la población indígena, es claro que la independencia o, mejor dicho, la lucha por la autodeterminación era inevitable.

Pero regresemos a la pregunta sobre los indígenas, si no participaron en una escala teórica e intelectual ¿de qué modo participaron? No había indígenas en el movimiento como líderes, los criollos encabezaban la lucha, el segundo lugar fue ocupado por los mestizos y el tercero, que eran los que luchaban cuerpo a cuerpo eran los indígenas. Como ya era tradición, ellos continuaban atrapados en la muerte.

35 Estas afirmaciones son quizá algunas de las más importantes en la investigación, ya que justamente la instauración de la visión de UN mundo es la que rige aún la sociedad actual y la que pretenden transformar los indígenas y que sustentan en los estudios del pluriverso, que se analizarán en cuarto capítulo de este trabajo. 
Los indígenas no encontraron su liberación en este momento, simplemente cambiaron de patrones; «la independencia política, el gobierno propio y una identidad nacional con temas muy originales pusieron fin a las colonias..., pero para los amerindios sólo el principio de un colonialismo interno que empieza a tomar forma a partir de la existencia de un nuevo Estado-nación» (Gutiérrez Chong: 2010: 124).

Y es así como se enseña la independencia, como en movimiento que surge del hastío de la dominación en la que un grupo de héroes, hombres blancos en su mayoría, que habían leído ideas revolucionarias francesas y alemanas entendieron que tenían que salir de su minoría de edad, debían liberarse de las cadenas de su explotador. Y en la madrugada del 15 de septiembre de 1810 iniciaron su liberación, la guerra de independencia que llegaría 11 años más tarde.

Sin lugar a dudas, es interesante ver cómo el mexicano se dibuja entre los indios conquistados y los mestizos liberados, provocando una sociedad mexicana independiente. Dos sujetos, uno "libre” y el otro atado. ¿Son los dos el mismo? ¿Quiénes son los mexicanos?

Se han derramado litros de tinta para contestar esta pregunta y considero que no hay una respuesta única, sino la existencia de dos sujetos inmersos en una espiral de dominación y violencia, dentro de la rueda colonial que sigue caminando hasta la actualidad.

En la independencia, se instauró en nuevo orden mundial, más sutil pero no por ello menos atroz que el de la colonia, pues la mexicanidad (y cualquier nacionalismo desde entonces) quedaba fincado en la simbología de una grandeza precolombina, plagada de nostalgia vacía, y mirando con añoranza la pertenencia a ese Mundo-Uno ${ }^{36}$. Nuestra cultura,

\footnotetext{
${ }^{36}$ Mundo-Uno es la forma en que Arturo Escobar, dentro de los estudios del pluriverso, le da al mundo moderno que se impuesto a través de la colonización y el capitalismo. En el cuarto capítulo se
} 
la de los pueblos originarios quedaba para las siguientes décadas como un recuerdo nostálgico y deprimente de nuestra impureza e incapacidad de pertenecer, pero también como colores de diferencias llenos de vacuidad. El Culturicidio se hizo forma de vida.

\section{EI nacionalismo posrevolucionario, la construcción de la nación por el Estado}

El apartado anterior ha terminado con la afirmación de culturicidio como esencia de la incipiente nación mexicana, pues a pesar del prestigioso origen étnico del país, México más que continuidad es una «construcción del Estado mediante la puesta en marcha de un amplio proyecto de educación y alfabetización... Es así que en la nación mexicana laten el pasado “muerto" y la etnicidad "viva"» (Gutiérrez Chong; 2010:124)

Desde 1821 hasta la Revolución en 1910, México como Estado-nación consolida su estructura colonial, comienza a girar la rueda pintada con los colores de la libertad y la etnicidad, de esta manera y bajo supuestas condiciones de igualdad jurídica, ganadas en la independencia, el indígena se fue integrando a la nueva economía como jornalero o asalariado, trabajando la tierra, pero sin poder recuperar su territorio y, por lo tanto, haciendo imposible la recuperación de su identidad y dignidad.

La consolidación del colonialismo interno descansa sobre dos premisas; la primera: «sustitución de dominio de los españoles por el de los criollos y por el hecho de que la explotación de los indígenas sigue teniendo las mismas características que en la época anterior a la independencia» (Stavenhagen, 1963:224). La segunda: «Dentro de las fronteras del nacionalismo de Estado, el colonialismo interno es al gran sector de los que no tienen

desarrollará en detalle esta noción que se encuentra en su libro Sentipensar la Tierra Sentipensar con la tierra. Nuevas lecturas sobre desarrollo, territorio y diferencia (2015). 
nada.» (González Casanova: 1969:76). En resumen, el colonialismo es la asimilación de la estructura colonial que tiene las siguientes características desde la perspectiva del indígena (Stavenhagen, 1973: 230):

1. Un territorio sin gobierno propio

2. Que se encuentra en una, situación de desigualdad con respecto de la metrópoli, en donde los habitantes sí se gobiernan a sí mismos

3. Que la administración y la responsabilidad de la administración conciernen al Estado que la domina

4. Que sus habitantes no participan en la elección de los más altos cuerpos administrativos, es decir, que sus dirigentes son designados por el país dominante

5. Que los derechos de sus habitantes, su situación económica y sus privilegios sociales son regulados por otro Estado

6. Que esta situación no corresponde a lazos naturales sino "artificiales", producto de una conquista, de una concesión internacional

7. Que sus habitantes pertenecen a una raza y a una cultura distintas a las dominantes y hablan una lengua también distinta.

Durante los primeros 200 años de México como nación independiente, pasando por un imperio, una república, hasta un estado-nación y una revolución, las siete características no sólo no se vieron afectadas, sino que marcaron el rumbo que hasta nuestros días rige el país: fincas escondiendo esclavitud en el trabajo asalariado, el capitalismo extendiendo todas sus ramas.

Otro de los elementos clave en la consolidación del colonialismo interno fue la administración de las contradicciones de la historia cultural y étnica del país con los grandes 
temas de indigenismo ${ }^{37}$, el mestizaje ${ }^{38}$ y la modernización ${ }^{39}$.

Existe un relato zapatista que muestra la relación entre la consolidación del sistema capitalista en la historia, no sólo de México sino del mundo y el colonialismo interno. Reproduciré la primera parte del texto pues la exposición es tan simple y clara que cualquier intento por mi parte simplemente enturbiaría las lentes que nos otorga el relato y los grandes aportes que tiene para la presente investigación. A lo largo de texto resaltaré algunas partes que comentaré a pie de página.

\section{Primera parte: UNA FINCA, UN MUNDO, UNA GUERRA, POCAS PROBABILIDADES ${ }^{40}$.}

Subcomandante Insurgente Moisés y Subcomandante Insurgente Galeano Subcomandante Insurgente Galeano:

Buenos días, gracias por haber venido por aceptar nuestra invitación y compartirnos su palabra.

Vamos a empezar a explicar cuál es nuestro modo para hacer análisis y valoraciones.

Nosotros empezamos por analizar qué pasa en el mundo, luego nos bajamos a qué pasa en el continente, luego nos bajamos a qué pasa en el país, luego en la región y luego en

37 «El indigenismo es la política gubernamental para la administración y asimilación de las poblaciones y no incluye ni en su concepción ideológica ni en su pragmatismo la participación indígena... el indigenismo inhibe la liberación, la autonomía, la toma de decisiones de las sociedades indígenas.» (Gutiérrez Chong, 2010:125)

38 «El mestizaje es la fórmula que ha servido de guía para la unidad nacional, tomando como base el mito nacionalista del encuentro entre europeos y amerindios.» (Gutiérrez Chong, 2010:125)

39 La modernización en el colonialismo interno está equiparada con la construcción de una unidad nacional que requiere de la movilidad social, el anonimato, la división del trabajo, la comunicación y la industrialización (Gutiérrez Chong, 2010:125)

40 El texto es la versión ampliada y escrita de la participación de la Comisión Sexta del EZLN (Ejército Zapatista de Liberación Nacional) en el Encuentro de Redes de Apoyo al CIG (Consejo Indígena de Gobierno) y su Vocera (Marichuy). La necesidad de reproducir el texto emerge del recorrido histórico que los zapatistas han realizado durante décadas para fundamentar su rebeldía y autonomía, cada uno de los simbolismos elegidos, así como las analogías construyen el ideario cultural de la resistencia zapatista. Fecha de consulta 20 de agosto de 2018: http://enlacezapatista.ezln.org.mx/2018/08/20/300-primera-parte-una-finca-un-mundo-una-guerrapocas-probabilidades-subcomandante-insurgente-moises-supgaleano/ 
lo local. Y de ahí sacamos una iniciativa y la empezamos a subir de lo local a lo regional, a lo nacional, al continente y al mundo entero.

Según nuestro pensamiento, el sistema dominante a nivel mundial es el capitalismo. Para explicárnoslo y para explicarlo a otros, usamos la imagen de una finca.

Le voy a pedir al Subcomandante Insurgente Moisés ${ }^{41}$ que nos platique de eso.

\section{Subcomandante Insurgente Moisés:}

Bueno, entonces compañeros, compañeras, entrevistamos a compañeros y a compañeras bisabuelos y bisabuelas que estuvieron en su vida -algunos todavía están vivos y vivas-. Esto es lo que nos contaron, que nos llevó a pensar -decimos ahora- que los ricos, los capitalistas, quieren convertir en su finca ${ }^{42}$ lo que es el mundo.

Está el finquero, el terrateniente, el dueño pues así de miles de hectáreas de tierra ${ }^{43}$, y ya eso cuando no está, pues el patrón tiene su capataz que es el que cuida la finca, y de ahí ese capataz busca su mayordomo que es el que va a ir a exigir que se trabaje su tierra; y ese capataz, ordenado por el patrón, tiene que buscar a otro que le llaman el caporal, que es el que cuida alrededor de la hacienda, de su casa, pues. Entonces nos contaron de que en las fincas hay distintas cosas de lo que se hace ahí en la finca: hay finca ganadera, hay finca cafetalera, hay finca de caña, donde hacen panela, y de milpa y de frijol. Entonces lo combinan, lo combinan eso; o sea en una finca de 10 mil hectáreas ahí está todo ahí, hay de

${ }^{41}$ El actual líder del Ejército Zapatista de Liberación Nacional.

${ }^{42}$ La finca representa uno de los escenarios paradigmáticos de la opresión en el colonialismo interno y por tanto de la resistencia y la autonomía. Textos como: Resistencia y utopía: memorial de agravios y crónicas de revueltas y profecías acaecidas en la Provincia de Chiapas durante los últimos quinientos años de su historia, de Antonio García de León o Decolonizing politics: Zapatista Indigenous autonomy in an era of neoliberal governance and low intensity warfare de la filósofa mexicana Mariana Mora muestran la importancia del recuerdo de la vida en las fincas: «Los dos hermanos identificaron las secuelas que las condiciones de esclavitud dejaron en la población. Los ancianos recordaron el periodo como uno de rupturas sociales y culturales de los que aún los pueblos intentan recuperarse. Lo cotidiano de las fincas se estableció como el contraste frente al cual se crean otros imaginarios de vida cotidiana, política y social. Doña Hortensia de Morelia fue muy explícita en este punto cuando dijo, "Si está viva la memoria de las fincas, del sufrimiento, nunca vas a dejar de luchar. Los que ya se conformaron con las migajas es porque ya no guardan la época de las fincas en su corazón"» (Mora 2008: 394).

${ }^{43}$ El periodo de auge de las fincas en México tiene su origen durante el Porfiriato (periodo de gobierno de Porfirio Díaz), aunque se pueden encontrar raíces desde 1860 (y más aún en el servilismo cultural fundado en la colonia). Sin embargo, es interesante ver como desde 1860 hasta 1930 con la reforma agraria, el sistema finquero fue el modo de consolidación del sistema capitalista en el país. Durante este periodo, se había logrado una cierta estabilidad política (después de décadas de guerra civil entre conservadores y liberales proyectos políticos antagónicos que iban de un imperio a una república). Tal estabilidad permitió la instauración por fin del tan anhelado progreso y desarrollo prometido en la Independencia por los criollos y mestizos, pero llevaban consigo la opresión y dominación de los indígenas como se verá en las menciones en este relato. 
ganadería, de cañería, de frijol, milpa. Entonces toda su vida la gente está circulando ahí, trabajando ahí pues -lo que decimos los mozos o los baldíos, la gente que está sufriendo ahí

De capataz, pues él completa su paga robándole al patrón de lo que produce la finca. O sea que además de lo que le da el patrón, el finquero, el capataz tiene su ganancia de robar. Por ejemplo, si nacen 10 vaquillas y 4 toretes, pues el capataz no reporta cabal, sino que le dice al patrón que sólo nacieron 5 vaquillas y 2 toretes. Si el patrón se da cuenta de la tranza, pues lo corretea al capataz y pone a otro. Pero siempre algo roba el capataz o sea que es la corrupción que dicen.

Nos cuentan que cuando el capataz, porque no está el patrón, y entonces el capataz es el que queda, y cuando el capataz también quiere salir, entonces busca a alguien de los que tiene ahí, que sea igual como él de cabrón pues, de exigente pues; entonces mientras él va a echar su vuelta deja nombrado a alguien o sea, como que busca a su amigo que va a dejar a su cargo para luego llegar y tomar otra vez en su mano el capataz ${ }^{44}$.

Y entonces vemos eso, que el patrón no está, el patrón está en otro lado pues, el capataz es el que decimos así de que como los países o los pueblos que nosotros decimos, porque vemos que ya no es país pues; es el Peña Nieto ${ }^{45}$ como decimos, el capataz. El mayordomo decimos que son los gobernadores, y los caporales los presidentes municipales. Está estructurado de una manera en cómo van a dominar, pues ${ }^{46}$.

También vemos que ese capataz, mayordomo y caporal son los que exigen a la gente. Y ahí en la finca nos cuentan los bisabuelos que ahí hay una tienda, que le dicen tienda de raya -así nos lo contaron pues- quiere decir que la tienda es ahí donde se endeuda ${ }^{47}$; entonces

\footnotetext{
${ }^{44}$ Algunos de los relatos que se pueden encontrar en el texto de Mora son: «Tenía que trapear, barrer, sacar la orina todas las mañanas en las recámaras. Cuidar los animales. Era yo el encargado del mono del patrón. ¡Pinche mono, le daban más comida que a mí! Me tenían amarrado a ese mono. Hasta que me di cuenta que le daba asco la caca de gallina, perdía el hambre. Entonces lo embarré de mierda. Dejó de comer y se murió. Así me libré de esa tarea... Un día me hicieron cargar una caja grande y no pude. Salí huyendo. Pero el patrón me agarró. ¡Bandido cabrón! Me dijo y me colgó de un árbol para mi castigo. Me estuvo dando chicotazos en los pies. Tenía yo 10 o 12 años». (Mora 2008: 397) Estas narraciones de opresión entremezclan diferencias de clase, diferencias biológicas y culturales, atravesando por completo (incluyendo el cuerpo especialmente en la violencia sexual contra las mujeres) la vida de los mozos en las fincas. Esta recolonización de la vida del indígena al modo dialéctico produce necesariamente de la búsqueda de la liberación, de una descolonización de cada uno de los ámbitos de acción y existencia.

${ }^{45}$ Presidente de México 2012 a 2018.

${ }^{46}$ Las analogías con la estructura política actual permiten mostrar los alcances históricos y culturales de la vida en las fincas, mostrando que en términos de real política la estructura capitalista instaurada de pleno a finales del siglo XIX es vigente aún.

${ }^{47}$ Las tiendas de raya eran los establecimientos que vendía todos los productos básicos para los peones y mozos de las fincas, los finqueros eran también los dueños. A los peones se les obligaba a comprar ahí a modo de crédito acorde a los precios que estipulaba el patrón, haciendo deudas impagables para
} 
los explotados, explotadas que están ahí, mozos o mozas como le decimos, pues, entonces ya se acostumbraron de que ahí van a comprar su sal, su jabón, lo que necesita, o sea, no manejan dinero; tiene ahí el patrón su tienda y ahí es donde se enlistan, porque necesitan la sal, el jabón, el machete, la limadora o el hacha, entonces compran ahí, no es porque van a pagar con dinero sino con su fuerza de trabajo.

Y nos cuentan los bisabuelos que su vida, tanto como mujeres y hombres, es que le dan lo poco para comer el día de hoy para que mañana continúa trabajándole al patrón, y así a lo largo de todas sus vidas que la pasaron.

Y comprobamos lo que dicen nuestros bisabuelos porque cuando nosotros salimos en el 94, cuando fuimos tomando las fincas para sacar a esos explotadores, encontramos a capataces y a gentes acasilladas, que están acostumbrados a eso lo que les dije de tiendas de raya, entonces esa gente acasillada nos dijeron que no saben qué van a hacer, que porque ahora dónde va a encontrar su sal, su jabón, porque ya no está su patrón. Nos preguntaban a nosotros que ahora quién va a ser el nuevo patrón, porque quiere ir ahí porque no sabe qué hacer, porque dónde va a encontrar su jabón, su sal.

Entonces nosotros les dijimos: ahorita estás libre, trabaja la tierra, es tuya, así como el patrón que te explotó ahora vas a trabajar, pero es para ti, para tu familia. Pero entonces se resiste diciendo de que no, de que esta tierra es del patrón.

Es ahí donde comprobamos que hay gente que ya está hallada pues a la esclavitud. Y si tienen su libertad, pues no saben qué hacer, porque sólo saben obedecer ${ }^{48}$.

Y esto que les estoy hablando es de hace 100 años, más de 100 años, porque nuestros bisabuelos -uno de ellos tiene más o menos como 125, 126 años ahorita, porque ya tiene más de un año que lo entrevistamos a ese compa- son los que nos cuentan.

Entonces así lo vimos, que sigue eso. Hoy pensamos que así está el capitalismo ahora. Quiere convertir en finca el mundo. O sea, pero son los empresarios trasnacionales: "Voy a mi finca La Mexicana", según lo que le antoja; "voy a mi finca La Guatemalteca, La Hondureña", y así.

Y va a empezar a organizar según su interés al capitalismo pues, así como nos cuentan nuestros bisabuelos, que en una finca hay de todo ahí, café, ganado, maíz, frijol, y en otra

comprar un poco de maíz o las mismas herramientas que necesitaban para trabajar. Era el sistema mediante el cual estaba encubierta la esclavitud en la que vivían los peones.

${ }^{48}$ El ejercicio de la libertad es quizá uno de los temas que más se han investigado en la filosofía occidental, sin embargo, es desde el pensamiento decolonial y la experiencia de autonomía en las diversas resistencias indígenas en el mundo donde se puede comprender en términos políticos. La liberación del sujeto colonizado en la comunidad no reconstruye su subjetividad en la toma del trono desposeído de colonizador, tal como lo propone Franz Fanon, sino que es a través de la experiencia de la vida comunitaria que su existencia encuentra sentido y por tanto elimina de sí mismo la estructura de opresión que abre camino a la violencia. La vida comunitaria, o mejor dicho la reconstrucción de la subjetividad en la vida comunitaria es quizá una de las muchas aportaciones de pensamiento de resistencia a la ontología pluriversal (como antagónica a la ontología occidental). 
finca no, es puro nomás de caña para sacar panela, y en la otra pues otra cosa. Así nos fueron organizando ellos, cada finquero pues.

No hay patrón bueno, todos son malos.

Aunque nos cuentan nuestros bisabuelos que nos cuentan de que hay unos buenos dicen- pero a la hora de que nos toca analizarlo, pensarlo, verlo, simplemente porque no hay tanto maltrato físico, es lo que dicen nuestros bisabuelos eso de que entonces son buenos, porque no los chicotean pues; pero de explotados, explotadas, no hay salvación. En otras fincas sí, aparte de que estás cansado ya del trabajo y si no les cumples más, pues los chicotean $^{49}$.

Entonces pensamos que todo eso lo que les pasó es lo que va a pasar con nosotros, pero ahora sí ya no sólo nomás en el campo, sino en la ciudad. Porque no es lo mismo el capitalismo de hace 100 años, 200 años, ya son diferentes, su modo de explotación y no sólo nomás en el campo explota ahora sino también en la ciudad. Y su explotación cambia de modo, decimos, pero igual es explotación. Como que es la misma jaula de encierro, pero cada tanto la pintan, como que es nueva, pero es la misma ${ }^{50}$.

Pero como quiera, hay gente que no quiere la libertad, sino que ya se halló a obedecer, y entonces sólo busca un cambio de patrón, de capataz, que no sea tan cabrón o sea que igual explote, pero trate bien.

Entonces nosotros no lo perdemos de vista eso porque viene, ya están empezando, y así. Eso es lo que nos llama la atención de que ¿será que hay otros, otras, que ven, piensan, comparan igual que así nos la van a hacer?

¿Y qué van a hacer estas hermanas y hermanos? ¿Será que se conforman con un cambio de capataz o de patrón, o es que lo que quieren es la libertad ${ }^{51}$ ?

\footnotetext{
${ }^{49}$ En las diversas representaciones culturales de la vida en opresión, se comprende la falta de violencia directa como escenario de justicia, pues de esta manera se perpetúa con lentes de paz, la estructura de dominación. Es por esto que una de las claras reivindicaciones del zapatismo es no sólo contra la violencia directa sin contra la violencia estructural y cultural que engañan y recolonizan a las personas.

${ }^{50}$ Es interesante ver cómo el centro de dominación siempre se ha visto libre, desarrollado y avanzado. El grado de dominación en las ciudades es tan grande que ni siquiera son conscientes de su dominación, finalmente están en envueltos en el sistema. Boaventura de Sousa Santos establece este paralelismo entre el campesino y el obrero (bajo las diferencias entre colonialismo y capitalismo): «el colonialismo es un sistema de apropiación/violencia que, para ser eficaz en el centro, crea múltiples márgenes donde las historias paralelas, las lealtades ancestrales, las economías propias, las resistencias pasivas, las identidades centrífugas son posibles y pueden convertirse en nudos de insubordinación» (De Sousa Santos: 2015: 19). De ahí, que las luchas y pensamientos de resistencia siempre se han originado en la periferia, dejando el centro fuera y así estos lugares es donde encontramos más acasillados.

${ }^{51}$ El concepto de libertad es de suma importancia dentro del pensamiento zapatista y de resistencia, es por eso que se analizará en detalle en el último capítulo de este trabajo. Por ahora sólo cabe
} 
Eso es lo que me toca explicarles eso porque viene con lo que nosotros pensamos y vemos con los compañeros, compañeras, como Ejército Zapatista de Liberación Nacional. -*.

\section{Subcomandante Insurgente Galeano ${ }^{52}$ :}

Entonces lo que nosotros vemos a nivel mundial es una economía depredadora ${ }^{53}$. El sistema capitalista está avanzando de forma de conquistar territorios, destruyendo lo más que pueda. Simultáneamente hay un ensalzamiento del consumo. Parece que el capitalismo ya no parece preocupado por quién va a producir las cosas, para eso están las máquinas, pero no hay máquinas que consuman mercancías.

En realidad, este enaltecimiento del consumo ${ }^{54}$, esconde una explotación brutal y un despojo sanguinario de la humanidad que no aparecen en la inmediatez de la producción moderna de mercancías.

La máquina que, automatizada al tope y sin la participación humana, fabrica computadoras o celulares, se sostiene, no en el avance científico y tecnológico, sino en el saqueo de recursos naturales (la necesaria destrucción/despoblamiento y reconstrucción/reordenamiento de territorios) y en la inhumana esclavitud de miles de ínfimas, pequeñas y medianas células de explotación de la fuerza de trabajo humana.

El mercado (ese gigantesco almacén de mercancías) contribuye a ese espejismo del consumo: las mercancías le aparecen al consumidor como "ajenas" al trabajo humano (es decir, a su explotación); y una de las consecuencias "prácticas" es darle al consumidor (siempre individualizado ${ }^{55}$ ) la opción de "rebelarse" eligiendo uno u otro mercado, uno u

mencionar que, para ellos, la libertad es igual a la vida, a vivir como siempre había vivido, bajo sus costumbres, bajo su cosmovisión.

${ }^{52}$ Antes Subcomandante Insurgente Marcos, quien, en 2015, después del asesinato de José Luis Solís López maestro zapatista del caracol La Realidad, en el municipio de Las Margaritas en medio de la Selva Lacandona, apodado Galeano, según cuentan, en recuerdo del escritor uruguayo Eduardo Galeano, dejó de existir para que Galeano renaciera. En un acto simbólico donde se refleja la idiosincrasia mexicana, Marcos deja de existir, para darle nueva voz, en colectivo a Galeano.

${ }^{53}$ Durante la colonia (1521-1810), Independencia (1810 - 1821), Revolución (1910 - 1921) y Socialismo en movimiento (1921-1938), el colonialismo y el capitalismo cohabitaban en diversos territorios, pero como Boaventura establece en su Epistemología del Sur, se desplegaban de maneras diferentes, mientras que el colonialismo buscaba la apropiación del territorio física y culturalmente, el capitalismo lo hacía de la economía, sin embargo en las últimas décadas, cuando el territorio se tenía, el mercado y la economía adquirieron una importancia superior, de esta manera el capitalismo se estableció como sistema dominante, apoyándose tanto en la teoría como en la práctica del colonialismo ya establecido en esos territorios.

${ }^{54}$ La representación del estado de bienestar, se establece bajo la lente del consumo, entre más puedo comprar, mejor me siento. El carácter totalizante del capitalismo se encuentra en su capacidad de mostrarse como necesario en la vida diaria de todas las personas.

${ }^{55}$ El sujeto individualizado, es quizá el concepto ontológico más interesante dentro del pensamiento de resistencia, pues su construcción requiere necesariamente de la desvinculación de éste, tanto de la 
otro consumo, o negándose a un consumo específico. ¿No se quiere consumir comida chatarra? No problema, los productos alimenticios orgánicos también están a la venta, y a un precio más elevado. ¿No consume conocidos refrescos de cola porque son dañinos a la salud? No problema, el agua embotellada es comercializada por la misma empresa. ¿No quiere consumir en las grandes cadenas de supermercados? No problema, la misma empresa le surte a la tiendita de la esquina ${ }^{56}$. Y así.

Entonces está organizando la sociedad mundial dándole, aparentemente, prioridad al consumo, entre otras cosas. El sistema marcha con esa contradicción (entre otras): quiere deshacerse de la fuerza de trabajo porque su "uso" presenta varios problemas (por ejemplo: tiende a organizarse, protestar, hacer paros, huelgas, sabotaje en la producción, aliarse a otr@s); pero al mismo tiempo necesita el consumo de mercancías por parte de esa mercancía "especial".

Por más que el sistema apunte a "automatizarse", la explotación de la fuerza de trabajo le es fundamental. No importa cuánto consumo mande a la periferia del proceso productivo, o cuánto extienda la cadena de producción de modo que parezca (de "simular") que el factor humano está ausente: sin la mercancía esencial (la fuerza de trabajo) el capitalismo es imposible. Un mundo capitalista sin la explotación, donde sólo el consumo prevalece, es bueno para la ciencia ficción, las elucubraciones en las redes sociales y los sueños perezosos de los admiradores de los suicidas de la izquierda aristocrática.

No es la existencia del trabajo la que define al capitalismo, sino la caracterización de la capacidad de trabajo como una mercancía que se vende y se compra en el mercado laboral. Esto quiere decir que hay quien vende y hay quien compra; $y$, sobre todo, que hay quien sólo tiene la opción de venderse ${ }^{57}$.

La posibilidad de comprar la fuerza de trabajo está dada por la propiedad privada de los medios de producción, de circulación y consumo. En la propiedad privada de estos medios está el núcleo vital del sistema. Sobre esta división de clase (la poseedora y la desposeída) y para ocultarla, se construyen todas las simulaciones jurídicas y mediáticas, así como las evidencias dominantes: la ciudadanía y la igualdad jurídica; el sistema penal y policíaco, la

naturaleza como de los otros, haciendo posible que su centro sea él mismo con sus necesidades y deseos. Esto sin lugar a dudas tiene raíces en el pensamiento de la ilustración y como se analizará más adelante, en la Filosofía Occidental. El individuo vive en solitario para que en caso de querer rebelarse sea aplastado sin mayor consecuencia por la maquinaria del sistema.

${ }^{56}$ Toda propuesta alternativa y de organización es absorbida por el sistema, desde ese sujeto individualizado. Las grietas que se parece hacer desde dentro del sistema no tiene repercusión, sino que fortalecen la estructura, es por eso desde el zapatismo toda propuesta de humanización del capitalismo, es inviable.

${ }^{57}$ La dominación, una vez que el capitalismo a desplegado toda su fuerza, está fincada en la capacidad de adquisición, en la capacidad de consumo, ya no en el trabajo, dividiendo la población entre los que se vende y los que compran. El valor de las personas se establece en el mercado y por tanto su capacidad de interacción con el otro, el espacio público no es más que un grande espacio donde sólo tienen fuerza los que pueden comprar, o al menos es así como lo proyecta el sistema. 
democracia electoral y el entretenimiento (cada vez más difíciles de diferenciar); las neo religiones y las supuestas neutralidades de las tecnologías, las ciencias sociales y las artes; el libre acceso al mercado y al consumo; y las tonterías (más o menos elaboradas) del "cambio está en uno mismo", "uno es el arquitecto de su propio destino", "al mal tiempo pon buena cara", "no le des un pescado al hambriento, mejor enséñale a pescar" "“y véndele la caña de pescar"), y, ahora de moda, los intentos de "humanizar" el capitalismo, hacerlo bueno, racional, desinteresado, light.

Pero la máquina quiere ganancias y es insaciable. No hay un límite para su glotonería. Y el afán de ganancias no tiene ética ni racionalidad. Si debe matar, mata. Si necesita destruir, destruye. Aunque sea el mundo entero.

El sistema avanza en su reconquista del mundo. No importa lo que se destruya, quede o sobre: es desechable mientras se obtenga la máxima ganancia y lo más rápido posible. La máquina está volviendo a los métodos que le dieron origen - por eso nosotros les recomendamos leer la Acumulación Originaria del Capital-, que es mediante la violencia y mediante la guerra que se conquistan nuevos territorios ${ }^{58}$.

Como que el capitalismo dejó pendiente una parte de la conquista del mundo en el neoliberalismo y que ahora tiene que completarlo. En su desarrollo, el sistema "descubre" que aparecieron nuevas mercancías y esas nuevas mercancías están en el territorio de los pueblos originarios: el agua, la tierra, el aire, la biodiversidad; todo lo que todavía no está maleado está en territorio de los pueblos originarios y van sobre ello. Cuando el sistema busca (y conquista) nuevos mercados, no son sólo mercados de consumo, de compra-venta de mercancías; también, y, sobre todo, busca y trata de conquistar territorios y poblaciones para extraerles todo lo que se pueda, no importa que, al terminar, deje un páramo como herencia y huella de su paso.

Cuando una minera invade un territorio de los originarios, con la coartada de ofrecer "fuentes de trabajo" a la "población autóctona" (me cae que así nos dicen), no sólo está ofreciendo a esa gente la paga para comprar un nuevo celular de gama más alta, también está desechando a una parte de esa población y está aniquilando (en toda la extensión de la palabra) el territorio en el que opera. El "desarrollo" y el "progreso" que ofrece el sistema ${ }^{59}$,

${ }^{58}$ El pensamiento zapatista, o mejor dicho, el pensamiento de resistencia es casi perfecto, hace un recorrido histórico donde la colonización aparece como origen de un sistema que establece la dominación como modo de vida, el capitalismo en este momento aparece como una herramienta más para fortalecer esa dominación, sin embargo la avaricia del sistema es tan grande que pronto se convierte en el centro y fuerza del sistema, utilizando estrategias más sutiles que las de la colonización de origen, pero lo hace solamente cuando el territorio pertenece ya al sistema, cuando no es así, despliega nuevamente todas las estrategias de violencia y muerte, ese periodo se entiende como el capitalismo extractivista, momento actual en prácticamente todo el planeta.

${ }^{59}$ Ambos conceptos son, dentro de una genealogía del pensamiento de resistencia, el centro bajo el que gira el sistema, el "progreso" encuentra sus raíces teóricas en el pensamiento kantiano y más aún en las circunstancias sociales y políticas de Prusia y, el "desarrollo" será el brazo ejecutor de la neocolonización y la instauración del capitalismo en la segunda mitad del siglo XX. Incluso, en la 
en realidad esconden que se trata de sus propios desarrollo y progreso; y, lo más importante, oculta que esos desarrollo y progreso se obtienen a costa de la muerte y la destrucción de poblaciones y territorios.

Así se fundamenta la llamada "civilización”: lo que necesitan los pueblos originarios es "salir de la pobreza", o sea necesitan paga. Y entonces se ofrecen "empleos", es decir, empresas que "contraten" (exploten pues) a los "aborígenes" (me cae que así nos dicen).

"Civilizar" una comunidad originaria es convertir a su población en fuerza de trabajo asalariada, es decir, con capacidad de consumo. Por eso todos los programas del Estado se plantean "la incorporación de la población marginada a la civilización". Y, en consecuencia, los pueblos originarios no demandan respeto a sus tiempos y modos de vida, sino "ayuda" para "colocar sus productos en el mercado" y "para obtener empleo". En resumen: la optimización de la pobreza.

Y con lo de "pueblos originarios" nos referimos no sólo a los mal llamados “indígenas", sino a todos los pueblos que originalmente cuidaban los territorios hoy bajo las guerras de conquista, como el pueblo kurdo, y que son subsumidos, por medio de la fuerza, en los llamados Estados Nacionales.

La llamada "forma Nación" del Estado, nace con el ascenso del capitalismo como sistema dominante. El capital necesitaba protección y ayuda para su crecimiento. El Estado suma entonces, a su función esencial (la de la represión), la de ser garante de ese desarrollo. Claro, entonces se dijo que era para normar la barbarie, "racionalizar" las relaciones sociales y "gobernar" para todos; "mediar" entre dominadores y dominados ${ }^{60}$.

La "libertad" era la libertad para comprar y vender (se) en el mercado; la "igualdad" era para cohesionar el dominio homogeneizando; y la "fraternidad", bueno, tod@s somos herman@s, el patrón y el trabajador, el finquero y el peón, la víctima y el verdugo.

Después se dijo que el Estado Nacional debía "regular" el sistema, ponerlo a salvo de sus propios excesos y hacerlo "más equitativo". Las crisis eran producto de defectos de la máquina, y el Estado (y el gobierno en particular), era el mecánico eficiente siempre alerta para arreglar esos desperfectos. Claro, a la larga resultó que el Estado (y el gobierno en particular) era parte del problema, no la solución.

Pero los elementos fundamentales de ese Estado Nación (policía, ejército, lengua, moneda, sistema jurídico, territorio, gobierno, población, frontera, mercado interno, identidad cultural, etc.) hoy están en crisis: las policías no previenen el delito, lo cometen: los ejércitos no defienden a la población, la reprimen; las "lenguas nacionales" son invadidas y modificadas (es decir, conquistadas) por la lengua dominante en el intercambio; las monedas nacionales se valúan conforme a las monedas que hegemonizan el mercado mundial; los sistemas jurídicos nacionales se subordinan a las leyes internacionales; los

historia de México palabras como "orden y progreso" lema del Porfiriato, muestran como la consolidación del Estado Mexicano descansa sobre ideales que encarnan la muerte.

${ }^{60}$ La consolidación del Estado Nación se analizará con más detalle más adelante, basta resaltar el cambio de papeles que sufren el capitalismo y la colonización con su instauración. 
territorios se expanden y contraen (y fragmentan) conforme a la nueva guerra mundial; los gobiernos nacionales supeditan sus decisiones fundamentales a los dictados del capital financiero; las fronteras varían en su porosidad (abiertas para el tráfico de capitales y mercancías, y cerradas para las personas); las poblaciones nacionales se "mezclan" con las provenientes de otros Estados; y así.

Al mismo tiempo que "descubre" nuevos "continentes" (es decir: nuevos mercados para extraer mercancías y para el consumo), el capitalismo enfrenta una crisis compleja (en su composición, en su extensión y en su profundidad), que él mismo produjo con este afán depredador. Es una combinación de crisis.

Una es la crisis ambiental que está pegando en todas partes del mundo y que es producto también del desarrollo del capitalismo: la industrialización, el consumo y el saqueo de la naturaleza tienen un impacto ambiental que altera ya lo que se conoce como "planeta Tierra". El meteorito "capitalismo" ya cayó y ha modificado radicalmente la superficie y las entrañas del tercer planeta del sistema solar.

La otra es la migración. Se están pauperizando y destruyendo territorios enteros y obligando a la gente a migrar buscando vida. La guerra de conquista, que está en la esencia misma del sistema, ya no ocupa territorios y su población, sino que pone a esa población en el rubro de "sobras", "ruinas", "escombros", por lo que esas poblaciones o perecen o emigran a la "civilización" que, no hay que olvidarlo, se sostiene sobre la destrucción de "otras" civilizaciones. Si esas personas no producen ni consumen, sobran. El llamado "fenómeno migratorio" es producido y alimentado por el sistema.

Y una más - en la que nosotros estamos encontrando coincidencias con varios analistas en todo el mundo- es el agotamiento de los recursos que hacen andar "la máquina": los energéticos. Los llamados "picos” finales en reservas de petróleo y carbón, por ejemplo, ya están muy cerca. Esos energéticos se agotan y son muy limitados, su reposición duraría millones de años. El previsible e inminente agotamiento hace que los territorios con reservas -aunque limitadas- de energéticos, sean estratégicos. El desarrollo de fuentes de energía "alternas" va demasiado despacio por la sencilla razón de que no es rentable, es decir, no se repone rápido la inversión.

Estos tres elementos de esa crisis compleja, ponen en entredicho la existencia misma del planeta.

¿La crisis terminal del capitalismo? Ni de lejos. El sistema ha demostrado que es capaz de superar sus contradicciones e, incluso, funcionar con ellas y en ellas.

Entonces, ante esas crisis que el mismo capitalismo provoca, que provoca migración, provoca catástrofes naturales; que se acerca al límite de sus recursos energéticos fundamentales (en este caso el petróleo y el carbón), parece que el sistema está ensayando un repliegue hacia dentro, como una antiglobalización, para poder defenderse de sí mismo y está usando a la derecha política como garante de ese repliegue.

Esta aparente contracción del sistema es como un resorte que se retrae para luego expandirse. En realidad, el sistema se está preparando para una guerra. Otra guerra. Una total: en todas partes, todo el tiempo y con todos los medios. 
Se están construyendo muros legales, muros culturales y muros materiales para tratar de defenderse de la migración que ellos mismos provocaron; y se está tratando de volver a mapear el mundo, sus recursos y sus catástrofes, para que los primeros se administren para que el capital mantenga su funcionamiento, y las segundas no afecten tanto a los centros donde se agrupa el Poder.

Estos muros van a seguir proliferando, según nosotros, hasta que se vaya construyendo una especie de archipiélago "de arriba" donde, dentro de "islas" protegidas, queden los dueños, digamos, los que tienen la riqueza; y afuera de esos archipiélagos quedamos todos los demás. Un archipiélago con islas para los patrones, y con islas diferenciadas -como las fincas- con labores específicas. Y, muy aparte, las islas perdidas, las de 1@s desechables. Y en el mar abierto, millones de barcazas deambulando de una a otra isla, buscando un lugar para atracar.

¿Ciencia Ficción de manufactura zapatista? Googlee usted "Barco Aquarius" y vea la distancia que media entre lo que describimos y la realidad. Al Aquarius varias naciones de Europa le negaron la posibilidad de atracar en puerto. ¿La razón? La carga letal que transporta: cientos de migrantes procedentes de países "liberados" por Occidente con guerras de ocupación, y de países gobernados por tiranos con el beneplácito de Occidente ${ }^{61}$.

"Occidente", el símbolo de la civilización por auto denominación, va, destruye, despuebla y se repliega y cierra, mientras el gran capital sigue con sus negocios: fabricó y vendió las armas de destrucción, también fabrica y vende las máquinas para la reconstrucción.

Y quien está apoyando este repliegue es la derecha política en varias partes. Es decir, los capataces "efectivos", los que controlan a la peonada y aseguran la ganancia para el finquero... aunque más de uno, una, unoa, se roben parte de las vaquillas y toretes. Y, además, "chicoteen" demasiado a su respectiva población acasillada.

Todos los que sobren: o consumen o hay que aniquilarlos; hay que hacerlos a un lado; son-decimos nosotros-1@s desechables. No cuentan ni siquiera como "víctimas colaterales" en esta guerra. No es que algo está cambiando, es que ya cambió.

Y ahora usamos el símil de los pueblos originarios porque durante mucho tiempo, en la etapa previa de desarrollo del capitalismo, los pueblos originarios quedaron como los olvidados. Antes nosotros usábamos el ejemplo de los infantes indígenas, que eran los nonatos porque nacían y morían sin que nadie les llevara la cuenta, y esos no-natos habitaban en estas zonas, por ejemplo, en estas montañas que antes no les interesaban. Las buenas tierras (las "planadas", les decimos nosotros), fueron ocupadas por las fincas, por los grandes propietarios, y aventaron a los indígenas a las montañas, y ahora resulta que esas montañas

\footnotetext{
${ }^{61}$ La lucidez de la retórica zapatista es evidente, la manera en la que juegan con el tiempo, pasando de la consolidación del sistema con las crisis actuales, muestra como su cosmovisión permite el desarrollo de un pensamiento crítico más amplio; no está constreñido a las lógicas de la razón occidental, por el contrario, muestra como el tiempo se parece más a un espiral sin destino definido que permite ver las historia desde distintos ámbitos.
} 
tienen unas riquezas, mercancías, que quiere también el capital y entonces ya no hay a dónde irse para los pueblos originarios ${ }^{62}$.

O luchan y defienden, incluso hasta la muerte, esos territorios, o no hay de otra, pues. Porque no habrá un barco que los recoja cuando naveguen a la intemperie en las aguas y tierras del mundo.

Está en marcha una nueva guerra de conquista de los territorios de los originarios, y la bandera que porta el ejército invasor a veces lleva también los colores de la izquierda institucional.

Este cambio en la máquina en lo que se refiere al campo o "zonas rurales", que se puede apreciar hasta con un análisis superficial, también se presenta en las ciudades o "zonas urbanas". Las grandes ciudades se han reordenado o están en ese proceso, después o durante una guerra despiadada contra sus habitantes marginales. Cada ciudad contiene muchas ciudades dentro, pero una central: la del capital. Los muros que rodean esa ciudad están formados por leyes, planes de urbanización, policías y grupos de choque.

El mundo entero se fragmenta; proliferan los muros; la máquina avanza en su nueva guerra de ocupación; cientos de miles de personas descubren que el nuevo hogar que les prometió la modernidad es una barcaza en altamar, la orilla de una carretera, o el hacinamiento de un centro de detención para "indocumentados"; millones de mujeres aprenden que el mundo es un gigantesco club de caza donde ellas son la presa a cobrar; la infancia se alfabetiza como mercancía sexual y laboral; y la naturaleza pasa la cuenta del largo debe que, en su saldo rojo, acumula el capitalismo en su breve historia como sistema dominante ${ }^{63}$.

Claro, falta lo que digan las mujeres que luchan, loas otroas de abajo (para quienes, en lugar del glamur de los closets entreabiertos de arriba, hay desprecio, persecución y muerte), quienes pernoctan en las colonias populares y se pasan el día trabajando en la ciudad del capital, 1@s migrantes que recuerdan que ese muro no estuvo ahí desde el principio de los tiempos, los familiares de desaparecid@s, asesinad@s y encarcelad@s que no olvidan ni perdonan, las comunidades rurales que descubren que fueron engañadas, las identidades que se descubren diferentes y suplen la vergüenza por el orgullo, y todas, todos, todoas 1@s desechables que entienden que el destino no tiene que ser el de la esclavitud, el olvido o la muerte mortal.

\footnotetext{
${ }^{62}$ Para conocer más sobre la historia de los indígenas tseltales, tsotsiles y tojolabales durante este periodo revisar: Zapatista Indigenous autonomy in an era of neoliberal governance and low intensity warfare de Mariana Mora.

${ }^{63}$ Ejemplos, desgraciadamente sobran, tanto en el contexto mexicano como en el contexto español. En ambos países hay noticias diarias sobre feminicidios, muertes de migrantes, discursos ultraderechistas que piden crear muros y separaciones con los "otroas". El capitalismo, un sistema fincado en la dominación de la vida para acumular cada vez más ganancia nos ha dejado aislado, despersonalizados y peor aún, con una colonización tal de la mente que el pensamiento crítico aparece como disruptivo y peligroso.
} 
Porque otra crisis, que pasa desapercibida, es la emergencia y proliferación de rebeldías, de núcleos humanos organizados que desafían no sólo al Poder, también a su lógica perversa e inhumana. Diversa en su identidad, es decir, en su historia, esta irrupción aparece como una anomalía del sistema. Esta crisis no cuenta para las leyes de probabilidad. Sus posibilidades de mantenerse y profundizarse son mínimas, casi imposibles. Por eso no cuentan en la cuenta de arriba.

De las rebeldías, para la máquina, no hay que preocuparse. Son pocos, pocas y pocoas, si acaso lleguen a 300 .

Es seguro que esta visión del mundo, la nuestra, esté incompleta y que, con alto grado de probabilidad, sea errónea. Pero así es como vemos el sistema a nivel mundial. Y de esta valoración se sigue lo que miramos y valoramos en los niveles continental, nacional, regional y local.

Desde las montañas del sureste mexicano Subcomandante Insurgente Moisés - Subcomandante Insurgente Galeano. El escenario que presentan los zapatistas muestra la interconexión del sistema en distintas partes del mundo desde hace siglos y específicamente con la consolidación del nacionalismo de la revolución y posterior en México que dejaron dos paradigmas de violencia o mejor dicho, construyeron la Nación Mexicana sobre dos -cidios, el primero; el ecocidio, la pérdida del valor real de la tierra en términos de intersubjetividad, de conexión, de natura naturans, el Ecocidio se hizo necesario para mantener la "mexicanidad”.

Años más adelante, el periodo que he denominado Socialismo en movimiento que comprende entre los años treinta y cuarenta, momento en el que la institucionalización de la revolución da sus frutos: el indio está sometido, el mestizo está adormecido, aparece una Europa en periodo de decadencia y nosotros nos abrimos como el espacio de crecimiento y protección que nuestros antiguos patrones necesitan, ahí estuvimos.

Pero sin darnos cuenta, frente a nosotros, creció un nuevo ideal; Estados Unidos de América, el auge del capitalismo se instauraba y por lo tanto nuestra tierra se veía ahora sólo como recursos y nuestra gente como mano de obra. Nuestro arte se volvió nostalgia del indio y marca registrada. La superstición mexicana se comercializó, nuestros dioses se 
desvanecieron en la bolsa de valores, mientras el discurso pide y toma como ejemplo la fuerza soviética. La sociedad erige nuevos dioses EUA y URSS.

Socialismo en movimiento con México como marca registrada, con la necesidad de entrar al mercado, con dinero en la cabeza, pero socialismo en la palabra, nuestros dioses se desvanecieron y así se encontramos el último -cidio que compone nuestra historia nacional. Deicidio como ticket de entrada a Wall Street.

La consolidación del nacionalismo tanto en la independencia y la revolución, llevan consigo la consolidación del capitalismo como sistema dominante y totalizante en el país. Es claro que tiene raíz en la conquista y época colonial y más aún en el colonialismo interno de 1810 a 1921 aproximadamente, pero es a partir de los años treinta del siglo XX que se instaura y expande a través de los proyectos de desarrollo y progreso en las próximas cinco décadas.

\section{EI nacionalismo en la era del multiculturalismo y el reconocimiento a la diversidad}

\section{Resistencia}

En los años sesenta y setenta, aunque existieron grandes movilizaciones y propuestas teóricas de suma importancia en América Latina en términos decoloniales (movimiento estudiantil del 68 y 71, desarrollo de la teoría de la dependencia y teología de la liberación) somos Tercer Mundo queriendo desarrollarse; Europa cómplice de Estados Unidos han vencido al gigante soviético y las estrategias de dominación más sutiles se pusieron en marcha en la región.

Es hasta mediados de los años ochenta (momento de organización) y principios de los noventa (levantamiento armado) que se encuentra una nueva resistencia y organización de las comunidades indígenas; una bola de indios encapuchados y con rifles de madera, se 
levantaron reclamando 500 años de opresión. Escenas dignas de una película de Buñuel aparecen en la televisión: «Los profesionales de la violencia quieren romper la unidad del país y nuestra entrada a los países desarrollados». Una mujer indígena pretende cambiar el orden, una mujer pretende hablar, la subalterna reclama su voz, pero la institución sigue funcionando y la resistencia lo único que hace es resistir, y la mujer lo único que le queda es ser valiente y resistir hasta su asesinato.

Resistencia, con la muerte acechando el indio regresa, se levanta y exige se le reconozca, en voz de una mujer indígena. Pero su muerte recuerda que el subalterno debe silenciarse, lo distinto, el otro, la otra, debe morir. Los Feminicidios se convierten en la herramienta para dar ejemplo. No se dieron cuenta que la sociedad estaba cambiando, murieron muchos y muchas, pero cada muerte significaba un nuevo levantamiento, la autonomía comenzó su construcción.

En términos políticos gubernamentales y sociales, la irrupción del Ejército Zapatista de Liberación Nacional provocó un hecho sin precedentes; los indígenas organizados reclamaban su participación en el espacio público y político, no ya como ciudadanos mexicanos, sino como mexicanos indígenas, defendiendo su propia cultura, su gobierno, su cosmovisión, poco a poco surgieron políticas públicas, expresadas con timidez y con altibajos, que apuntaban a un nuevo proyecto de nación con carácter multicultural (Gutiérrez Chong 2010:128). Esta gran transformación ponía fin o por lo menos el inicio del fin, a la fórmula de homogeneidad del nacionalismo para encontrarse con una democratización de la vida política donde se comenzarán a sentar las bases jurídicas de un verdadero reconocimiento de la diferencia.

La propuesta que defienden algunos como Gutiérrez Chong (González Casanova 2003; Bonfil 1987; Stavenhagen 1968) apunta que el colonialismo español provocó 
necesariamente las guerras de libertarias del siglo XIX, sin que estas rompieran con el dominio colonial, por el contrario, la estructura se mantuvo a través del colonialismo interno. Cabe preguntar entonces ¿qué provocó el colonialismo interno además de la consolidación del capitalismo como sistema dominante? La respuesta es la organización política de los indígenas y su irrupción en el espacio público con una propuesta que no sólo rompe con el colonialismo de más de 500 años, sino con el sistema de dominación totalitaria, el capitalismo.

Esta gran transformación lenta y aún en construcción tiene algunas representaciones claras (Gutiérrez Chong 2010:133-134):

- Aprobación de la Ley en Materia de Derechos y Cultura Indígenas (28 de abril de 2001). Esta legislación es considerada "letra muerta" por carecer de legitimidad social, ya que en los términos en que fue redactada ha "incumplido" los Acuerdos de San Andrés Larráinzar.

- Vigencia de la Ley de Derechos de los Pueblos y Comunidades Indígenas del Estado de Oaxaca (21 de marzo de 1998), que incluye derechos político-electorales y la aceptación de elección por usos y costumbres. Actualmente, ciento cuarenta municipios del estado de Oaxaca eligen a sus autoridades de acuerdo con su tradición jurídica (Labastida et al., 2009).

- Aprobación de la Ley Reglamentaria en Materia de Derechos y Cultura del Pueblo Maya de Yucatán (Agencia Internacional de Prensa Indígena, 2009).

- Experiencias heterogéneas sobre la construcción de instituciones autónoma y autogobiernos en estados de la República ${ }^{64}$

- Elección de Marichuy como candidata independiente y vocera del Concejo Nacional Indígena en las elecciones federales de $2018^{65}$.

\footnotetext{
${ }^{64}$ Por un lado, como reflejo de la creación de instituciones autónomas se tiene la Policía Comunitaria de Guerrero que nació formalmente el 15 de octubre de 1995, en la comunidad de Santa Cruz del Rincón, municipio de Malinaltepec, Guerrero. Como ejemplo de autogobierno, se tiene la creación de Junas de Buen Gobierno en las cinco regiones rebeldes reconocidas por el EZLN, integradas por los cinco caracoles: Selva Fronteriza (La realidad), Tzots Choj (Morelia), Selva Tseltal (La Garrucha), Zona Norte de Chiapas (Roberto Barrios), Altos de Chiapas (Oventic). En el cuarto capítulo se explicará con más detenimiento la formación de estos gobiernos autónomos.

${ }^{65}$ Marichuy no participó como candidata oficial, ya que no recolecto el porcentaje de firmas necesarias ante el Instituto Nacional Electoral, sin embargo, otro candidato presentó el porcentaje necesario, aunque se demostró que era firmas falsas, pudo participar en las elecciones, mientras que
} 
El nacionalismo multicultural en el que ahora vivimos, lamentablemente se enfrenta a un gran enemigo, el sistema capitalista extractivista. Es verdad que se ha avanzado en organización y se ha puesto en marcha una transformación radical del modo en el que la nación está conformada, la emancipación de los indígenas y la defensa de sus culturas es algo real, pero ahora la lucha colonial ha regresado a sus orígenes más violentos, a la completa devastación de los territorios en busca de mayores ganancias, es así que aunque en términos políticos ya existe una cierta preocupación y representación indígena, en términos fácticos siguen estando violentados para robarles sus territorios.

Esto no es un plano específico de México, el extractivismo es una realidad que comparten todos los pueblos indígenas de la región: los mapuches (Chile), los aymaras (Bolivia), los zapatistas (México), entre muchos otros. El colonialismo que viven las comunidades puede verse desde tres esferas: la nacional (colonialismo interno), la internacional (políticas financieras establecidas por el FMI) y el trasnacional (las empresas trasnacionales que saquean sus territorios: mineras, petroquímicas entre muchas otras).

Este breve recorrido histórico muestra cómo los principios de violencia que descansan en la necesidad de dominación: dominar la vida, la cultura, la tierra, los dioses y a la mujer. Los -cidios que emergen de los hechos históricos muestran que es necesaria una transformación de fondo en términos culturales para que las acciones en el ámbito político, público y privado tengan realmente efectos.

México tiene una historia y una realidad plagada de violencias, conocerlas y recorrerlas permiten entender el momento histórico que vivimos y por lo tanto las vías y posibilidades

a Marichuy la dejaron sin participar, aunque se demostró que el 100\% de las firmas presentadas eran reales. 
de paces que ante nosotros se abren. Comprender la historia permite que comprendamos nuestro presente.

\section{Conclusiones}

Este primer capítulo muestra un panorama general de México desde las estadísticas, los relatos de vida y un análisis historiográfico de donde emergen los seis paradigmas de la violencia que pueden ayudar a comprender el escenario de violencia y decadencia que vive el país en la actualidad.

Me he servido de la filosofía para poder analizar tanto las estadísticas como la historia. Sin embargo, es pertinente apuntar la definición de filosofía que en este punto fundamenta el desarrollo de este capítulo:

La actividad filosófica pone en cuestión las creencias adquiridas al pertenecer a una sociedad, para acceder a otras basadas en la propia razón. Cada quien debe examinar por sí mismo los fundamentos de sus creencias. Por eso la transmisión de una verdad filosófica es lo contrario del adoctrinamiento. No consiste en comunicar opiniones, sino en hacer ver las razones en que se funda una creencia, de tal modo que el otro solo hará suya esa creencia si los fundamentos en que se basa se le imponen a su propio entendimiento. (Villoro, 1978: en línea)

Es así que la propuesta que emerge de este camino de actividad filosófica no intenta crear un sistema de análisis sobre el país, y menos aún una sola visión sobre lo que ocurre; es más una postura que invita al diálogo y más aún a la búsqueda de una propuesta de construcción de paz que es el objetivo principal de esta investigación doctoral.

Uno de los elementos principales a destacar en este capítulo es la relación entre colonización española y la neo-colonización con el colonialismo interno, así como la guerra entre la otología relacional y la ontología dual que se empieza a vislumbrar, aunque se analizará en detalle en los capítulos posteriores. De los elementos en común que se han 
destacado entre el periodo colonial y la consolidación de Estado-Nación mexicano surgen los -cidios, aquellos paradigmas de violencia en los que está fincada la construcción del país: genocidio, ecocidio, culturicidio, feminicidio y deicidio. Existe uno más que no ha se ha mencionado, pues atraviesa los otros cinco y se entenderá mejor después de leer el capítulo III; epistemicidio.

Estos paradigmas quieren mostrar cómo fue a través de matanzas que la sociedad mexicana se fue configurando, haciendo de cada-cidio un principio en el modo de actuar y, por lo tanto construyendo un mundo fincado en la dualidad. Explicaré brevemente cada uno de los paradigmas.

1. Epistemicidio: a través de la eliminación de todo conocimiento fuera del método científico europeo, se relegó todo tipo de sabiduría que no fuera objetiva y por lo tanto se generó una escisión devastadora en el conocimiento, la división de la mente con el cuerpo, del pensamiento con los sentidos. Se despersonalizó la sabiduría, convirtiéndola en técnica, no en conocimiento. El proyecto de la razón moderna llega a México a través de los criollos que lo imponen como una dominación más fincada en el concepto de raza, pero se consolida en el país gracias al proyecto de progreso y desarrollo posterior a la revolución.

2. Culturicidio: con la eliminación de todo el conocimiento previo a la época colonial, se eliminaron de la sociedad formas de relación y mundos de acción, provocando que para los seres humanos de nuestra sociedad, las tradiciones y formas de actuar de la comunidad perdieran sentido. La cosmovisión indígena se desvaneció del horizonte de prosperidad quedando relegada a un mundo de superstición y saberes. 
3. Feminicidio: tal y como el pensamiento de María Lugones ${ }^{66}$ muestra, el patriarcado llega a nuestro continente con la colonización, patriarcado que ha supuesto, y lamentablemente lo sigue haciendo, la muerte de miles de mujeres en todo el planeta, mujeres que son concebidas como objetos de dominación, como todo aquello que se sale de los esquemas de la ontología dual. La representación del patriarcado en la explotación y dominación de la mujer indígena es clara, es por ello que la voz que se levanta con el zapatismo en 1994 adquiere un tono feminista como símbolo de resistencia y por lo tanto los deseos de su muerte se hace paradigma para continuar la dominación.

4. Ecocidio: dejar de concebir a la naturaleza como sujeto activo y transformarlo en objeto de dominación, se erigió la muerte por encima de la vida, se construyó un paradigma que ponen en riesgo nuestra misma existencia. El Ecocidio representa la ruptura y la desvinculación de ser humano consigo mismo.

5. Genocidio: durante la conquista, el genocidio no sólo fue un hecho histórico, sino el primer paradigma de violencia bajo el que se cimentaría toda la "nueva sociedad" mexicana. Desde 1521, las mujeres, la naturaleza, las personas, todas se convirtieron en objetos de dominación; la vida dejo de ser fin en sí misma para convertirse en el medio para la acumulación.

6. Deicidio: la religiosidad y creencia del pueblo mexicano está marcada por una doble culpabilidad, por un lado, la culpabilidad del pecado del cristianismo y por otro la culpabilidad de no comprender la vida bajo los designios de un solo dios. Cuando

\footnotetext{
${ }^{66}$ Esta afirmación se comprenderá con el análisis de término raza en el capítulo III. Sin embargo, es de vital importancia considerarlo aquí, pues es un paradigma que se refleja tanto en las estadísticas como en la historia del país.
} 
mataron a los dioses indígenas, mataron una forma de relacionarles con el mundo dejando en su lugar un vacío que se llena algunas veces de culpa y otra de ambición, desapego y desesperación.

Identificar estos paradigmas como sustento de la conformación de la sociedad mexicana permiten comprender las dinámicas sociales y más aún la violencia estructural en el país. El recorrido histórico que se ha realizado en este capítulo aunado a las estadísticas y los relatos de vida permiten profundizar sobre las condiciones actuales de México, pero también para comprender que una propuesta de construcción de paz pasa necesariamente por una transformación radical de la forma en que nos relacionamos ya que, como se analizará a lo largo de esta investigación, las relaciones son las que construyen el mundo. 


\section{Capitulo II: Panorama general sobre la $\mathbf{P a z}^{67}$}

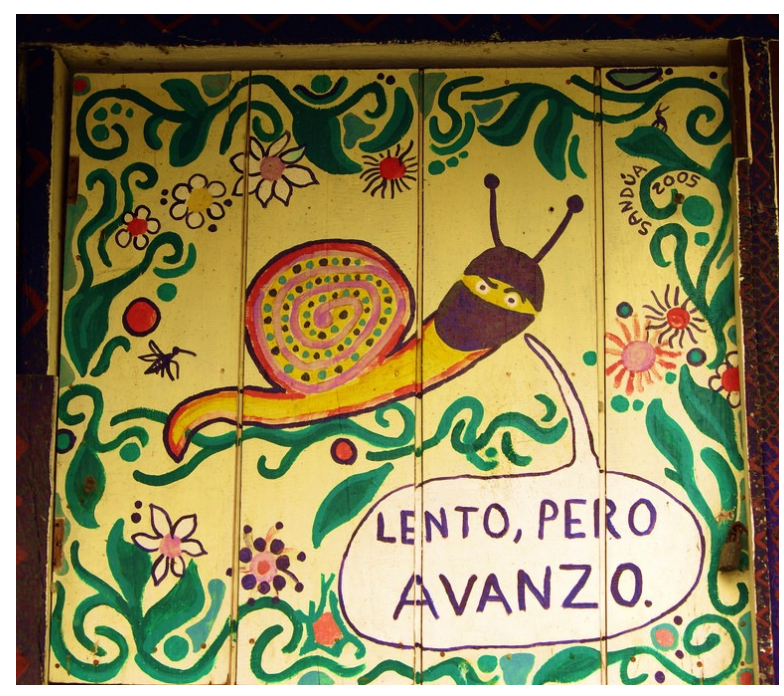

\section{Introducción}

En este breve capítulo se abordará el análisis de tres conceptos fundamentales para la presente investigación: paz, violencia y política. A través de un análisis teórico sobre ellos se podrán comprender, por un lado, el marco que sustenta la visión de paz de esta tesis y por otro las afirmaciones sobre la violencia estructural y los paradigmas en los que está cimentada la sociedad mexicana.

Es interesante mencionar que este capítulo, a diferencia del primero, tiene un trabajo más teórico, donde la metodología aplicada ha sido principalmente un análisis de la literatura sobre los conceptos, sin un estudio de caso específico, aunque siempre se ha tenido en consideración el escenario zapatista, y por tanto la complejidad de los actores involucrados ahí, sobre todo en el análisis del concepto paz/paces y violencia.

\footnotetext{
${ }^{67}$ Este capítulo es parte de la Tesis de Máster: El origen de la violencia: un estudio sobre el poder como dominación y el poder como consenso que presenté en 2013 en la Universitat Jaume I, que es la segunda parte de una investigación que da el marco general de mi investigación doctoral que considero la tercera parte de 10 años dedicada a la investigación filosófica.
} 
A diferencia de los conceptos antes mencionados, el concepto de político tiene como marco general el pensamiento de Hannah Arendt, pues como se verá más adelante en la investigación, es su diálogo con Franz Fanon el que nos permitirá comprender las bases de reconciliación en las que descansa la propuesta zapatista y más aún, la fundamentación metafísica en la que descansa la propuesta de ontología del pluriverso.

\section{Aproximaciones a la $\mathbf{P a z}^{68}$}

¿Qué es la paz? ¿Es posible dar una definición cerrada y aceptada universalmente? Al hacer un repaso rápido sobre la historia de México es fácil darse cuenta de cómo las palabras paz y violencia han sido utilizadas indistintamente provocando muchas veces lo contrario a lo que parecería su definición original. Hay innumerables ejemplos de esto, sólo basta recordar los discursos de declaración de guerra en el último siglo, incluso se puede ir más atrás si se recuerda la frase: «si quieres la paz, prepárate para la guerra». Casi todos los discursos en los que se emplea la palabra paz, la violencia está en el fondo, algunas veces para denunciarla, pero otras como herramienta para alcanzarla.

Johan Galtung, padre de los estudios de paz, es quien otorga este camino de análisis de la paz en relación a la violencia; podría asemejarse esta relación con la que San Agustín analizó el bien y el mal, pero como se verá es bastante limitada cuando se analiza la construcción de paz en diversas comunidades.

\footnotetext{
${ }^{68}$ A lo largo de esta investigación se utilizará la palabra paz y no paces, únicamente porque el zapatismo no lo hace, aunque en el fondo ambas se unen al comprenderla como un proceso inacabado y en constante movimiento, como una construcción constante de armonía, justicia, libertad y dignidad, desde la singularidad de quien la emplea. La palabra "paz" en plural señala el reconocimiento de las muchas maneras de entender y articular la paz, pero en este caso quiero descarta la propuesta zapatista, que su vez tampoco tiene una definición cerrada.
} 
John Paul Lederach, por otro lado, otorga un camino de análisis de la paz en relación a la paz:

Educar para la paz significa colaborar a que el individuo se libere de todo lo que le impide gozar de las cosas más elementales de la vida, debido a la violencia directa o estructural. Estamos demasiado habituados a concebir la paz en términos negativos, es decir, en considerarla como la ausencia de condiciones no deseadas, pero hay que acostumbrarse a entender y querer la paz en términos positivos, esto es, a concebirla como la presencia de condiciones y circunstancias anheladas. Hay que dar oportunidades a la ilusión y a la esperanza, pero de forma seria y rigurosa, y de la mano de personas formadas en la crítica y en la auto-crítica. (Lederach; 2000: 10)

Es necesario dotar de significado a la paz para que sea posible reconocerla en los lugares y momentos en que aparece y mejor aún entender como la paz es la constante y no la violencia.

Lederach brinda cuatro puntos que ayudaran a definir la paz en este sentido (Lederach, 2000:22-23):

1. «La paz es fundamentalmente un concepto negativo. Se define como la ausencia de violencia (bélico/explotación) o como el estado o tiempo de no-guerra. Es la ausencia de "una condición anhelada". Por eso es un concepto muy limitado, que se ha definido cada vez más en función del fenómeno de la guerra y el hecho bélico, hasta el extremo de que, fuera de su contraste con la guerra, la paz parece de contenido palpable»: definir la paz sólo en relación a la violencia deja sin contenido el concepto y más aún hace creer que sólo es posible pensar la paz como espacio en el tiempo en el que no hay una guerra, simplificando la complejidad de las relaciones humanas dentro de una sociedad pues se entiende que el conflicto lleva necesariamente a la guerra y por lo tanto sólo es cuestión de tiempo para que inicie. Pensando en la paz de esta forma se comprende la frase latina: «si quieres la paz, prepárate para la guerra». 
2. «Debido a que la estructura occidental (social, cultural y política) es la dominante en el mundo de hoy, también prevalece su concepción de la paz. Esta concepción nació en gran parte del imperialismo romano, estando muy influenciada por el desarrollo de los estados-naciones. Así, la paz se concibe en función de dos fenómenos. Por una parte, es asimilada al mantenimiento de la unidad y el orden interior (que beneficia normalmente a los intereses dominantes), con una preparación defensiva exterior. Por otra, sólo el Estado nación tiene derecho a usar la fuerza, es decir, la paz es materia y competencia exclusiva de los Estados.» Las relaciones internacionales, como estudios que precedieron a la Investigación para la Paz, revelan esta estructura de la paz, y más aún, se puede relacionar esta línea con las definiciones que tiene Aristóteles o Kant. El primero, al comprender que la estructura social al interior de la polis es la que define la vida y la posibilidad de alcanzar la felicidad, sólo si se vive bajo esta estructura se puede pensar en la felicidad (paz). En Kant, la postura es un tanto más compleja, pues en la Paz Perpetua habla sobre el ideal de una sociedad cosmopolita, donde «seamos» ciudadanos del mundo capaces de desarrollar nuestra racionalidad y aceptar las leyes no por la imposición del Estado sino por la deliberación de nuestra razón. A primera vista esto parece ideal, el problema, como ya he mencionado en el apartado anterior, es que para Kant sólo existía un tipo de sociedad perfecta y es aquélla que se basaba en los ideales de la Ilustración y la modernidad; todas aquellas sociedades que no tuvieran esta base tenían que ser absorbidas por el sistema Estado-Nación, de tal suerte que pudieran evolucionar hasta la sociedad cosmopolita. Incluso en esta absorción era legítimo el uso de la violencia, tal es el caso de las referencias de este autor a las medidas usadas con 
los «salvajes americanos». La cita de Lederach, es fundamental dentro de esta investigación, pues trataré de mostrar cómo las resistencias indígenas, especialmente el zapatismo en Chiapas, son una lucha por la reivindicación de su concepción de paz $^{69}$ y desarrollo; su uso de la violencia es el lenguaje mediante el que les han enseñado los gobiernos eurocentristas. No estoy diciendo que su uso de la violencia sea legítimo, sino que es parte de la sociedad a la que ellos se están resistiendo; más adelante se analizará a profundidad esta afirmación, sólo basta con mencionar que la paz en Occidente, al ser cerrada, es causa de la violencia en cualquiera de sus apariciones.

3. «Esta concepción de la paz ha sido potenciada y propagada por la educación. Normalmente la educación otorga un papel dinámico e importante a la guerra y a la formación de la política internacional actual. La paz, en cambio, queda reducida un proceso estático y poco potente, como una especia de intermedio entre actos en la obra maestra que es la historia». En esta cita Lederach denuncia la necesidad de hablar de la paz desde la educación, pero ¿cómo se puede enseñar algo que no se sabe qué es, que no tiene contenido? Además, el concepto prevalece en relación a la historia y en ella ni siquiera se estudian los momentos de paz, sólo los de violencia. Regresa esta noción hegeliana de que el motor de la historia es la violencia y la guerra. Así, no es posible pensar ni educar para la paz.

\footnotetext{
${ }^{69}$ La palabra paz dentro de la resistencia zapatista se entiende como libertad, justicia y dignidad. Cabe mencionar que esta concepción emerge de la necesidad de liberación frente al horror colonial, como se detalló en el análisis historiográfico, pero no limitan el concepto pues ellos no buscan hacerlo universal. Ellos entienden la paz de esta forma para ellos, pero comprenden que hay otros mundos y otros escenarios en los que no es así, incluso su propia definición está en constante movimiento, pues la libertad, la justicia y la dignidad no son metas que se alcanzan sino ideales que regulan la acción.
} 
4. «Como último punto, podemos reconocer que la paz, hoy en día, está limitada casi literalmente al concepto de paz, en el sentido de pactos, dominación interior y fuerte preparación militar exterior. Igual que en el Imperio Romano, la paz contemporánea refleja los intereses de los que se benefician de la estructura internacional tal como es, es decir, los del centro y no los de la periferia. Por ello hemos de destacar la pobreza de esta comprensión de paz y la manipulación de la misma. Si nuestro propósito es el de estudiar y enseñar la paz, deberemos buscar una concepción más rica y profunda de ella». En esta última cita, Lederach muestra cómo es extremo limitante pensar la paz como acción política o estrategia, y se podría decir incluso que la paz así entendida es sólo un paso previo antes de la guerra, como si no pudiera evitarla más que a través de los pactos. Sin dejar de darle valor a los trabajos de negociación y mediación de conflictos armados en el mundo y su necesaria existencia, se debe ampliar el concepto de paz, dotarlo de un sentido y significado que permitan trascender las circunstancias históricas y/o violentas sin olvidarlas, y aparecer como procesos, actitudes y comportamientos entre los seres humanos y entre los seres vivos.

En resumen, se puede afirmar que Lederach a través de estos puntos motiva una Investigación para la Paz cercana a la antropología y la filosofía, alejándose (sin hacerlo completamente) de la política internacional que la comprende como mediación entre Estados-nación.

Vicent Martínez Guzmán asume los desafíos que presenta Lederach desde su área de conocimiento y presenta una nueva manera de entender la filosofía para la paz como «el conjunto de capacidades humanas para pedirnos y darnos razones o expresar sentimientos por los que nos hacemos a nosotros mismos y a la naturaleza» (Martínez Guzmán, 2001:16), transformando así la teorización y el racionalismo instrumental característico del 
pensamiento occidental europeo ${ }^{70}$, y que fueron y son la causa de muchos de los problemas estructurales (pobreza, injusticia, opresión e inequidad) del mundo contemporáneo.

De este modo, decir que eliminar o erradicar la violencia de las sociedades y por ende

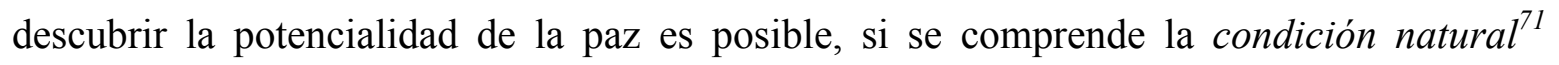
dialógica de las mujeres y los hombres que permite solucionar cualquier conflicto entre los seres humanos de manera pacífica. Aquí se asume una cuestión importante para la nueva definición de la paz y es la existencia constante de conflictos en las relaciones interpersonales $^{72}$. Sin embargo, éstos no tienden necesariamente a la violencia, al contrario, y siguiendo de cerca las teorías de Tortosa, son los elementos que posibilitan el dialogo.

En el artículo «Guerras por la identidad: de la diferencia a la violencia» de José María Tortosa, la diferencia es la base de la unión y la paz, pues ella brinda la posibilidad de dialogar para llegar a consensos empáticos e intersubjetivos; sólo gracias a la existencia de la diferencia es posible la armonía. Sin embargo, también la guerra y la violencia existen por la diferencia, pero se pueden evitar a través del diálogo. Entonces cabe preguntar ¿qué se

\footnotetext{
${ }^{70}$ Hago énfasis en estas palabras ya que la definición de estos conceptos llevan consigo un reduccionismo epistemológico peligroso en el trabajo directo para la transformación de conflictos. Sin embargo es pertinente en este párrafo, pues Martínez Guzmán se refiere específicamente al pensamiento desarrollado por Kant que constituyó el modelo filosófico imperante del siglo XVIII al XX.

${ }^{71}$ Esta condición natural la pongo en cursiva, pues creo que conlleva varios problemas en el terreno teórico de la transformación de conflictos, pues si el diálogo se entiende como una expresión natural y no construida, es posible que la violencia se entienda del mismo modo. Dentro de esta investigación se asumirá que la violencia no es una condición natural de los seres humanos, sino una construcción social y más aún como una posibilidad de acción inadecuada.

${ }^{72}$ Sólo menciono las relaciones interpersonales ya que las relaciones de los seres humanos con la naturaleza y los animales no las concibo como conflictivas, han sido así por una visión antropocentrista, colonialista y masculina, siguiendo los argumentos del artículo de Vandana Shiva Abrazar la vida. Mujer, ecología y desarrollo.
} 
necesita para iniciar el diálogo y evitar la violencia? Según Tortosa tres elementos, según Martínez Guzmán, dos principios y según Lederach una estrategia abierta.

Antes de analizar la violencia en relación a la paz y la diferencia como fundamento de la paz es necesario apuntar algunas de las cuestiones que se han planteado en este apartado para definir o aclarar el concepto de paz que se utilizará en esta investigación.

Primero si se estudia la paz únicamente desde la violencia, se le otorga un estatuto ontológico que es fuertemente perjudicial para la construcción de la paz (Comins, 2018). Sin embargo, de acuerdo a Arendt (1978), es necesario otorgarle ese estatuto ontológico al mal (injusticia y violencia) si es que se quiere entender y minimizar en la sociedad.

Segundo, la paz es un proceso, y por lo tanto no puede tener una definición cerrada, es una potencia del conflicto a través de herramientas como el diálogo intersubjetivo (Martínez Guzmán, 2001, 2005; Cascón, 2000).

Tercero, la paz no puede estar garantizada por el poder, tal y como se presenta en la visión Estado-Nación europea, puesto que se trata de la relación entre los individuos y las capacidades que emergen de este encuentro. En resumen, la paz es el proceso de diálogo que surge del encuentro entre los seres humanos y que privilegia la armonía, la empatía y la intersubjetividad (Vázquez Vidal, 2013).

Ahora para continuar con la argumentación y entender la diferencia como fundamento de la paz que une a Vicent Martínez Guzmán, John Paul Lederach y José María Tortosa, es necesario explicar la noción de conflicto de acuerdo a Ramón Alzate Sáez.

La palabra conflicto deriva del latín conflictus significando "para atacar juntos. El diccionario de la Lengua Española, de la Real Academia, en su edición de 1994, define conflicto en su primera" acepción como: "combate, lucha, pelea", en su segunda como "enfrentamiento armado", en su tercera como "apuro, situación desgraciada y de difícil salida", y, finalmente en cuarto lugar como "problema, cuestión, materia de discusión". Una definición simple que puede ser usada por todos es que 
el conflicto es: "un desacuerdo entre dos o más personas". (Alzate, 2000:38)

Estas variadas definiciones de conflicto muestran, según Alzate, el acercamiento negativo que la mayoría de las personas tiene hacia la diferencia o hacia los desacuerdos, pues los ven como algo que se debe evitar a toda costa ya que necesariamente producen sufrimiento y enfrentamiento violento. Sin embargo, y como bien apunta el autor a lo largo de su trabajo, los desacuerdos entre personas son inherentes a la humanidad y por lo tanto existirán siempre, es imposible evitarlos, pero es plenamente posible transformarlos.

Para esto el autor sugiere una transformación en la percepción inicial de las diferencias, usando cuatro características distintivas de la humanidad: tomar conciencia, tener buena disposición, desarrollar habilidades (para dialogar) y apoyar constantemente a las personas que busquen esta transformación.

En resumen, Alzate defiende la existencia natural de conflictos en toda relación social interpersonal, pero que sólo producen violencia si no se entienden como una posibilidad para dialogar y para ponernos en la posición del otro ${ }^{73}$ ( $u$ otra).

El conflicto como herramienta de transformación social y crecimiento humano también ha sido desarrollada y aplicada desde la educación para la paz con autores como Paco Cascón quien apunta ciertas cuestiones a tomar en cuenta. Los conflictos son (Cascón: 2000):

- Divergencias que tienen como raíz intereses o necesidades antagónicas entre dos o más personas.

- Son connaturales a las relaciones entre seres humanos.

73 Esta frase es vital para la compresión de la intersubjetividad de acuerdo a Hannah Arendt en $L a$ condición humana. A pesar de que no hago mención directa en este trabajo a la obra, me parece pertinente apuntarlo pues toda referencia que hago a la palabra intersubjetividad es bajo esta definición. 
- Se debe transformar nuestra visión y verlos de manera positiva: primero como una herramienta pedagógica valiosísima pues nos enseñan a desarrollar habilidades y aprender herramientas. Por otro lado, es una palanca de transformación social muy potente pues gracias a que entramos en conflicto con estructuras injustas y violentas, el mundo avanza hacia modelos de convivencia más armónicos.

- Se debe entender que no siempre que hay una disputa, que inclusa entra en tono de pelea, estamos frente a un conflicto, muchas veces más que una confrontación de necesidades o intereses, simplemente tenemos un problema de comunicación y respeto. A estos se les conoce como pseudoconflictos.

- Existen otro tipo de conflictos, los latentes que parecen estar en calma que no han estallado y que son fáciles de ver pues no han entrado en crisis. Hay una contraposición de intereses y/o necesidades, pero no es visible. Y muchas veces se queda en un estado de latencia hasta que estalla de manera violenta. Ejemplo: cuando alguien habla en nombre de todo un grupo sin realmente consensuar antes. También la humillación encubierta en "juego" se concibe como un conflicto latente, pues la persona afectada puede ni siquiera ser consciente de la situación de opresión en la que puede estar, la violencia estructural aparece en este escenario.

- El conflicto es un proceso, no es un hecho específico de ahí que sea importante reconocer las fases por las que pasa y tratar de llegar siempre a las causas originarias que lo provocan (antagonismo de necesidades y/o intereses).

Comprender el conflicto bajo estas características ayuda a entender la violencia, tal y como propone Galtung, como una estrategia o un modo de resolver o enfrentar las diferencias o los desacuerdos. Según este autor, hay tres tipos de violencia: directa, estructural y cultural. La primera es la privación inmediata de la vida, la segunda es la privación lenta de la vida y la tercera la legitimación de la violencia directa o estructural a través de discursos hegemónicos principalmente (Martínez Guzmán, 2001: 71) que en el siguiente apartado se analizarán en detalle. 
Ligado a estos tipos de violencia se descubren los tipos de paz posibles; paz negativa como respuesta a la violencia directa. Paz positiva como respuesta a la violencia estructural y, finalmente cultura de paz como respuesta a la violencia cultural. Sin embargo, esta categorización no define ni explica el concepto de paz, por lo que parece pertinente regresar a la definición de filosofía de Martínez Guzmán. Al entender la filosofía como la capacidad de dar razones, se asume una responsabilidad del filósofo/a de buscar y luchar porque todas las personas tengan la posibilidad de dar y pedir razones de las acciones (Martínez Guzmán, 2001:20), y generar espacios para desarrollar esa capacidad dialógica humana es lo que permitirá construir o mejor dicho hacer las paces.

Hasta aquí se han encontrado y explicado los elementos teóricos para hacer las paces, así como mostrar las características humanas que permiten transformar los conflictos. Sin embargo, en la práctica surgen nuevos problemas, pues muchas veces la violencia en un país o grupo no está dividida y se pueden encontrar los tres tipos, además de que se encuentran arraigos culturales que más allá de recordar nuestras afinidades o capacidades naturales, las divide y la diferencia se vuelve tan radical que parece irreconciliable, como es el caso del conflicto histórico-actual de México que se ha analizado con los paradigmas de la violencia en la sociedad mexicana.

En este punto, Martínez Guzmán guía la discusión y muestra que, a pesar de las diferencias culturales, sociales o personales, hay elementos o, mejor dicho, ideales regulativos que son «aquellos ideales que los seres humanos intuimos que nos podemos proponer y que, aunque ideales, son capaces de regular, servir de criterios y criticar nuestras conductas» (Martínez Guzmán, 2001:19). Específicamente, el autor se refiere al consenso de aquellos mínimos que fuercen a buscar el diálogo y la intersubjetividad, y que al mismo tiempo se 
hayan generado de manera intersubjetiva, empáticos e intersubjetivos en sus definiciones; como ya se ha mencionado, son los valores que comparte con el zapatismo.

De acuerdo a Tortosa la transformación de conflictos debe guiarse a través de tres alternativas: «en primer lugar, habrá que afirmar que reconocer el derecho a la identidad personal no es afirmar la necesidad de la homogeneidad del grupo al que se pertenece» (Tortosa, 2000:111).

Esta afirmación establece que toda pertenencia a un grupo, nación, cultura, o todo aquello que consideremos forma nuestra identidad, está condicionada por nuestra individualidad, o mejor dicho, está condicionada por cómo cada persona accede al grupo y, por lo tanto, la homogeneidad es imposible en cualquier escenario social. Con esto se descartan las justificaciones culturales que conducen a la violencia, y relacionándolo con la categorización de Galtung, entender la pertenencia como algo heterogéneo protege, en primera instancia, de los discursos hegemónicos.

En segundo lugar, y frente a la tendencia reciente a fijar las diferencias y hacerlas estables y "normalizadas", hará falta reconocer que la historia de la Humanidad es la historia de sus mestizajes, probablemente la gran constante a lo largo de los siglos por más que haya sido alterada de vez en cuando. Pero hay más: hará falta, además, promover el mestizaje. (Tortosa, 2000:111)

La segunda alternativa que presenta Tortosa se centra en la interesante discusión sobre el colonialismo y el post-colonialismo del que se explicará en detalle en el siguiente capítulo, y que suponía una existencia de «razas» entre los seres humanos pero que queda descartada al reconocer en la Historia la existencia constante de los mestizajes.

Entendiendo esto, es claro lo Tortosa propone, y es que toda transformación de conflictos debe basarse en una aceptación constante y evidente de la mezcla entre culturas y naciones. Esta mezcla debe ser horizontal e intersubjetiva, nunca siguiendo los modelos opresivos de la colonización como los que se han llevado a cabo en toda América. 
Promover el reconocimiento del carácter histórico de los nacionalismos (y no se diga de las naciones) sino que es preciso promover formas de lealtad que no sean a un pretendido Volkgeist o a una civilización sino al resultado del pacto entre individuos libres que libremente han decidido vivir juntos mediante un "plebiscito cotidiano" llamado nación, patria, país o Estado. (Tortosa, 2000:112)

La tercera alternativa se presenta como una estrategia para superar la más común justificación ante la aparición de la violencia, es decir, la justificación nacionalista. Toda aparición de conflicto entre naciones o al interior de una nación debe tener como fundamento aquel plebiscito ciudadano que no es otra cosa más que un consenso intersubjetivo en movimiento.

En resumen, Tortosa muestra un camino práctico y claro para la transformación de conflictos basado en una concepción de la identidad como construcción social-individual en constante cambio, de ahí que sea tan importante reconocer el camino histórico que las naciones han recorrido, en específico el de México que podrían estar (aunque no de manera única) en un periodo de nacionalismo multicultural que abre las puertas a un proceso de construcción de paz real.

Lederach propone una estrategia más difícil de explicar en términos académicos, pero más fácil de reconocer en el mundo $\operatorname{real}^{74}$ para transformar conflictos, a saber, la imaginación moral.

Para definirla el autor lleva (Lederach, 2007) de la mano por cuatro historias de conflictos armados sin aparente relación entre ellos, uno situado en Ghana, otro en Kenia, uno más en Colombia, y el último en Tayikistán. Las causas de la violencia, diversas, los tipos (de acuerdo a la categorización de Galtung) diversos y las soluciones, diversas, pero con un sólo

\footnotetext{
${ }^{74}$ Enfatizo esta palabra para dividir el mundo académico del que no lo es, sin entender que el mundo académico no es real en términos de existencia.
} 
punto en común: fueron propuestas, desarrolladas e implementadas, sin institucionalización o

teorización, por la gente de cada una de las comunidades.

No fue la experiencia técnica introducida por profesionales de la construcción de la paz en Wajir o el Magdalena Medio, o por el profesor-filósofo y su contraparte, el señor de la guerra. No fueron el poder político local o nacional, las exigencias, los temores a una guerra más extendida, ni la influencia y la presión de la comunidad internacional los que generaron el cambio. No fue una particular tradición religiosa: de hecho, los relatos rebasan las religiones. No fue el poder político, económico o militar en ninguno de los casos. ¿Qué fue, por tanto, lo que creó un momento, un punto de inflexión, de tal magnitud que cambió aspectos completos de un escenario de conflicto violento, prolongado? Creo que fue la serendípica aparición de la imaginación moral en los asuntos humanos. (Lederach, 2007:51)

¿Qué es entonces esta estrategia que muestra Lederach? El retorno y desarrollo a esa capacidad de dar razones y exigirnos razones sobre las acciones de la que habla Martínez Guzmán. Es esa creatividad y naturaleza humana de construir relaciones armónicas; es esa capacidad de admiración e indignación sobre la que descansan el amor a la sabiduría de la filosofía; es una muestra inequívoca y evidente de que la paz, o mejor dicho las paces, son la forma más común de relacionarnos.

En resumen, la paz es un proceso humano de construcción que guía las acciones, no puede definirse de forma cerrada y debe entenderse siempre como un concepto en movimiento.

\section{Aproximaciones a la violencia}

El origen de la violencia es la concepción del poder como dominación, tanto en el ámbito público como en el privado (Vázquez Vidal, 2013). Esta afirmación le otorga un estatuto ontológico particular a la violencia, pues no la entiende como algo necesario, sino como una herramienta o instrumento que permite la dominación, es decir, nunca se concibe en sí misma, sino siempre como accidente a algo, en este caso, el poder como dominación. 
Esta primera definición es bastante lejana a la concepción moderna europea de la violencia que se encuentra claramente descrita en autores como Thomas Hobbes, Friedrich Hegel o Karl Marx. Grosso modo, el primero entiende la violencia como una característica natural del ser humano, inherente a su esencia y que por lo tanto debe ser regulada por un ente superior (Hobbes, 1651). El segundo y tercero (Marx, 2010) conciben la violencia como el motor de la Historia, aunque Marx entendía la necesidad de la revolución hasta la última etapa de la historia, el comunismo. En este sentido, la violencia no continuaría siempre.

Estas argumentaciones tienen como consecuencia una normalización de la violencia en la vida cotidiana y que comúnmente se justifican en escenarios como ¿matarías al asesino de tu padre si no tuvieras ninguna consecuencia? La respuesta busca fundamentarse en instintos básicos de agresividad, sobrevivencia y venganza, pero como se analizará más adelante, estas justificaciones son construidas y mitificadas por la cultura y nada tienen que ver con la naturaleza humana, pues como se argumentará a lo largo de esta investigación, la violencia es una forma aprendida de enfrentarse a los conflictos.

La mitificación o violencia cultural es quizá el tipo de violencia más peligroso que se puede conocer en el mundo, pues es aquélla que pasa desapercibida por muchos, aquélla que se enseña en el colegio por tradición, aquélla que forma parte de la idiosincrasia de un pueblo, es aquella violencia que algunas veces se presenta en el discurso como paz. Justo los paradigmas de la violencia que se han analizado en el primer capítulo, son los que a mi juicio conforman la violencia cultural que sostiene el aparato colonial desde hace más de 500 años en México.

Antes de analizar cuidadosamente la tipología de la violencia hecha por Johan Galtung, se debe mencionar un punto de unión de la filosofía para la paz y el pensamiento 
decolonial que posibilitan y fundamentan el desarrollo esta investigación, aunque se detallará la exposición en el siguiente capítulo.

El pensamiento único de la modernidad, justificado lamentablemente en repetidas ocasiones por la filosofía occidental, ha sido causante de una búsqueda de la dominación del ser, del pensar y actuar en el espacio público y privado a nivel mundial a través de la colonización del siglo XVI a XVIII y la nueva colonización económica y cultural a través de la globalización en siglo XX (además de la colonización interna que trae consigo a cada región donde llega); esto le otorga a la violencia un lugar predominante en la construcción cultural de las sociedades, como se ha justificado en el caso de México, pues no es posible mantener la dominación sin el uso de la violencia y es necesario legitimar ese uso mediante un principio incuestionable: la naturaleza.

Este recurso ha sido utilizado un sinfín de veces dentro de la historia de la humanidad, basta con recordar los fundamentos naturalistas del derecho en Europa (ius naturalis), los fundamentos naturalistas de las religiones más difundidas en el mundo (cristianismo, islam y judaísmo), los fundamentos naturalistas de los gobiernos totalitarios como el de Adolf Hitler y los de la teoría de la esclavitud y la política en Aristóteles. Todas ellas tienen como consecuencia común la necesaria existencia de la violencia en el mundo y la imposibilidad de erradicarla.

En la actualidad estas teorías se pueden comprender a través del sistema económico en donde la pobreza, la marginación, la injusticia, etc. se vuelven necesarias para que exista la paz $^{75}$. Por ejemplo, la acumulación del capital de unos cuantos seres humanos en el mundo es posible si existen seres humanos a los que no les toca nada o gracias a que en el sur se

\footnotetext{
${ }^{75}$ Entendiendo ésta como riqueza únicamente bajo esta estructura de pensamiento.
} 
explotan recursos naturales y a la gente, es posible que en el norte se cubran y excedan todas las necesidades. Es como si en el mundo existieran 10 patatas y la paz se entendiera como la posibilidad de tener esas 10 patatas y más aún, que ese deseo de dominación de esas 10 patatas fuera condición necesaria y natural de la humanidad.

El pensamiento decolonial, la filosofía de la liberación y la filosofía para la paz, mediante su denuncia al pensamiento único de la modernidad, la marginación y el empobrecimiento de algunas regiones del continente, se unen en la comprensión de la violencia como herramienta y vía de acción frente a un conflicto. Es importante recordar que el auge de estas corrientes de pensamiento se da después de la caída del muro de Berlín, cuando la comprensión del mundo se transforma; ahora no se comprenden las regiones de acuerdo a sistemas políticos y económicos (socialismo y capitalismo) sino en las regiones del norte (desarrolladas) y las regiones del sur (en vías de desarrollo). Esto es particularmente interesante, pues la violencia en el escenario internacional aparece ahora como consecuencia de un retraso en el desarrollo y por la tanto es posible transformar radicalmente su definición hacia un instrumento del poder. En resumen, estas corrientes de pensamiento reconocen la violencia como herramienta y ya no como elemento natural, y es así cómo se comprenderá a lo largo de esta investigación. La siguiente cita muestra en detalle algunas de estas afirmaciones:

Efectivamente, en el mundo actual la violencia se manifiesta en las guerras y en todas las instituciones que las soportan (ejércitos, armamentismo), en el ejército (obediencia irreflexiva del soldado, castigos fuertes, autoritarismos, jerarquización), en la economía (falta de recursos, explotación, discriminaciones, marginación), en la política (dominio de uno o varios partidos, totalitarismo, exclusión de los ciudadanos en la toma de decisiones, lucha armada por el poder), en la ideología (subordinación de la información a intereses ajenos a la "verdad", manipulación de la opinión pública, propaganda de conceptos de trasfondo violento y discriminador), en la familia(autoritarismo, discriminación de la mujer, subordinación de los hijos), en la enseñanza 
(pedagogías no liberadoras, autoritarismos pedagógicos, castigos corporales, intransigencias, desobediencia injustificada), en la cultura (etnocentrismo, racismo, xenofobia, discriminación de género, androcentrismo, consumismo). Aunque la violencia se institucionaliza socialmente, sólo en la historia "reciente" de la humanidad se fija como un modo de mantener el poder y la supremacía de algunos grupos. (Jiménez-Bautista, 2012: 18)

Incluso, la UNESCO a través del «Manifiesto de Sevilla, en el que participaron 17 especialistas mundiales, representantes de diversas disciplinas científicas, mediante una reunión en mayo de 1986 en Sevilla, España» defiende esta postura, al considerar a la violencia como un ejercicio de poder, «refutando el determinismo biológico que trata de justificar la guerra y de legitimar cualquier tipo de discriminación basada en el sexo, la raza o la clase social» y por lo tanto la violencia «es evitable y debe ser combatida en sus causas sociales (económicas, políticas y culturales).»(Jiménez-Bautista, 2012: 16). En éste se declara como científicamente incorrecto:

- Afirmar que el ser humano haya heredado de sus ancestros los animales la propensión de hacer la guerra, puesto que es un fenómeno específicamente humano, producto de la cultura.

- Pretender que hemos heredado genéticamente la propensión de hacerla guerra, puesto que la personalidad está determinada también por el entorno social y ecológico.

- Inscribir la violencia en la selección realizada, a través de nuestra evolución humana, a favor de un comportamiento agresivo en detrimento de otros tipos de conducta posibles como la cooperación o la ayuda mutua.

- Afirmar que la fisiología neurológica nos obliga a reaccionar violentamente, puesto que nuestros comportamientos están modelados por nuestros tipos de acondicionamiento y nuestros modos de socialización.

- Decir que la guerra es un fenómeno instintivo que responde a un único móvil, pues la guerra moderna pone en juego tanto la utilización de una parte de las características personales (obediencia ciega o idealismo) y aptitudes sociales como del lenguaje, como planteamiento racional 
(evaluación de costes, planificación, tratamiento de la información) (Jiménez-Bautista, 2012:16)

En resumen, esta investigación sostiene que cualquier tipo de jerarquización provoca, causa y sostiene todo tipo de violencia, mientras que los movimientos igualitarios y la construcción social y política de comunidades horizontales son aquéllas que son capaces de generar soluciones pacíficas a los conflictos, como sucede en las comunidades zapatistas de Chiapas, en el sureste mexicano.

Ahora, dentro de los grandes avances de la Investigación para la paz, y gracias a Johan Galtung, como ya se ha mencionado, se tiene un estudio profundo sobre las formas o tipos de violencia en el mundo; el teórico noruego, como ya hemos visto, las divide en tres: violencia directa, violencia estructural y violencia cultural (Galtung, 1998), pero como se argumentará, las tres tienen origen en el poder como dominación, y a la vez no pueden existir por sí solas hablando en un plano ontológico, demostrando así la afirmación con la que se ha abierto este apartado.

La tipología de Galtung está fundamentada en su famoso triangulo ABC en el que A representa las actitudes, $\mathrm{B}$ el comportamiento y $\mathrm{C}$ la contradicción subyacente al conflicto (es la raíz del conflicto). El desarrollo del conflicto define la relación entre estos sectores y la violencia emerge de esta relación y se relaciona con cada tipo de violencia Galtung, 1998: $15)$. 


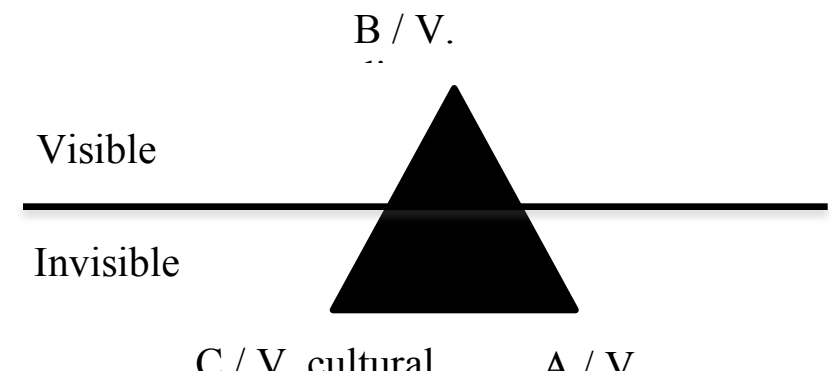

$$
\text { C/V. cultural A / V. }
$$

La violencia que es visible en forma de conductas es la violencia directa. Este tipo de violencia se caracteriza por la privación de las necesidades básicas de supervivencia mediante el homicidio o el genocidio, de bienestar mediante la mutilación, sanciones y miseria, de la identidad mediante la resocialización desde la propia cultura y la ciudadanía de segunda clase, de la libertad mediante la represión, detención y expulsión.

En resumen, la violencia directa «es la privación inmediata de la vida» (Martínez Guzmán, 2001: 71). Se puede comprender la violencia directa como las conductas dentro de una guerra o conflicto armado ${ }^{76}$. Como la imagen lo muestra, la violencia directa tiene raíces en la cultura de la violencia y en la estructura de la sociedad, es decir, la violencia directa emerge de «una cultura de la violencia (heroica, patriótica, patriarcal, etc.) y una estructura

\footnotetext{
${ }^{76}$ De acuerdo a la investigación de Francisco Jiménez-Bautista: el conflicto armado es definido como un conflicto que produce al menos 25 muertes anuales en el campo de batalla. Hay tres tipos de conflictos armados: menor, intermedio y guerra. Un conflicto armado menor se caracteriza por causar no más de 1000 muertes en el campo de batalla durante todo el conflicto. Un conflicto armado intermedio causa más de 1000 muertes en el campo de batalla en el curso del conflicto, pero no más de 1000 por año. Las guerras se caracterizan por causar más de 1,000 muertes anuales en el campo de batalla. Los civiles están incluidos en el conteo de muertes. En América Latina, entre 1989 y 1993 , con una interrupción en 1991, Colombia estuvo técnicamente en guerra y, desde entonces, ha permanecido en un estado de conflicto intermedio. Similarmente, Perú estuvo en guerra hasta 1993 y El Salvador hasta 1991 (Wallesnteen y Sollenberg, 1996 y 2000); lo mismo se podría decir de México desde el año 2009 y Colombia durante toda la década del presidente Álvaro Uribe (20022010) (Jiménez-Bautista, 2012: 22). México bajo estos parámetros se encuentra en medio de una guerra desde 2006.
} 
que en sí misma es violenta por ser demasiado represiva, explotadora o alienadora» (Galtung, 1998: 15)

Específicamente, «la violencia estructural es la suma total de los mitos de todos los choques incrustados en las estructuras sociales y mundiales, y cementados, solidificados, de tal forma que los resultados injustos, desiguales, son casi inmutables» (Galtung, 1998: 15); es decir, la violencia estructural es aquélla «privación lenta de la vida debido a las condiciones de vida del barrio o de la ciudad» (Martínez Guzmán, 2001: 71). Aquí entran la marginación, la pobreza, la exclusión social, la explotación, la muerte por enfermedades curables, entre otras. Los efectos de la violencia estructural son visibles en el tiempo, es por eso que el teórico noruego las pone en la invisibilidad. Sin embargo, hay escenarios como el chiapaneco en donde la violencia estructural se funde con la directa y es prácticamente visible a diario, como se detallará en el capítulo IV.

Por último, «la violencia cultural es la suma total de los mitos de gloria y trauma y demás, que sirven para justificar la violencia directa» (Galtung, 1998: 15), es decir, «es la legitimación de las otras: religión, ideología, lenguaje, banderas, himnos...» (Martínez Guzmán: 2001: 71) donde se glorifica y mitifica el uso de la violencia. Es aquí donde se inserta el pensamiento único que antes se ha mencionado; esa construcción que legitima en cualquier esfera y con cualquier medio el uso de la violencia. Lo más peligroso de este tipo de violencia es su invisibilidad y la potencia de alienación mediante discursos públicos, propaganda, moda, medios de comunicación masivos y normalización de actos violentos en la vida cotidiana.

La violencia cultural es fundamento de la violencia estructural, y ambas de la violencia directa y por lo tanto la búsqueda de la paz debe estar orientada a la transformación 
de la violencia cultural, que dentro de la obra de Galtung, se comprende como la construcción de una cultura de paz.

Asumir esta postura implica afirmar que la violencia es herramienta e instrumento y aparece no por naturaleza, sino por elementos que la construyen. Estos elementos son la búsqueda de dominación. Por lo tanto, la transformación del poder como dominación, al poder como consenso y diálogo, es la que posibilitará la construcción de paz. Sin embargo, esta transformación puede ser violenta, pacífica o noviolenta. La primera se analizará desde la perspectiva decolonial y la segunda y tercera desde la filosofía para la paz con Hannah Arendt en el cuarto capítulo, de tal suerte que se puede analizar la construcción de paz que existe en las comunidades zapatistas de Chiapas.

Antes de terminar este capítulo es necesario abordar una última noción fundamental para el desarrollo de la investigación y es el concepto de política en la filosofía arendtiana. Se toma como referencia la obra de Arendt, pues comparte tanto con la filosofía para la paz y el pensamiento decolonial, la comprensión de la política como el entre de los sujetos y no la capacidad de mandar sobre una sociedad.

\section{El concepto de política en Hannah Arendt}

Hannah Arendt es quien puede ayudar a la transformación de la política través de la crítica que hace a la modernidad. En su crítica (La vida del espíritu, 1978), Arendt se da cuenta que desde el siglo XVI con Maquiavelo, la política se convirtió en sinónimo de poder (dominación), olvidando lo que los griegos ya habían dicho sobre la verdadera ciencia práctica. Aristóteles: 
«es evidente que existe una ciencia a la que corresponde indagar cuál es la mejor constitución, cuál, más que otra es adecuada para satisfacer nuestros ideales, cuando no existen impedimentos externos, y cuál se adapta a las diferentes condiciones para ser puesta en práctica. Ya que es casi imposible que muchos puedan realizar la mejor forma de gobierno, el buen legislador y el buen hombre político deben saber cuál es la mejor forma de gobierno dentro de las determinadas condiciones». (Aristóteles, IV, 1, 1288 b 21)

En esta definición se ve la doble tarea de la acción política, o, mejor dicho, las tareas naturales que emanan de la esencia de la política: la primera, plantear la constitución de un Estado ideal que regule las acciones del mundo como el lugar que se desea alcanzar; y segundo, la de especificar cuál es el gobierno adecuado para una sociedad, según las condiciones y circunstancias que se tengan.

De esta manera, puede decirse que la principal función de la política es establecer los lineamientos para tener una sociedad justa y buena, lo que lleva a otro punto, olvidado desde el siglo XVI: entender que la verdadera política sólo existe cuando está en relación directa con la ética. Según expone Adela Cortina en su libro, Justicia Cordial (2010) «la justicia es lo socialmente exigible, aquello que se puede racionalmente universalizar, el corazón ético que late en la buena economía, la buena política, la buena actividad social, el buen derecho» (Cortina, 2010: 12). Es decir, sólo a través de la unión entre política y ética es posible la existencia de la justicia en el mundo; esto es de gran relevancia para el estudio que se hará a lo largo de esta investigación, pues quien guía los pasos de la política es la ética, la búsqueda de lo justo, de lo digno y de lo armónico.

La armonía de acuerdo a la estructura de Arendt se hace mediante la intervención de la phronesis, la virtud propia de la parte deliberante o racional del alma; la que nos permite dar cuenta de aquello que es bueno en un mundo donde existe el mal (injusticia y violencia). De aquí surge otra cuestión importante, discutida en la época de Aristóteles: la condición 
(moral) que debe tener el gobernante. En ese entonces se establecía que el hombre más virtuoso debía ser el que dirigiera a la sociedad, pues sólo él sabría qué es lo mejor para el pueblo. En resumen, política era la ciencia que establecía los parámetros para una relación armónica entre los ciudadanos y, al mismo tiempo, forzaba a los hombres a encontrar la virtud en la acción pública.

Finalmente se puede decir que política para los griegos era una búsqueda constante de justicia y virtud, cuestión que cambia radicalmente siglos después. Es claro que también con la definición aristotélica se entendió a la política como una teoría ética del Estado, pues lo que se quería era encontrar el Estado perfecto.

Cuando el Estado, a partir de Hegel, se entiende como "el Dios real", la forma de hacer política adquiere un carácter tanto descriptivo, como normativo. Heinrich Von Treitschke, politólogo alemán del siglo XIX, explicaba esta función:

The task of Politics is three-fold. It must first seek to discover, through contemplation of the actual body politic, what is the fundamental idea of State. It must then consider historically what the nations have desire in their political life, what they have created, what they have accomplished, and how they have accomplished it. This will lead on to the third object, the discovery of certain historic laws and the setting forth of some moral imperatives (Treitschke, 1916: 33)

En otras palabras, la divinización del Estado lleva a entender la política como fuerza y poder (como dominación). Pero el estudio que hace Arendt sobre este tema suele ser más apegado a las concepciones originarias; ella trata de explicar la naturaleza de la política para entonces entender el ámbito en el que se desarrolla y las repercusiones que tiene en la vida de los seres humanos.

En ¿Qué es política? (1993), Arendt ofrece una primera definición; justo la que se ha mencionado en varias ocasiones a lo largo de este apartado. Para ella, política es la simple 
relación entre los hombres ${ }^{77}$, pero el énfasis queda puesto en el entre, pues ahí es donde se pueden establecer las reglas de la relación, lo que lleva a la segunda definición que no es ya sobre la palabra misma, sino sobre el medio en el que la política se lleva a cabo, a saber, la esfera política o pública, que es el modo de organizar la vida en común de una sociedad a través de leyes e instituciones.

En el Diario Filosófico (2006), Arendt establece que la política se define como «Un ser visto y oído en oposición al estar consigo mismo, como la pluralidad frente a la singularidad, como convivencia (animal social), acción conjunta (animal politikon) y un habla entre sí (logon éjon), en contraposición al uno individual, a la intuición pura y al noein. Como la vida activa frente a la vida contemplativa, como lo social a diferencia de lo íntimo, como seguridad de la vida de las especies en contraste con la vida del individuo, como comunidad frente al individuo» (Arendt, 2006: 519)

Según se establece en esta cita, lo político es el mundo, es el lugar donde puede darse esta contraposición entre lo individual y lo múltiple, es el lugar en el que se da la convivencia entre los seres humanos, donde se unifican la vida contemplativa y la vida activa; el lugar donde los seres humanos son verdaderamente humanos.

Para clarificar qué es lo político de acuerdo con Arendt, se tienen que explicar tres términos:

1. «Lo privado: (el) metabolismo con la naturaleza, o trabajo, o metabolismo con lo necesario, mejor dicho, sometido a lo coactivo» (Arendt, 2006: 513): es el ámbito donde se resuelve la necesidad, es decir, la alimentación y la reproducción, lugar también donde encontramos la amistad y el amor.

\footnotetext{
${ }^{77}$ El uso sexuado del lenguaje en la obra de Arendt, está siempre presente y es por eso que lo encontraremos en algunas citas y explicaciones que hago de la autora.
} 
2. «Lo público: es aparecer, mostrarse en libertad; es el lugar donde lo privado se convierte en embarazoso» (Arendt, 2006: 513) es el ámbito donde los seres humanos aparecen ante los demás y se relacionan a través del diálogo, dejando de lado la violencia. Según Arendt, éste es el espacio propio de la libertad, pues es allí donde se atienden los temas que no conciernen a la necesidad, entendiendo esto como lo indispensable para vivir, además de que es el lugar en donde todos los seres humanos son iguales y nadie le debe obediencia a nadie, al menos en la teoría, pero es justo en este ámbito donde se encuentra la violencia estructural, pues al no estar resueltas las necesidades en el ámbito privado surgen las inequidades del espacio público que se muestran como opresión y voces silenciadas.

3. «La sociedad: la unión de la referencia recíproca en la necesidad» (Arendt, 2006: 514). Es aquello que surge de la relación entre los seres humanos y la fusión de los dos ámbitos que se mencionaron arriba, lo público y lo privado.

Los espacios de los que se está hablando aquí muestran que lo más importante de la política es la relación, pues la necesidad se transforma con la ayuda, y los conflictos de la convivencia social se transforman con el diálogo.

La relación entre la vida pública y la privada está basada en la unidad entre cuerpo y alma, en la acción social que surge de la relación privada. Es decir, la relación entre la vida activa y la contemplativa es la política, pues el origen de ella está en las relaciones que se hacen en el ámbito privado y se ven desarrolladas en el ámbito público.

\section{Conclusiones}

A lo largo de este breve capitulo se han analizado los conceptos principales en los que descansa la investigación. Si bien en el primer capítulo ya se utilizaron sin una definición 
académica para poder comprender la complejidad de la realidad mexicana, en este segundo capítulo se han delimitado teóricamente para poder así construir lo que en el siguiente capítulo se denominará como "puentes de entendimiento".

De los elementos a destacar en el análisis de los conceptos se debe resaltar que, si se estudia la paz únicamente desde la violencia, se le otorga un estatuto ontológico que es fuertemente perjudicial para la construcción de la paz, pues se le deja de considerar como accidente. Sin embargo, de acuerdo a Arendt (1978), es necesario otorgarle ese estatuto ontológico al mal (injusticia y violencia) si es que se quiere entender y minimizar en la sociedad.

Segundo, que la paz es un proceso y por lo tanto no puede tener una definición cerrada, es una potencia del conflicto, que también es un proceso, que se construye a través de herramientas como el diálogo intersubjetivo.

Tercero, la paz no puede estar garantizada por el poder, tal y como se presenta en la visión Estado-Nación europea, puesto que se trata de la relación entre los individuos y las capacidades que emergen de este encuentro. En resumen, la paz es el proceso de diálogo que surge del encuentro entre los seres humanos y que privilegia la armonía, la empatía y la intersubjetividad.

Por otro lado, la violencia tiene dos características interesantes. Por un lado, tal y como pide Arendt, es necesario que tenga un estatuto ontológico que dota de sentido su existencia, este estatuto le viene otorgado por la concepción arendtiana de mal (injusticia y violencia), es así que se le quitan todos los elementos irracionales para concebirlo como un modo de hacer algo. Y es aquí donde surge su siguiente característica, y es que la violencia es siempre instrumental, es siempre accidental, depende de otros para existir y de quien lo hace directamente es el poder entendido como dominación. 
Además, la violencia aparece en el mundo de tres maneras, directa, estructural y cultural. De estas tres, la más peligrosa, pues es el fundamento de las otras dos, es la violencia cultural, justamente donde descansan esos paradigmas identificados en el primer capítulo. Es así que se puede afirmar que la base de la violencia cultural de la sociedad mexicana está constituida por: genocidio, deicidio, feminicidio, culturicidio, epistemicidio y ecodidio.

Por último, se ha analizado rápidamente el concepto de política dentro del pensamiento arendtiano para mostrar dos cuestiones importantes a tener en cuenta, primero el momento histórico en el Arendt descubre la gran transformación de la política, que es el siglo XVI con la obra El Príncipe de Maquiavelo, mismo siglo de la conquista de América, y por lo tanto de la expansión del modelo de dominación por toda la tierra, como ya se ha argumentado en el primer capítulo. Y segundo, que la política es el lugar donde la ética aparece, donde se debe y se puede hablar sobre paz, este es justamente uno de los elementos principales que se tomarán en cuenta, pues la paz es política, aunque no sólo (ya que aparece también en el ámbito privado). 


\section{Capitulo III. De marcos teóricos a puentes de entendimiento}

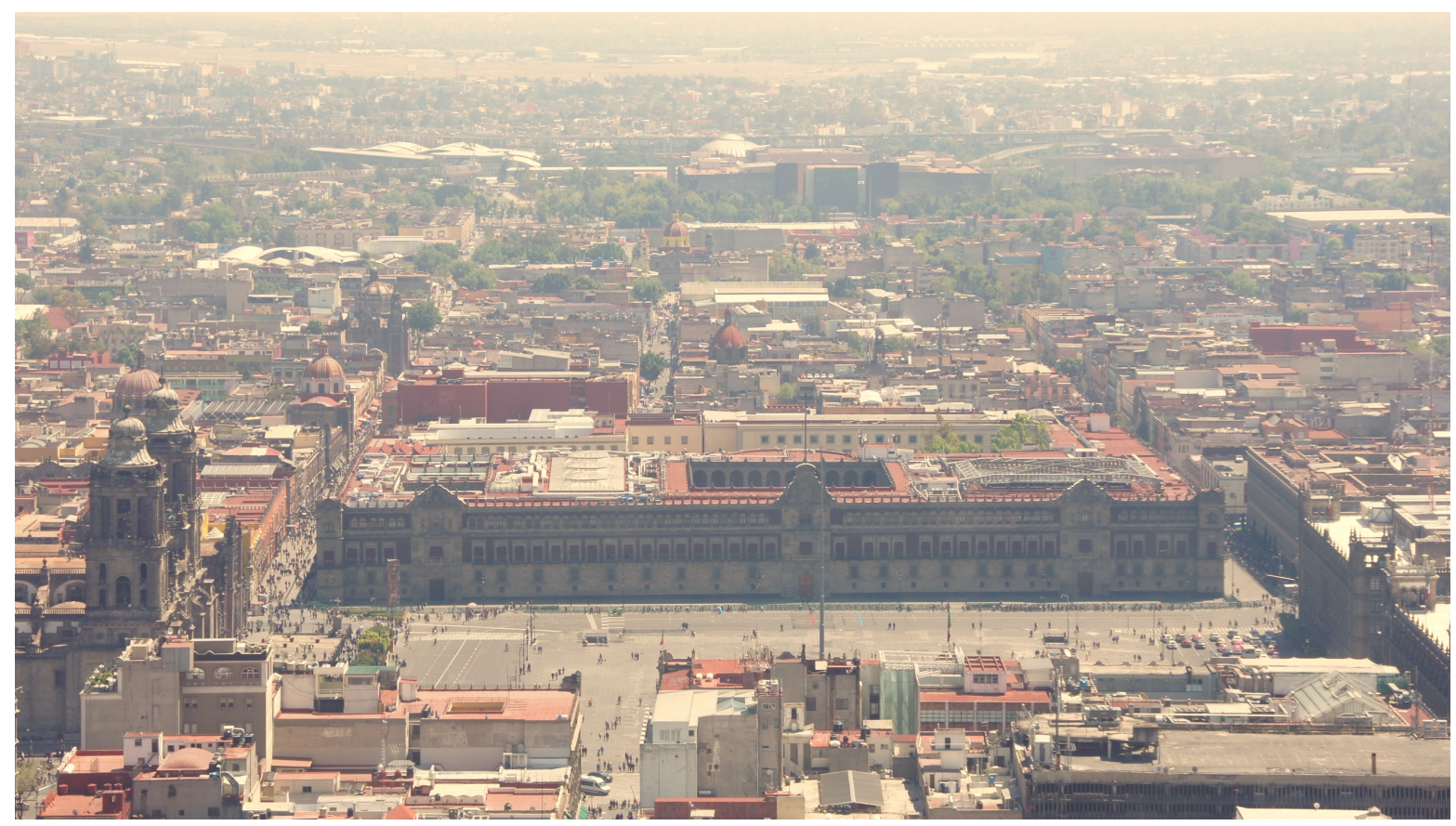

Iniciar este capítulo con una imagen del centro histórico de la Ciudad de México no es algo casual; por el contrario, quiero que el lector o lectora intente perderse en la fotografía. Este lugar es la representación de toda la belleza y magnificencia de México, pero a la vez, del caos, la contaminación y el encuentro (pacífico y violento) constante de sus habitantes. En la imagen se puede apreciar el Palacio de Gobierno, la Catedral Metropolitana y los restos arqueológicos de Templo Mayor (capital azteca). Cada uno representa los pilares de la sociedad mexicana: el gobierno federal, las raíces indígenas y la fuerza de la iglesia católica.

Con esto en la mente y en los ojos se debe comprender que la metodología de esta investigación es entender la realidad mexicana desde mi subjetividad (con intencionalidad y compromiso), generando un pensamiento reflexivo y en diálogo constante con el otro, capaz de reconocer para eliminar las relaciones de poder-dominación y generar así un pensamiento emancipador, abierto y en movimiento. 
Para iniciar este recorrido que además tiene como objetivo teórico la creación de puentes de entendimiento entre diversas corrientes de pensamiento, es necesario describir el lugar de donde vengo en términos epistémicos y así emprender un camino que nos llevará a analizar primero la filosofía clásica occidental en la que está fundada mi formación, después el salto a la filosofía para la paz de las investigaciones realizadas en el marco de la Cátedra UNESCO de Filosofía para la Paz de la Universidad Jaume I. Más adelante el análisis del pensamiento decolonial y las corrientes que lo construyen, después el enriquecimiento teórico que surge de los estudios de paz, para finalmente regresar a lo que considero como el puente de entendimiento a través del pensamiento de Hannah Arendt y su respuesta al pensamiento de Frantz Fanon y la propuesta epistémica del pensamiento en resistencia (varios autores).

Este capítulo es quizá uno de los más complejos y largos de toda la investigación, porque se mueve casi en su totalidad en el ámbito teórico y utiliza un lenguaje bastante académico, por lo que he decidido intercalar fotografías como un acto de resistencia epistémica que ayudará a completar y al mismo tiempo complejizar la investigación.

\section{De la Filosofía Clásica Occidental a la Filosofía para la Paz}

La filosofía para la paz es una corriente de pensamiento particularmente nueva si se toma en cuenta la tradición filosófica europea (más de 2500 años de historia). Su novedad y originalidad se fundamentan en una reestructuración y reinterpretación de los valores y pilares de la filosofía occidental tradicional en favor de la paz. Su origen histórico temporal y conceptual son de suma importancia para esta investigación, así como las teorías de dos grandes representantes: por un lado, Vicent Martínez Guzmán y por otro Hannah Arendt, a pesar de que esta segunda no es claramente una pensadora para la paz, sino una teórica 
política, pero como se verá, su concepción política es el pilar filosófico de la construcción de paz en el pensamiento de Martínez Guzmán.

Antes de adentrarnos en el pensamiento de estos autores es de vital importancia un repaso de la historia de la filosofía occidental, ya que ha sido utilizada como justificación teórica de la violencia en las tres vías que define Johan Galtung (directa, estructural y cultural) (Martínez Guzmán, 2001) y por lo que se plantea como necesaria una transformación.

Se hará un breve recuento histórico haciendo especial hincapié en la Grecia antigua (siglo IV a. C), la época de la conquista de América y la modernidad (a partir del siglo XVI), para comprobar sus relaciones con la violencia.

En la historia de la filosofía occidental $^{78}$ la palabra filosofía, según la tradición:

[...] ha sido forjada por un espíritu religioso, que presuponía como posible una sofía (una sabiduría) es decir, la posesión cierta y total de lo verdadero, sólo para los dioses mientras reservaba para el hombre solamente una tendencia hacia la sofia, un continuo acercarse a lo verdadero, un deseo de saber nunca satisfecho del todo, justamente el nombre de la filo-sofía, es decir, "amor por la verdad" (Reale, 2007:29).

Como se puede ver desde esta antigua explicación emerge uno de los rasgos característicos del pensamiento occidental, la búsqueda de la universalidad, la construcción de verdades absolutas y el incesante deseo de los seres humanos por acercarse al «pensamiento absoluto». Para los pensadores griegos la filosofía era una aspiración de los seres humanos por la verdad,

\footnotetext{
${ }^{78}$ Para este recorrido histórico me baso en las obras de Giovanni Reale, quien dedica varias páginas en el primer tomo de Historia de la Filosofía, para decir que no existió filosofía en ningún otro lugar antes que en Grecia, algo que no es correcto pues la cultura egipcia, árabe o japonesa muestran grandes avances en este ámbito. Sin embargo es necesario apuntarlo porque pensar que la filosofía es un descubrimiento de occidente, nos enmarca ya en un contexto universalista y eurocéntrico, que como trataré de explicar más adelante, serán las características por las que la Filosofía puede construir más la violencia que la paz en ciertos contextos, incluso dentro del pensamiento de Vicent Martínez Guzmán.
} 
es un deseo de los hombres por saber. Aquí es necesario hacer hincapié en los hombres ${ }^{79}$ que comenzaron esta ciencia:

[...] ¿Por qué sintió el hombre la necesidad de filosofar? Los antiguos respondían diciendo que tal necesidad está radicada estructuralmente en la misma naturaleza del hombre: "Todos los hombres - escribe Aristóteles- por naturaleza aspiran al saber" (Metafísica $\left[985 \mathrm{a} 23^{\mathrm{l}}\right.$ ). Y también: "El ejercitar la sabiduría y el conocer son deseables para el hombre por sí mismos: en efecto, no es posible vivir como hombre sin estas cosas" (Reale, 2007:29).

Esta cita es particularmente importante para esta investigación pues éste será uno de los principios de la filosofía para la paz de Martínez Guzmán: el descubrimiento de la racionalidad humana por los pensadores occidentales. Tales afirmaciones traerán consecuencias políticas y éticas peligrosas, pues de manera muy sutil, justificarán la violencia hasta nuestros días. Pero sigamos con la historia de la filosofía griega antes de adentrarnos en el pensamiento de Vicent Martínez Guzmán.

La acción de filosofar en la antigua Grecia condicionaba la vida de los seres humanos, siguiendo muy de cerca las enseñanzas de Platón y Aristóteles, hacia la felicidad, pues desarrollaban su potencial natural. Para el Estagirita: «los hombres tienden al saber porque se sienten llenos de “estupor” y de “asombro”» (Aristóteles, 980a-981a), así se puede afirmar que el origen de la filosofía radica en el asombro de los seres humanos frente a la realidad que les rodea:

Este "asombro" pues, que surge en los hombres, se pone en confrontación con el Todo (el Entero) y se pregunta por el origen y el fundamento del mismo y qué lugar ocupa él mismo en ese universo, es la raíz de la filosofía. Y si es así, entonces la filosofía es ineludible e irrenunciable justamente porque no se puede eliminar el asombro frente

\footnotetext{
${ }^{79}$ En este caso me permito decir hombres, pues justamente es parte del carácter inicial de esa filosofía aunque haya grandes filosofas de la época como Hipatía de Alejandría que hizo grandes aportes a las matemáticas, la astronomía y es considerada como la primera filósofa en la historia occidental.
} 
al ser, como es irrenunciable la necesidad de satisfacerlo. (Reale, 2007:29)

En resumen, en la Grecia Antigua hay dos elementos esenciales del filosofar, la naturaleza humana (la razón) que busca desarrollarse y el asombro ante la realidad (el ser) que motiva el quehacer filosófico. Al unirse regresan a la definición etimológica de la filosofía: amor a la sabiduría.

Estos principios parecen inofensivos e incluso podríamos decir que son universales y justifican en toda medida nuestro actuar académico. Sin embargo, el problema que surge es en el paradigma de racionalidad y asombro que establecen. Quedará mejor explicado a través de unos de los puntos más duros del gran pensador griego; Aristóteles.

\section{Del asombro de la realidad a la construcción de una episteme dominante}

Es de sobra conocida la fundamentación aristotélica sobre la esclavitud y la sumisión de los bárbaros frente a los ciudadanos de polis griega, pero a pesar de ser una de las teorías más estudiadas dentro del corpus, algunos autores la minimizan al grado de arrinconar a la douleia como «curiosidades inconexas» (Zagal, 1996: 154) o de los condicionamientos culturales de las obras. Sin embargo, la esclavitud natural para Aristóteles es un acto irrefutable:

Es también necesidad, por razones de seguridad, la unión entre los que por naturaleza deben respectivamente mandar y obedecer. (Quien por su inteligencia es capaz de previsión, es por naturaleza gobernante y por naturaleza señor, al paso que quien es capaz con su cuerpo de ejecutar aquellas providencias, es súbdito y esclavo por naturaleza, por lo cual el amo y el esclavo tienen el mismo interés. (I, 1252 $27 \mathrm{ss})$.

La teoría esclavista de Aristóteles surge del estudio de la polis donde los esclavos, a pesar de tener una naturaleza inferior, pertenecen a ella gracias al logos (racionalidad) mínimo que tienen, que les permite vivir en la polis, esos sí, única y exclusivamente como esclavos. 
De igual manera, los bárbaros o extranjeros y las mujeres, tienen una mínima posibilidad de incorporarse a la ciudad ya que tienen la misma naturaleza que los esclavos y, por ende, su posición dentro de la polis será la misma. Aristóteles afirma esta igualdad de naturaleza entre los esclavos y los bárbaros en la Política:

Pero entre los bárbaros, la hembra y el esclavo tienen la misma posición, y la causa de ellos es que no tienen el elemento gobernante por naturaleza, sino que su comunidad resulta de esclavo y esclava. Por eso dicen los poetas "justo es que los helenos manden sobre los esclavos" (énfasis mío) entendiendo que bárbaro y esclavo son lo mismo por naturaleza. (Política $[\mathrm{I}, 2,1252 \mathrm{~b} \mathrm{5ss}])$.

Al mostrar que naturalmente existen personas que no pueden gobernarse a sí mismos, es claro que la acción del sabio y prudente, es guiarlos por el mejor camino, y en este sentido dominarlos; por lo tanto, queda justificada la dominación de un hombre sobre otro, como un acto ético. Sin embargo, es difícil distinguir a aquéllos que son naturalmente esclavos de los que no, pues la diferencia radica principalmente en la belleza de su alma, que no es heredable, y que en el caso de los griegos esclavos se entiende como una enfermedad o deformación.

En el caso de los bárbaros es más clara la naturaleza de su alma, puesto que no pertenecen originariamente a la polis:

Y así como es raro encontrar a un varón divino, como acostumbran calificarlo los lacedemonios cuando admiran vehementemente a alguno es, dicen, varón divino-, así también la bestialidad es rara entre los hombres. Encuéntrense sobre todo en los bárbaros. En ciertos casos en los griegos, sin embargo, en éstos se produce como consecuencias de enfermedades y deformaciones (Ética Nicomaquea [VII, 1, 1145 23ss]) ${ }^{80}$

\footnotetext{
${ }^{80}$ Es sumamente interesante como la afirmación de esta cita es actual y utilizada frecuentemente por la sociedad occidental. Recordemos los atentados terroristas que han sufrido algunos países en los últimos años, y si el actor principal no es "blanco" es un bárbaro al puro estilo griego de "extranjero" directamente se le reconoce como terrorista, mientras que si el acto es perpetrado por un ciudadano "occidental" se presenta siempre como un desequilibrado, como un enfermo. No cabe de duda que la filosofía ha sido cómplice activa durante siglos de la violencia cultural en el mundo.
} 
A pesar de la posibilidad que los bárbaros tienen de pertenecer a la polis, en el libro Límites de la argumentación ética en Aristóteles, Héctor Zagal se pregunta «si los bestiales son aptos para ser esclavos, al fin y al cabo, el esclavo es parte de la casa» (Zagal; 1996:166) Aristóteles consciente de este peligro, advierte que en ciertas etapas de la educación de los hombres libres, es decir de los niños griegos, es necesario evitar un continuo trato con los esclavos para no correr el riesgo de "contagio".

Incluso líneas adelante en este mismo trabajo, expone cómo de la ética aristotélica es posible llegar a la violencia:

Es manifiesto que, para este tipo de bárbaros, las posibilidades de éxito de la argumentación ética son mínimas, y más útiles serían los azotes. Por supuesto, Aristóteles no se atreve a sacar estas consecuencias, pero se siguen lógicamente de sus tesis. Ginés de Sepúlveda y sus seguidores, sí se atrevieron a hacerlo. No hace mucho tiempo en los pueblos mexicanos, la población se dividía en "gente de razón" (blancos) e indios. (Zagal, 1996:166)

A pesar de todos estos pasajes, donde se muestra el trato que deben tener los esclavos dentro de la polis, su identificación es prácticamente imposible. Aristóteles hace un estudio de las características del doulos para tratar de identificarlo en el mundo:

- Identificación del doulos o esclavo natural: Doulos es «el que, siendo hombre, no se pertenece por naturaleza a sí mismo, sino a otro, ése es por naturaleza esclavo. $\mathrm{Y}$ es hombre de otro el que, siendo hombre, es una posesión y la posesión es un instrumento activo y distinto» (Zagal; 1996:155) El doulos está condicionado por su naturaleza, carece de aptitudes físico-psicológicas para poder gobernarse a sí mismo y a los demás. El doulos tiene logos en un sentido participado, en la medida que obedece al spoudaios.

Según Zagal y Aguilar, Aristóteles no tiene reparos en manifestar que existe la esclavitud natural, al tiempo que considera que es muy difícil saber quién es esclavo y quién es señor. 
Ni la complexión física ni la filiación son pruebas de que alguien es doulos por naturaleza.

La prueba definitiva proviene del alma; pero, como observa el mismo Aristóteles, es muy difícil ver la belleza (kalos) del alma.

Para comprender esto en detalle se analizarán tres aspectos fundamentales de la teoría esclavista de Aristóteles:

1. Belleza del alma: una característica del doulos es que no tiene o tiene muy poca «belleza» psíquica, pero ésta es una característica invisible, por lo tanto ver la diferencia del doulos respecto de los hombres normales es prácticamente imposible. Para la tradición griega, kalos tiene una connotación moral, pues envuelve tanto a la ética como a la estética. Por lo tanto, las acciones que realiza el spoudaios son siempre buenas y bellas. Por ejemplo, el heroísmo de Héctor al enfrentar a Aquiles no sólo es un acto de valentía, sino también un acto estético. De tal suerte que se puede decir que el doulos es aquel hombre que por su naturaleza está incapacitado a realizar actos estéticos y éticos.

2. Filiación: la naturaleza obra con necesidad, pero no absoluta, de tal suerte que de padres normales pueda salir un hijo deforme:

Por eso los griegos, no quieren llamarse a sí mismo esclavos, sino a los bárbaros, y cuando dicen esto no pretende hablar de otra cosa que, del esclavo por naturaleza, como dijimos desde el principio; en efecto, es forzoso reconocer que unos son esclavos en todas partes y otros no lo son en ninguna. Y lo mismo con la nobleza: los griegos, se consideran a sí mismos nobles no sólo entre ellos, sino en todas partes, pero a los bárbaros, sólo en su país, juzgando que hay una nobleza y libertad absoluta y otra no absoluta, como afirma la Helena de Teodecto: "fruto de dos raíces divinas, ¿Quién se atrevería a llamarme sierva?” Al hablar así no se distinguen al esclavo del libre, ni a los alto y bajo linaje, sino por su virtud o vileza, pues estiman que lo mismo que los hombres engrandan hombres, y las bestias, bestias, los hombres buenos engendran hombres buenos, no obstante, aunque la naturaleza tienda a esto, no siempre lo consigue. (Política [I, 6, 1255 28ss] en Zagal 1996:156). 
En esta parte es donde Aristóteles deja ver la mínima posibilidad que tiene un hijo de esclavos de nacer como hombre libre, o mejor dicho, con las disposiciones naturales para dominarse a sí mismo. De la misma manera, muestra cómo ni siquiera el lazo sanguíneo puede definir la naturaleza de las personas y, por lo tanto, resulta más complicado, y como ya se ha dicho, prácticamente imposible distinguir a los esclavos por naturaleza, dejando la puerta abierta a al reconocimiento de un esclavo a la percepción individual.

3. Educación: este punto muestra cómo el entorno y la educación son fuentes determinantes del desarrollo de esclavos o griegos por naturaleza. Zagal y Aguilar, lo explican de esta manera:

Desde su niñez, todos los hombres están sujetos a la influencia de los endoxa, o mejor dicho, crecen en los endoxa. La presencia de unos endoxa contrarios a la recta razón estropearán las buenas disposiciones naturales de un muchacho. El hijo de un sátrapa corrupto, habitante de una comunidad afeminada, seguramente no llegará a desarrollar la frónesis perfecta. Las disposiciones naturales requieren del pivote del entorno. Sólo unas disposiciones naturales muy marcadas, fuertes y definidas podrían superar este entorpecimiento. Y al revés, un muchacho con disposiciones naturales muy limitadas, pero educado en la polis ideal $\mathrm{y}$ teniendo como amigos, maestros y padres a hombres sabios y prudentes, seguramente optimará sus pobres recursos psíquicosnaturales. Como es lógico, Aristóteles, "no se moja la mano", y deja el asunto en una sana incertidumbre. No enuncia un límite de optimación o atrofiamiento de las disposiciones naturales (Zagal; 1996:159).

Una vez explicada las dificultades de la teoría esclavista de Aristóteles, se debe analizar, de manera muy breve, los tipos morales dentro de la ética aristotélica:

Tipos morales ${ }^{81}$ :

- Espoudaios: diligente, celoso; ágil, rápido; activo; serio, grave; bueno, virtuoso, honrado, digno; precioso, caro, importante, conveniente, útil. Caballero virtuoso

\footnotetext{
${ }^{81}$ Las definiciones se toman de: Límites de la argumentación ética en Aristóteles, glosario, página 223 a 230.
} 
- Akrates: débil, impotente; no dueño de la propia cólera, incapaz, incontinente, intemperante.

- Akolastos: sin freno, desenfrenado, indisciplinado, intemperante, no castigado.

- Doulos: siervo, esclavo

- Bárbaros: bárbaro, extranjero, no griego; concerniente a los extranjeros; la tierra extrajera, no griega; forastero, exótico, extraño; incivil, rudo, salvaje, grosero.

Las circunstancias socioculturales de la Grecia de Aristóteles, específicamente de la Atenas en ese momento, les permitía considerar a todo aquél que no fuera Heleno como un bárbaro, ya que la civilización y el progreso estaban en las polis griegas. Ese es el inicio del etnocentrismo europeo; creer que son "la civilización”. El helenocentrismo es el fundamento del eurocentrismo actual en el mundo.

Estas afirmaciones están en sintonía con prácticamente todos los pensadores occidentales, aunque es claro que a lo largo del tiempo han matizado la postura; ahora no se cree en la esclavitud, pero en ningún momento se ha dejado de creer en que Europa (Grecia) es la cuna de la civilización mundial. Lamentablemente bajo estos patrones es que nos han enseñado a comprender la realidad ${ }^{82}$.

\section{La teoría de la esclavitud aristotélica; justificando la Conquista de América}

El salto de Aristóteles a la llegada de Cristóbal Colón (aproximadamente dieciocho siglos) lo podemos dar con cierta facilidad gracias a la teoría esclavista. Sin embargo, es pertinente

\footnotetext{
${ }^{82}$ Como se verá más adelante cuando se explica la Filosofía para hacer las paces de Vicent Martínez Guzmán, el orgullo epistémico de la tradición occidental, es uno de los lastres que hay que transformar, él propone como cambio del orgullo pasar a la responsabilidad, sin embargo, esto no transforma la premisa original pues aún se asume como ejemplo primero de racionalidad, más adelante se analizará esta afirmación en detalle.
} 
mencionar que estos siglos, bajo el lente europeo, son considerados un tiempo oscuro, un tiempo medio de estancamiento entre el origen y el desarrollo civilizatorio. He decidido no tomar en cuentas estos siglos, no para tratar de seguir en la línea marcada por el eurocentrismo, sino porque considero que es la conquista de América la que trastoca de manera considerable el rumbo del planeta, tanto para acercarnos más a un mundo violento e injusto, como para acercarnos a uno intercultural y por tanto más pacífico.

Lo que nos posibilita un salto sin tantos problemas metodológicos o conceptuales es la teoría sobre los griegos y los bárbaros, sobre la superioridad helena, ya que fue el fundamento de la conquista de las indígenas de América.

Esta noción de naturaleza superior o inferior en la Política muestra como el autor asume una postura etnocentrista, "donde la raza griega es naturalmente superior a cualquier otra y esto justifica que pueda gobernar a otras razas. Los bárbaros, los no griegos, están por naturaleza incapacitados para gobernarse, en consecuencia, la conquista griega no sólo es una posibilidad justificable es una consecuencia lógica del etnocentrismo aristotélico. Juan Ginés de Sepúlveda no estaba muy equivocado en legitimar el imperialismo de los Austria amparado en la Política" (Zagal, 1996:164)

Dentro del pensamiento latinoamericano y la llamada «filosofía de la conquista» es bien conocido el debate público entre Juan Ginés de Sepúlveda y Bartolomé de las Casas, respecto de la naturaleza de indios y la legitimidad de la dominación española. En un brevísimo resumen, se puede decir que Sepúlveda fincó todos sus argumentos en la política aristotélica al decir que los indios, gracias a sus diferencias fenotípicas, tenían otra naturaleza, una salvaje, bárbara e inferior, por lo que esclavizarlos, usarlos para servidumbre mediante el uso excesivo de la violencia, era legítimo:

El ser "bárbaros" de los indígenas - nombre con que Sepúlveda se refiere a ellos siempre- se pone de manifiesto según el autor en dos cosas: su "torpeza de entendimiento" y sus "costumbres inhumanas" (82-83). Sostendrá que estos "hombrecillos" -nombre que también utiliza para hablar de los indios-, por una parte, carecen de cultura, de ciencia, de 
escritura, de historia, no tienen leyes escritas, lo que demuestra su falta de racionalidad (105-113) y, por otra parte, son antropófagos, hacen sacrificios humanos, tienen cultos impíos a ídolos, lo que prueba que sus costumbres son inhumanas (133). En esta falta de racionalidad, con su consecuente inferioridad natural, y en sus atentados contra la ley natural, testimonios de su evidente barbaridad, encontrará Ginés de Sepúlveda dos de sus principales argumentos para justificar la conquista. Porque son torpes de entendimiento se les considera inferiores y por ello determinados por naturaleza a estar al servicio de otros: los superiores, los racionales. Porque sus costumbres son inhumanas y atentan sistemática e impunemente contra la ley natural, es necesario hacerles la guerra y conquistarlos. A estas naciones, dice el autor, "[...] podrían con pleno derecho los cristianos, si rehúsan someterse a su imperio, destruirlas por sus nefastos delitos y barbarie e inhumanidad" (125). (Herceg; 2011:169170)

El debate se finca en el análisis de la racionalidad de los indígenas que se sigue directamente de la ética aristotélica en donde el hombre griego es el hombre racional, civilizado, ético. Pero ¿quién ha definido estas palabras? ¿Quién establece los límites de lo racional? Para Sepúlveda la respuesta es sencilla; el pensamiento europeo y específicamente la cultura mediterránea en la que surge el pensamiento filosófico griego.

Cabe mencionar que la experiencia de Sepúlveda sobre la naturaleza de los indígenas de América es completamente teórica, ya que nunca visitó el continente, y más que entenderlo como una desventaja, Sepúlveda muestra que sus argumentos son razones tan sólidas como evidentísimas para una mente racional que no ha sido afectada por la experiencia. Sin lugar a dudas se puede afirmar que Sepúlveda es un gran representante de su tiempo y geografía; su confianza excesiva en la razón, y más aún, en el solipsismo de la mente al igual que Descartes le harán justificar atrocidades.

Por otro lado, su gran oponente Bartolomé de las Casas, conocido como el defensor de los indígenas, que viajó y vivió en América durante muchos años, intentó rebatir la postura de la servidumbre natural de los indios mostrando su capacidad de entendimiento, la racionalidad dentro de sus costumbres y la apertura para abrazar el catolicismo. Para este 
fraile, mostrar la racionalidad de indios, permitiría invalidar la conquista y la esclavitud de los indios.

Todas sus obras, desde Del único modo de atraer a todos los pueblos a la verdadera religión (1566) hasta Brevísima relación de la destrucción de las Indias (1552), su objetivo fue denunciar las atrocidades cometidas por los conquistadores y defender los derechos de los indígenas. Sin lugar a dudas fue una labor loable, pero no se puede olvidar que su trabajo estuvo motivado esencialmente por la caridad cristina ${ }^{83}$.

Si analizamos en detalle algunas de sus obras, podemos concluir que no hay una crítica a la esclavitud, no niega la existencia de la servidumbre natural, ni niega la superioridad racional de los europeos, sólo dice que los indios pueden llegar a ser como los españoles, tal y cómo apunta Aristóteles en la Política y en la Ética, es posible mediante la educación salir de la condición natural de esclavo. Su defensa asume los principios de la dominación y del eurocentrismo, y el mejor ejemplo de ello fue que en todas las discusiones sobre la naturaleza de los indios y sobre el trato que deberían recibir, jamás estuvo un indio. De las Casas, sin darse cuenta, silenció a los indios que tanto defendió ${ }^{84}$.

${ }^{83}$ Este punto se debe tomar en cuenta especialmente pues la participación de la iglesia en prácticamente todos los movimientos indígenas posteriores a la conquista es muy fuerte, en los zapatistas es sin lugar a dudas vital. Las bases zapatistas sobre las que se sostiene toda la autonomía son las bases católicas del Pueblo Creyente. Quizá una de las pocas resistencias indígenas actuales que escapan a la cosmovisión católica es la resistencia purépecha de Cherán, Michoacán, quienes además se han desmarcado en agosto de 2017 de la propuesta política nacional del Concejo Nacional Indígena (CNI) de participar en las elecciones federales que se llevaron a cabo en 2018.

${ }^{84}$ Debe quedar claro que se debe asumir la situación de cada pensador, tal y como propone Gayatri Spivak, 1998 no como un juicio personal, sino un trabajo de concienciación epistémica. Actualmente, muchos de los trabajadores y defensores de los derechos humanos en Chiapas y muchos otros lugares de México y el mundo, llegan a tomar la voz de quienes defienden perpetuando así la sumisión, y el carácter de subalternidad de los indígenas, esto a mi juicio, debe erradicarse poco a poco, abriendo espacios donde los subalternos hablen de su situación. Más adelante, en la explicación del pensamiento en resistencia ahondaremos en varias propuestas que superan la idea del héroe blanco 
La filosofía de la conquista, como algunos autores ${ }^{85}$ llaman a la producción de pensamiento originada durante el encuentro entre estas culturas y que corresponde al periodo histórico denominado la modernidad, «es un reflexión neta y exclusivamente europeooccidental, hecha por europeos y mezclada - por no decir revuelta- con asuntos y argumentos de orden teológico-misional.» (Herceg; 2011:168)

Sigamos adelante con el recorrido histórico y centremos la explicación en uno de los grandes representantes de la modernidad europea, René Descartes $(1596$ - 1650). Fue un filósofo francés que recuperó de los griegos el modo de hacer filosofía, olvidado durante la Edad Media; la duda.

¿Por qué existe este todo? ¿De dónde resultó? ¿Cuál es su razón de ser? Esos son los problemas que equivalen a la siguiente: ¿por qué el ser y no la nada? Un momento particular de tal problema general es también el siguiente: ¿por qué existe el hombre? ¿Por qué existo? (Reale, 2007:29)

Esta cita muestra un carácter importante y muy interesante sobre el nuevo modo de hacer filosofía de Descartes, y que ya hemos mencionado brevemente líneas arriba; la confianza y la soledad de la razón, característica distintiva de la modernidad.

Es imprescindible recordar aquí el valor de la sustancia (el ser en sí) en Grecia y que se lleva hasta el límite en la modernidad, omitiendo casi en su totalidad a los accidentes (relación, pasión, etc.) del quehacer filosófico. Descartes muestra esa imperiosa necesidad de la modernidad de alejar la razón humana de la evidencia de la realidad, desconfiando de los sentidos que muestran la realidad tal como es.

conmovido por las injusticas y promueven un dialogo entre personas con circunstancias de vida, y cosmovisiones, simplemente diferentes.

${ }^{85}$ Silvio Zavala, por ejemplo, con su libro Filosofía de la Conquista, Fondo de Cultura Económica, México, 1947. 
Fue así como fundamentó la existencia del hombre en la capacidad de pensar; cogito ergo sum (Descartes [1637], 2001:23-24). Pero esta frase, a mi juicio, es una mala interpretación de nuestro yo como un yo pensante, pues no toma en cuenta que el puro pensamiento no ama, no siente, no percibe, no se relaciona y por lo tanto no es el yo. En resumen, Descartes le otorgó a la razón un lugar privilegiado y que siglos más tarde se convertiría en un arma de doble filo para la sociedad europea, por un lado, ayudó a legitimar la Conquista de América, pero también siglos después el actuar del gobierno nazi, al descansar toda acción en la fuerza del pensamiento ${ }^{86}$.

Para seguir con este recorrido, hay que avanzar dos siglos más y encontrar al gran pensador de Königsberg, Immanuel Kant (1724-1804), quien transforma radical e irreparablemente la filosofía, pues la convierte en una ciencia positiva. A través de sus Críticas le da un lugar predominante a la razón, construyendo un sistema para el pensar, el actuar y la convivencia en sociedad. La primera a través de la Crítica de la razón pura (1781), la segunda a través de la Crítica de la razón práctica (1788) y la tercera, a través la Crítica del juicio (1790) (aunque también aquí podría entrar la Paz Perpetua (1795)).

La representación del deber, y en general de la ley moral pura y no mezclada con un ajeno añadido de atractivos empíricos, tiene, por el camino de la razón sola (que aquí se percata por primera vez de que por sí misma puede ser también práctica), un influjo sobre el corazón humano tan superior en poder al de todos los demás resortes que se quiera tomar del campo empírico, que en la conciencia de su dignidad desprecia a estos últimos y se puede convertir poco a poco en su dueña, en cambio una doctrina moral mezclada, que esté compuesta de resortes tomados de los sentimientos e inclinaciones, y a la vez los conceptos racionales, tiene que hacer oscilar al ánimo entre causas motoras que no se dejan reducir a un principio y que pueden conducir

${ }^{86}$ Para ahondar más al respecto es interesante ver el análisis que Hannah Arendt hace en la introducción a La Vida del Espiritu, su última obra (inconclusa, 1978 inglés, primera traducción al español, 1984) 
al bien sólo de modo muy contingente, pero frecuentemente también al mal". (Critica de la razón pura. 410:25-411:07)

Su sistema en la ética, que es lo que interesa en esta investigación, plantea una lógica discursiva en la que toda premisa se sigue de un principio. Esto hace posible que todo pueda entrar y se justifique en un sistema, además provoca una soledad total en el ser humano, pues éste ya no necesita de los demás para interpretar y darle sentido a la realidad y su acción, pues todo sigue una lógica racional:

Sobre lógica y soledad: brevemente, un hombre así (es decir, un hombre solitario) deduce siempre una cosa de otra y lo piensa todo con sumo rigor. La lógica es el pecado de la soledad, de ahí la tiranía de lo demostrable contundentemente: la conquista por medio de los solitarios. En toda comunidad se pone de manifiesto la insuficiencia lógica en forma de pluralidad de opiniones, que no pueden ponerse de acuerdo por la fuerza ineludible de los argumentos. Deducir siempre lo uno de lo otro, significa prescindir de los hombres y del mundo, significa convertir una opinión en premisa. (Arendt, 2006:113)

Con estas características, ahora fundamentales del quehacer filosófico, se debe avanzar unos siglos más, no sin antes mencionar los avances de grandes autores como Hegel y su noción de historia en La Fenomenología del Espíritu ${ }^{87}$ (1807). Husserl con la nueva fenomenología en Investigaciones Lógicas (1900). Heidegger con su definición del mundo como el espacio donde existe el Dasein en Ser y Tiempo (1927). Nietzche con su interpretación de la filosofía como un quehacer artístico en Más allá del bien y del mal (1886. Todos ellos brindaron nuevas herramientas a la filosofía para su transformación y apertura, muchas aún se utilizan.

\footnotetext{
${ }^{87}$ El pensamiento hegeliano es sumamente interesante para la Filosofía de la liberación y su justificación sobre una nueva interpretación histórica. Dussel está en constante debate filosófico e histórico con Hegel, ya que gracias a la construcción de su sistema, la subjetividad quedó en el olvido y centralizo la historia desde Europa; para Hegel el mapa del mundo es donde Europa es el centro y lo demás la periferia, pero la realidad muestra como Europa es periferia y Medio Oriente el Centro, gracias a los flujos migratorios originales en los que el mundo se pobló. A este respecto es muy interesante ver una de las clases de Enrique Dussel en Quito: https://youtu.be/6GLzHS1Gf4o (última fecha de acceso: 26 de diciembre de 2017).
} 
Finalmente, en el siglo XX aparece la decepción y horror humano dentro de la "civilización", fue atroz no por la cantidad de muertos, sino por la civilidad de la matanza: la Segunda Guerra Mundial. Esta fue considerada por muchos autores de la Escuela de Frankfurt y Hannah Arendt como el ejemplo paradigmático del siglo XX que mostró el mal, entendido como violencia e injusticia; el mal originado por la manipulación ideológica (concepto de alienación ideológica de Arendt) que se desarrolló al no ser plenamente conscientes de las consecuencias de cada acción.

En este momento histórico se debe hacer énfasis en el nacional socialismo que es heredero de una tradición kantiana, empleando una rígida estructura racional en la que, a través de procesos lógicos estrictamente deductivos, fortalecían su ideología (Arendt, 2006:72). Por ejemplo, Adolf Eichmann, Teniente Coronel del SS, encargado de la deportación de los judíos a los campos de concentración y más adelante a los campos de exterminio, era un persona irreflexiva, solitaria, envuelta en la banalidad del mal ${ }^{88}$ que por confiar en su sola razón y olvidarse de que el sentido de las acciones se encuentra en la pluralidad, participó en la mayor industrialización de la muerte en la historia del siglo XX.

Después de la Segunda Guerra Mundial, y el horror ahí ocurrido, el paradigma moderno de la razón se desplomó. La gran mayoría de los intelectuales europeos, después de ver las imágenes de Auschwitz, no pudieron seguir confiando en esa razón que pensaban emancipadora, se dieron cuenta que la razón de Aristóteles, Sepúlveda, Descartes y Kant pudieron ser la causa teórica de los campos de exterminio.

\footnotetext{
${ }^{88}$ La banalidad del mal dentro del pensamiento arendtiano hace referencia específicamente a la facilidad de su aparecer en el mundo y la falta de pensamiento, nos enseña que la radicalización de la búsqueda del bien común puede llevarnos muy fácilmente al mal (injusticia y violencia), precisamente por esa alienación ideológica que antes he mencionado.
} 
Después de la Segunda Guerra Mundial sólo quedaba preguntar: ¿dónde quedó el asombro ante el mundo y la vida que originaron la filosofía occidental? ¿Dónde quedó la ética de Kant? ¿Dónde quedó ese amor a la sabiduría si por saber ahora entendemos conocimiento tecnológico e instrumental? ¿Dónde quedó nuestra responsabilidad moral frente al otro? ¿Cómo seguir pensando después de Auschwitz? ¿Cómo confiar en una razón racista que sólo hasta Auschwitz quedó paralizada mientras que en la colonización, la esclavitud y la conquista se quedó callada porque no fueron cometidas contra el "hombre blanco"?

La Segunda Guerra Mundial no es otra cosa que la bomba que el pensamiento occidental siempre había puesto en otros territorios, y que ahora le explota en la cara. Después de Auschwitz, nadie pudo seguir confiando en esa razón dominante, aunque algunos miembros de la Escuela de Frankfurt, trataron de salvar el proyecto de la modernidad, sin olvidar ser duros críticos con sus consecuencias.

Sin embargo y como trataré de demostrar; fundamentar la existencia y el desarrollo de la filosofía en la sola razón hace imposible la construcción de paz, sólo a través de una reinterpretación, redefinición y reconstrucción de la filosofía es que se podrá construir la paz. Sólo si somos capaces de quitarle ese carácter universalizador que siempre la distinguió, si la sacamos de su marco eurocéntrico, si la alejamos de sus construcciones ideológicas alienantes, es que podremos usarla como herramienta para construir la paz.

Comprender esto hace posible que se entiendan autores como Enrique Dussel, Aníbal Quijano e incluso Vicent Martínez Guzmán, que a pesar de seguir en un marco eurocéntrico muestra la necesidad de transformación de la filosofía, que ahora no sólo está basada en la admiración ante el mundo, sino en la indignación ante el sufrimiento de los seres vivos. 
De manera muy sencilla voy a entender por filosofía el conjunto de capacidades humanas de pedirnos y darnos razones o expresar sentimientos por lo que nos hacemos a nosotros mismos y a la naturaleza. (Martínez Guzmán, 2001:16)

Ahora, surge una pregunta: ¿se puede tomar algo de aquella antigua filosofía para construir la paz? Este trabajo mostrará que es posible, siempre que iniciemos en un origen distinto y en compañía de las múltiples cosmovisiones del planeta.

\section{Una perspectiva diferente: la Filosofía para hacer las paces}

A través de la Filosofía para la paz, veremos cómo se pueden retomar ciertas propuestas de la filosofía europea, pero también mostraremos cómo falta mucho camino por recorrer dentro de este pensamiento, ya que sigue sin romper patrones claves del eurocentrismo.

Vicent Martínez Guzmán, filósofo español contemporáneo, representante de la Filosofía para hacer las paces, toma la concepción de paz (paces) de los Estudios para la Paz de Johan Galtung para desarrollar un nuevo quehacer filosófico, retomando desde su origen algunas ideas del filósofo alemán Jürgen Habermas quien:

Considera que la filosofía ya no es el juez de las otras ciencias que ha de decir el lugar que ocupa. Ya no tiene el rol insostenible de acomodador (Platzanweiser) sino el más humilde guarda o vigilante (Platzhalter) y mediador o intérprete de los diferentes saberes y los mundos de la vida cotidiana en que se realizan. (Martínez Guzmán, 2001:23)

Además, Habermas con su propuesta filosófica de una ética discursiva dota a la filosofía de ese carácter intersubjetivo que debe tener y refuerza la definición de Martínez Guzmán, donde la filosofía ya no será un modelo, sino una actitud y capacidad de diálogo, interpretación y reconocimiento.

Los principios de la Filosofía para la paz radican en el giro epistemológico; una transformación de la teoría del conocimiento aplicada a la filosofía (y en general a todas las 
ciencias) y que presenta las características con las que se debe producir cualquier conocimiento. Este giro es consecuencia directa de la nostalgia posterior a la Segunda Guerra Mundial en la que estaban sumidos todos los pensadores europeos. Recoge las posturas de varios autores posibilitando la filosofía para la paz (Martínez Guzmán, 2001: 114-115):

1. Frente a objetividad, intersubjetividad: ésta será clave en la transformación de conflictos y más aún en el análisis de la violencia, ya que es ella la que ayudará a sentar las bases de un diálogo que llegue a consensos.

2. Sustituir la perspectiva del observador por la del participante: se deja de hablar desde la teoría a la práctica, ahora será desde la práctica a la teoría y a la práctica.

3. El conocimiento se convierte en una relación entre sujetos (personas) que tienen derecho a la interlocución. Ya no entre sujeto y objeto: esta característica es esencial ya en el pensamiento de Arendt, y como se mencionó líneas arriba, es parte fundante de la cosmovisión indígena en México, pues la sustancia deja detener la primacía en la teoría del conocimiento y la relación se establece como el pilar.

4. No hay hechos puros. Los hechos forman parte de lo que nos contamos y son algo de lo que siempre podemos pedirnos cuentas. No hay dicotomía entre hechos y valores: todo el campo de estudio está definido por lo que nos hacemos unos a otros, en este sentido, toda la realidad se comprende desde la relación, los hechos y los valores dejan de existir por separado.

5. Asumir una epistemología comprometida con valores: al establecer que somos parte activa de la realidad que analizamos y más aún, que somos responsables de 
aquello que nos hacemos, se comprende que la creación de conocimiento requiere de un compromiso ético.

6. Pasamos del paradigma de la conciencia al paradigma de la comunicación: esta característica sigue claramente las teorías de Habermas y su ética dialógica y más aún, en la teoría sobre la acción en Hannah Arendt, donde la actividad plenamente humana que salva de la experiencia del mal (injusticia y violencia); el diálogo.

7. Defendemos que somos los trabajadores por la paz los realistas: un estudio sobre la paz, desde la filosofía, muestra que la capacidad de construir la violencia o la paz está en nuestras manos, y más aún en nuestra capacidad de dar y pedirnos razones de nuestra acción.

8. Superamos la unilateralización de la razón, para hablar de las razones, los sentimientos, las emociones, el cariño y la ternura. No hay dicotomía entre razón y cuidado: con este giro epistemológico se supera el solipsismo de la razón moderna; cartesiana o kantiana, y se establece un conocimiento que unifica al ser humano a través de razones y sentimientos.

9. No se aspira a una justicia neutra, sino a una justicia comprometida, solidaria y con cuidado: este punto es clave en la comprensión del zapatismo, pues la búsqueda de la justica requiere necesariamente de la reconciliación que a su vez requiere de un encuentro intersubjetivo y por lo tanto comprometido y responsable.

10. El mundo no se concibe como un espacio abstracto, sino como una diversidad de lugares: como Arendt lo deja claro en La vida del espiritu (1978), el mundo es 
un terreno sin sentido hasta que aparece el ser humano, es el que lo construye y por lo tanto hay tantos mundos como lugares y seres humanos en el mundo.

11. La naturaleza deja de ser distante. Los seres humanos somos parte de ella. (humus). Se reivindica la terrenalidad de los seres humanos, el compromiso con el medio ambiente: al comprender que lo principal en la teoría del conocimiento es la relación, todas las acciones comprometen y no solamente con otros seres humanos, sino con ese mundo que construimos.

12. Se supera la dicotomía entre naturaleza y cultura: se condenan los principios biologisistas, naturalistas o culturales que no reconocen la construcción (filosófica) del mundo que posibilita una comprensión más amplia sobre la complejidad de las relaciones humanas.

13. Se reconstruye como instrumento de análisis y estudio la categoría de género: se reconoce la histórica marginación y exclusión de las mujeres en el ámbito público e intelectual para construir sociedades no simplemente igualitarias, sino equitativas, responsables y comprometidas.

14. Se reconoce que la vulnerabilidad también puede originar ternura. El miedo a la vulnerabilidad puede superarse con medios pacíficos: se comprende la paz desde la unicidad del ser humano y en este sentido la vulnerabilidad se presenta como un elemento fundamental para la construcción armónica de las sociedades:

15. Hacer las paces es para gente como nosotros y nosotras: al comprender que la paz no es perfecta y que la vida es un entramado de relaciones complejas, es posible ver que no se necesitan santos para construir la paz, pero también, y como Arendt lo deja ver en Eichmann en Jerusalén: un estudio sobre la banalidad del 
mal, no se necesita ser demonio para hacer el mal. De ambas somos capaces todos, sólo basta con decidirlo.

Además del giro epistemológico, la propuesta de Vicent Martínez Guzmán se puede esquematizar en catorce puntos ${ }^{89}$ :

1. Como resultado de la Segunda Guerra Mundial Europa comprende la necesaria reconstrucción y reconfiguración de la filosofía, renunciando primero al orgullo epistemológico que pretende un pensamiento universal y, segundo, al orgullo etnocéntrico europeo, para transformarlos respectivamente en compromiso y responsabilidad. Establece como marco teórico, para llevar a cabo esta reconfiguración, la cosmología social occidental.

2. Elimina principios y paradigmas filosóficos: establece que el objeto de la filosofía no será ya la sustancia (ser) sino la relación y en este sentido pasa de la heteronomía a la autonomía (fincar razones que nos responsabilicen). Filosofar será, en este marco, la capacidad de razonar; dar y pedirnos cuentas de nuestras acciones.

3. Se asume al pensamiento occidental como descubridor de la racionalidad humana, es decir que fueron los pensadores occidentales los que se dieron cuenta de la capacidad racional de los seres humanos. "Los manuales de historia de la filosofía occidental apuntan a la Grecia clásica y a los siglos VI y V antes de Cristo como el momento de aparición de la conciencia de la capacidad de los seres humanos de dar razones de lo que sucede en la naturaleza -razón teórica, pero, sobre todo, de la capacidad de dar razones y de exigirnos razones uno a

\footnotetext{
${ }^{89}$ Análisis del libro Filosofía para hacer las paces, Icaria, Barcelona, 2001.
} 
otros de las normas que rigen nuestra conducta -razón práctica. Según mi interpretación, con este descubrimiento de lo que llamamos la filosofía heredad de los griegos, la especie humana ha de asumir la responsabilidad y el compromiso derivados del descubrimiento de la autonomía de la racionalidad." (Martínez Guzmán: 2001:17)

4. Establece que razonamos para encontrar unos mínimos éticos, unos ideales regulativos que nos permitan criticar nuestras acciones. Que lo hacemos a través del análisis de nuestros discursos, para hacer una reconstrucción racional de la comunicación. Y lo hacemos porque intentamos comprender el sentido del ser humano.

5. La reconstrucción de la filosofía deber ser:

a. Crítica: para que nos permita ver los engaños de la comunicación

b. Constructiva: interdisciplinar para ampliar el horizonte de análisis

c. Teórica: para encontrar vías para una descripción universal

d. Trascendental: al modo kantiano.

6. Se seguirá usando la división kantiana entre razón práctica y razón teórica para:

a. Reconocer las razones de la naturaleza: comprender la realidad como aparece a nuestro entendimiento.

b. Reconocer las razones de nuestras acciones: para comprender el sentido de nuestras acciones y responsabilizarnos de ellas.

7. Define a la filosofía como: «una reconstrucción normativa de las competencias de los seres humanos para hacer las paces, con atención vigilante a las razones y sentimientos que se expresan desde las diferentes investigaciones para la paz.» (Martínez Guzmán, 2001:24) 
8. Establece que la filosofía como metodología es una «autocrítica hacia los desarrollos unilaterales de la racionalidad, como lo es hacia su occidentalidad, usando elementos de denuncia de la relación entre racionalidad y poder como Foucault, deconstruyendo y reivindicando las diferencias y los márgenes como Derrida, reconociendo las limitaciones contextuales de la razón situada como Rorty.» (Martínez Guzmán, 2001:24)

9. La filosofía se comprende como universalidad comunicativa, como capacidad de comunicación al estilo de Habermas. Sin embargo, el diálogo intercultural que se propone intentar priorizar la comprensión intercultural de la realidad.

10. La filosofía se comprende a su vez como actitud performativa, como paso a una perspectiva autorreferencial reflexiva y transcendental, esto quiere decir que es debe ser crítica, abierta y en movimiento, no lineal y sistemática

11. Los usos de la razón práctica (al modo kantiano, es decir la razón del actuar) se dividen en tres y cada uno tendrá dos usos dentro del sistema:

a. Estratégico, responde a dos preguntas. Su origen está en la filosofía y su resultado es la poética (del logos a la praxis)

i. ¿Qué quiero?

ii. ¿Cuál es la mejor estrategia para alcanzar lo que quiero?

b. Ético (costumbre): responda a una pregunta y otorga tres lentes. Su origen esté la capacidad crítica y su resultado es la performatividad

i. ¿Por qué quiero lo que quiero?

1. Contexto

2. Situación (al modo existencial de Beauvoir)

3. Circunstancia

c. Moral: que responde a dos peguntas. Su origen está en la educación y su resultado es la democracia participativa.

i. ¿Afecta lo que quiero a los demás?

ii. ¿Cómo hago que lo que quiero sea justo?

Estos usos responden a una interpretación de la propuesta ética de Kant, asumiendo, también su parte más peligrosa: «si todos podrían querer que en mi 
situación cada uno actuara según las mismas máximas» que analizaremos más adelante en la crítica a la filosofía para la paz.

12. La filosofía, recogiendo lo anterior es ahora una herramienta de los Estudios para la paz, ya que a través de la teoría crítica de la occidentalidad está obligada a un diálogo intercultural con las teorías de la democracia, la educación para la adquisición del punto de vista moral. Así se establecerán dos principios fundamentales para el quehacer filosófico de la paz:

a. Nueva definición de persona como sujetos de actos de comunicación en el marco de un reconocimiento universal de los derechos de interlocución

b. El sentido de la responsabilidad solidaria manifestada en las razones que damos al comunicarnos y los compromisos que al hablar asumimos como los seres humanos, para superar el sentido de la solidaridad emotiva; la caridad.

13. Dentro de la propuesta de Martínez Guzmán hay una clara recuperación de Kant y podemos destacar tres puntos:

a. El principio filosófico kantiano sobre la necesidad del uso de la razón práctica.

b. Comprender la paz como el ejercicio de la racionalidad práctica de Kant.

c. Comprender la paz perpetua no como estado al que llegar sino como una forma de dirimir los conflictos, de esta manera nuestra paz se transforma en paces. 
14. Ya que la filosofía se establece en gran medida como metodología será una reconstrucción racional constante de la comunicación que se aplicará a los cuatro ámbitos principales de los estudios de paz:

a. Johan Galtung y su teoría de las violencias y la paz imperfecta de Francisco Muñoz.

b. Sistema-mundo de Immanuel Wallenstein

c. Códigos de Paz de Dorothy V. Jones

d. Concepto de seguridad en la Guerra Fría y años posteriores.

En estos catorce puntos he resumido lo que considero fundamental dentro de la filosofía para la paz, en ningún momento pretendo establecerlo como un esquema cerrado. Sin embargo, bajo estos puntos podré hacer una crítica que más adelante me ayude a construir ese añorado puente de entendimiento con el pensamiento decolonial.

\section{Aportes para seguir dialogando entorno a la Filosofía para hacer las Paces}

Para la construcción del marco teórico, o, mejor dicho, para la construcción de los puentes de entendimiento, haré un ejercicio crítico a la filosofía de la paz con el fin de contribuir al diálogo iniciado por Vicent Martínez Guzmán. También, pues creo los aportes que una filosofía para la paz deseurocentralizada puede dar a la sabiduría colectiva, son de vital importancia para esta investigación.

Las críticas las haré desde la esquematización del apartado anterior, específicamente de los puntos 3,5 y 13. Los demás puntos considero que son los puntos de encuentro claves y que utilizaremos para comprender la realidad mexicana tanto histórica como filosófica:

1. Critica al punto 3: la postura de Vicent Martínez Guzmán de asumir al pensamiento occidental como descubridor de la racionalidad humana es un 
error, puesto que la historia desde los egipcios hasta los aztecas, texcocanos o mayas, reconocen la capacidad racional de los seres humanos. Si bien es cierto que dentro del pensamiento occidental se desarrolla la epistemología o teoría del conocimiento como una las ramas fundamentales y más fuertes de la filosofía, que hacen referencia directa a la pregunta sobre la razón y la racionalidad, esto no es argumento suficientemente fuerte para decir que son los europeos los que se dan cuenta de que los seres humanos razonamos; si acaso podremos aceptar que son los primeros que hacen una sistematización de cómo conocemos, aunque pueda estar a debate con algunos historiadores decoloniales como Enrique Dussel (Política de la liberación: historia mundial $y$ crítica, 2007). Se debe reconocer que los problemas que surgen de esta casi ingenua afirmación son el eurocentrismo y la colonización de la mente, ya que la racionalidad quedará limitada a las definiciones europeas determinadas cultural y geográficamente; es decir, la epistemología europea será la primera producción de pensamiento universal dominante. Afirmarse como descubridor, por más que el autor lo haga para responsabilizar y comprometer a los pensadores occidentales, es egocentrista, universalista y peligroso. Immanuel Kant, uno de los pensadores más importantes en Europa y que sin lugar a dudas marcó prácticamente todas las líneas de investigación filosófica desde el siglo XVIII y especialmente el pensamiento de Martínez Guzmán, se atribuye en primera medida el descubrimiento de la razón (en términos conceptuales) y por lo tanto, según él y su tradición, el deseo de emancipación. Pero, ¿es realmente ¿Qué es la Ilustración? (Kant, 1979) un texto que busca la liberación, la emancipación y la transformación de poder político? La respuesta es clara y 
tajante: ¡No! El problema del sapere aude de Kant fue que pensaba únicamente desde el hombre dentro del Estado prusiano y del que asumía que elegiría vivir dentro de aquella sociedad moderna y enriquecida por la Revolución Industrial y el «descubrimiento de América». Jamás imaginó que alguien no deseara vivir ahí, asumía que los "salvajes americanos" que no quisieran unirse a la modernidad, demostraban simple y llanamente su falta de madurez e incluso su «sub-humanidad», y por lo tanto había que obligarlos y/o eliminarlos (Kant, $1788)^{90}$. Este gran filósofo sentó de manera radical e inamovible que la razón, el hombre racional, el hombre civilizado, el verdadero filósofo, es el hombre europeo. Todos por ende querremos llegar a esa sociedad cosmopolita, la sociedad de los principios racionales europeos (Paz perpetua). En estas afirmaciones se fundamentan muchas discusiones sobre la discriminación contra las comunidades indígenas: ¿es acaso inmoral querer una vida mejor para todos los seres humanos? ¿No es acción de verdadera comunidad y justicia, construir el espacio para salir de la minoría de edad y desarrollarse? Si se piensa que estas preguntas pueden contestarse afirmativa o negativamente, entonces es que no se ha pensado desde la intersubjetividad decolonial, ya que las preguntas muestran que el problema radicaba en la imposibilidad de fusionar la

\footnotetext{
${ }^{90}$ Siglos antes con la discusión entre Bartolomé de las Casas, Francisco de Vitoria y Juan Ginés de Sepúlveda ya había quedado claro el perfil que tomaría la clase intelectual europea respecto de los indígenas americanos (incivilizados que debían adoptar la cultura europea para ser salvados). Sin embargo el aporte de Kant a este respecto es mucho más interesante ya que lo plantea en términos de política internacional y ética; establece un sistema universal donde todo ser racional (racional al modo europeo) debe querer la sociedad europea, sino es así, su racionalidad es insuficiente y quedará confinado a servidumbre de por vida. Estas afirmaciones, a pesar del ser del siglo XVIII nos permiten comprender la realidad actual a nivel mundial, especialmente desde las periferias.
} 
cosmovisión occidental con la indígena, la imposibilidad de tener una comunicación semánticamente significativa si no se busca esto desde el principio, es hablar con categorías occidentales frente a una realidad diferente. Si se pretende desarrollar una verdadera filosofía para la paz, alejada del pensamiento de dominación, será fundamental establecer otro origen; partir desde otra perspectiva que la dominante.

2. Crítica al punto 5: los principios del quehacer filosófico de la paz; crítico, constructivo, teórico y trascendental, es una metodología conveniente para el trabajo académico; sin embargo, contiene esa pretensión de validez universal que, como hemos mencionado varias veces, es peligrosa, ya que impone modelos de pensamiento y acción. Aunque en todo su pensamiento, Martínez Guzmán se caracteriza por reconocer otras expresiones filosóficas como válidas y critica duramente el carácter universal de la filosofía occidental, su metodología no escapa a ella. Finalmente, la universalidad en el pensamiento europeo, y especialmente en el kantiano, es que el filósofo debe sistematizar y revisar la coherencia lógica de su sistema (actividad principal del filósofo académico) y lamentablemente Martínez Guzmán no se libera de esa pretensión. Creo que el problema radica principalmente en la acepción kantiana de trascendental, ya que, para el pensamiento del pensador alemán, como para el pensador español, lo trascendente es aquello que trasciende el espacio y el tiempo, trasciende las circunstancias y nos permite estar más cerca del noúmeno. Pero como ya se ha mencionado, el noúmeno no puede ser el centro de estudio de la filosofía porque nos aleja y despersonaliza. De hecho, creo que el uso de la trascendentalidad en el pensamiento de Martínez Guzmán es una 
contradicción muy fuerte, pero que representa aquello que quiere negar, la imposibilidad de quitarnos la circunstancia al pensar.

3. Crítica al punto 13: la recuperación del pensador alemán como fundamento de la filosofía para la paz, resume todo lo que se ha expuesto hasta el momento sobre los peligros del pensamiento occidental. Es verdad que Martínez Guzmán, al inicio de su libro Filosofia para hacer las paces (2001), dice: «somos conscientes de las limitaciones de sus propuestas.» Sin embargo, como ya hemos mencionado, tomar como principios la confianza en la razón, el ideal de paz (que enmascara el ideal de progreso moderno) y la teoría de la verdad (teoría de la adecuación) en términos generales, lleva a construir una propuesta desde el universalismo y desde el eurocentrismo. No niego las grandes aportaciones del pensador alemán, pero considero un error usarlo como fundamento, ya que de una manera u otra nos llevará a fundamentar sus propios principios: la fuerza de la racionalidad europea cómo única para la construcción de la paz.

En resumen, podemos decir que gracias a la propuesta de Vicent Martínez Guzmán la filosofía puede ser una herramienta para construir la paz. Sin embargo, y como tratamos de apuntar con la crítica que se ha esquematizado, esta paz queda fincada en la posibilidad de un diálogo intercultural, constante y permanente en donde la construcción de argumentos se dé de manera intersubjetiva, y la forma de decirlos sea empática. Donde se comprende la concepción de bien común como búsqueda de convivencia activamente armónica.

Como ya se había mencionado, sólo a través de una reinterpretación, redefinición y reconstrucción de la filosofía es que se podrá construir la paz. Sólo si somos capaces de quitarle ese carácter universalizador que siempre la distinguió, si la sacamos de su marco 
eurocéntrico, si la alejamos de sus construcciones ideológicas alienantes, es que podremos usarla como herramienta para construir la paz.

Comprender esto hace posible que se entiendan autores como Enrique Dussel, Aníbal Quijano e incluso Vicent Martínez Guzmán, que a pesar de seguir en un marco eurocéntrico muestra la necesidad de transformación de la filosofía que ahora no sólo está basada en la admiración ante el mundo, sino en la indignación ante el sufrimiento de los seres vivos.

\section{II.3 Pensamiento decolonial}

El pensamiento decolonial es sin duda uno de los marcos teóricos más importantes de esta investigación, pero como se analizará, tiene muchos matices, autores, y movimientos sociales en los que descansa, por lo que se detallarán los rasgos más importantes y que ayudan a la comprensión de la realidad mexicana,

Uno de los grandes pensadores del pensamiento decolonial es el peruano Aníbal Quijano, en quien centraré el análisis de esta corriente de pensamiento. Sin embargo, la decolonialidad es una propuesta que excede los planteamientos teóricos y propone una nueva forma de hacer filosofía, historia y política; propone una transformación radical de la manera en la que la historia se interpreta desde el siglo XVI. Y de la misma manera que la filosofía de la liberación, proponen una reconstrucción histórica en la que grandes personajes como Bartolomé de las Casas son considerados como los padres del pensamiento decolonial (Quijano; 2005). 
Su punto de partida teórico e histórico es el encuentro de dos mundos en el siglo $\mathrm{XVI}^{91}$, pero salen de la versión oficial de los hechos y comienzan a indagar en los relatos de los vencidos y marginados. Y más importante aún, dan cuenta de la producción de pensamiento y sabiduría de los olvidados.

El pensamiento decolonial es una mirada sin los presupuestos europeos, pero asumiendo la fusión cultural y la historia desde la llegada de Cristóbal Colón hasta nuestros días.

\section{Diferencias con el pensamiento postcolonial}

Antes de desarrollar una explicación sobre el pensamiento decolonial es importante debatir sobre la diferencia que existe con el pensamiento postcolonial que, aunque comparten semejanzas, sus diferencias nos abren las puertas a un debate interesante.

Ambas corrientes tienen raíces en el pensamiento de Frantz Fanon (Los condenados de la tierra, 1961) y Aimé Césaire (Discourse on colonialism, 1972), así como el movimiento de la negritud, pero como se verá al término de este apartado ambas caminan por ámbitos de acción y objetivos distintos.

El pensamiento postcolonial es una propuesta de análisis que surge directamente del post-estructuralismo francés, de los movimientos de independencia de las colonias francesas e inglesas del siglo XX y tienen como grandes representantes a Gayatri Spivak (Puede hablar

\footnotetext{
${ }^{91}$ Normalmente se tiene como fecha simbólica de este encuentro 1492, la primera llegada de Cristóbal Colon a América, sin embargo, para los efectos de esta investigación, se tomará como punto inicial del complejo encuentro, la caída de Tenochtitlán en 1521, pues ese día es visto, por muchos indígenas en resistencia como el día que comenzó la sumisión. Hay que tomar en cuenta, que durante toda la investigación nosotros nos referiremos al siglo XVI como el siglo del encuentro, pues en México los primeros exploradores europeos no llegan hasta 1519 al mando de Hernán Cortés conquistador del Imperio Azteca.
} 
la subalterna, 1998) y Edward Said (Orientalismo, 1978), entre otros, que ponen en entredicho las bases filosóficas, legales y éticas de la superioridad europea. Incluso se podría afirmar que esta corriente de pensamiento tiene una situación geográfica específica, aunque no limitativa; África, India y Australia.

Resumiendo la esencia de este pensamiento, se puede decir que su análisis parte de la construcción de discursos que muestran las relaciones de poder: en Orientalismo (1978) obra indispensable para comprender las bases del pensamiento post-colonial, Edward Said muestra cómo Oriente es una construcción del pensamiento eurocéntrico, partiendo del miedo al otro y el exotismo de la diferencia. Explica cómo a través de las narrativas se construyó un sujeto oriental que pudiera ser dominado y administrado por el europeo.

Es muy interesante el trabajo de Said en esta obra, no sólo por su brillante comprensión del pensamiento de Foucault (y en general del post-estructuralismo francés), sino también porque pone al descubierto la ayuda de la academia para establecer las relaciones de poder en diferentes zonas. Sin embargo y a mi juicio, queda claro que el análisis de este autor se mantiene en la esfera del pensamiento europeo en boga en los años 70 y 80 , abre las puertas a un pensamiento distinto y vanguardista, pero al menos en esta obra, no da un paso hacia afuera, su discurso se mueve limitativamente dentro de la comprensión de la realidad europea.

Por otro lado, otra de las obras principales dentro del pensamiento post-colonial es el texto de Gayatri Spivak ¿Pueden hablar las subalternas? (1988) donde a partir de una pregunta central desarrolla una crítica fortísima a la posición de los investigadores con respecto a las colonias y desde las colonias. Spivak pregunta: «¿cómo es representado en el discurso occidental el sujeto del tercer mundo?» (2003:301) A través de Foucault y Deleze, 
Spivak muestra la imposibilidad para el intelectual de realmente hablar de y por el subalterno sin perpetuar su condición de subalternidad ${ }^{92}$.

En la interpretación de Sidi Omar (2008), Spivak nos enseña a resistirnos al deseo de recuperar las voces silenciadas por el imperialismo, por dos razones, la primera porque la voz es irrecuperable debido a la violencia epistémica programada por el proyecto imperialista y en segundo porque tal pretensión se adheriría a la noción humanista de la voz como la expresión libre de una “individualidad” auténtica ${ }^{93}$.

Sin lugar a dudas, este es un texto clave y atemporal para todos aquéllos que construimos un pensamiento crítico desde la periferia. Su pensamiento, al igual que Said, se mueve en el marco teórico del eurocentrismo, siguiendo muy de cerca a Derrida, aunque abre una grieta que a primera vista nos muestra un escepticismo del colonizado "emancipado", para después mostrar un camino hacia algo parecido a un giro epistemológico post-colonial.

Tanto la obra de Said como la de Spivak nos muestran el carácter general del pensamiento post-colonial y las esferas en las que se mueve. Su trabajo está desarrollado principalmente desde la academia y desde, a mi juicio, una posición de poder que limita las posibilidades de transformación. Su crítica, sin duda indispensable para la realidad actual, está confinada al trabajo intelectual y carga, algunas veces sin darse cuenta, con una aceptación impotente de las relaciones de poder que se establecen en el mundo. Para algunos, esta corriente de pensamiento es mucho más sensata y coherente que el pensamiento

\footnotetext{
${ }^{92}$ Situación que como ya se mencionó, sucedió con Bartolomé de las Casas y sucede actualmente con algunas y algunos defensores de derechos humanos, entre otros.

${ }_{93}$ Ambas cuestiones son la base fundamental del actual proyecto epistémico de las resistencias indígenas, que tiene como representantes a Boaventura Do Santos, Xochitl Leyva, María Lugones, entre otras. Más adelante desarrollaremos esta propuesta basada en la obra colectiva Prácticas Otras de conocimiento, Tomo I, II y III., México, 2015. Además, es muy interesante el concepto de individuo frente a la comunidad, cuestión que también se analizará más adelante.
} 
decolonial, no sólo porque su objetivo no sea la lucha libertaria utópica que marcó las independencias africanas en el siglo $\mathrm{XX}$, sino porque comprende que una ruptura con la forma de pensamiento europea, acarrearía muchos problemas teóricos en términos culturales y epistemológicos, y porque fácticamente es imposible debido a la fuerza globalizadora del capitalismo, e incluso caeríamos en una conceptualización de occidente al modo que ellos nos han conceptualizado.

Más aún, hay autores como Sidi Omar que fundamentándose directamente en la propuesta de Spivak, muestran un rechazo a la primera propuesta del pensamiento decolonial, aquella que pretende desprenderse por completo del pensamiento europeo; pues a su juicio no sólo realizan un acto que es imposible, ya que todos estamos marcados por nuestra "experiencia" con y en el sistema, sino también porque la sola pretensión parece eximir a los críticos decoloniales de reconocer sus posicionamientos epistémicos institucionales. Bajo esta lente el pensamiento de Spivak debe ser una llamada de atención para que los críticos seamos conscientes, y reconozcamos nuestros posicionamientos y las condiciones que informan y posibilitan nuestros trabajos y prácticas intelectuales.

Dentro del pensamiento decolonial, con el paso de años, el posicionamiento comienza a tomar importancia, tal como dice Xochitl Leyva fundamentándose en el pensamiento de Walter Mignolo, «partimos de la premisa básica de que el conocimiento no es abstracto ni deslocalizado, por el contrario, la producción del conocimiento está marcada geohistóricamente y, además, tiene un valor y un lugar de origen» (Leyva, 2015, 200-201), de tal manera que la fusión entre el pensamiento postcolonial y decolonial se ve más claramente. Sin embargo, su gran diferencia es el campo de acción de ambos; el pensamiento postcolonial apuesta por la conceptualización de una realidad, pero desde los mundos narrativos y por ende limitado al mundo académico, mientras que el pensamiento decolonial 
(y más específicamente el pensamiento de resistencia) pretende hacer academias ex-céntricas y subalternizadas y está íntimamente ligado con el activismo político destinado a la transformación radical de las relaciones de poder y modo de actuar ${ }^{94}$.

Mi postura frente a este debate está marcada por mi nacionalidad, mi situación de privilegio en un país tan desigual como México, por mi acercamiento a las resistencias indígenas y al trabajo de los de abajo en el sureste de mi país. Y en este sentido puedo decir que el pensamiento postcolonial nos hace reconocer la problemática, pero el pensamiento decolonial nos exige la lucha por la transformación y en este sentido, su propuesta nos ayuda más claramente a comprender la realidad de las resistencias indígenas en México.

Sin embargo, leer el postcolonialismo desde esta perspectiva creo que también nos hace reconocer la espiritualidad india que se siente en el texto de Spivak o la resistencia palestina en Said, por lo que más allá de establecer las diferencias, la búsqueda deber ser ver las semejanzas para seguir luchando.

\section{La decolonialidad: un pensamiento de resistencia}

La decolonialidad tiene raíces en tres esquemas teóricos del siglo XX: la teoría de la dependencia, la teoría del sistema mundo del grupo Modernidad/Colonialidad/Decolonialidad y la filosofía de la liberación (que se desarrollará en detalle más adelante). Para comprender el contexto general de estos marcos teórico, es

\footnotetext{
${ }^{94}$ Es muy interesante la división que Xochitl Leyva usa para distinguir el activismo que se dedica a reproducir el sistema de aquél que tiene por objetivo la transformación radical (Xochitl Leyva, 2015: 202) pues es justo el punto donde creo que se supera al pensamiento postcolonial; no sólo hay que explicar las relaciones de poder que tenemos, no sólo hay que evidenciar las voces silenciadas, hay que transformarlas.
} 
necesario explicar el concepto de desarrollo, pues es a través de este que surgen las propuestas teóricas latinoamericanas.

De acuerdo al antropólogo colombiano Arturo Escobar, en quien he basado el análisis de este concepto, el «inicio de la época del desarrollo se puede identificar con el famoso discurso de posesión del Presidente Truman el 20/01/1949, cuando anunció al mundo la nueva doctrina del "trato justo" para las que, desde entonces, fueron vistas como "áreas subdesarrolladas"» (Escobar, 2015:25). A partir de ese momento los altos niveles de industrialización y urbanización, el rápido crecimiento de la producción material y los niveles de vida y adopción generalizada de la educación y valores modernos, fueron las características de las sociedades avanzadas (2015:26). Además, debía existir una juiciosa combinación de capital, conocimientos expertos y tecnología. Y fue así como en pocos años este sueño recibió el respaldo universal y se convirtió en el hegemónico de la vida económica, social y cultural.

Según Escobar, la era del desarrollo puede dividirse en cuatro grandes fases, tres de ellas se corresponde a tres momentos y corrientes de pensamiento:

\section{Teoría de la modernización y el crecimiento económico (décadas cincuenta y} sesenta): en este momento se establece que el "desarrollo" inevitable se lograría si los países seguían las prescripciones trazadas desde las grandes instituciones como el Banco Mundial, y si aplicaban toda la gama de conocimientos que a partir de los años cincuenta empezaron a producirse en las universidades del Centro y, con el paso del tiempo, en las de la periferia. El objetivo era pasar de sociedades "tradicionales" a “sociedades modernas", en las que, tal y como lo dice Escobar, todos seríamos ricos, racionales y felices (Escobar; 2015:27). Esta etapa estuvo marcada por el pensamiento liberal de la época. 
2. Teoría de la dependencia (sesenta y setenta): en esta se etapa se planteaba que las raíces del subdesarrollo se encontraban en la conexión entre la dependencia económica externa (dependencia de los países de la periferia a los del centro) y la explotación social interna (especialmente de clase), y no en una supuesta carencia de capital, tecnología o de los valores modernos. La teoría de la dependencia estuvo marcada por el pensamiento marxista de la época, que permitía asegurar que el problema residía en el capitalismo y no tanto en el concepto de desarrollo, por lo que una transformación al socialismo permitiría el desarrollo y la modernización de las sociedades ${ }^{95}$.

\section{Aproximaciones críticas al desarrollo como discurso cultural (años noventa): Es} esta la etapa más cercana al pensamiento postcolonial pues se analizaba el desarrollo como un discurso de origen occidental que operaba como un poderoso mecanismo para la producción cultural, social y económica del Tercer Mundo. Uno de los elementos más relevantes de este momento es la pregunta: «¿cómo llegaron África, Asia y América Latina a ser representados ("inventados") como "subdesarrollados" y cómo ha funcionado el discurso del desarrollo para moldear la realidad de estos países de formas particulares?» (Escobar, 2015:28) e incluso de manera más directa «¿cómo ha operado "el desarrollo" como estrategia de dominación cultural, social, económica y política?» (2010:28). Esta pregunta que nos hace Escobar, plantea los

\footnotetext{
${ }^{95}$ La teoría de la dependencia es una corriente de suma importancia para la política representativa y gubernamental de la región, ya que en ella encontramos las bases de lo que a partir de los ochenta y noventa serán los gobiernos de izquierda en Latinoamérica (Lula en Brasil y los Kirchner en Argentina, por ejemplo). El elemento esencial a considerar es que el desarrollo de las sociedades al modo europeo y anglosajón seguirá siendo el ideal, la ruptura y búsqueda de nuevos ideales no se presentará sino hasta finales del milenio sobre todo con el crecimiento de los movimientos anti sistémicos como el zapatismo.
} 
fundamentos y características clave, no sólo del pensamiento postcolonial, sino de los movimientos sociales en América Latina, especialmente los movimientos de resistencia y autonomía indígena. La necesidad de una liberación de la mente, se concibe como necesaria para la sobrevivencia de la gente.

4. Globalización y el inicio de los movimientos antisistema: en la esquematización que otorga Escobar hay una década que analiza por separado y con un poco más de detalle; la década de los años ochenta ya que la presenta como el periodo más virulento del reduccionismo del mercado con sus concomitantes tecnologías político-económicas, tales como: ajuste estructural, las privatizaciones, liberalización de los mercados, desmantelamiento de políticas sociales, etc. Y casi de la misma manera como el pensamiento decolonial presenta la modernidad, para Escobar, la gran victoria del neoliberalismo en los años ochenta es la globalización, que paradójicamente abre una grieta en el sistema-mundo que permitirá el avance de movimientos sociales como el zapatismo.

Además de la dialéctica que presenta Escobar como fundante de la crisis del desarrollo, enlista cuatro causas más que muestran no sólo la crisis del sistema, sino algunas de las bases teóricas de las que hoy en día conocemos como resistencias indígenas:

a. El enorme papel asumido por China y en menor medida el bloque BRIC en la economía mundial.

b. Los reajustes en la geopolítica mundial sucedidos a raíz de los ataques contra el World Trade Center el 11 de septiembre de 2001 y la posterior invasión de Irak en marzo de 2003.

c. El fin del llamado Consenso de Washington, más comúnmente conocido como neoliberalismo y ahora remplazado por el Consenso de los commodities. 
d. El desmantelamiento del socialismo realmente existente y de las economías de planificación centralizada.

e. La crisis ambiental traída a la luz pública en los debates nacionales y mundiales por las cumbres de la ONU sobre cambio climático. Sin lugar a dudas, es la crisis ecológica la que tiene el potencial de desestabilizar cualquiera de los marcos de desarrollo existentes en la actualidad si se toma en serio, tal y como está ocurriendo en América Latina y es aquí donde encontramos la base ontológica del zapatismo y las resistencias indígenas de México que más adelante se analizaran en detalle.

Finalmente, son cuatro las conclusiones que se pueden sacar del análisis que presenta Escobar y que, como será evidente para el lector y lectora, tienen su fundamento en lo que en esta investigación hemos esbozado como pensamiento decolonial. Es interesante remarcar que el antropólogo colombiano nos ofrece una manera de considerar tanto el pensamiento postcolonial como el decolonial no como separado ni opuestos, sino como teorías continuas que se complementan, como teorías que serán los cimientos de nuestros puentes de entendimiento, tanto en fondo como en forma.

1. El "desarrollo" como discurso surgió a principios del periodo posterior a la Segunda Guerra Mundial, si bien sus raíces yacen en procesos históricos más profundos de la modernidad y el capitalismo, fue en esa época que se dio realidad a la invención del "Tercer Mundo".

2. El "desarrollo" hizo posible la creación de un vasto aparato institucional a través del cual el discurso se convirtió en una fuerza social real y efectiva, transformando la realidad económica, social, cultural y política de las sociedades en cuestión.

3. El discurso del desarrollo ha operado a través de dos mecanismos principales: la profesionalización de «problemas de desarrollo», incluyendo el surgimiento de 
conocimientos especializados, así como vastas áreas del saber para lidiar con todos los aspectos del "subdesarrollo": y, la institucionalización del desarrollo y la enorme red de organizaciones arriba mencionadas.

4. El análisis postestructuralista destacó la exclusión de los conocimientos, las voces y preocupaciones de aquellos quienes, paradójicamente, debería de beneficiarse del desarrollo: los pobres de Asia, África y Latinoamérica.

La década de los ochenta, como ya se mencionó, Escobar la desarrolla por separado, fuera de su esquema, pues a su juicio presenta una dialéctica muy interesante, por un lado es una época de grandes pérdidas sociales y económicas para nuestra región gracias a las políticas neoliberales del momento, pero en el ámbito académico y cultural América Latina se convirtió en el epicentro mundial de las perspectivas críticas con la teoría de la dependencia, la teología de la liberación, la investigación-acción participativa y la educación y comunicación popular bajo la influencia de Freire (Pedagogía del oprimido, 1970) y Fals (La ciencia y el pueblo 1980) en los sesenta y setenta.

La gran victoria del neoliberalismo se impuso con tal fuerza que desató quizá la grieta más grande que ha tenido el sistema desde su inicio y es el levantamiento de la periferia, el levantamiento de los nadies, de los olvidados, de los de abajo. Y estos son los que, sin lugar a dudas, al comienzo del milenio, son la fuente más clara de pensamiento contra-hegemónico, o alternativo, a nivel global.

Ahora, tal y como lo presenta Escobar y desde una perspectiva académica, el grupo Modernidad/Colonialidad/Decolonialidad (MDC) o pensamiento decolonial, ha sido quizá el marco interpretativo más visible que haya surgido en el nuevo milenio en dicho espacio, asociado principalmente con los nombres de Aníbal Quijano, Walter Mignolo, Enrique Dussel, Catherine Walsh y Edgardo Lange, entre otros. 
Según Escobar, puede considerarse un marco consistente y elegante, con categorías fundacionales tales como: colonialidad del poder, colonialidad del saber y del ser, descolonización epistémica, sistema-mundo moderno/colonial. También poseen una característica novedosa que es la reinterpretación de la historia del continente (tal vez con especial énfasis en la conquista) y del eurocentrismo como forma de conocimiento fundante de dicho sistema-mundo. Sin embargo, son tres los elementos clave que destaca de esta corriente de pensamiento y que la distinguen de la vasta producción académica e intelectual de las últimas décadas (Escobar: 2015:42):

a) «Aborda el concepto de "modernidad" de una manera novedosa, crítica y decidida.»

b) «Identifica la descolonización epistémica (del espacio de producción del conocimiento) con dominio crucial de lucha y de transformación del mundo.»

c) «Hace un esfuerzo valioso por ir más allá de las perspectivas intra-europeas e intramodernas sobre la modernidad y la realidad.»

El MCD puede ser visto como un marco de teoría social fuerte con una orientación cultural y epistémica determinante. Sin embargo, una de las críticas más fuertes a esta corriente de pensamiento es la falta de relación directa con luchas y con situaciones concretas, con contadas excepciones -y el lenguaje academicista que sigue caracterizando a la mayoría de sus textos. No obstante, es indudable que el marco conceptual que este grupo ha introducido ha permeado en alguna medida las producciones de conocimiento situadas geográfica y epistemológicamente en América Latina ${ }^{96}$.

96 Es pertinente recordar que antes se ha dicho que el pensamiento decolonial a diferencia del postcolonial pretende la transformación de las relaciones de poder y necesita teóricamente del activismo, y aunque los representantes que se han mencionado hasta ahora no han logrado salir del esquema académico, en su esencia el pensamiento si lo tiene en cuenta. Y podría decir, que es el pensamiento decolonial fusionado con el pensamiento postcolonial es el que se traduce en un 
Además, el pensamiento decolonial responde a una separación y ruptura con la propuesta de la escuela de Frankfurt y la teoría crítica, como lo pone de manifiesto Walter Mignolo en su texto El pensamiento decolonial: desprendimiento y apertura, en el que explica por qué es necesario para una verdadera decolonización, alejarse del pensamiento moderno.

Mignolo asegura que la racionalidad moderna es parte fundamental de la teoría crítica (Mignolo, 2007: 25) y, la geografía (en términos geopolíticos) determina las consecuencias de este pensamiento. Además, Mignolo, a través del grupo MCD, descubre que la modernidad, como época histórica y conceptual, es necesariamente colonial, es decir, es imposible (para este autor) concebir toda la producción del pensamiento desde el siglo XVI sin ese carácter eurocéntrico y superior. Incluso, propuestas que parecen decoloniales dentro del pensamiento europeo son coloniales, y se alejan del discurso hegemónico sólo gracias a la caridad cristiana expuesta en la retórica salvacionista de los frailes enviados a América, como es el caso de Fray Bartolomé de las Casas (Herceg, 2011).

Mignolo acepta en varias ocasiones que ser crítico (escuela crítica europea) y decolonial (escuela decolonial americana) es lo mismo, ya que las dos apuntan a reconocer el carácter colonial y hegemónico, entre otros grandes peligros del pensamiento moderno europeo, pero dado que su genealogía es diferente, es imprescindible distinguirlos en el ámbito académico.

En el texto de Mignolo, que se considera el manifiesto decolonial, se establece que es un pensamiento que se desprende de la modernidad y de sus lógicas de pensamiento y acción,

pensamiento de resistencia y retaguardia como el que propone Boaventura Do Santos entre otros que más adelante se analizará. 
y que abre las puertas a una reconceptualización de la historia, la política y la propia existencia del ser, es decir, establece nuevas herramientas de análisis (como la analéctica de Dussel) para alcanzar nuevos marcos teóricos. Digamos, para ejemplos más claros, que el pensamiento decolonial es contar la historia desde los que perdieron, explicar la política desde los que no tienen poder, interpretar la realidad desde los nadies.

Sueñan las pulgas con comprarse un perro y sueñan los nadies con salir de pobres, que algún mágico día llueva de pronto la buena suerte, que llueva a cántaros la buena suerte; pero la buena suerte no llueve ayer, ni hoy, ni mañana, ni nunca, ni en lloviznita cae del cielo la buena suerte, por mucho que los nadies la llamen y aunque les pique la mano izquierda, o se levanten con el pie derecho, o empiecen el año cambiando de escoba.

Los nadies: los hijos de los nadies, los dueños de nada.

Los nadies: los ningunos, los ninguneados, corriendo la liebre, muriendo la vida, jodidos, rejodidos:

Que no son, aunque sean.

Que no hablan idiomas, sino dialectos.

Que no profesan religiones, sino supersticiones.

Que no hacen arte, sino artesanía.

Que no practican cultura, sino folklore.

Que no son seres humanos, sino recursos humanos.

Que no tienen cara, sino brazos.

Que no tienen nombre, sino número.

Que no figuran en la historia universal, sino en la crónica roja de la prensa local.

Los nadies, que cuestan menos que la bala que los mata.

(Eduardo Galeno; 1989:59)

Si se asumen las palabras de Mignolo, desde la poesía de Galeano, es fácil comprender que la lucha decolonial, es y han sido, todo proceso de resistencia a la conquista, al olvido y a desaparecer.

Sin embargo, es necesario hacer algunas puntualizaciones respecto a la crítica a la modernidad del pensamiento decolonial, así como el grupo de investigación que se denomina Modernidad/Colonialidad/Decolonialidad (MDC). 
Juan Ricardo Aparicio y Mario Blaser en su texto La "ciudad letrada" y la insurrección de saberes subyugados en América Latina (2015), recuerdan que es necesario siempre precisar lo que llamamos modernidad, de tal suerte que podamos situarnos en avanzar en nuestro camino para «reconocer que hay otros mundos (diferentes del mundo moderno, pero ciertamente no tradicionales) y comprender las dinámicas de poder y la productividad (en el sentido foucaultiano) de sus interacciones mutuas» (Blaser y Aparicio: 2015:106).

Su propuesta pasa por el argumento de Bruno Latour en su libro Nunca hemos sido modernos en la que establece la Gran División entre nosotros los modernos y los Otros:

Por tanto, la Gran División interior [entre la Naturaleza y la Cultura] explica la Gran División exterior [entre Nosotros y Ellos]: nosotros [modernos] somos los únicos que hacemos una diferencia absoluta entre la naturaleza y la cultura, entre la ciencia y la sociedad, mientras que todos los Otros, ya sean chinos o amerindios, azandeces o baruyas, no pueden separar realmente lo que es conocimiento de lo que es sociedad, lo que es signo de lo que es la cosa, lo que viene de la naturaleza tal como es de lo que requieren las culturas (Latour 2007: 148)

Con esta cita, se puede ver que la modernidad surge como un sistema o cosmovisión única, que se erige como un sistema superior capaz de dominar a la naturaleza dividiendo y exaltando la racionalidad ascética por encima de la conexión con la naturaleza y más aún, como Martínez Guzmán afirma: «la distinción entre naturaleza y cultura, lejos de expresar objetividad y neutralidad como predica [acorde a cánones del pensamiento científico] es una manifestación de la dominación androcéntrica.» (Martínez Guzmán; 2000:69).

El grupo MDC es quizá una de las representaciones del pensamiento decolonial más elegantemente construidas, como apunta Escobar. Sin embargo, la propuesta decolonial no se limita al trabajo de este grupo y engloba más propuestas, como las que Blaser y Aparicio denominan «patrones de movilización insurreccional», que son los tres proyectos políticos 
coexistentes que Arturo Escobar ha distinguido en América Latina, y que se han desarrollado en las últimas décadas (Blaser y Aparicio: 2015:105):

1. Desarrollo alternativo: que se enfoca a la satisfacción de las necesidades y el bienestar de la población sin cuestionar las nociones de progreso y desarrollo

2. Modernidades alternativas: aquellos proyectos que se construyen sobre la base de tendencias contestatarias, que operan sobre las intervenciones del desarrollo y critican los diseños globales ${ }^{97}$.

3. Alternativas a la modernidad: quizá el proyecto más radical y visionario que pretender redefinir y reconstruir los mundos locales y regionales desde las prácticas de diferencias culturales, económicas y ecológicas ${ }^{98}$.

Desde el grupo MCD, sin embargo, se contribuye a la construcción de este pensamiento con la idea de que las divisiones entre Naturaleza y Cultura son co-emergentes y durante la historia se han reforzado mutuamente. Blaser y Aparicio lo afirman de esta manera:

Así, la ejecución de un mundo moderno, en el que la distinción entre Naturaleza y Cultura constituye un presupuesto ontológico, implica mantener bajo control la amenaza que significa la existencia de otros mundos que no operan sobre los mismos supuestos ontológicos $\mathrm{Y}$ esto se ha conseguido negándoles a esos mundos una existencia real. (Blaser y Aparicio: 2015:107)

\footnotetext{
${ }^{97}$ Quizá es en este proyecto político que se podría encontrar cabida para la práctica de la Filosofía para la paz y más específicamente para la lucha no violenta de algunos movimientos urbanos.

${ }^{98}$ Este proyecto político es el de mayor importancia para la presente investigación, pues es en él donde se enmarca la propuesta del zapatismo y la Concejo Nacional Indígena en México. Además, es justo en este proyecto que veo interesante la interacción con la propuesta filosófica de la Cátedra UNESCO de Filosofía para la Paz de la Universidad Jaume I, en la que se enmarca esta investigación. Toda la disertación se mueve entre los proyectos políticos de las modernidades alternativas y las alternativas a la modernidad, pues ambas comparten dos puntos fundantes: "1) una politización y una defensa de las diferencias culturales ligadas a la noción de autonomía y territorio y, 2) una forma de acción política que es no estatista, que rechaza la lógica de la representación y favorece una lógica que podemos llamar relacional (Prácticas otras de conocimiento, 2015: 108).
} 
La modernidad de esta manera, al constituirse, refuerza la existencia de su Otro negándole "existencia real y razonable". Y justo en este punto es donde el régimen de saber/poder de la colonialidad moderna adquiere toda su razón y sentido, pues las diferencias entre el mundo moderno y el mundo no moderno, se constituyen como diferencias coloniales, diferencias dentro de una relación jerárquica en la que el no moderno es sometido.

La subordinación de los no modernos en la mayoría de los casos es impuesta por medios violentos («campañas militares contra "los salvajes”, extirpación de idolatrías, escolarización obligada y monolingüe, desplazamientos forzados para "liberar" tierras “improductivas”, entre otros» (2015: 107), pero también por medios sutiles, y aquí es donde la academia moderna y los intelectuales modernos han hecho todo el trabajo.

Un elemento interesante que a mi juicio muestra una de las diferencias radicales con el pensamiento postcolonial, es que para el pensamiento decolonial no sólo basta con decir lo que nos han hecho, no sólo basta con visibilizar la violencia epistémica y directa, es necesario ir más allá, observar y analizar lo que se reafirmó como existente en el mundo de la exterioridad de la modernidad colonial.

La post-colonialidad habla de las narrativas que construyeron el mundo de los Otros, y a pensar que su aportación es invaluable y fundamental para el pensamiento decolonial como corriente teórica y práctica, la visión se construye dentro del sistema y no logra salir de los márgenes académicos. El pensamiento decolonial, por el contrario, apunta a la salida, y más aún, el inicio o el lugar desde donde revisar la historia es desde fuera de los límites del sistema. Esto no significa que lo haga desde un mundo paralelo, sino que reconoce la existencia de un mundo y un conocimiento fuera de los cánones de modernidad, un 
conocimiento invisibilizado o tachado de irracional, que desde el momento de la imposición de los dogmas de la modernidad ${ }^{99}$ se ha erigido como un pensamiento de resistencia.

Es necesario comprender que la unión del pensamiento decolonial con el pensamiento postcolonial es evidente y fundamental, pues ambos se nutren en gran medida de la propuesta de Foucault para comprender las dinámicas de poder u la productividad de las interacciones entre los modernos y los no modernos, pero el pensamiento decolonial ahonda tal vez un poco más en la idea de que siempre ha existido una exterioridad a la modernidad/colonialidad y que, en conexión con esto, siempre ha existido un conocimiento otro, muchas veces articulado con las luchas por la transformación y la justicia social (Mignolo 2000, Dussel 2000, Escobar 2004, Blaser y Aparicio 2015).

Un elemento más a destacar del grupo MDC es que ellos han puesto de manifiesto incluso que los intelectuales de la "ciudad letrada"100 han sido afectados por la desafección hacia la modernidad, que a su vez se ha unido con la creciente visibilidad y viabilidad de las propuestas alternativas que se ofrecen desde fuera.

Quizá uno de las cuestiones que más confunde y hace compleja la comprensión del locus desde donde se pretende construir el pensamiento decolonial, es la exterioridad de la modernidad. Asumir la existencia de un mundo no moderno suele ser complejo para los intelectuales de la ciudad letrada, pero más aún, para los intelectuales de las ciudades del Sur

\footnotetext{
${ }^{99}$ Los dogmas de la modernidad son: verdad (impuesta a través de la régime de saber/poder, el progreso a través del capitalismo y más adelante el neoliberalismo y la libertad como una consecuencia de la aplicación de la modernización (racionalidad ilustrada). Cfr. Blaser y Aparicio: 2015, 114)

${ }^{100}$ La "ciudad letrada" es el término acuñado por el crítico literario Ángel Rama (1996) para mostrar la configuración espacial y simbólica de lo que se conoce como el régimen moderno de saber /poder. Es la cuna del intelectual (letrado) que a su vez representa al sujeto moderno e ilustrado y por supuesto, con esta construcción emerge el indio en el campo como modelo de lo primitivo "lo salvaje".
} 
global, pues se comprende que ninguna ciudad en el mundo ha permanecido intacta y sin contacto con la modernidad, pero es justo aquí donde el concepto de co-emergencia adquiere relevancia. La imposición de una forma de vida, despertó un mundo que se resistía a cambiar, esos mundos los conocemos, han estado ahí al margen siempre, algunas se presentan de manera artística como las canciones de los afroamericanos esclavizados en las plantaciones de Estados Unidos o de las tradiciones textiles de los indígenas mayas en Centro América. Las expresiones del mundo no moderno son evidentes y más aún en las últimas décadas con el levantamiento de movimientos como el zapatismo.

Estar en Chiapas y recorrer los caracoles zapatistas muestran claramente un mundo donde la modernidad existe, pero al margen de sus vidas, la mayoría de las veces para complicarles la existencia, sobre todo cuando esa modernidad se traduce en extractivismo, y es justo el mundo que no le interesa al colonizador, el que ha estado al margen del sistema, el hoy aparece y muestra su sabiduría. Boaventura lo resume perfectamente:

El colonizado sólo interesa al colonizador como natura naturata, como recurso natural, y por eso puede seguir viviendo sus vínculos ancestrales con la natura naturans, en todo que no colisiona con la expropiación sistémica. Ósea el colonialismo, al contrario del capitalismo, permite el gobierno indirecto, esto es, el control del colonizado sobre lo que no interesa al colonizador [...] en otras palabras, el obrero pertenece más íntimamente al capitalista que el colonizado al colonizador y por eso las historia del Sur globlar son más diversas y ricas que las historias de los obreros en cuanto obreros (Boaventura 2015: 19)

Los márgenes de la modernidad son poco vistos en las urbes "modernas", aunque tal y como apuntan Blaser y Aparicio (2015), la crisis del capitalismo ha agrietado irremediablemente sus muros de tal manera que el conocimiento Otro a infectado ya el seno de la modernidad al interior, una modernidad sin afecto por muchos de sus intelectuales desde la segunda guerra mundial. 
En resumen, el pensamiento decolonial es una corriente en proceso constante de construcción que surge por la indignación frente al dolor humano y que a mi juicio construye nuevos marcos interpretativos, algunos que siguen en la academia, pero la vasta mayoría son el resultado de aquellos patrones de movilización insureccionales que han aprovechado las grietas y la reconfiguración de los límites de la modernidad para mostrar otros mundos, desde siempre existentes.

\section{Giro epistemológico decolonial}

Es muy interesante, sobre todo en relación a la propuesta teórica de Vicent Martínez Guzmán de la filosofía para hacer las paces, hablar del giro epistemológico decolonial, pues tal y como más adelante se verá, el giro epistemológico de Martínez Guzmán se enmarca en la Ética Discursiva de Habermas, pero sobre todo mama la indignación y la desafección característica de la Escuela de Frankfurt, eso sí apostado por una transformación un tanto más radical aunque siempre dentro de los márgenes de la modernidad (Martínez Guzmán; 2001:87).

Si recorremos brevemente la historia de esta desafección e indignación de los intelectuales letrados, aparece como primera imagen la Escuela de Frankfurt con la que tanto el pensamiento poscolonial a través del post-estructuralismo francés, como el decolonial con algunas de las investigaciones de Mignolo, están en constante diálogo. Pues antes de la segunda guerra mundial, el intelectual trabajaba para reconstruir esa razón técnica ${ }^{101}$ y más

\footnotetext{
${ }^{101}$ Es claro que en la historia occidental encontramos grandes pensadores que no ayudaban a construir esta racionalidad técnica, mucho antes de la Segunda Guerra Mundial, tal es el caso de Spinoza, que algunos autores como Boaventura de Sousa Santos toman como eje para explicar la diferencia entre Naturaleza/Cultura. También y de manera muy clara, el pensamiento nietszcheano con su célebre frase "Dios ha muerto" se interpreta como una expresión del fracaso de todo planteamiento de una
} 
aún, como se explicó en los primeros apartados con la teoría esclavista de Aristóteles, la filosofía justifica la colonización, la violencia, y sienta las bases de una ontología única que niega la existencia a los mundos fuera de sus cánones.

Una de las cuestiones más interesantes también y que ya se han esbozado brevemente, es la concepción ilustrada en la que, a través de la aplicación de la modernización, la eliminación de las desigualdades y de la exclusión de ciertos sectores de la población sería una realidad. La propuesta de Paz Perpetua de Kant, del ciudadano cosmopolita, es sin lugar a dudas deseable desde la cosmología occidental, pero, ¿qué pasa con aquellos mundos que no comparten esos principios? Bajo el pensamiento kantiano, y aristotélico, la subordinación por la fuerza de aquéllos que no adoptan esos ideales, es un acto de caridad, un acto ético al nivel más alto. ¿Qué hacemos entonces? ¿Cómo dialogar con todas las propuestas sin tomar los aspectos negativos y alienantes del pensamiento? «¿Cómo confrontar la desigualdad y la exclusión producida por una metanarrativa basada en un régimen de verdad en particular sin situarse uno mismo en otra metanarrativa y régimen de verdad, que generaría por necesidad otras exclusiones y desigualdades?» (Blaser y Aparicio; 2015:117).

Al respecto, la propuesta decolonial señala que la tarea de mantener abierto el proceso de articular verdades debe ser llevada a cabo por el colectivo y no por el intelectual ascético individual. Por otro lado, la propuesta de Martínez Guzmán con la filosofía para hacer las paces, reconoce que el proyecto moderno necesita enmiendas «como la superación de la dicotomía hechos y valores o la recuperación de la comprensión y la comunicación en los mundos de la vida, o la inclusión de la historia frente a la objetividad y la mera racionalidad

racionalidad y una cultura occidental, monoteísta no sólo tecnológicamente sino respecto del saber que viene desde Platón, tal y como lo afirma Martínez Guzmán (2000:59). 
instrumental» (2000:59) aunque se comprende dentro de lo que aquí se entiende como la "ciudad letrada".

Aquello que comparten las dos corrientes de pensamiento es la necesidad de un giro epistemológico, ya se ha analizado el giro propuesto por Martínez Guzmán, ahora es pertinente el giro decolonial.

El concepto de giro des-colonial en su expresión más básica busca poner en el centro del debate la cuestión de la colonización como componente constitutivo de la modernidad, y la descolonización como un sinnúmero indefinido de estrategias y formas contestatarias que plantean un cambio radical en las formas hegemónicas actuales de poder, ser, y conocer. (Maldonado, 2008: 66)

El giro decolonial propone comprender desde la necesidad de liberación de los pueblos indígenas y esta liberación tendrá que estar dada en todos los ámbitos del ser humano: en el ser, en el pensar y en el hacer. El peruano Aníbal Quijano, parte del grupo MCD, establece las cuatro categorías que permitirán reconocer la opresión y así comenzar con el proceso de la decolonialidad, es decir establece cuatro conceptos fundamentales de los que debemos $\operatorname{liberarnos}^{102}$ :

\section{Raza}

Esta categoría se utilizó por primera vez en la Conquista de América hacia los «indios» con la que se buscaba cimentar la superioridad de los europeos. Probablemente se originó por las diferencias fenotípicas entre los españoles y los habitantes originarios de América, sin embargo, rápidamente estas diferencias biológicas fueron constitutivas de una clasificación social discriminatoria y atroz. (Quijano, 2000).

\footnotetext{
${ }^{102}$ Estos cuatro conceptos son de suma importancia, pues son los grandes enemigos a vencer de las resistencias indígenas de México, especialmente el zapatismo. Sin embargo, es interesante apuntar que liberarnos de estos conceptos en el norte global marcaría también una diferencia donde podría emerger mucho del conocimiento del Norte Global invisibilizado como ya se ha apuntado.
} 
La idea de raza fue el modo más sencillo de otorgar legitimidad a las relaciones de dominación impuestas por la conquista que no sólo afectó a relaciones sociales en el territorio conquistado, sino a la sociedad europea que experiencialmente se definió como superior, materializando la teoría esclavista de Aristóteles. Desde ahora el ser y el no-ser filosófico era lo mismo que ser europeo y no-ser europeo en el mundo, que son las bases de la ontología dual del pensamiento occidental.

La clasificación social se dio mediante una estratificación de castas en la Nueva España (México) ${ }^{103}$ :

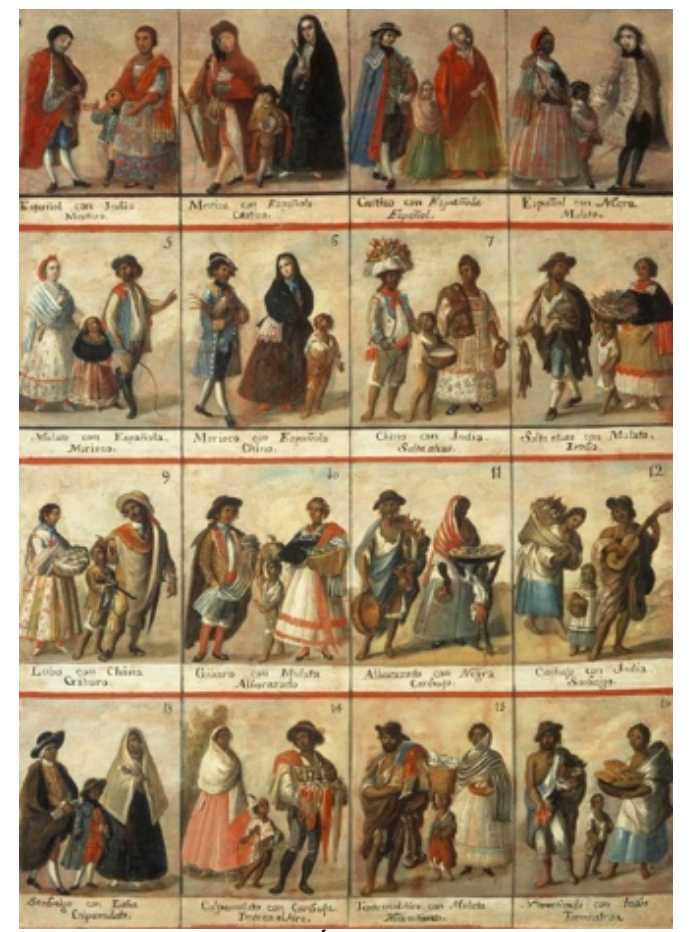

"Cuadro de castas", Óleo sobre tela siglo XVIII

Museo Nacional del Virreinato Tepoztlán, México

103 Para mayor detalle sobre pinturas y documentos sobre las castas coloniales recomiendo: Castro Morales, Efraín: "Los cuadros de castas de la Nueva España" Jahrbuch für Geschichte von Staat, Wierschaft, un Gesellschaft Lateinamerikas, 20(Köln, Böehlau Verdag, 1983) 671-690. 
En esta pintura aparecen $16 \operatorname{castas}^{104}$, sin embargo, algunos historiadores como Nicolás León hablan de 53 castas, pero un punto en el que todos coinciden es en la superioridad del europeo y en cómo la dominación por género también queda de manifiesto. Quijano a este respecto dice:

Históricamente, esto no significó una nueva manera de legitimar las ya antiguas ideas y prácticas de relaciones de superioridad/inferioridad entre dominados y dominantes. Desde entonces se ha demostrado ser el más eficaz y perdurable instrumento de dominación social universal, pues de él pasó a depender inclusive otro igualmente universal, pero más antiguo, el inter-sexual o de género: los pueblos conquistados y dominados fueron situados en una posición natural de inferioridad y, en consecuencia, también sus rasgos fenotípicos, así como sus descubrimientos mentales y culturales. (Quijano, 2000:203)

La categoría racial fue un elemento que se sumó a la lista de conceptos que legitimaban la opresión, y el caso más emblemático es el de las mujeres, siempre por debajo y siempre oprimidas. Desde la época prehispánica, con especial deterioro durante la conquista y hasta nuestros días, las mujeres indígenas quedan en el último eslabón cargando doble o triplemente con sus categorías mujer-indígena-pobre, visibilizando sólo las categorías que el sistema les permite tener e invisibilizando a la persona; debe quedar claro que la raza y el género son las categorías que permiten comprender la realidad dada, no la realidad que somos.

Es gracias a Aníbal Quijano que se puede hoy hablar sobre la relación intrínseca entre la categoría racial y la categoría de género en el contexto histórico de la colonialidad, ya que

\footnotetext{
${ }^{104}$ La imagen muestra: 1. Español con india: mestizo 2. Mestizo con española: castizo 3. Castizo con española: español 4. Español con negra: mulato 5.Mulato con española: morisco 6. Morisco y española: chino 7. Chino con india: salta atrás 8.Saltra atrás con mulata: lobo 9. Lobo con mulata: gíbaro 10. Gibaro con india: alvarasado 11. Alvarasado con negra: cambujo 12. Cambujo con india: sambaigo 13. : sambaigo con loba: calpamulato 14.Calpamulato con cambuja: tente en el aire 15.Tente en el aire con mulata: no te entiendo 16 . No te entiendo con india: tornatrás
} 
ambas parten de las mismas premisas para alcanzar el mismo objetivo: diferencias biologisistas para oprimir y dominar a la otra, pero es gracias a María Lugones (Lugones, 2008) que se puede entender que el sólo hecho de mencionar las palabras género y raza lleva a la conceptualización real y racional dada por el pensamiento europeo moderno.

Esto implica que el término «mujer» en sí, sin especificación de la fusión no tiene sentido o tiene un sentido racista, ya que la lógica categorial históricamente ha seleccionado solamente el grupo dominante, las mujeres burguesas blancas heterosexuales y por lo tanto ha escondido la brutalización, el abuso, la deshumanización que la colonialidad del género implica. (Lugones, 2008:82)

En resumen, se puede afirmar que las categorías de género y raza, son conceptos fundantes de la dominación europea, y representan una realidad dada y construida únicamente para la explotación y dominación de los seres humanos.

Las consecuencias de este sistema arbitrario de clasificación se pueden sentir aún en nuestros días, incluso como si el tiempo se hubiera detenido, y aunado al clasismo económico desarrollado por el capitalismo, sume a las sociedades coloniales en una dominación que en algunos momentos parece natural ${ }^{105}$, tal y como se ha analizado en el primer capítulo de esta investigación con el colonialismo interno.

\section{Capitalismo}

Otro de los elementos esenciales dentro del pensamiento decolonial, es la identificación del capitalismo como arma económica de explotación y dominación humana. Para Quijano, «en

\footnotetext{
${ }^{105}$ Los -cidios perpetrados en México durante la Conquista y la Colonia (primer capítulo), permiten comprender esta afirmación, además de reconocer como el concepto de raza es uno de los principios de la cultura de violencia que cubre a la sociedad mexicana. De igual manera para ahondar sobre el racismo en México recomiendo la obra de historiador mexicano Federico Navarrate Alfabeto del racismo mexicano, (2017) donde a través de dichos, refranes, y frases cotidianas de la vida el autor nos muestra lo vivo del racismo en la sociedad mexicana.
} 
el proceso de constitución histórica de América, todas las formas de control y de explotación del trabajo y de control de la producción-apropiación-distribución de productos fueron articuladas alrededor de la relación capital-salario y del mercado mundial» (Quijano, 2000: 204).

En este sentido el concepto de raza se supeditó a los deseos capitalistas, haciendo una distribución racista del trabajo donde la esclavitud y servidumbre se volvieron engranajes vitales de los deseos del mercado mundial.

Algunos podrían comentar que el capitalismo no es consecuencia de la Conquista de América, incluso muchos autores coinciden que su aparición en el mundo debió ser alrededor del siglo XI - XII cerca de la región meridional de las penínsulas íberica y/o itálica, y por consiguiente en el mundo islámico. Pero este capitalismo (relación capital-trabajo-salario) no estaba articulado. «Sólo con América pudo el capital consolidarse y obtener predominancia mundial, deviniendo precisamente en el eje alrededor del cual todas las demás formas fueron articuladas para los fines del mercado mundial. Sólo de ese modo, el capital se convirtió en el modo de producción dominante.» (Quijano, 2000: 220). Y tal como se ha visto en el repaso de los años de consolidación de la nación mexicana, de 1810 a 1910, se fusiona la colonización y el capitalismo, ya que este segundo se instaura ya, no sólo como modelo económico sino como sistema mundial. 


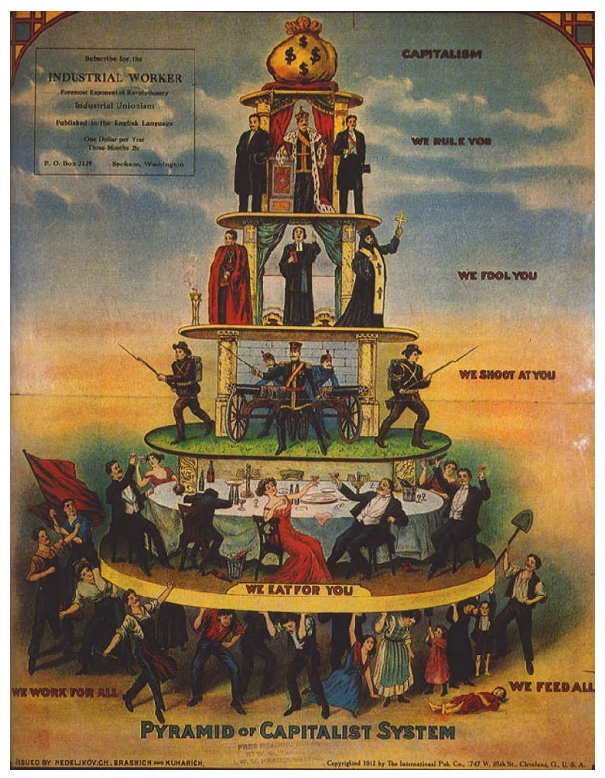

Pirámide del Sistema Capitalista, Nedeljkovich, Brashick and Kuharich, Cleveland, The International Publishing Co., 1911

La conquista de América materializó la ambición más fuerte y voraz, el dinero ocupó a partir de este momento el lugar predominante en la cultura humana. Ahora las personas eran medios para acumular producción y capital: poder dominante. La realidad económica mundial es ejemplo claro de esto, lo importante son los mercados para la economía de un país, no la vida de sus ciudadanos.

El capitalismo es una herramienta de control, un sistema desigual que distribuye el trabajo de acuerdo a conceptos racistas en el que el valor de la vida no encuentra lugar, los hombres, mujeres y niños dejan de ser seres humanos para convertirse en recursos humanos. (Galeano; 1989:60)

La despersonalización a la que se enfrenta el sujeto en el capitalismo es tan voraz pero contradictoriamente tan sutil que se hace de manera voluntaria. La representación del individualismo, a través del supuesto egoísmo natural de los seres humanos, presenta este sistema económico como un proceso histórico natural de los humanos y así deja a su 
antagonista, el comunismo, como un proceso utópico, irrealizable, que no escucha la naturaleza del «hombre».

Con estas afirmaciones se pretende mostrar que el capitalismo, desde su origen, es un sistema alienante que busca la despersonalización a favor de la acumulación del capital, pero debe quedar también claro que no es sino hasta el siglo XXI cuando ese capital dejó de tener un referente real, es decir cuando la riqueza de las naciones deja de medirse en la cantidad de oro, y cambio al dólar, un referente regulado por instituciones que protegen únicamente la funcionalidad del mercado (años cuarenta), y por lo tanto su capacidad alienante encuentra uno de sus puntos más altos. De igual manera la financiarización del sistema en los años ochenta muestra la gran victoria del capitalismo, y los dos son lo que hoy llamamos neoliberalismo (Anselm Jappe 2015).

En resumen, se debe comprender que después de la Conquista de América, o mejor dicho, gracias a ella, surgió un sistema de explotación mundial que unió cada una de las formas de control en el trabajo y explotación para la comercialización en el mercado mundial. (Quijano: 2005:56).

\section{Estado-Nación}

El poder colonial tiene un tercer elemento muy complejo; la imposición de una estructura de organización jerarquizada que oprime y silencia las voces de grupos determinados de la sociedad: el Estado-Nación.

Naciones y Estado son un viejo fenómeno. Sin embargo, aquello que llamamos moderno Estado Nación es una experiencia específica. Se trata de una sociedad nacionalizada y por eso políticamente organizada como un Estado Nación $\{. .$.$\} Es una suerte de sociedad individualizada$ entre las demás. Por eso, entre sus miembros puede ser sentida como identidad. $\{\ldots\}$ Es una estructura de poder, del mismo modo en que es producto del poder. En otros términos, del modo en que han quedado 
configuradas las disputas por el control del trabajo, sus recursos y productos. (Quijano, 2000:226)

El Estado-nación moderno es la forma política en el que queda centralizado el poder, construyendo así la hegemonía del estado; es una delimitación territorial, cultural y social que comúnmente conocemos como identidad nacional. Sin embargo, esta identidad es una homogenización cultural, generalmente acompañada por una democratización del trabajo.

El proceso histórico de construcción del Estado-nación en Europa se dio a través del surgimiento de núcleos políticos que conquistaron su espacio de dominación y se impusieron sobre los diversos y heterogéneos pueblos e identidades de los territorios ocupados (Quijano, 2000:227). Es así que se puede afirmar que el estado-nación surge de los procesos de colonización (externos e internos) dentro de territorios extranjeros en Europa, se perfeccionaron con las colonias de América y África y llegaron a su máximo esplendor durante la Revolución Francesa y el pensamiento ilustrado.

Como ejemplos claros del proceso de construcción del Estado-nación, tenemos a Francia y a España, el primero considerado el gran éxito y el segundo el gran fracaso. Analicemos cada uno.

Francia, «a través de la democratización radical de las relaciones sociales y políticas con la Revolución Francesa» (Quijano: 2000), provocó que toda la colonización previa en territorios como la Bretaña o el país vasco sufrieran una francesización, una homogenización cultural para centralizar el poder; ahora eran primero franceses que vascos o bretones. Es muy interesante la democratización o, mejor dicho, el discurso igualitario que utilizaron, para hacer ver que todos eran franceses, pero que detrás tenía una consiga clara, universalista y racista: ¡O Francia o la muerte! 


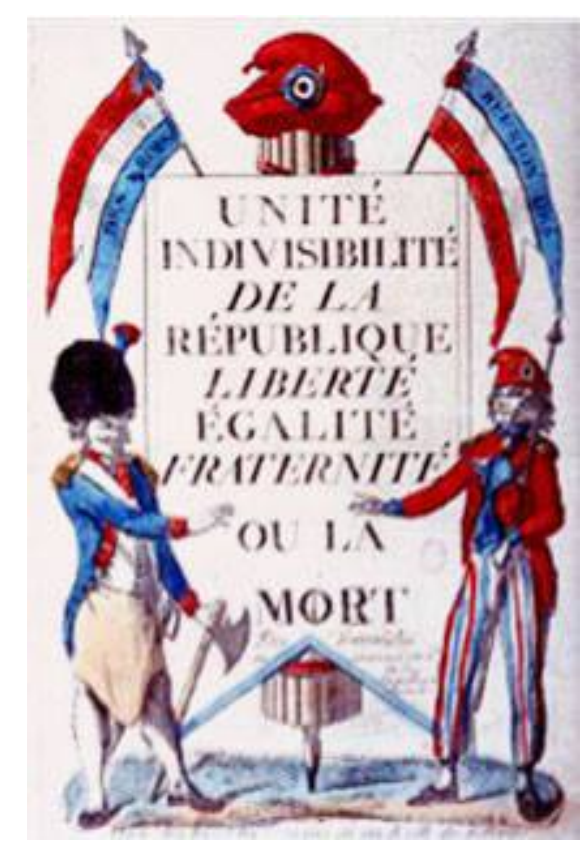

Nuevamente el otro, el extranjero, aparecía como el enemigo. Un ejemplo claro de esto es la negativa del estado a reconocer las diversas lenguas del territorio francés, e incluso el decreto presidencial dado en 2015 para eliminar un territorio histórico y culturalmente conocido como Alsacia.

Por otro lado, el caso español es en términos de construcción de Estado-nación un proyecto fallido, ya que ha sido imposible centralizar el poder y la identidad. El reconocimiento histórico de sus comunidades ha permitido la supervivencia de la cultura vasca o catalana sin olvidar, por supuesto, el trabajo directo de las comunidades que han trabajado directamente por la supervivencia de su cultura. La razón del fracaso del Estadonación español radica en la poca democratización de discurso y el uso constante de una estrategia bélica para derrotar a sus enemigos ${ }^{106}$.

\footnotetext{
1062017 y el denominado, por los medios de comunicación y el gobierno, "problema catalán" ha sacado a la luz la vertiente más peligrosa de los nacionalismos cuando la comunicación se rompe. La participación de las fuerzas de control del estado el 1 de octubre de 2017, así como las distintas manifestaciones violentas a favor de un nacionalismo u otro, muestran no sólo la incapacidad de un gobierno como el español para hacer frente a los retos de la multiculturalidad social, sino reflejan el
} 
En resumen, «un importante proceso de democratización (hegemonización cultural) de la sociedad es la condición básica para la nacionalización de esa sociedad y de su organización política en un Estado-Nación moderno» (Quijano, 2000:229). Es decir, en una sociedad jerarquizada, con un poder político centralizado, y completamente homogénea.

\section{Eurocentrismo}

He dejado esta última característica del pensamiento decolonial para el final, ya que será uno de los puntos clave para comprender mi crítica a la filosofía para la paz, pero paradójicamente es también la razón por la que es posible la construcción de un puente de entendimiento.

El eurocentrismo: «es un nuevo modo de producción y control de la subjetividad, la imaginación, la memoria y por encima de todo, el conocimiento» (Quijano 2005:57). Es el arma más potente de la colonización, es a la vez fundamento y consecuencia, recoge las tres características anteriores y las impulsa. Es el legado más terrible que se ha dejado en todas las excolonias en el mundo. Es la punta más alta del saber/poder.

Históricamente el eurocentrismo se fundamenta en el etnocentrismo y por ende en la teoría política aristotélica (que podría considerarse la teoría etnocéntrica que más ha sobrevivido en el tiempo), donde el "bárbaro" o "extranjero" tiene un nivel cultural, político, social y principalmente racional, inferior a los ciudadanos de la polis griega.

El eurocentrismo es el proceso de homogenización del Estado-nación llevado a todas las esferas del ser humano, la meta es que todas y todos queramos ser europeos, porque Europa es la cumbre civilizatoria y porque es el lugar donde se centra el poder.

fracaso de la sociedad individualista siempre acostumbrada a imponer y no a dialogar. El fallo de la supuesta fractura entre la sociedad catalana y española es, a mi juicio, el reflejo más claro del pensamiento colonizador que busca siempre la dominación. 
Debe quedar claro que el eurocentrismo no se refiere a un espacio territorial específico, es por ello que es mejor identificarlo como pensamiento occidental o modernidad, pues hace referencia a los valores y principios de la sociedad europea pero que ahora se ha extendido a diversas partes del globo.

Sin lugar a dudas, el gran auge del eurocentrismo emerge de la relación con América y con el concepto de raza, pues creen haber comprobado la superioridad europea a través de las diferencias fenotípicas. Después del gran encuentro, Europa se posiciona como el territorio civilizado, racional y desarrollado, como el lugar del progreso, como el camino para el progreso, como el objeto de deseo de todos los seres humanos; el eurocentrismo transforma la ética aristotélica posicionándose como la verdad, la belleza, la bondad y la felicidad. Finalmente es en Europa donde los ideales de la modernidad se ven materializados.

Desde esta posición, como ya se ha mencionado líneas arriba, se desprende el régimen de saber/poder, pues toda la producción de pensamiento, tendrá que ser desde Europa o para Europa (aunque sea en términos aspiracionales) y que a partir de ese momento se conocerá como el pensamiento occidental. Sin lugar a dudas, «la expansión mundial del colonialismo europeo, lleva también a la expansión mundial de la hegemonía eurocéntrica» (Quijano; 2005:57).

El pensamiento eurocéntrico u occidental, presenta algunas características definitorias: tiene pretensiones universalistas, mantiene como principio guía el ideal de progreso, establece a la razón como la característica más importante de los seres humanos, establece al Estado-nación como vía ideal para la organización de un territorio, al capitalismo como la forma natural de la economía y la racialización como un proceso natural-biológico.

Además, presenta como arma más definitoria el concepto de ciencia con su metodología (método científico), de tal suerte que todo lo que escape a él será considerado, 
absurdo, irracional y más específicamente inexistente (en términos de verdad y existencia lógica). El eurocentrismo es la ontología única, dominante y violenta que deja fuera toda realidad que no comparta sus principios.

La tan anhelada objetividad, neutralidad y universalidad del pensamiento científico no es otra cosa que una herramienta de dominación epistémica a través de la cual se han erigido los muros límites de la modernidad, dejando a más de la mitad de la población mundial fuera ${ }^{107}$.

El reconocimiento de estas cuatro características en la historia, la política, las relaciones sociales, de acuerdo a Quijano iniciará un proceso de descolonización, pues nos habremos dado cuenta de las consecuencias coloniales en las que aún vivimos.

Estas cuatro características son fundantes del pensamiento decolonial, son un nuevo marco interpretativo que permite repensar la historia, la política y las relaciones sociales de la región, permite pensar más allá de los límites de la modernidad, la pregunta inicial bajo es este nuevo marco de interpretación de la realidad es: ¿qué ha pasado allá fuera mientras aquí seguíamos esperando que la modernización llegara?

El pensamiento decolonial, además del grupo de MCD y los patrones de movilización insurreccional, tiene un tercer elemento que es la propuesta teórica de Enrique Dussel, la filosofía de la liberación, propuesta que surge de la experiencia colonial, surge como su opuesto y tiene como reto reconstruir la historia desde las miradas decoloniales, desde las personas, hechos, y principios que se resistieron al olvido, que se resistieron a la conquista.

\section{Filosofía de liberación}

${ }^{107}$ A este respecto recomiendo el texto de Santiago Castro Gómez, La hybris del punto cero, 2008, donde muestra la imposición del saber eurocéntrico en las luchas de emancipación en América Latina y que sin lugar a dudas, determinaron las relaciones educativas de los siglos posteriores en esa región. 


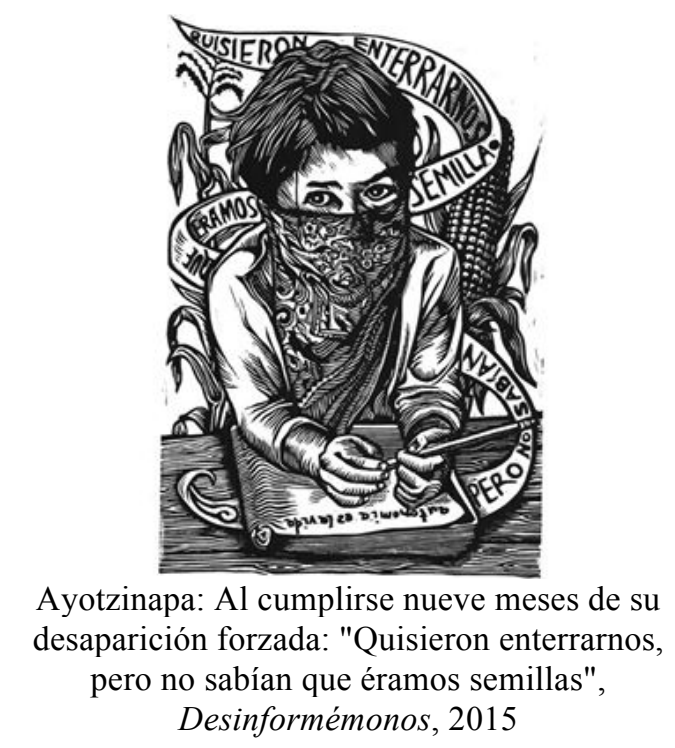

La Filosofía de la Liberación (FL) no surge como respuesta política a las circunstancias latinoamericanas, sino como consecuencia de la experiencia colonial, de tal suerte que es posible decir que sin la conquista de América no hubiera sido posible este pensamiento. Evidentemente esto no afirma que fue el imperio español quien trajo el conocimiento a América, pues se afirmaría el eurocentrismo, sino que el hecho de la conquista produjo, como pensamiento antagónico, la filosofía de la liberación, de igual manera que a gran escala construyó el pensamiento decolonial, se comprende al modo dialéctico

Se puede decir que la creación del pensamiento occidental eurocéntrico y la filosofía de la liberación se da, de manera simbólica, el 12 de octubre de 1492 con la llegada de Cristóbal Colón a América y se consolida en 1521, con la caída de Tenochtitlán (capital azteca). Sin embargo, no es sino hasta 1968, con lo diversos movimientos sociales y estudiantiles que este pensamiento sale a la luz.

El acontecimiento fundador debe situarse a finales de la década de los sesenta, en una situación de crisis filosófica, cultural, política y económica de contornos explosivo s, que parte de la experiencia del 68 (en París, en Berkeley, en Tlatelolco en México o en el Cordobazo de Argentina). De cierta manera la filosofía de la liberación es una herencia del 68. (N.L Solís Bello Ortiz, J. Zuñiga, 2009) 
Los argentinos Horacio Cerruti y Enrique Dussel son los principales representantes de esta corriente de pensamiento y según ellos (especialmente Cerruti) existen 7 equívocos (Beorlegui, 2004: 670-671) que hay que superar para verdaderamente entenderla:

1. «Entender la FL como un movimiento sin fisuras, cuyos integrantes tuvieran ya claras y comunes una problemática, una metodología, unos presupuestos filosóficos, etc. en los que se apoyaría su filosofar». Para superar este equívoco se tendrá como pilar la metodología y las categorías de Dussel quien, a partir de una lectura de Heidegger, Marcuse, la teoría crítica de la Escuela de Frankfurt y el concepto de exterioridad de Levinás, construye un modo de pensar que tiene como primer principio la necesidad de la experiencia de la subjetividad a través del sufrimiento del otro, reconociendo una capacidad comunicativa que muchas veces es coartada por los procesos de poder como dominación. Dussel se pregunta ${ }^{108} \mathrm{si}$ es posible filosofar desde abajo, desde la situación de América Latina y es así que se construye un pensamiento desde las categorías de opresión, mundo dependiente, explotación, ser periférico y finalmente liberación, que al final otorga nuevas categorías para hacer política, economía, antropología y por supuesto filosofía tal y como también propone el pensamiento decolonial en su conjunto.

2. «Pensar la FL fuera de la reflexión epistemológica sobre la "teoría de la dependencia" y/o la "teología de la liberación"». En este punto es necesario comprender que no son dependientes, pero tampoco son excluyentes y ambas se apoyan en la posible construcción de un mundo más justo. Sobre todo, es la

\footnotetext{
${ }^{108}$ Aunque no es el primero, se dice que A. Salazar Bondy con su libro ¿Existe una filosofía en nuestra América? Es el primero que cuestiona este punto.
} 
Teología de la Liberación la que tendrá un impacto directo en los movimientos autonómicos y de resistencia en América Latina. Además, y como ya se ha mencionado, es la teoría de la dependencia una de las propuestas teóricas que ayudó al desarrollo académico del pensamiento decolonial y, por ende, a la Filosofía de la Liberación. Las tres propuestas teóricas abren las puertas a un nuevo marco interpretativo de la realidad y la historia en los países periféricos, pero es claro que utilizan diversas herramientas para desarrollar su propuesta y llegan a conclusiones que pertenecen a ámbitos distintos, pero con un mismo objetivo, superar la dominación desde la conciencia de la sumisión y el pensamiento de resistencia.

3. «Se suele etiquetar a veces a la FL como "marxista" y/o "revolucionaria", o como un discurso puramente populista sobre Latinoamérica.» La FL, como la Escuela de Frankfurt, la filosofía para la paz, y muchas otras corrientes de pensamiento, toman principios y presupuestos de teorías anteriores, pero esto se vuelve aún más complejo cuando los conceptos o las corrientes que se toman como referencia son controversiales y poco comprendidas, como el populismo y específicamente el de América Latina. En esta investigación este concepto se entiende como «estilo de gobierno siempre sensible a las presiones populares, o como política de masas, que buscaba conducirlas manipulando sus aspiraciones, el populismo sólo puede ser comprendido en el contexto del proceso de crisis política y de desarrollo económico que se abre con la revolución» (Weffort; 1970: 54). Y en este sentido comparte con la FL la aspiración por hablar desde la base, por tener como punto de origen las voces silenciadas. De igual manera, la FL apuesta por una reconstrucción histórica que exceda los presupuestos eurocentristas, pero esto no 
significa que no pueda tomar ciertas propuestas, con bastantes matices y enmiendas al pensamiento, en pos de un enriquecimiento cultural. Por otro lado, desde principios del siglo $\mathrm{XX}$, las circunstancias históricas han planteado una dicotomía en todas las discusiones políticas o académicas, ser de izquierdas o de derechas, capitalistas o comunistas, pero la FL intenta superar estos presupuestos apostando por una perspectiva desde aquéllos que no han tenido participación en la historia universal, aquéllos que han sido olvidados por los grandes conceptos.

4. «También se le suele etiquetar a veces de "filosofía cristiana".» Esto se fundamenta en el trabajo de algunos autores que entienden el pensamiento liberador «como una concreción y desarrollo de la doctrina social de la iglesia católica» específicamente en la relación a la liberación de los judíos de Egipto. (Beorlegui, 2004:671). Se entiende de esta manera por la cercanía con la teología de la liberación, una transformación teórica de la religión católica gracias a la experiencia de opresión en las colonias de América. Históricamente podemos entender esta transformación en las Misiones Jesuitas o el trabajo de Bartolomé de las Casas sobre el fin de la esclavitud de los indígenas. Sin embargo, la FL logra un paso más que la teología de la liberación: ponen en entredicho los principios de superioridad y civilidad de los europeos, utilizando su propio marco teórico y en algunos sentidos superándolo, por ende, no se puede considerar como una propuesta cristiana, comparte intereses comunes con la doctrina social de la iglesia, pero supera los propios principios de la doctrina católica. Cuestiona la dominación en su sentido más amplio y por ende cuestiona los fundamentos de la evangelización en América. 
5. «Otro malentendido consiste en entender la FL como el primer logos latinoamericano, la primera filosofía auténtica de Latinoamérica, pero definir así a la FL supone ignorar y despreciar toda la filosofía que anteriormente se ha hecho en Latinoamérica.» Como ya se mencionó líneas arriba, antes de la FL existieron autores que iniciaron unos procesos de construcción desde Latinoamérica para Latinoamérica. También en este punto se pueden tomar en cuenta las resistencias indígenas en la masacre de La Conquista y durante el periodo de oscuridad colonial. De igual manera se deben tomar en cuenta las enseñanzas de grandes pensadores como Nezahualcóyotl en Texcoco antes de la llega de los españoles a la región o las concepciones de guerra, sociedad y arte previos a la Conquista que muestran una episteme avanzada incluso bajo los cánones de la filosofía griega. Además, este presupuesto trae consigo la esencia misma del saber/poder, pues sólo aquello que se adecue a la normativa moderna se considera logos, y como se ha demostrado ya en varias ocasiones aquello que interesa al pensamiento decolonial y a la filosofía de la liberación es precisamente lo que no se adecua, interesa lo que está más allá de los límites de la modernidad.

6. «Un nuevo equívoco consiste en atribuir a la FL la exigencia de una nueva y original (de Latinoamérica) lógica y epistemología, esto es, una nueva racionalidad que se traduce, en el aspecto metodológico, en nuevas propuestas: ana-lectic, en oposición a la dialéctica.» Esta es una crítica directa al modo de construcción del pensamiento de la Liberación de Dussel, quien propone la analéctica como el método más adecuada para filosofar en Latinoamérica. Las críticas que le merecen es el hecho de buscar estructuras que validen el conocimiento en occidente buscando un reconocimiento, que, a mi juicio, no es 
más que la búsqueda de la subjetividad compartida, necesaria para la construcción del diálogo. Sin embargo, en esta investigación no se utilizará este aspecto metodológico de la teoría de Dussel ${ }^{109}$.

7. «Por último, es también un malentendido considerar la FL como una práctica antiacadémica o extracadémica, falta de rigor, y en gran medida, irracional e ideológica.» Muchas de las metodologías que se utilizan en la FL no son académicas bajo las estructuras occidentales y bajo estructuras coloniales, específicamente como el conocimiento indígena del Buen Vivir, pero en el proceso de decolonización que hay en esta investigación, se tratará de invertir el régimen saber/poder utilizando y dialogando con los conocimientos otros.

Mantener en la mente estos equívocos permite tener una postura crítica sobre la FL y de este modo parece coherente decir que la Filosofía de la Liberación podría definirse como la conceptualización de una realidad de liberación vivida por el pueblo Latinoamericano desde su primer contacto con occidente.

109 La analética de Dussel supone una revolución teórica interesantísima ya que propone una superación ontológica y epistemológica de la totalidad; «quiere indicar el hecho real humano por el que todo hombre, todo grupo o pueblo, se sitúa más allá del horizonte de la totalidad» (Dussel, 2011:238). Más aún, la analéctica supone como necesario la aceptación ética de la interpelación del oprimido y la mediación de la praxis como constitutivo primordial de la conciencia crítica, y a pesar de la fuerza de esta argumentación para la búsqueda de la liberación, a mi juicio sigue conservando el eje de la discusión dentro de la conciencia racional europea, y en este sentido se alinea con el pensamiento de Vicent Martínez Guzmán de una racionalidad responsable, pero como se ha mencionado con la responsabilidad, la apuesta de los movimientos indígenas y especialmente el zapatismo, se aleja de la racionalidad crítica como centro, aunque sus metas/consecuencias finales sean nobles. Para los indígenas se comprende la praxis de la liberación y la comunalidad como hechos vivenciales y por lo tanto inefables desde la racionalidad. Esta argumentación se clarifica sobre todo con el concepto de comunalidad que se analiza en el quinto capítulo. Basta mencionar que ella, la comunalidad, no puede entenderse ni desde la dialéctica ni la analéctica, pues sólo puede vivirse y en este sentido, mi investigación intenta adentrarse a su pensamiento sin una metodología epistemológica determinada, es por esto que no se usará la propuesta metodológica de Dussel. 
Específicamente lo que busca la FL en esta investigación es entender la fragilidad de la vida en los escenarios de opresión, que no es otra cosa que la fragilidad de la vida en la violencia estructural y cultural o la necesaria fragilidad de la vida en el proyecto colonial al que hay que hacer frente para no seguir muriendo.

Uno de los elementos filosóficos más importantes a destacar en la FL es su fenomenología, pues gracias a esta podremos construir un puente de entendimiento con la filosofía occidental, especialmente con la filosofía política de Hannah Arendt y la filosofía para la paz de Vicent Martínez Guzmán. De esta manera seguimos avanzando en la espiral de conocimiento que recoge lo pasado y dialoga con lo presente y futuro, una espiral que no se enmarca en los límites de la modernidad, sino en los límites de la experiencia y reflexión humana.

\section{Construyendo puentes: de regreso a la filosofía occidental con lentes del pensamiento}

\section{decolonial}

Para ahondar en este apartado es necesario explicar, a grandes rasgos, qué es la fenomenología dentro del pensamiento occidental ${ }^{110}$, para que se entiendan los aportes desde la filosofía de la liberación y por supuesto el diálogo con el pensamiento en resistencia. Hacerlo es necesario pues tanto Hannah Arendt, como Enrique Dussel parten de la fenomenología para desarrollar su pensamiento.

Edmund Husserl (1859 - 1938) filósofo alemán, padre de la fenomenología trascendental y el pensamiento fenomenológico propone una nueva forma de hacer filosofía.

\footnotetext{
${ }^{110}$ Todo lo referente a la fenomenología dentro del pensamiento occidental se ha trabajado desde la investigación realizada de 2007 a 2011 en la tesis de licenciatura: El origen del mal: un estudio sobre los gobiernos totalitarios de mi autoría.
} 
De manera sencilla, a la fenomenología le compete el estudio de los fenómenos, aquellos objetos (y sujetos) que aparecen.

Dentro de la jerga kantiana, el fenómeno es aquello que aparece ante el sujeto, aquello del objeto que podemos conocer. El nóumeno, la cosa en sí, la esencia, la sustancia aristotélica, no se puede conocer, sólo se pueden ver los fenómenos, esto presupone que algo siempre excederá nuestro pensamiento. Es imposible conocer el noúmeno de las cosas dentro del pensamiento kantiano, imposible conocer la cosa en sí. Para Husserl, esto es un error, ya que lo que aparece, es lo que es, el noúmeno si no aparece no es; el fenómeno es lo que es ${ }^{111}$.

Estas afirmaciones están cargadas de la tradición psicológica del pensamiento de Husserl, a quien la verdad le preocupa menos que el sentido, mostrando así su descontento con los cánones modernos. Para él, y gran parte de la tradición filosófica posterior, lo más importante será el significado de las cosas; la intencionalidad del fenómeno es lo más importante, ya sea en términos de lenguaje, en la ética o en la política. Esto implica una trasformación radical en la epistemología, ya que todo el proceso de conocimiento estará condicionado por la intencionalidad, por el me parece, de tal suerte que lo que importará será la capacidad del aparecer de los objetos y más específicamente nuestra capacidad de aparecer.

El desarrollo de la fenomenología en la historia cuenta con grandes pensadores como Heidegger y Arendt entre otros, sin embargo, para los fines de esta investigación se abordará

\footnotetext{
${ }^{111}$ Este breve repaso de la fenomología que crítica fuertemente el pensamiento kantiano es un salto grande dentro de la historia de la filosofía occidental, sin embargo he decidio no profundizar en los diversos aportes de grandes pensadores que separan a Husserl de Kant, ya que para los fines de esta investigación es el pensamiento de Hannah Arendt con la superación de la distinción entre noumeno y fenomeno la que posiblilitará concebir la política como la acción plenamente humana, tal y como lo establece en La Condición Humana (2005) [1958].
} 
la propuesta fenomenológica de Heidegger desde Arendt, pues será la filósofa alemana la que fundamenta el puente de entendimiento desde el pensamiento europeo.

Primero debe quedar claro que en la fenomenología se hace necesario emprender un nuevo camino en la ontología, de tal suerte que se comprenda, ya no el ser, sino la existencia del ser:

El ver, el oler y el sentir con el tacto son actos en que se perciben los respectivos objetos, los colores y las formas, el olor, la suavidad y blandura, o son actos de percepción. Los objetos de estos actos, los objetos percibidos, se llamas perceptos. Hay que distinguir bien la percepción y el percepto. Para distinguir hay dos procedimientos. El más convincente es la separación material de las dos cosas. Pero hay que, siento distintas, siendo dos, van siempre juntas, no pueden separarse. Entonces se las distingue, se sabe que son dos, si tienen cualidades o propiedades diferentes, sobre todo si las tienen contrarias. Ahora bien, no es posible separar la percepción del percepto. No puede haber percepción sin percepto. Anteriormente se dijo que a la flor le es indiferente todo, ser vista, olida, tocada o gustada, para ser la flor que es. Esto quiere decir que un fenómeno físico puede ser lo que es sin estar siendo visto, olido, tocado, en suma percibido por nadie o sin ser percepto de ninguna percepción. En cambio, es absolutamente imposible un ver que no sea un ver algo, un color o una forma, un oler que no sea un oler algo, un olor; un sentir con el tacto que no un sentir algo, una forma o una cualidad con la suavidad o la blandura; en suma, es absolutamente imposible una percepción que no sea percepción de algo, de un percepto. Pero si esta imposibilidad es la de separar la percepción y el percepto, hay la posibilidad de distinguir la percepción y el percepto por las cualidades o propiedades. El percepto es un fenómeno físico. La percepción es un fenómeno psíquico. (Gaos, 2000:139)

Del mismo modo, el ser no puede concebirse sin el mundo en el que aparece, no somos hasta que aparecemos, estamos arrojados al mundo para poder existir. Nosotros somos percepto y percepción unidas y todo el conocimiento será, necesariamente de esta manera.

De estas afirmaciones surge el existencialismo a manos de Jean Paul Sartre quien concibe este arrojo al mundo como la angustia de la existencia, la angustia del gerundio; existiendo, viviendo, sintiendo, muriendo, pero es Hannah Arendt, filósofa alemana quien llevará el pensamiento de Heidegger más allá y sin pasar por el existencialismo, pero dirigido 
totalmente al ámbito de la política. Para Arendt «el mundo no tiene principio ni fin, afirmación que sólo parece adecuada para seres que siempre llegan a un mundo que les precedió y que les sobrevivirá» (Arendt; 2002:45). El mundo es un espacio existente antes de la vida, pero es la vida la que aparece como fenómeno ante el mundo.

En el Diario Filosófico la autora dice que el mundo sólo existe cuando los seres humanos se relacionan, afirma pues que el mundo no existe sin la vida, existe el espacio, pero no es mundo: «mundo es aquello que se forma como dimensión espacial y temporal tan pronto como los hombres están en plural; no hace falta que estén los unos con los otros o los unos junto a los otros, sólo basta la pura pluralidad» (Arendt, 2006:524). El mundo sólo existe, se conoce y tiene sentido en la pluralidad; el mundo no es sólo, es uno donde caben muchos mundos (tantos como relaciones de vida), no hay universo sino pluriverso.

El mundo existe para nosotros ${ }^{112}$ cuando hay pluralidad; vivimos para oír y ser oídos, somos en el mundo porque sólo en el entre podemos ser conocidos. Es claro que la definición que da tiene grandes matices políticos, ya que Arendt entiende que lo verdaderamente humano es lo político, es decir la relación, el entre de los sujetos.

Hay fuertes matices idealistas en las afirmaciones de Arendt, aunque no llega al a una postura hegeliana. Reconoce que el mundo existe antes que nosotros pero que no es capaz de lograr su desarrollo sino hasta la aparición de los seres humanos. Nuevamente, el mundo es mundo sólo hasta que hay Dasein.

\footnotetext{
${ }^{112}$ Con este nosotros lo que se está tratando de decir es que, a pesar de que el mundo exista antes de y después de mí, o de alguien más, yo soy el que le da sentido. A la manera de Heidegger en Ser Tiempo (\&9) (2007:57) soy el único que se puede preguntar por el sentido, y el único que puede aparecer voluntariamente y que puede darle significado a la percepción.
} 
Existe otra definición de mundo en el pensamiento arendtiano que es mucho más clara e introduce las nociones más importantes para entender cuál es la función al vivir. Estas nociones son cuestiones metafísicas fundamentales en la filosofía de Arendt, quien basa su política en una metafísica fenomenológica: «mundo es el ámbito de aparición que generan los hombres [y mujeres] entre sí cuando actúan y hablan en libertad» (Galindo; 2004:7). Para Arendt, el mundo es el mundo común: el espacio donde los seres humanos pueden conocerse y desarrollarse, construido en cada generación, por todos los sujetos o individuos, que deben ganar la libertad y renovar el mundo común.

Todos los seres humanos deben tener interés en participar en los asuntos públicos para que se pueda llevar a cabo un mundo donde sea posible reconocerse, o mejor dicho, conocerse en el otro. Además, Arendt afirma que la naturaleza del mundo es fenoménica, es decir, que todas las cosas que existen en él comparten una cualidad y es que todas aparecen, todas son fenómeno.

La noción de apariencia difiere nuevamente y en gran medida de la noción kantiana. Para los dos lo que aparece es el fenómeno, aunque para Kant el fenómeno no es realmente, pues es sólo lo que conocemos y no lo que la cosa verdaderamente es. Mientras que para Arendt (y evidentemente toda la corriente fenomenológica) fenómeno, aquello que aparece, es. La apariencia por antonomasia $\boldsymbol{e s}$ el ser, y es justo aquí donde la filósofa alemana se aleja del idealismo y se acerca en gran medida a la fenomenología heideggeriana.

La gran diferencia con Kant ${ }^{113}$ radica en la definición de dos nociones: ser y apariencia. Fenómeno es aquello que se muestra, que se da, que aparece. Todas las cosas que pueden ser percibidas en el mundo: oídas, olidas, tocadas, vistas, etc. Y apariencia es, de

\footnotetext{
${ }^{113}$ Y con toda la tradición moderna europea desde Descartes hasta Hegel.
} 
igual manera, aquello que aparece. Ser y Apariencia en la filosofía de Arendt, coinciden, puesto que aquello que aparece, aquello que se muestra es el ser. La radicalización del pensamiento de Arendt se encuentra presente ya en el pensamiento inicial de Husserl y por ende en todos los pensadores posteriores como José Gaos (en México), sin embargo, la postura de Arendt es especialmente interesante, ya que en ella está fundamentada la política.

Es importante destacar que la apariencia, tanto en términos filosóficos como coloquiales, siempre se ha distinguido por ser como una copia del ser. Se entiende como aquello que realmente no es, y justo lo que la autora establece, siguiendo muy de cerca a Husserl, es que la apariencia, lo que aparece a nuestros sentidos, es el ser ${ }^{114}$.

Lo antes mencionado se explica en la primera parte de La vida del espíritu (1978) donde trata de hacer ver al lector y lectora que no hay una ruptura verdadera entre aquello que llamamos la vida del espíritu y la vida activa, aunque sí son diferentes. Más adelante se entenderá cómo no hay ser sin apariencia en el mundo, como también se entenderá que no hay vida activa sin vida contemplativa y viceversa.

Otra característica de la nueva concepción de apariencia y de naturaleza fenoménica del mundo, es que, en éste, todo aquello que aparece se muestra ante un sujeto, mostrando así que el mundo está formado por fenómenos que aparecen, es decir que está formado por sujetos que aparecen ante otro sujeto volviéndose así en objetos, entonces podemos decir que el mundo se forma por la relación entre sujetos y objetos ${ }^{115}$.

\footnotetext{
${ }^{114}$ En lenguaje platónico, lo que hace Arendt es reivindicar la copia de las cosas dejando en claro que no hay necesidad en creer en un mundo superior que realmente sea, pues lo que vemos en este mundo es.

${ }^{115}$ Entender esta relación será una de las cosas más importantes para Arendt, pues es la esencia de la política.
} 
En el libro Amor y responsabilidad de Karol Wojtyla existe una cita que explica mejor

esto:

En el mundo en que vivimos se compone de gran número de objetos. "Objeto" es aquí sinónimo de "ser". El significado, con todo, no es exactamente el mismo, porque propiamente hablando, "objeto" designa lo que queda en relación con un sujeto. Pero el sujeto es igualmente un ser, ser que existe y que actúa de una manera o de otra. Puede, por tanto, decirse que el mundo en que vivimos se compone de un gran número de sujetos. Incluso estaría mejor hablar antes de sujetos que de objetos (Wojtyla, 1969:15)

Esta cita es relevante ya que de la fenomenología surge otra corriente de pensamiento ligada enteramente al catolicismo europeo y renovado por la relación con las culturas de América: el personalismo, donde se lleva hasta las últimas consecuencias la relación de los sujetos. Tanto para Arendt, como para la FL y la filosofía para la paz, es de suma importancia, ya que los tres tienen como principio que el mundo es un espacio de relación entre sujetos y no de sujeto-objeto. La metafísica de la dominación, o mejor dicho, la ontología de la dominación empieza a resquebrajarse, aunque aún hay mucho todavía que hacer.

La eliminación de la escisión en la relación ontológica entre ser y apariencia ha provocado, como se verá más adelante, un rompimiento fundamental en las principales ciencias de la vida activa; ética y política, que a su vez provocan el mal en el mundo, el mal entendido como violencia e injustica y poder como dominación.

Según Arendt, esta escisión es una actitud medieval muchas veces inevitable, pues se cree que al dividir al ser humano se estudiará mejor qué es, sin entender que al mismo tiempo se ocasionan rupturas en el conocimiento que provocan una diferencia irremediable entre lo que conocemos y lo que la cosa realmente es; es decir, la división del conocimiento planteada por Aristóteles siglos atrás, es el fundamento de la escisión entre lo real y lo conocido, y justo 
lo que Arendt intenta mostrar es que lo que conocemos es lo que es, pues lo que se muestra no es una copia del ser sino el ser mismo.

Al establecer que el mundo es de apariencias, el siguiente paso que debe dar y da Arendt es explicar que la apariencia no es un error en la percepción, o algo malo, sino que es la naturaleza de la cosas. El problema, como ya se puede ver, ha estado dentro de la epistemología planteada por Platón y desarrollada al máximo por el idealismo alemán, donde la superioridad de las ideas frente a la realidad, eliminó todas las consecuencias en el ámbito ético-real. Gracias a esta radicalización, las ideas fueron más importantes que la vida de un ser humano, gracias a este pensamiento, fue posible (y sigue siendo) la colonización, la dominación y el genocidio de América ${ }^{116}$.

Para Arendt apariencia es fenómeno, es decir lo que aparece, lo que se muestra, pero que al mismo tiempo oculta algo, y ese ocultamiento es lo que ha hecho que muchos filósofos hayan pensado que eso que se oculta es el fundamento que causa la apariencia y como no se muestra (y todo lo que existe en este mundo se muestra) pertenece a una naturaleza ontológica superior, es decir se entiende como principio y causa del fenómeno ${ }^{117}$.

Es claro que el error en el que han caído varios filósofos no está en entender el ocultamiento como causa y fundamento, sino en creer que la causa y el fundamento son de orden superior, esto está explicado en el segundo apartado, es decir en el «Ser auténtico y la mera apariencia; la teoría de los dos mundos» de la Vida del Espíritu (1978). En esta parte

\footnotetext{
${ }^{116}$ Esta afirmación y explicación es esencial para la presente investigación, ya que muestra como el siglo XX ha sido desde dentro como desde fuera el siglo donde el proyecto moderno ha comenzado a resquebrajarse. Es interesante ver como las ideas de Arendt abren una puerta desde la filosofía y la política para dialogar con todos los conocimientos que habían quedado en la exterioridad.

${ }^{117}$ Recordemos que Arendt fue discípula de Heidegger desde 1923 hasta 1930 aproximadamente, por lo que la ontología heideggeriana será el fundamento de la tesis que aquí se menciona.
} 
se trata de establecer que la relación ${ }^{118}$ entre ser y apariencia es la misma; es decir el ser necesita de la apariencia del mismo modo en que la apariencia necesita de ser, Arendt para explicar esto utiliza una cita del Gorgias: «El ser es oscuro si no llega a la apariencia (ante los hombres: dokein) y la apariencia (ante los hombres) es débil si no llega al ser» ${ }^{119}$

Además encontramos en el Diario Filosófico algo que esclarece esto; «el ser siempre presupone a otros» (2006:1969) y de este modo se puede entender que ser y apariencia no están escindidos, porque aquello que hace posible que el ser se muestre a otros es la apariencia y como el ser necesita de los otros por su naturaleza, ser y apariencia son lo mismo. El ser no es superior a la apariencia pues sin apariencia no hay ser. Establecer que la apariencia es en un sentido el ser, invita a ver que el mundo es real y verdadero. Todo lo que conocemos es el ser, aunque no es su totalidad, porque todo lo que aparece es percibido por la subjetividad, cambia a un me parece, pero esto no es malo, aunque sí en muchos casos lleva al error, del cual es posible salir a través de la intersubjetividad ${ }^{120}$.

La relación que tiene la propuesta de Arendt con el pensamiento de resistencia y especialmente con la ontología del pluriverso es muy interesante, pero se desarrollará en el último capítulo cuando se analice el pensamiento indígena del sureste mexicano.

Ahora, la propuesta metafísica y fenomenológica encaja con la filosofía de la liberación, aunque Dussel va un paso más allá y establece que si iniciamos cualquier discurso

\footnotetext{
${ }^{118}$ Es importante destacar que la solución que Arendt da a todos los problemas sobre el fenómeno y el fundamento radica en su noción de relación, que a mi juicio podemos decir que es la noción más importante para entender gran parte de su filosofía.

${ }^{119}$ Diles, H. y Kranz, W., Los sofistas, Testimonios y fragmentos, Barcelona, Círculo de Lectores, 1996, página173. En la obra Arendt, H., La vida del espíritu traducción Carmen Corral y Fina Birúles, Paidos, Barcelona 2002, página 49.

${ }^{120}$ Una vez más encontramos que Arendt ve que la verdad de las cosas se da en la pluralidad y en la relación.
} 
filosófico afirmando que la relación es lo más importante y no ya la sustancia o el ser, como establecían Aristóteles y los pensadores modernos europeos, estaremos dando un origen distinto a todo el pensamiento (Dussel; 2011:44), en este sentido el origen ya no es lo UNO sino lo MÚLTIPLE, ya no hay UNIVERSO hay PLURIVERSO.

Si ahora el centro del pensamiento filosófico deja de ser el ser y es el mundo, y mejor, el mundo de apariencias, entonces toda la argumentación, discurso y comprensión de la realidad será completamente distinta. Si se comprende el mundo desde los seres humanos que se relacionan, desde la proxemia, que es el aproximarse al otro desde la subjetividad, entonces se establece una relación de corresponsabilidad.

Esta proxemia es una praxis, es decir un aproximarse intencionalmente, un aparecer intencionalmente para el otro, y por lo tanto constitutiva de una sociedad más justa; aunque ello suponga un acortamiento en la aproximación a la libertad:

Imaginémonos una asociación de hombres libres - dice Marx. Una comunidad de miembros, cara-a-cara, sin opresiones; sociedad utópica de los prójimos, que no son un "nosotros" porque producen bienes para un mismo mercado, sino que son un nosotros por la práctica actualidad de la proximidad originaria. Un nosotros por la proxemia Dussel: 2011:46).

El avance en el pensamiento de Dussel, nos lleva a una profundización del análisis de la relación, o proxemia como él lo llama, en la que la experiencia originaria o primigenia de los seres humanos es una aproximación natural:

El ser humano no nace en la naturaleza. No nace desde los elementos hostiles, ni de los astros o vegetales. Nace desde el útero materno y es recibido en los brazos de la cultura. El sujeto, la persona por ser un mamífero nace en otro y es recibido en otro. (...) el ser humano, en cambio, nace en alguien y no en algo. Se alimenta de alguien y no de algo. La proximidad primera, la inmediatez anterior a toda inmediatez, es el mamar. Boca y pezón forman la proximidad que alimenta, calienta, protege. Las manos del niño que se abrazan a la madre ni juegan, ni trabajan todavía. El pequeño pie no ha andado ni se ha internado en la lejanía. (...) La proximidad del mamar es sin embargo escatológica; se proyecta al futuro 
como el pasado ancestral; llama como el final y el origen. Sin embargo, es sólo el comienzo personal, singular, de cada uno. (Dussel; 2011:46-47)

De esta manera parece fácil afirmar que antes del mundo está ya la proximidad e incluso, que el mundo es la proxemia constante. Ver las cosas de esta manera reivindica la validez de todos los discursos no dichos por los dominados, aquellos a los que se les ha negado la naturaleza de los seres humanos. Aquellos a los que se les ha negado aproximarse, pero que por más esfuerzos, más teorías o más filosofías, ha sido imposible eliminar; la naturaleza humana es un aproximarse a todos los sujetos, es aproximarse al mundo.

Tal vez algunos dirán que todo el discurso antes mencionado, es enteramente eurocéntrico, ya que nos hemos basado en pensadores formados en el pensamiento occidental $^{121}$, pero esta apertura del pensamiento es parte fundante del pensamiento maya y azteca y la mayoría de las poblaciones indígenas de América, es un puente para comprender su cosmovisión.

Se extiende semánticamente el nosotros tojolabal para incluir no sólo a la sociedad humana sino a todo el cosmos, porque desde la perspectiva tojolabal todo vive; es decir, no hay nada que no tenga corazón, que es lo que vivifica. Por eso los humanos somos una especie en el contexto de un sinnúmero de especies, a las que nos toca respetar y con las que tenemos que aprender a convivir sin tratarlas como objetos a nuestra disposición. En efecto, no hay objetos. Esto quiere indicar que la relación de los seres humanos con la naturaleza no consiste en dominación, sino en respeto y convivencia. Porque la naturaleza misma es ja jnantik lu'um, es decir, Nuestra Madre Tierra, que no es meramente el medio ambiente o lo que nos rodea, sino Nuestra Madre que nos da vida y nos mantiene vivos. No es ningún "neutro" lo que nos rodea, sino otro sujeto muy particular por ser madre nuestra. ((Dussel, Lenkersdorf: 2009:34)

La cosmovisión maya, en términos generales que incluye a los tojolabales, tsotsiles y tseltales, choles, entre otros, establece que la relación, el nosotros, es la prioridad, o mejor

\footnotetext{
${ }^{121}$ Incluso el mismo Dussel estudió diez años en diversas universidades europeas y enfocó sus investigaciones iniciales en autores eurocéntricos como Marx y Hegel.
} 
dicho es el ser (para utilizar términos del pensamiento occidental), es por eso que las relaciones al interior de la comunidad no son de dominación, sino de convivencia horizontal.

De igual manera esto se ve representado en su lengua:

La relación sujeto-sujeto en la cual diferentes clases de sujetos se relacionan dentro de las mismas frases expresa la intersubjetividad en la cual no hay objetos. Es una particularidad distintiva del tojolabal, de otras lenguas mayas y de otros idiomas diera del contexto tojolabal y maya. En la lingüística suele llamarse lenguas ergativas que nosotros preferimos llamar intersubjetivas, porque este término, a nuestro juicio, explica mejor su idiosincrasia ${ }^{122}$. (Lenkersdorf, 2004:148)

En resumen, podemos decir que el problema no es la falta de ética en la construcción de modelos occidentales, es que tienen una ética que no se comparte, que no permite el diálogo. Y más aún que su cosmovisión es UNA dentro de un mundo que desde la evidencia es pluriversal.

Con el fin de construir un puente de entendimiento se puede hablar de la construcción de nuevas categorías (abiertas y en movimiento guiadas por el colectivo, acorde a como apunta el pensamiento de resistencias) que permita una verdadera comunicación, de tal suerte que se pueda recuperar «la buena intención occidental» del desarrollo con el pensamiento indígena. Sin embargo, antes de la construcción de estas categorías es necesaria la liberación y la decolonización; es decir, la recuperación de la subjetividad y el establecimiento de un espacio público que posibilite el diálogo y la producción de un pensamiento que tenga como origen y destino la liberación de la opresión, como lo hace la Filosofía de la Liberación y como antes y en términos de desarrollo económico hizo la Teoría de la Dependencia (TD).

\footnotetext{
${ }^{122}$ Tal es el caso de algunas de las lenguas originarias dentro de Europa como el bretón o el euskera, es así que podemos afirmar que el pensamiento filosófico occidental ha sido una construcción de dominación, lejos de la realidad tanto de su geografía como de otras. El pensamiento eurocéntrico, junto con sus lenguas coloniales (castellano, inglés, francés y portugués) son la representación de un mundo de dominación construido por los dominadores.
} 
Con todo lo anterior, se puede afirmar que la decolonización como experiencia emancipadora es necesaria justamente porque al sentir el peso de la opresión, del silencio, y al ser conscientes de ello, la única vía es la búsqueda de la liberación, de la transformación de ese poder como dominación que genera violencia en un poder que genere justicia y dignidad.

Por último, también es necesario recordar la relación intrínseca entre la búsqueda de la liberación o la decolonización con la política y el poder como dominación, pues gracias a la existencia de estos ha sido posible y real un mundo injusto y colonial. En resumen, es la experiencia del horror la que potencia tanto la filosofía para la paz como la FL, una como actitud epistemológica y la segunda como experiencia política de la liberación, pero ambas se traducen por la búsqueda de un mundo donde quepan muchos mundos, como el que plantea el zapatismo como movimiento decolonial.

También en la construcción de este puente de entendimiento se debe dejar de ver a los indígenas como meras víctimas, objetos de análisis o de políticas indigenistas, en términos de manipulación política y "movilización de recursos". El problema indígena se debe ver como una reflexión sobre los problemas de alcance global, mediante el análisis de estos particulares movimientos.

\section{Conclusiones}

A lo largo de este capítulo se han analizado las diferentes corrientes de pensamiento en las que descansa esta investigación; pensamiento decolonial y filosofía para la paz, y a su vez las corrientes que las fundamentan (filosofía de la liberación, teoría de la dependencia, estudios de desarrollo). Todo ello con la intención de construir un puente de entendimiento 
entre el pensamiento decolonial y la filosofía para la paz, que permita comprender la propuesta ontológica y política de las resistencias indígenas del sureste mexicano.

Por un lado, se analizó como el pensamiento decolonial tiene grandes diferencias con el pensamiento postcolonial, tanto en la forma como en el fondo; primero se estableció el lugar geográfico que identifica a ambas corrientes de pensamiento: el pensamiento decolonial habla desde la realidad Latinoamericana mientras que el pensamiento poscolonial se desarrolla más en lo conocido como "Oriente", y aunque esta diferencia no es excluyente ni limitativa, sí refleja diferencias importantes. Segundo, se identificó cómo el pensamiento poscolonial surge directamente del pensamiento post-estructuralista francés y por lo tanto habla desde la construcción de los discursos hegemónicos de dominación (que engloba todas las regiones, no solo Oriente). Tercero, a pesar de las diferencias entre estas corrientes de pensamiento, se afirmó que ambas son necesarias para una mejor comprensión de las realidades en la nueva ontología pluriversal, aunque se le dará prioridad al pensamiento decolonial en este trabajo, por su marcado trabajo activista y su cercanía con las resistencias en México.

Otro de los elementos a destacar del pensamiento decolonial es el trabajo del grupo Modernidad/Colonialialidad/Decolonialdad donde se encuentran autores como Walter Mignolo, Aníbal Quijano, Arturo Escobar, entre otros. Este grupo es quizá la representación académica más importante de pensamiento decolonial, ya que parte de un nuevo marco de interpretación que será conocido como el giro de-colonial, que concibe la indignación ante el horror colonial como origen y comprende la modernidad como punto de inflexión histórica donde emerge el pensamiento de resistencia. Asimismo, intenta recorrer la historia, analizar la política y la ética, no ya desde los discursos dominantes y la realidad europea, sino desde los vencidos, desde los dominados, desde los nadie. 
Por último, sobre el pensamiento decolonial, se explicó como tiene raíces en dos estudios importantes del siglo XX, la teoría de la dependencia y los estudios de desarrollo. Gracias a estos, tiene un acercamiento claro a la realidad Latinoamérica y los grandes retos que ha enfrentado en materia económica y de neocolonización en las últimas décadas.

Ahora, sobre la filosofía para la paz, se analizó en detalle la propuesta de Vicent Martínez Guzmán, en quien descansa el marco de interpretación sobre la paz de esta investigación. Se explicó el camino que llevó a su autor a la construcción de esta corriente de pensamiento, sin embargo, se estableció como limitante la ontología occidental única y eurocentrista en la que se enmarca. Especialmente se critica las fundamentaciones en Kant y Habermas que conciben la modernidad como un proyecto inacabado, pero que sigue poniendo en el centro de la racionalidad los valores europeos.

A primera vista, tanto la decolonialidad como la filosofía para la paz parecen un tanto alejadas y en algunos escenarios antagónicas, sin embargo, gracias al giro epistemológico de Martínez Guzmán y las similitudes con el giro decolonial, se empieza a comprender como ambas pretenden la construcción de un mundo más justo y con cosmologías diversas. Y es gracias a la fenomenología y al pensamiento de Hannah Arendt en dialogo con Enrique Dussel en donde se encuentra el fundamento de un puente de entendimiento entre ambas. Esto permite, a mi juicio, una mejor comprensión del pensamiento de las resistencias indígenas.

La propuesta de Arendt de dejar de centrar la metafísica en la sustancia aristotélica o el noúmeno kantiano, siguiendo muy de cerca la fenomenología de Husserl, y cambiarla por la relación, permite, por un lado, comprender que el mundo no sólo es aquello que nos antecede, sino que cobra sentido gracias a nuestras relaciones; y por otro, éstas relaciones son las que conformarán la realidad que vivimos, es así que si cambiamos nuestra forma de 
relacionarnos cambiamos el mundo. Por otro lado, gracias al concepto de proxemia de Dussel entiende que la relación no sólo es constitutiva del mundo, sino de nuestra propia existencia al ser originaria, abriendo el camino para comprender la comunidad como el camino de existencia de los seres humanos.

Tanto la fenomenología, como la proxemia en la Filosofía de la Liberación de Dussel, son los pilares de ese puente de entendimiento entre la filosofía para la paz (pensamiento occidental) y el pensamiento decolonial; y ambas pueden así comprender la propuesta ontológica del pluriverso y la vida política de la comunalidad que se analizará en el último capítulo de esta investigación. 


\section{CAPITULO IV: Análisis filosófico de la historia de EZLN; sobre cómo superar la violencia}

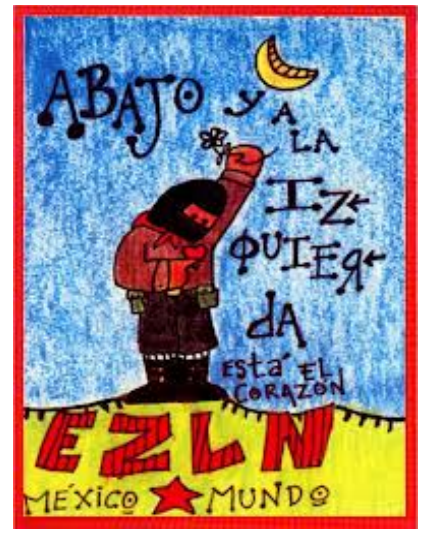

Hasta aquí la presente investigación se ha desarrollado dejando al margen la historia específica de la resistencia indígena, quizá, más importante del México y una de las más importantes en el mundo, la resistencia zapatista.

A lo largo de 25 años, los zapatistas han podido construir una propuesta política, ética y ontológica que no responde a la lógica ni al mercado, ni a los valores europeos; han logrado la consolidación de una forma de ser y existir que para muchos en el mundo es imposible. Sin embargo, su historia no ha sido sencilla y está plagada de violencias, es por eso que he decidido hacer un análisis desde la filosofía para la paz (buscando los elementos que nos permitan superar la violencia) de su historia. Para ello es necesario analizar su situación geográfica y la realidad específica que pude conocer en el tiempo que viví ahí; Chiapas.

Chiapas representa, por un lado, los contrastes desgarradores del México moderno, pero también la posibilidad transformadora de los procesos comunales y las resistencias, todo ello enmarcado por una naturaleza apabullante. El recorrido por esta región comienza en San Cristóbal de las Casas, capital cultural y simbólica del estado.

Desde 1994 la forma en que se mira Chiapas y en especial San Cristóbal de las Casas, no ha vuelto a ser igual. Durante casi veinticinco años, detractores y partidarios del EZLN 
han escrito miles de páginas para tratar de comprender la realidad de un lugar remoto y casi olvidado al sureste de México. Pero ¿qué es lo que intriga más sobre esta región? ¿Qué hay en este lugar para que personas de todo el mundo lo visiten? Después de pensarlo varios años, la única respuesta que encuentro es: Chiapas es un lugar de lucha y esperanza.

No pretendo que esta respuesta sea única, por el contrario, creo que Chiapas le da a cada viajero, investigador o turista lo que necesita, pero creo que estas dos palabras resumen gran parte de la realidad que el tiempo vivido ahí pude ver.

La lucha en Chiapas no tiene 25 años y surge del levantamiento zapatista, la lucha se puede rastrear desde por lo menos 500 años atrás, con la colonización de la región y las dificultades de la zona; el calor, la altura, la humedad, etc. Es posible que se pueda rastrear siglos atrás. Sin embargo, para los fines de este trabajo es importante marcar como origen (no único) de la lucha, el encuentro con la sociedad europea.

Para comprender Chiapas, considero que hay que entender tres conceptos fundamentales, poder, violencia y relacionalidad, que ya se han trabajado a largo del texto; es así que este capítulo intentará dar un marco general sobre la historia del EZLN y su relación con estos conceptos, aunque es en el quinto capítulo que se abordará de forma más contundente a través de la ontología pluriversal y la comunalidad.

Primero, se esbozarán los datos estadísticos de Chiapas para que el lector y la lectora, tenga una idea más clara del territorio y las problemáticas que emergen de él. Tal y como se hizo en el primer capítulo con las cifras sobre México, las cifras irán acompañadas de un relato de vida, donde contaré las experiencias que pasé durante el tiempo que viví en Chiapas.

Después, se presentará una breve historia del EZLN y el zapatismo, y finalmente el capítulo cerrará con una discusión teórica sobre cómo abordar las acciones violentas de los zapatistas, desde la propuesta de Hannah Arendt frente al pensamiento de Fanon, 
enmarcándolas en una visión crítica de la paz y su construcción en escenarios de extrema injusticia.

\section{La vida en Chiapas}

Chiapas ocupa el segundo lugar en grado de marginación a nivel nacional, precedido por Guerrero y seguido por Oaxaca. Tiene 48 municipios con comunidades en la categoría de muy alta marginación y 39, en situación de alta marginación, los cuales se ubican principalmente en los Altos y la Selva. Un $55,05 \%$ de la población chiapaneca vive en municipios con estas características y nada más dos municipios son de muy baja o baja marginación. El municipio de Sitalá, ubicado en la zona Norte-Selva, ocupa el primer lugar dentro de los municipios más marginados a nivel estatal y el sexto a nivel nacional (INEGI 2010; INEGI: Catálogo General de Localidades, diciembre de 2011; CONAPO 2010).

La elección de estos datos no ha sido de forma azarosa, por el contrario, la marginación

es una de las situaciones cotidianas de la realidad chiapaneca, marginación consecuencia no sólo de la desigualdad económica que gobierna el estado, sino de una tradición racista que ya tiene muchos siglos en práctica.

Con 4796580 habitantes, ocupando el séptimo lugar de las entidades estatales más pobladas del país, Chiapas tiene una composición pluriétnica y pluricultural. Según el Instituto Nacional de Estadística y Geografía (INEGI) 2010, en Chiapas, 1141499 personas mayores de 5 años hablaban alguna lengua indígena, lo que representa un 27,2\% de la población de la entidad, 12 de los 62 pueblos indios reconocidos oficialmente en México se encuentran en Chiapas. La población de más de 5 años que habla una lengua indígena se divide principalmente en 5 grupos: tseltal 37,9\%, tsotsil 34,5\%, ch'ol 16\%, zoque 4,5\%, tojolabal 4,5\% y los grupos mam, chuj, kanjobal, jacalteco, lacandón, kakchikel, mochó (motozintleco), quiché e ixil representan el 2,6 \% de la población indígena del estado. 
Sobre la desigualdad económica los datos no mienten; un 16\% de la población activa de Chiapas no recibe ingresos, el 45,78\% de la población económicamente activa ocupada gana hasta un salario mínimo (alrededor de 2000 pesos mensuales). Y de manera general, los ingresos promedios son menores en zonas rurales e indígenas.

La precariedad económica también se refleja en la precariedad de salud, el 43\% de la población no tiene garantizado el acceso a la salud (lejanía de los hospitales, muchas veces sin suficientes doctores o medicinas), según las estadísticas en Chiapas se cuenta con un médico por cada 1000 habitantes (Gobierno del estado de Chiapas basado en INEGI 2010).

Esto se refleja en: $18,8 \%$ de los menores de un año de edad mueren por mil nacidos vivos mientras la media nacional es de 13,7. La entidad ocupa el segundo lugar a nivel nacional en mortalidad infantil, el quinto lugar a nivel nacional en riesgo de que una mujer muera por causas relacionadas al embarazo. En el 2006, se registraron 82 casos de muerte materna, en el 2007 fueron 78 mujeres las que perdieron la vida por causas relacionadas al embarazo, en el 2008 la cifra se elevó a 92 mujeres y en el 2009 se registraron 71 casos de muerte materna. (Secretaría de Salud de Chiapas, 2010). Las principales causas de muerte materna en Chiapas son: hemorragia obstétrica, trastornos hipertensivos, complicaciones del embarazo o parto, causas indirectas, abortos mal practicados, VIH y complicaciones después del alumbramiento. Muchas de las causas de mortalidad materna en el estado serían evitables de tener atención oportuna de calidad y una mejor calidad de vida (Informe que el Centro Nacional de Equidad, Género y Salud mostró en la reunión de noviembre del 2007).

Los problemas de salud no son la única gran problemática en Chiapas. Para muchas personas, sobre todo indígenas, y aún más, mujeres, el derecho a la educación no se cumple por varios motivos. La situación de pobreza obliga a los niños a trabajar para mejorar la economía familiar. Además, muchas comunidades aisladas no cuentan con la infraestructura 
adecuada para facilitar la educación (falta de aulas, mobiliario, libros, servicios básicos, falta de maestros, clases sobrellenas...). Un 16,5\% de la población mayor de 15 años no tiene ningún grado de escolaridad, el 37,13\% de la población chiapaneca de quince años o más no tiene primaria completa y un $10,6 \%$ de los 5-14 años no asisten a la escuela.

Chiapas ocupa el primer lugar de los estados con la escolaridad más baja, con 6,7 años (Oaxaca el penúltimo con 6,9) y tiene el nivel más alto en el país en analfabetismo. El 17,8\% de la población general chiapaneca de 15 años o más no sabe leer ni escribir. El 39,2\% de la población indígena que tiene 15 años o más es analfabeta.

Aunque en la frontera sur no hay una incidencia delictiva de narcotráfico o crimen organizado, tan alta en comparación con otros estados del norte, en 2011 la Secretaría de la Defensa Nacional (SEDENA) detectó en Chiapas la presencia de los Zetas y el Cártel del Golfo. Según la PGJE (2012), la incidencia delictiva más alta se presenta en los municipios de Benémerito de Las Américas, Frontera Comalapa, Comitán, Ciudad Hidalgo, Juárez y Reforma.

También según la SEDENA, el narcotráfico en Chiapas desde hace varios años dejó de ser únicamente un puente de la droga que viene de Centro y Sudamérica, para convertirse en un territorio donde el cultivo de amapola y marihuana ha proliferado, ya que por su geografía se presta para a este tipo de cultivo y negocios. Los municipios más señalados han sido en el Centro y los Altos: Pueblo Nuevo, Solistahuacán, Rincón Chamula, Rayón, Chalchiuitán, Larráinzar y Chenalhó; en la región de Los Chimalapas (colindante con Oaxaca); en Las Cañadas y la Selva Lacandona, Altamirano, Las Margaritas, Chanal, Nuevo Orizaba y El Ocotalito. El punto más vulnerable sigue siendo la línea fronteriza con Guatemala (Tapachula y Ciudad Hidalgo principalmente), lugar también neurálgico para todo tipo de tráficos ilícitos además del narcotráfico (armas, trata de personas, entre otros). 
A pesar de todas estas dificultades sociales, Chiapas es uno de los estados de la República más ricos en recursos naturales, en sus 73311 km2 de extensión, que corresponden al 3,7\% de la superficie nacional, tiene más de $300 \mathrm{~km}$ de litoral, una plataforma continental de $67000 \mathrm{Km} 2$, un vasto sistema hidrológico y una gran riqueza de flora y fauna. En el estado se concentra el 30\% del agua superficial del país; cuenta con los dos ríos más caudalosos del país: el Usumacinta y el Grijalva.

En cuanto a servicios energéticos cuenta con cuatro centrales hidroeléctricas, que son: Belisario Domínguez (La Angostura), Netzhualcoyotl (Malpaso), Manuel Moreno Torres (Chicoasén, la más grande en todo el país) y Peñitas. Chiapas produce el 7,5\% de la energía eléctrica del país, y el 44,5 \% de la energía hidroeléctrica (1er lugar a nivel nacional).

Existen 116 pozos en explotación en los municipios de Juárez, Reforma, Pichucalco y Ostuacán. (Fuente: Ecosur, INEGI 2010). En 2010, Chiapas produjo 17,2 millones de barriles de petróleo crudo, equivalente al 1,8 \% de la producción nacional.

E1 77\% de la superficie estatal está dedicada a actividades agropecuarias o forestales. El estado produce maíz, frijol, sorgo, papa, sandía, cacahuate, ajonjolí, caña de azúcar, plátano (35,3\% de la producción nacional), café (41\%), palma africana $(78 \%)$, papaya $(18,7 \%)$ y mango. La explotación forestal también es variada: se utilizan las maderas de pino y otros coníferos $(25,6 \%$ de la producción nacional), encino, árboles tropicales y maderas preciosas.

Por último, una problemática fundamental en el estado es la alta militarización, Amnistía Internacional sostiene en su último reporte que 35000 soldados están destinados a nivel nacional a la lucha contra el narcotráfico en la región, aunque es bien sabido que su estrategia es parte de la puesta en marcha de la contrainsurgencia en estado desde el 
levantamiento zapatista, así como una forma de control y expropiaciones ilegales de territorios de comunidades indígenas ricos en recursos naturales, como ya se ha mencionado.

Tal y como se analizó en el primer capítulo estas cifras están acompañadas por un relato de vida, y en esta ocasión serán las experiencias que marcaron mi andar los Altos de Chiapas en 2016.

Mi primer contacto con el EZLN fue al ver las noticias con mi madre el $1^{\circ}$ de enero de 1994, hablaban de un levantamiento armado en el sur del país, "un ejército de indígenas”, mi madre estaba preocupada, yo tenía 10 años y no entendía nada. Sólo recuerdo aquella icónica imagen de los rebeldes encapuchados tomando el palacio de gobierno de San Cristóbal de las Casas, aún la tengo grabada como si yo hubiera estado ahí. Supe en ese momento que estaba viendo algo histórico, y así fue, a partir de ese día nadie en México pudo entender nuestra historia de la misma manera.

Mi madre cada domingo leía la columna que el Subcomandante Marcos publicaba en el periódico nacional La Jornada. Durante años tuvimos centenares de ejemplares del periódico en casa. Cuando veíamos las noticias y salía algo sobre Marcos, mi madre siempre lo escuchaba. El zapatismo siempre estuvo en casa. Años más tarde cuando decidí estudiar su propuesta descubrí que mi madre tenía varios libros de historiadores e intelectuales sobre el EZLN y del mismo Marcos.

Después de terminar el master y estar en el doctorado, me aventuré con mi pequeña familia (marido, hijo y mascotas) y me fui a San Cristóbal de las Casas para vivir por primera vez todo aquello que durante años había estudiado. Ilusionada y creo que cegada por la idea 


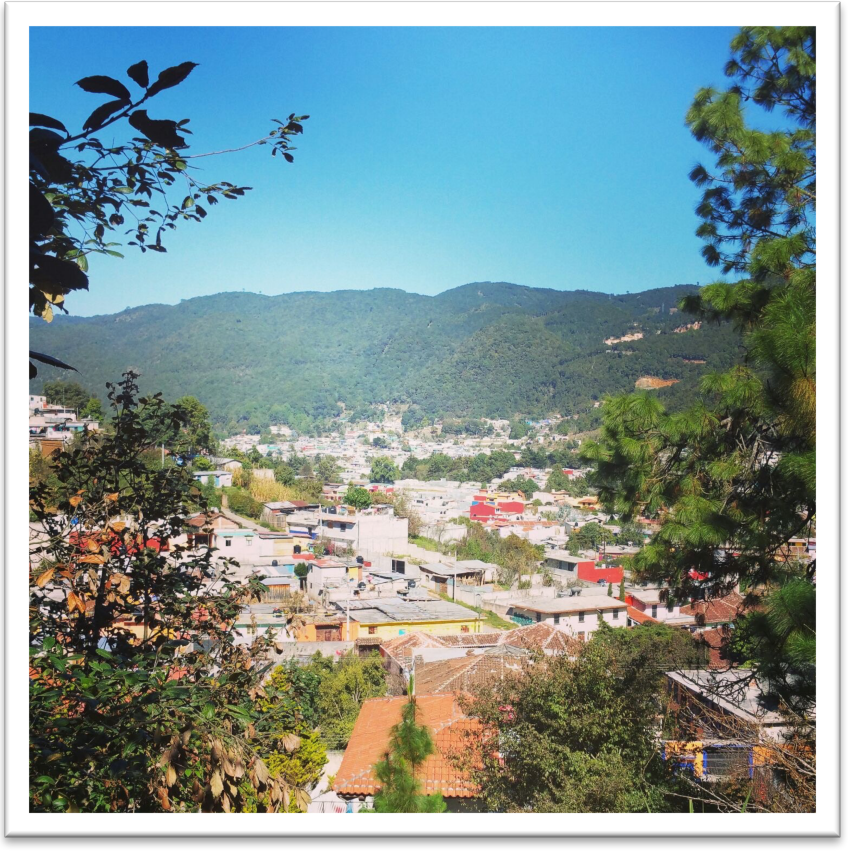

romántica de revolución llegamos a Chiapas, y la realidad excedió todo aquello que habría podido imaginar.

Llegamos el 5 de enero de 2016 y logramos con cierta facilidad encontrar una casa en uno de los barrios más antiguos de la ciudad, justo donde se tiene noticia de los primeros asentamientos de habitantes, el barrio de Cuxtitali. El primer día conocimos a una familia que sin lugar a dudas marcó nuestro paso por los Altos de Chiapas; Roberto, Adelina y Carla.

Nuestra casa era una pequeña cabaña en la cima de un cerro, teníamos que subir 115 escalones para poder llegar. Era un lugar precioso, pequeño, pero tenía todo lo que en ese momento buscábamos.

La primera tarde con Roberto y Deli, aprendimos que en el barrio se comunica a través de silbatos y chiflidos, sobre todo cuando hay algún "maleante” (ladrón); comienzan a chiflar y saben que es para cerrar la calle porque algo ha pasado. Así unos años atrás, detuvieron a un ladrón que intentó robar un coche.

Roberto es un hombre de 30 años, estatura mediana, pelo negro igual que sus ojos, moreno de manos pequeñas pero fuertes y rasposas. Su primer saludo es con una sonrisa pero con mucha desconfianza, ha visto pasar centenares de intelectuales "comprometidos con la causa". Él nació y ha vivido toda su vida en Cuxtitali, no hay rincón o persona del barrio que no conozca. Ha visto como la montaña, y todo lo que ahí habitaba, ha desaparecido. 
Se casó con Adelina que es una mujer de la misma edad, robusta, simpática y con una mirada muy nostálgica. Cuando hablé con ella esa primera tarde, me contó que siempre había soñado con ser costurera y no había podido estudiar, sabía usar la máquina y arreglar cosas, pero ella quería hacer faldas y vestidos, hacer todo lo que necesitara. Tienen una niña preciosa de 6 años, Carla, que los días que no va a la escuela ayuda a su padre a trabajar. Roberto es albañil, carpintero, jardinero, fontanero y todo lo que sus manos le permitan crear. Le hubiera gustado ser arquitecto, pero sólo terminó la primaria. Adelina no trabaja, o lo hace algunas veces cuando Roberto se lo permite y siempre y cuando no descuide sus obligaciones en casa. Viven en la casa de los padres de él, en una habitación donde cocinan también. Llevan años construyendo otra habitación, pero no han podido terminarla.

Ninguno de los dos se considera zapatista, dicen que no tienen tiempo para andar de revoltosos, pero les gusta mucho lo que han hecho, consideran al EZLN como su ejército, más de una vez Roberto decía: "parece que este pinche gobierno quiere que el EZ se levante otra vez, cada día nos friega más, pero esta vez creo que yo también le entraría”. Cuando comenzó el levantamiento eran unos niños.

San Cristóbal de las Casas es una ciudad hermosa, ofrece todo lo que turistas, intelectuales o activistas andan buscando. Muy rápidamente SanCris (como le dicen los locales) te hace entender si eres bienvenido para vivir o sólo para estar de paso. Es curioso la rapidez con que nosotros encontramos la casa, parecía que todo estaba destinado.

No pasó mucho tiempo para que entendiera la realidad del movimiento en la ciudad, ni la cerrazón y desconfianza que los intelectuales y activistas zapatistas tienen. Desde el levantamiento, San Cristóbal ha recibido a personas de todo el mundo para conocer el zapatismo, miles como yo habían llegado antes para comprometerse con la causa, para estudiarla y luchar. Muy pocos se han quedado, la realidad chiapaneca es bastante cruda. 
Cuando caminas por los andadores (calles peatonales hechas para los turistas) te das cuenta de que hay tres realidades que conviven diariamente, la de los coletos (mestizos), los extranjeros y los indígenas. Para los dos primeros está puesto todo, para los segundos siempre y cuando se comporten como espectáculo para los turistas.

Roberto y Adelina comenzaron a trabajar en nuestra casa, él como jardinero y ella como empleada de hogar, siempre que iban a la casa llevaban a su hija que rápidamente se hizo buena amiga de mi hijo, igual que nosotros de sus padres. Pasamos muchas tardes hablando sobre las diferencias de vida que teníamos; trabajo, pasatiempos, amigos, pero a la vez lo cercanos que nos sentíamos.

Gracias a ellos pude comprender las cifras sobre educación y economía. Roberto, no tenía un trabajo fijo, siempre estaba buscando empleo, haciendo lo que fuera necesario para darle dinero a Adelina y que pudiera tener un plato de comida en la mesa. Adelina por otro lado, tenía que hacer malabares para que el dinero que le daba Roberto alcanzara para todos, recuerdo que decían que siempre alcanzaba para un buen plato de frijoles con tortillas. Detrás de su casa tienen un pequeño terreno donde pueden sembrar, además Roberto es aficionado a la pelea de gallos, así que gallos y gallinas deambulan siempre por su casa. Eso les permite tener cierta seguridad en la comida.

Adelina terminó la secundaria y eso le permite ayudar a Roberto cuando tiene que hacer cálculos en los trabajos como albañil, también le permite ayudar a su hija que está en la primaria. Ambos han encontrado como buena alianza trabajar para los extranjeros que han llegado a Chiapas para comprometerse con el zapatismo, aunque no siempre consiguen trabajo.

La vida de Roberto, Adelina y Carla es prácticamente la más normal dentro del barrio de Cuxtitali, y quizá es muy tranquila, siempre y cuando no se enfermen. Adelina ha tenido 
varios problemas de salud durante algunos años, en uno necesitó de una intervención quirúrgica, pero como ninguno de los dos trabaja oficialmente, la seguridad social no podía cubrirla, además de que está sobre saturada en el país, es así que tuvieron que hacer la cirugía en un hospital privado. Para ello, Roberto tuvo que trabajar día y noche durante un mes (dormía tres horas), y todo el dinero que ganó fue exclusivamente para la operación. Cuando cuenta la historia, Roberto se siente muy orgulloso porque no necesitó del "pinche gobierno" para sacar adelante a su familia.

La historia de Roberto y Deli, es quizá de las historias de vida más normales en SanCris; andar buscando trabajo para comer, encontrar trabajo con los extranjeros, rezar a Dios para no enfermar o dejarse la salud para pagar una enfermedad y mirar con tristeza cómo el lugar donde crecieron cada día les pertenece más a los turistas y menos a ellos.

Miles de intelectuales y estudiantes como yo han llegado a Chiapas buscando respuestas a la cruenta realidad violenta de nuestro país y la desesperanza que se respira en las grandes ciudades del mundo, pero cuando llegamos ahí nos damos cuenta de que la violencia directa que aparece en los noticieros ahora, no es la más atroz, la violencia estructural de la pobreza y el racismo es apabullante.

Los extranjeros de países europeos viven un racismo interesante, por un lado, no tienen problemas para encontrar trabajo y ganar más dinero que cualquier mexicano, para ellos el "Nuevo Mundo" sigue siendo un lugar para lograr sus sueños. Pero también son tratados como tontos, se les suele cobrar todo más caro y muchas veces son estafados; el ingenio mexicano, la creatividad que han tenido que desarrollar frente a la precariedad de su realidad, se impone como un arma para vengarse por toda la humillación que han vivido.

Y como escenario de todas estas realidades tienes las montañas del sureste, que se imponen con fuerza ante el asfalto, aunque hay momentos en que la batalla parece perdida, 
la devastación de algunas montañas es irremediable. Así es Chiapas, escenario de desigualdades y de luchas que parecen no tener fin, pero que, al modo dialéctico de la modernidad y la resistencia, es un escenario de esperanza donde la creatividad y la conexión con la naturaleza se hacen cada vez más fuertes. Este es el mundo de los zapatistas; un mundo plural, algunas veces contradictorio y violento, pero que no se rinde y está dispuesto a todo con tal de no desaparecer.

Así lo reflejan sus caracoles y, en SanCris, el CIDECI-Universidad de la Tierra. Un lugar que no deja indiferente a quien lo pisa. Es al mismo tiempo una escuela de oficios, una universidad, una residencia de estudiantes y el punto de encuentro de todos los intelectuales, artistas y activistas de la región. El centro lo dirige el Dr. Raymundo Sánchez Barraza. Su oficina está abierta desde las diez de la mañana, momento en que llega y pone música clásica que se escucha por todos los rincones.

El CIDECI es un centro de educación indígena intercultural no formal, los estudiantes que llegan ahí aprenden todo lo necesario para sobrevivir y resistir. Cuentan con una imprenta, una sala de música donde construyen sus propios instrumentos, un taller mecánico, una zona de computación, zonas de pintura, idiomas, taller de albañilería, carpintería, herrería, tejido, zapatería y peluquería. Además cuentan con la residencia para hombres y mujeres, un comedor general en el que participan todos. El centro es completamente autónomo, generan su propia electricidad y tienen pozos para el agua, además de un centro de medicina tradicional, zona de huerto, zonas para animales (gallinas, patos y algunas ovejas).

El centro se ha construido y se mantiene gracias al trabajo de los estudiantes; cuando necesitan un nuevo espacio, ellos lo construyen en los talleres y lo que no saben hacer se dan el tiempo para aprenderlo. Siguen la propuesta de educación convivencial de Ivan Illich, 
siguiendo también un camino marcadamente religioso, su capilla es un ejemplo perfecto del sincretismo que se vive todos los días en Chiapas entre el catolicismo y la espiritualidad indígena.

Además, una vez a la semana se lleva a cabo el seminario CIDECI que está abierto a todo el público. En él se analizan las principales noticias a nivel nacional y mundial sobre resistencias y movimientos antisistema (las lecturas las establece el Centro de Derechos Humanos Fray Bartolomé de las Casas, institución hermana que se encarga de la defensa de los derechos humanos de los indígenas en la región). Es un momento de debate y diálogo de todas las perspectivas que llegan a aparecer en ese lugar. Las sesiones se llevan a cabo siempre en tres idiomas; español, tseltal y tsotsil.

Desde el momento en el que llegué, el Dr. Raymundo me enseñó todo el centro y me abrió las puertas para tratar de comprender un poco mejor la realidad de Chiapas, su apertura era casi antagónica con la de algunos activistas que llevaban trabajando en CIDECI y comprometidos con el zapatismo desde hace años. Fue difícil entrar y que mis argumentos se tomaran como válidos en los seminarios. Hablar de paz, al modo académico desde autores europeos, era invalidado inmediatamente. Más de una vez catalogaron mis posturas como eurocentristas y alejadas de su realidad, y muchas otras veces yo me sentía en un discusión marxista-comunista como las que imaginaba se tendrían en los años sesenta. El sueño de la revolución brilla en los ojos de los activistas mestizos y se matiza con la añoranza de paz de los indígenas.

Esta es una breve mirada al mundo zapatista, una realidad dura, compleja y que a menos que hayas nacido ahí jamás comprenderás completamente. Su resistencia responde a una cosmovisión que trataré de explicar a través de su historia y de donde emerge una 
ontología nueva, compleja y que parece ser uno de los caminos más realistas para la construcción de paz.

\section{¿Quiénes son los zapatistas? ${ }^{123}$}

El movimiento zapatista es quizá la resistencia indígena más importante de las últimas décadas y esto se debe a tres razones: 1) por su organización político-militar pero subordinada a la política democrática comunitaria de las comunidades mayas; 2) por su capacidad de desarrollar en tres décadas de trabajo constante un modelo decolonial, altermundista y que responde a las necesidades de las comunidades indígenas de la región; 3) por su proyecto de construcción de paz mediante la lucha noviolenta que ha convertido la lucha indígena en un nuevo paradigma de resistencia.

Para entender estas afirmaciones es necesario responder a varias preguntas: ¿Qué es el Ejército Zapatista de Liberación Nacional? ¿Quiénes lo integran? ¿De dónde viene? ¿Por qué surge? ¿Cómo surgen? ¿Qué buscan o qué demandan del gobierno o de la población? Y ¿Qué han hecho durante tres décadas?

A lo largo de este apartado se intentará contestar a cada una de estas preguntas. Sin embargo, es importante mencionar que la historia de Chiapas, estado del sureste mexicano, es tan antigua como compleja. Han sido muchos los factores que ayudaron a la formación de este movimiento, pero en esta investigación se tomarán en cuentan los factores geográficos, la ideología de los primeros integrantes, así como la ideología política de las comunidades

\footnotetext{
${ }^{123}$ Este apartado es parte de la investigación presentada en la Universitat Jaume I con la Tesis de Máster: El origen de la violencia: un estudio sobre el poder como dominación y el poder como consenso, de mi autoría en 2013.
} 
mayas de la región y la construcción de un hibrido cultural y político que define hoy los caracoles zapatistas.

Otro factor de suma importancia es el interés de empresas transnacionales, así como el gobierno federal de México por explotar las tierras y eliminar todos aquellos obstáculos que existen para alcanzar su objetivo. Lamentablemente, estos obstáculos son personas y comunidades enteras que viven en la región desde antes de la llegada del imperio español a tierra maya y así lo denuncia el EZLN:

Desde su nacimiento como nación independiente, México viene arrastrando el eco de un reclamo: no hay lugar digno para sus habitantes originales (los mismos que lucharon por darle independencia, los mismos que los defendieron de las agresiones extranjeras, los mismos que pelearon la revolución (La Jornada, 27/10/97, p. 6, ver II:44).

A estas cifras y antecedentes hay que sumar los diversos movimientos sociales que son el fundamento histórico e ideológico del EZLN. De acuerdo al profesor Abelardo Hernández de la Universidad Autónoma del Estado de México

[...] dos procesos históricos estuvieron presentes en sus orígenes: los movimientos sociales ocurridos en los años sesenta y setenta [...] y la centenaria lucha de resistencia de los pueblos indios de Chiapas en contra de distintos tipos de subordinación que, a principios de los años setenta [...] produjo un vigoroso y pujante movimiento indígena y campesino en torno a demandas agrarias. (Hernández, 2006: 265)

También es necesario recordar los movimientos a nivel nacional, como el magisterial de 1958, el ferrocarrilero de 1958-1959 y el médico de 1965 que se enfrentaron al poder político de la época y que alcanzaron su máxima expresión en el movimiento estudiantil de 1968 en México. Sin embargo, es bien conocida la respuesta del gobierno de esta época: matanza del 2 de octubre de 1968 y del 10 de junio del 1971 (ambas suman más de 300 estudiantes asesinados). Éstas produjeron «el desconcierto y la frustración de los estudiantes, pero, al mismo tiempo, [lograron] abrir opciones nuevas de acción y participación políticas: partidos 
políticos, organizaciones sociales de masas, asociaciones cívicas y guerrilla.» (Hernández, 2006: 265).

El EZLN es consecuencia de todos estos movimientos y etapas. Así lo afirma el Subcomandante Marcos, hoy Subcomandante Galeano y segundo al mando, «el EZLN más que ser una organización, es una confluencia de organizaciones» (Zeitschrift der Informationsstelle Latinamerika, 1994: 48). Sin embargo, Hernández apunta que son «dos (movimientos) que se destacan; el grupo guerrillero urbano de las Fuerzas de Liberación Nacional (FLN) y el movimiento campesino e indígena chiapaneco, cuya exitosa fusión orgánica logró conformar un ejército popular» (Hernández, 2006: 271).

El Ejército Zapatista de Liberación Nacional aparece ante la mirada internacional por primera vez el $1^{\circ}$ de enero de 1994 , pero esta organización tenía ya 10 años trabajando, consolidándose y apostando por un mundo donde la violencia es innecesaria. El ejército zapatista es el «producto del encuentro de la sabiduría y la resistencia indígena con la rebeldía y la valentía de la generación de la dignidad que alumbró con su sangre la oscura noche de las décadas de los sesenta, setenta y ochenta» (II: 434, ver La Jornada, 13/10/99: 22).

En la presentación del libro EZLN: 20 y 10, el fuego y la palabra en 2003 de Gloria Muñoz Ramírez ${ }^{124}$ el vocero y líder más conocido del EZLN, el Subcomandante Insurgente Marcos, explicó la formación del ejército indígena; habló de 7 etapas: selección, implantación, supervivencia y contacto con comunidades, crecimiento (llegan a Los Altos y al Norte), votación acerca de la guerra, preparación de la insurrección, levantamiento (días

\footnotetext{
${ }^{124}$ Gloria Muñoz Ramírez es la única periodista que ha podido vivir la realidad zapatista, del ejército y las bases durante años, después de años de participación directa en las comunidades, fue aceptada para vivir con ellos y plasmar en este libro la historia del movimiento.
} 
30 y 31 de diciembre de 1993, así como al 1º de enero de 1994) y la palabra (febrero 1994 a la fecha).

La primera etapa inicia en noviembre de 1983 y dura aproximadamente tres años. Comienza con la llegada de un pequeño grupo de activistas estrechamente relacionados con las FLN con una estructura político-militar definida, con un planteamiento revolucionario marxista-leninista (Vázquez, 2000: 105) que se planteaba «como objetivo la toma del poder político por la vía armada, el derrocamiento del gobierno autoritario, la instalación de un gobierno de transición y la construcción del socialismo» (Hernández, 2006: 272). Durante esta época el grupo guerrillero estaba enfocado a "hacerse parte del terreno", conocer los caminos y padecer las dificultades de la selva. No tenían como objetivo relacionarse con la gente de la zona, pero las necesidades de la vida en la selva les llevó conocer poco a poco a los indígenas tseltales y tojolabales (ambos de origen maya).

Las dificultades del terreno y la aún escasa participación de la gente de la zona hacían casi imposible hablar sobre un levantamiento armado real, según cuenta el Subcomandante Marcos, las veces que se tocaba el tema se planteaba en un futuro aún muy lejano.

La segunda etapa de finales de 1986 a mediados de 1991 es la etapa de mayor evolución y transformación del movimiento, se le conoce como la etapa de contacto e interacción, pues aquel grupo de guerrilleros comenzó a interactuar de manera profunda con las comunidades indígenas, cambiando sus ideas originales por un híbrido que lo caracteriza hoy en día, en palabras del Subcomandante Marcos:

[éramos] un grupo de "iluminados" que llega desde la ciudad para "liberar" a los explotados y que se encuentra con que, más que "iluminados", confrontados con la realidad de las comunidades indígenas, parecíamos focos fundidos (La Jornada, 25/07/03:6). 
Tal fue el choque y la transformación de ideas que, en 1998, Marcos, en una entrevista afirmó que «el EZLN nace como tal a la hora en que las comunidades lo agarran y lo moldean como lo que ahora es» (Rocha, 1998: 33).

Uno de los cambios radicales fue la lucha armada, pues a pesar de que era una convicción del grupo original que llega en el 84, evoluciona por las necesidades de la región pues se ve que no se necesitan más ataques, sino que se necesita una defensa real en «comunidades de la región ante el despojo de tierras a cargo de terratenientes y ganaderos, así como de la creciente represión por parte de guardias blancas, Policía de Seguridad Pública (estatal) y Policía Judicial (federal).» (Hernández, 2006: 274) y es así que el EZLN se transforma en una organización político-militar de autodefensa. En 1994, el Subcomandante Marcos afirmó que los nueve años anteriores se prepararon para la defensa, sólo para la defensa» (La Jornada, 4/03/94).

El ejercito zapatista, como ya se ha mencionado, es un híbrido interesante ya que une dos concepciones organizativas y hasta cierto punto irreconciliables: la organización político-militar y la organización comunitaria tradicional previa a la conquista de los indígenas de la zona. En la primera, es donde la jerarquía define la acción, incluso la estructura de mando suele considerarse como colonial al existir sólo un mando superior que tomas las decisiones y los subordinados tienen que cumplirlas. El ejército es un reflejo de la racionalidad kantiana ${ }^{125}$ usada por los gobiernos totalitarios, pues no cabe espacio alguno para el diálogo, la discusión y en este sentido (siguiendo la teoría arendtiana del mal) la violencia se convierte en la herramienta más efectiva. La segunda, donde la acción está

\footnotetext{
${ }^{125}$ Con racionalidad kantiana me refiero al pensamiento deductivo que parte de premisas y principios que se consideran universales y a través de los cuales es posible fundamentar las acciones éticas de los seres humanos.
} 
fundada y garantizada por los acuerdos y su cumplimiento es resultado de la deliberación y las acciones de la comunidad.

Hernández afirma que el cambio en la estructura político militar es tan fuerte que el EZLN desde ese momento ya no pudo tomar decisiones sin contar con el parecer de los habitantes de las comunidades, e incluso éstas le exigieron subordinarse a la toma de decisiones colectivas, es decir, que «mandar obedeciendo» (Hernández: 2006: 275). «Esta fue la primera derrota del EZLN», comenta el Subcomandante Marcos (Video Los más pequeños, 1994)

La tercera etapa; crecimiento y consolidación fue durante 1991 y algunos meses de 1992. Aquí el EZLN pasó de un grupo pequeño perdido en la selva para convertirse en el ejército propio y que radica con las comunidades indígenas. Dejaron de ser un grupo guerrillero para configurarse como una organización al servicio y defensa de las comunidades mayas del sureste mexicano. Miles de hombres, mujeres, niños y niñas se sumaron a un proyecto de esperanza que les permitiría, años más adelante, recuperar la dignidad de su cultura, su tierra y su vida.

La cuarta etapa es el este momento en el que se hace la consulta para levantarse en armas contra el gobierno federal y el ejército. La consulta duró casi un año y es uno de los ejemplos más claros de desesperación, consecuencia de años de violencia directa y estructural.

Las adversas condiciones económicas y sociales imperantes en el país impactaban severamente la vida cotidiana en las comunidades indígenas de Chiapas, las cuales vivían un acelerado proceso de pauperización y, al mismo tiempo, de concientización acerca de cómo cambiar su situación. (Hernández, 2006: 276)

La decisión no se tomó a la ligera, desde la comandancia general se analizaron los pros y contras de la guerra, de la coyuntura nacional con la entrada del Tratado de Libre comercio 
(TLC), la coyuntura internacional con la reciente caída del muro de Berlín y los sistemas socialistas. Analizaron las consecuencias de la guerra en El Salvador, en Nicaragua y en Guatemala, reconociendo el camino de dolor que se abrirían, pero cuando lo comparaban con la muerte y la miseria que vivían y la impotencia frente los procesos legales y gubernamentalmente pacíficos como el choque de comisiones que iban a solicitar recursos y regresaban sólo con un montón de papeles (La Jornada, 4/03/94: 3), la mayoría de las comunidades decidió el levantamiento armado, pero teniendo como objetivo principal la recuperación de su dignidad y no la búsqueda del poder, elemento que lo alejó por completo de los diferentes levantamientos armados en América Latina.

No pretendían derrocar el gobierno, sino recordarle el lugar que ellos necesitaban. La mayoría de las actas de las asambleas en las distintas comunidades se firmaban diciendo: «Tantos niños, tantos hombres, tantas mujeres, tantos que sí a la guerra, tantos que todavía no» (Gilly, et al., 1995: 141).

La quinta etapa sucede en 1993, la denominaron «preparación de la insurrección». A pesar de que en ningún documento se establece la fecha en la que se armó el EZLN, si hablan de lo que para ellos significó su formación militar y conseguir armar a las comunidades: consiguió organizarlos con un objetivo claro, acabar con su miseria o morir en el campo de batalla. Además, durante este año cada comunidad eligió a sus representantes para así conformar el Comité Clandestino Revolucionario Indígena-Comandancia General del Ejército Zapatista de Liberación Nacional CCRICG-EZLN que desde ese momento hasta la inauguración de los Caracoles zapatistas en 2003 era quien mandaba-obedeciendo en las comunidades. Es en 1993 cuando el EZLN buscaba despertar a la población mexicana e internacional «del dulce sueño de la modernidad». 
La sexta etapa comprende los días previos al levantamiento; 30 y 31 de diciembre de 1993, la toma de cinco cabeceras municipales: San Cristóbal de Las Casas, Altamirano, Las Margaritas e Ocosingo, y Chanal el $1^{\circ}$ de enero. Y los doce días combate hasta el cese al fuego temporal del ejército federal y el cese al fuego permanente del EZLN.

Durante esta etapa salió a luz un grupo de indígenas encapuchados gritando ¡Ya Basta! mediante un comunicado que llamaron Primera Declaración de la Selva Lacandona, en ella explicaron el porqué de sus acciones y así continuaron, hasta publicar la Sexta Declaración que los rige hasta el momento y que se concibe como el periodo de mayor apertura y protagonismo de las bases zapatista y ya no del ejército.

Ahora, la séptima etapa comprende desde el 12 de febrero de 1994 hasta la fecha (casi 25 años) en donde el zapatismo ha evolucionado y se ha convertido en in icono de las resistencias indígenas en América Latina y el mundo. Se mencionarán en lista algunos de los momentos más importantes durante estos casi 25 años:

- 1994:

- 12 de febrero: Primera marcha por la paz de la sociedad civil para detener el fuego

- 22 de febrero al 2 de marzo: primeros diálogos de paz. Segunda Declaración de la Selva Lacandona.

- Junio: convocatoria para la Convención Nacional Democrática de la que emane un gobierno de transición y desemboque una nueva Constitución (movimiento pacifista)

- 1995:

- Tercera Declaración de la Selva Lacandona

- Febrero: nuevo ataque del ejército federal y orden de aprehensión contra líderes del EZLN: segunda marcha por la paz de la sociedad civil «Todos somos Marcos»

- Octubre a febrero 1996: Acuerdos de San Andrés

- 1996:

- Febrero: Cuarta Declaración de la Selva Lacandona. Fundación del Frente Zapatista de Liberación Nacional. Firma de los acuerdos sobre derechos y cultura indígenas

- 1997:

- Septiembre: Marcha del EZLN (1,100 zapatistas) a la Ciudad de México. 
- Diciembre: matanza de Acteal - 45 asesinados por un grupo paramilitar PRIista.

- 1998:

- 19 de julio: Quinta Declaración de la Selva Lacandona. Consulta nacional sobre la iniciativa de la COCOPA y fin de la guerra de exterminio.

- 2000:

- Diciembre: Se anuncia una marcha para defender la propuesta de la COCOPA (resultado de la consulta) y exige 3 señales para reanudar el diálogo con el gobierno: cumplimiento de los Acuerdos de San Andrés, liberación de los presos zapatistas y retiro y cierre de 7 posiciones militares de las 259 que hay en la zona.

- 2001:

- Inicio de la marcha del color de la tierra a la Ciudad de México: Discurso de la Comandanta Esther al Congreso de la Unión.

- Abril: aprobación de la contra-reforma sobre derechos y cultura indígena. El EZLN anuncia suspende todo contacto con el gobierno y afirma que no reanudará el diálogo.

- 2003:

- Enero 2003: 20,000 zapatistas toman la ciudad de San Cristóbal de las Casas. Se denuncia la traición de los partidos políticos a los Acuerdos de San Andrés.

- 2005:

- Agosto: inauguración de los Caracoles y las Juntas del Buen Gobierno

- Junio: Sexta Declaración de la Selva Lacandona

- 2006:

- La Otra Campaña: unión con todas las personas que quieran hacer política de otra manera. 3 y 4 de mayo en la represión contra los ejidatarios de Atenco ( 2 adolescentes asesinados y 27 mujeres violadas por elementos de la policía estatal), el EZLN suspende el recorrido hasta el 13 de septiembre por alerta roja en territorio zapatista

- Diciembre 2006: termina el recorrido del subcomandante Marcos en la Otra Campaña.

- Diciembre 2006 - enero 2007: encuentro de los pueblos zapatistas con los pueblos del mundo.

- 2007:

- Marzo 2007: inicia la segunda etapa de La Otra Campaña con comandantes de la Comisión Sexta del EZLN.

- 2012:

- 21 de diciembre 2012: más de 40,000 hombres, mujeres y niños toma pacíficamente y en silencio de las cinco cabeceras municipales que 18 años atrás tomaron por la vía armada.

- 2013: 
- Convocatoria a participar en la "Escuelita Zapatista": apertura de los caracoles para conocer la forma de educación en las comunidades autónomas zapatista.

- 2014

- Asesinato del Maestro Galeano en el caracol La Realidad, muerte simbólica del Subcomandante Marcos.

- Desaparición y asesinato de los estudiantes de Ayotzinapa. Apoyo de la comandancia general y bases zapatistas a los padres de Ayotzinapa en su Caravana.

- 2015

- Muerte de Luis Villoro y comunicación de su pertenencia al Ejército Zapatista, único integrante hasta el momento que no cumplía con el requisito de taparse la cara, al ser un personaje público.

- Convocatoria y realización al Seminario Internacional "El pensamiento Crítico frente a la hidra capitalista"

- Convocatoria y realización del segundo año de la Escuelita Zapatista.

- 2016

- Convocatoria y realización al primer encuentro "CompArte": Festival de arte en resistencia.

- Convocatoria y realización del primer encuentro "ConCiencias por la Humanidad": congreso sobre desarrollo de ciencias en resistencia

- Anuncio de la Comandancia General y el Concejo Nacional Indígena de la intención de participar en los comicios electorales de 2018 por la Presidencia de la República. Convocatoria y realización de una consulta a todas las comunidades del Concejo para saber si apoyan la propuesta.

- 2017

- Convocatoria y realización del Congreso "Los Muros del Capital"

- Anuncio de la aceptación de las bases indígenas del Concejo de participar en el proceso electoral federal de 2018.

- Presentación de María de Jesús Patricio Martínez como Vocera del Concejo Nacional Indígena y candidata a las elecciones de 2018

- 2018 
- Participación en el proceso electoral: recolección de firmas para presentar la candidatura oficial independiente de Marichuy. Recorrido por toda la República, a las comunidades más vulnerables del país.

- Atentando contra la Caravana de Marichuy en Tierra Caliente Michoachan para quitar los dispositivos que permitían la recolección de firmas.

- No se logran las firmas necesarias para acceder a la candidatura oficial, pero se reconoce por parte del Instituto Nacional Electoral que el 98\% de las firmas presentadas son válidas. Se acepta la candidatura de otro aspirante independiente que presentó las firmas necesarias, pero más de la mitad se comprobó que eran falsas, aun así participó oficialmente.

- Nuevo enfrentamiento entre el gobierno electo y el EZLN sobre las políticas para Chiapas.

En este breve recorrido histórico es posible ver las muchas caras del zapatismo y especialmente la construcción de pensamiento que ha marcado quizá los últimos cinco años. Por otro lado, deben quedar claras tres cuestiones fundamentales que ayudarán a comprender cómo se supera el uso de la violencia en el levantamiento de 1994, de modo que podamos superar la discusión para enmarcarlos dentro de los estudios de paz, priorizando el trabajo que han realizado en la consolidación de un espacio público organizado, autónomo y con una base teórica original:

1. El EZLN es un ejército de autodefensa supeditado a las órdenes de las comunidades autónomas zapatistas de Chiapas.

2. La declaración de guerra del EZLN tenía como objetivo político la visibilización de la guerra de baja intensidad que se vivía y vive en el estado, así como la situación de empobrecimiento, explotación y marginación en la que vivían y viven los indígenas en México. 
3. Paz para el EZLN significa justicia y dignidad, y es el objetivo político, social y privado de las comunidades. Desde el inicio su búsqueda se ha distinguido por el uso de la noviolencia, el diálogo y la comunicación.

El uso de la violencia en los proyectos decoloniales obliga a preguntar: ¿cuál es el origen de su violencia? y si se habla sobre el zapatismo, se debe preguntar ¿el EZLN hubiera existido si las condiciones fueran distintas? La negación o afirmación depende de muchos factores y podría o no legitimar la acción, de acuerdo a los nuevos estudios de Adela Cortina sobre la guerra justa, quien, en palabras de Vicent Martínez Guzmán, afirma que es aquella que cumple con los siguientes requisitos: «que sea la mínima indispensable, con finalidad justa, después de agotar los medios no bélicos, con probabilidades de éxito, que no traiga males mayores y que desenmascare la mentira que encubre la violencia originante y ponga fin a la injusticia» (Martínez Guzmán, 2001:133).

Siguiendo esta línea se debe preguntar: ¿cuánto tiempo duró la guerra? 12 días ¿Hay más pobreza, más desigualdad, más opresión, más explotación? No, desde 1994 se recuperó la dignidad de las comunidades autónomas zapatista de Chiapas y se trabaja todos los días en la construcción de una sociedad más justa, más armónica y más pacífica ¿La sociedad mexicana recordó ese rincón del país? Después del levantamiento nadie volvió a ver a Chiapas igual y mucho menos a los indígenas, nadie se atreve a negar sus derechos, aunque el aparato mediático gubernamental sigue tratando de desviar la atención y hay mucho trabajo aún por hacer en la violencia cultural del país que los sigue discriminando.

¿La estrategia de trabajo ha sido la violencia o la noviolencia? Sin lugar a dudas, el EZLN, especialmente las bases de apoyo del zapatismo, son un movimiento noviolento. El uso de las armas en las comunidades actuales es única y exclusivamente de defensa, además 
de que el sistema de gobierno se aleja de las estructuras jerárquicas y se fundamenta en la democracia participativa y asamblearia, transformando el significado de poder como dominación a poder por consenso con su propuesta política del mandar-obedeciendo.

Sin embargo, en las resistencias pacíficas mayas desde la época de la colonia hay un sinfín de historias sobre acciones que buscaban parar las muertes de los indígenas en México, lamentablemente ninguna surtió efecto, como se ha presentado ya en el primer capítulo de la presente investigación. Las voces eran silenciadas, las muertes olvidadas y las vidas desechables. El EZLN cambió esto. Sí, estaban armados, sí, eran un ejército, pero uno que respondía a las órdenes del pueblo oprimido desde hace siglos, era un ejército que se armó para unirse y cuando inician la guerra lo hacen contra su opresor, no pensando en que podían ganar la guerra, ni en que a través de ella pudieran obtener la paz, sólo querían que los voltearan a ver, como ellos lo dicen: «nos tapamos la cara para que nos vieran».

En entrevista en 1994 les preguntan: ¿Por qué la violencia, por qué la lucha armada?

Venimos de algunas organizaciones independientes. Así hemos luchado, pero no hemos logrado nada. Muchos de nuestros pueblos hemos luchado así, pero lo que hemos logrado [son] encarcelamientos, asesinatos, represiones. Estas [son] las razones por las que estamos participando en una lucha armada (entrevista al Comité Clandestino Revolucionario Indígena-Comandancia General del EZLN [CCRI-CG] (La Jornada, 04/02/94: 6).

Como un proceso y lucha decolonial el uso de la violencia es prácticamente innegable, pero si deja de entenderla como herramienta del poder para la dominación y en la que sólo unos privilegiados son los que pueden utilizarla, se entenderá que la violencia decolonial lleva necesariamente a la noviolencia como estrategia para alcanzar objetivos políticos como la dignidad y la justicia. 
Debe quedar claro que la paz no es un objetivo político, por lo tanto no se puede alcanzar, pero se puede experimentar cuando hay vida digna y condiciones justas dentro de la sociedad.

La búsqueda del reconocimiento hace posible la lucha noviolenta, si no existe este reconocimiento y no hay un mínimo espacio para el diálogo, la noviolencia pierde eficacia y en algunos escenarios se presenta como imposible.

Para seguir adelante con la argumentación, es necesario tomar una excelente distinción que apunta Muller en «La no-violencia como filosofía y como estrategia»:

Conviene distinguir bien, no para separarlas, sino para no confundirlas, la noviolencia como filosofía, que constituye la búsqueda de un sentido a la existencia y a la historia y la no-violencia como estrategia, que es la búsqueda de la eficacia en la acción. La filosofía es el amor de la sabiduría. La filosofía implica una escogencia, una opción, una decisión personal. Pero, es necesario que el individuo pueda hacer esta escogencia en pleno conocimiento de causa. Para ello, es necesario que este conocimiento le sea propuesto en el marco de la enseñanza. Debe ser el objeto de la educación. (Muller, 2006)

Al mostrar que a la violencia le es imposible alcanzar un objetivo político tal y como lo defiende Arendt, debe quedar claro que se tienen que crear nuevas alternativas de acción, y es ahí donde surge la noviolencia. Sin embargo, hay dos maneras en las que se puede utilizar, una como ideal regulativo, y la otra como estrategia de acción.

En términos teóricos la más importante sería la filosófica (ideal regulativo), puesto que permite desarrollar diversas estrategias y maneras de transformar un conflicto y vivir en el colectivo de manera responsable y activa, tal y como lo propone Vicent Martínez Guzmán en la filosofía para paz, con el reto de potenciar el poder comunicativo. Sin embargo, la noviolencia estratégica es la que permite alcanzar los objetivos políticos y sociales que le son imposibles a la violencia. 
Es importante aclarar también que ambas son inseparables, es decir, no puede haber acción noviolenta que no la entienda como un estilo de vida y no hay estilo de vida noviolento que no lleve a la acción.

Una característica más sobre la noviolencia que brinda Muller, que es relevante para la construcción de una verdadera cultura de paz, es la falta de conocimiento que se tiene sobre esta posibilidad.

[...]Pero, ¿no es uno de los dramas de nuestras sociedades que la educación no ofrece a nuestros hijos una enseñanza sobre la noviolencia? ¿Cuáles son los momentos, cuáles son los lugares que son propuestos a nuestros hijos para que ellos puedan reflexionar sobre la no-violencia? La educación sólo ofrece a los jóvenes un saber tecnológico que tiene como objetivo volverlos competitivos en la rivalidad económica que pronto los va a oponer. $\mathrm{Y}$ este aprendizaje tiene el riesgo de no darles el espacio para reflexionar sobre el sentido mismo de su existencia y de construir convicciones fuertes para afrontar el porvenir. Ciertamente, habría que re-pensar la educación en este sentido. (Muller, 2006)

En la noviolencia no sólo se atacan las estructuras, sino que se revisa el sistema con una mirada crítica; sucede lo mismo que con la paz. La paz no es la ausencia de guerra como quedó claro en el capítulo II, y la no-violencia no es la ausencia de violencia, sino la transformación y reinterpretación de la realidad y las relaciones desde la búsqueda del sentido en el colectivo y con responsabilidad.

Debemos construir estas relaciones a través de la defensa de nuestros derechos, a los cuales no debemos renunciar y del respeto a los derechos de los demás. Debemos, por lo tanto, vivir el conflicto, transformarlo de tal manera que podamos construir una relación de justicia con los otros. (Muller, 2006: 1).

Es así que se puede afirmar que el ejército zapatista es una organización y un movimiento noviolento. Y es en este sentido la descolonización aplicada a la violencia y a la noviolencia se convierte en un proyecto de liberación y de construcción de la justicia donde la paz puede aparecer. Esta es la realidad de las comunidades de Chiapas. Este es el proyecto 
en el que se trabaja todos los días, y como el conocido Subcomandante Marcos dice: «se construye desde abajo y a la izquierda».

Ahora, es posible que no sea suficiente la argumentación dada y que la crítica de Martínez Guzmán a las guerrillas y a la teorización de Adela Cortina pueda aplicarse a esta investigación, de tal suerte que se analizarán los puntos por los que Martínez Guzmán apuesta en lugar de la lucha armada (Martínez Guzmán, 2001: 133-143). Todos estos argumentos ayudarán a comprender cómo el EZLN es mucho más que un levantamiento armado.

1. «Estamos aprendiendo a que no hay violencia última que acabe, por fin, con la violencia originante» (Martínez Guzmán, 2001 133): es claro que plantear el origen de la violencia es sumamente problemático ya que esta depende de muchos factores, actores y circunstancias. Sin embargo, a lo largo de esta investigación, se ha sostenido y argumentado que el proyecto colonial del siglo XVI y que sigue hoy en día, es fundamento de la violencia estructural que se vive en regiones indígenas como Chiapas y a pesar de aceptar que el levantamiento armado no eliminó la marginación, sí logró reunir los requisitos mínimos para la lucha noviolenta, uno el encuentro y reconocimiento en el espacio público, que hicieron posible el trabajo constante de las comunidades hacia la paz. Es imposible negar la visibilidad y la recuperación de dignidad frente a las constantes opresiones del gobierno que las comunidades mayas adquirieron después del levantamiento.

2. «Estamos comprometidos en la reconstrucción normativa de las instituciones, relatos, creencias, opciones ideológicas, metáforas, etc. que muestren las competencias originarias de los seres vivos para vivir en paz» (Martínez Guzmán, 2001 133): el trabajo de las comunidades zapatistas antes y después del levantamiento armado han fomentado la recuperación de la sabiduría antigua y ha roto con los patrones que 
limitaban las capacidades comunicativas y sociales de las personas. El ejemplo es claro en la participación de las mujeres en el ejército, la vida pública y en la toma de decisiones, así como la participación de los hombres en las mal llamadas actividades propias de la mujer, como el cuidado de la casa y los hijos. Esto muestra una reconstrucción del tejido social que prioriza la relación y la capacidad comunicativa, elementos esenciales en la filosofía para la paz.

3. «Este aprendizaje y este compromiso supone una transformación del orden mundial que nos hemos dado desde Westfalia: sólo el Estado nacional ya no nos proporcionan seguridad, ni es el límite del ejercicio de la soberanía y la gobernabilidad. Necesitamos un orden mundial con reparto de la gobernabilidad y ejercicio de la soberanía por encima y por debajo del Estado nacional, en donde quepan reconocimientos de identidades colectivas y formas de gobernación y ejercicio de la soberanía más allá y dentro mismo de los actuales Estados nacionales, con la recuperación de naciones sin Estado, pueblos, etc.» (Martínez Guzmán, 2001 134): en definitiva este punto reivindica el trabajo del movimiento zapatista en Chiapas, ya que ellos apuestan por una estructura no jerárquica donde la gobernabilidad no emerge de la autoridad del estado-nación sino de las relaciones horizontales de mandar-obedeciendo en la comunidad.

4. «El ejercicio de la soberanía y la gobernabilidad también se puede realizar desde los movimientos sociales comprometidos con el empoderamiento, la emancipación y las luchas pacíficas de resistencia contra el globalismo autoritario que ahoga las economías de supervivencia y las luchas por el reconocimiento de las identidades colectivas de los apoderados» (Martínez Guzmán, 2001 134): la lucha por el reconocimiento, en términos teóricos y filosóficos, es la que detono la lucha del 
EZLN hace tres décadas, incluso autores como Enrique Dussel, afirman que es por la necesidad del re-conocimiento del indígena como sujeto digno que todos los procesos decoloniales inician (Dussel, 2007). La búsqueda del reconocimiento y mediante ésta, la recuperación de la dignidad son elementos esenciales en la lucha noviolenta y en la construcción de paz.

El trabajo del EZLN por la paz no queda eclipsado por el uso de las armas en el levantamiento del 94, por el contrario, muestra el camino de la violencia de acuerdo a la teoría de Galtung, y mejor aún, la potencian para visibilizarla y exigir el reconocimiento como seres humanos y como indígenas.

A este respecto es interesante recordar brevemente la discusión aún vigente entre Hannah Arendt y Franz Fanon entorno a la violencia, pues a través de ella es que se podrá comprender el proyecto político del zapatismo.

Arendt hace una crítica a Fanon en Sobre la violencia (1963) y se enfoca principalmente en dos cuestiones, el uso de la violencia para alcanzar objetivos políticos y el reconocimiento de la violencia como un proceso natural y necesario en los procesos de decolonización, como establece Fanon en su obra Los condenados de la Tierra (1961).

Para la filósofa alemana, el uso de la violencia queda en entredicho al mostrar la capacidad de acción política de los seres humanos por encima de la reacción violenta, e incluso afirma que la violencia es intencional y jamás natural, y en este sentido puede modificarse en cualquier momento. Es importante recordar que la violencia en Arendt no es otra cosa que lo opuesto a la política, ya que aparece cuando el poder político (consenso entre iguales) es muy bajo.

Fanon and Arendt begin by offering us alternative theorizations of the relation between politics and violence. In the case of Fanon, violence is an instrument for the achievement of political ends, and it is also a libidinale natural to all 
human beings and capable of being channelled for good or ill. In the case of Arendt, violence in itself is by definition anti-political. This is because violence, in which obedience is secured through coercion, is the opposite of power, which is based on free consent. We have suggested in our discussion of these two theorists' work that the insights they provide are in some sense complementary. Arendt's argument gives us a useful corrective to Fanon's instrumental and psychoanalytic claims. Fanon, on the other hand, gives us an equally useful corrective to the abstract and disembodied way in which Arendt thinks about violence as a tool. (Frazer y Hutchings: 2007)

La posibilidad de reconciliar estos autores y verlos como complementarios, permiten tener una visión más amplia donde el zapatismo y su levantamiento armado puede comprenderse mejor. Para ello es necesario afirmar que para ambos autores la violencia surge para tratar de comprender como eliminarla de esfera política. En Arendt quizá es más claro que en Fanon, pero si se recuerda aquella esperanza casi ingenua del autor por la construcción de una nueva humanidad donde prevalezcan los valores colectivos y la participación activa de la gente, se puede entender que hay una búsqueda de la paz, la justicia, la armonía y la dignidad en los escenarios de opresión; mismo objetivo para Arendt como para la filosofía para la paz y evidentemente para el pensamiento decolonial.

Por otro lado, el estudio de ambas posturas, más allá de ser contradictorio o antagónico, es complementario como lo proponen Frazer y Hutchings:

We conclude by suggesting that the cases to which Fanon draws attention in the last chapter of The Wretched of the Earth point to a set of issues about the relation between politics and violence that are not explicitly addressed by either Arendt or Fanon, nor by any of the thinkers whose approaches to politics and violence frame Arendt's and Fanon's critical contributions. While Fanon acknowledges that the entrenchment of violence in individual and collective life makes revolutionary violence possible, he fails to explain how the vicious circle between the doing and 'being' of violence can be broken through the doing of further violence. Meanwhile, Arendt banishes violence from politics conceptually, but fails to engage with the problem how violence might both be, on occasion, constitutive for politics, and not contaminate it. (Frazer y Hutchings: 2007) 
Es interesante como Frazer y Hutchings plantean los limitantes de ambas posturas como puntos de complemento. Para los estudios de paz, así como para el pensamiento de Arendt, el uso de la violencia dentro de la política y más aún el reconocimiento de ésta como constitutiva del poder, suele ser controversial. Sin embargo, creo que puede superarse al no entender su vinculación como una legitimación, sino como una comprensión de ciertas acciones, que más que violencias originarias son consecuencias de la espiral. En Fanon es claro, pues él acepta que la colonialidad ha enseñado un solo lenguaje y éste es violento, por lo tanto, toda acción en respuesta a él, será en principio violenta. Arendt no llega hasta ahí, pero sí se da cuenta que hay escenarios en los que no es posible aplicar la política y por lo tanto la noviolencia no tiene cabida:

She argues that although violence can never be legitimate, it may nevertheless sometimes be justified (p. 52). This is because there is not a political solution to every problem, sometimes the only solution to injustice or horror is the violent one. In On Violence, there are two contexts in which violence is presented as justifiable. Firstly, it may be justified as a response to extreme injustice (p. 64). Secondly, it may be justified insofar as it opens up the space for politics (p. 79). Both of these justifications are bound up with a sense of violence as having a certain kind of effectiveness, and also being appropriate in certain contexts. Violence can make things happen in the immediate sense. It is also the right response, for instance, to the victimization of the innocent. Arendt argues that the use of non- violence as a tactic requires, as its prerequisite, that there already be some space of politics and therefore for power. Ghandi's campaign, she suggests, could not have been effective had he been faced with a more purely anti-political regime, such as Nazi Germany or Stalinist Russia (p. 53). In the latter contexts violence would be necessary in order to make politics possible. (Fraiser- Hutchings: 2007)

Hay cuestiones interesantes en este fragmento, el primero es la comprensión del uso de la violencia en escenarios donde existe extrema injusticia, pero siempre y cuando ésta se utilice para abrir el espacio para la política. Así Arendt le pone un prerrequisito al uso de la noviolencia y es que exista un espacio público que garantice la política (que incluye el reconocimiento del otro como interlocutor), e incluso pone como ejemplo los gobiernos 
totalitarios en este sentido ${ }^{126}$. Es claro que cuando Arendt hace esta afirmación también afirma que los resultados del uso de la violencia son imprevisibles y más aún dice: «la violencia pude destruir siempre al poder; del cañón de un arma brotan las órdenes más eficaces que determinan la más instantánea y perfecta obediencia. Lo único que no podrá brotar de ahí es el poder» (Arendt, 2005:73).

El uso o la justificación que Arendt le otorga a la violencia no está en contra de los estudios de paz, por el contrario, reafirma la idea de que es posible construir la paz en escenarios sumidos en la violencia. Incluso se puede ir más allá si se analizan los casos de Rwanda o los procesos de reconciliación que Lederach menciona en La imaginación moral o en Building peace, donde se establece que después de la violencia existe la reconciliación; la justicia, la verdad, el perdón y la misericordia.

La estrategia de reconciliación en relación a la teoría del perdón de Arendt y el concepto de justicia zapatista, que se analizarán dentro de la ontología pluriversal, se unen al superar, las tres, el calor de venganza al que siempre ha estado sumida la justica, apostando por la construcción de una que sea la sea base de relaciones empáticas y armónicas mediante el ejercicio constante de diálogo y la reflexión colectiva.

126 Esta afirmación permite recordar las esporádicas resistencias violentas de los campos de exterminio nazi explicadas por Primo Levi en Los hundidos y los salvados, en donde se ve claramente la imposibilidad de diálogo e incluso la imposibilidad de defenderse sin perder la vida, pues su vida no valía nada para su opresor, inimaginable es una lucha noviolenta en un contexto como el de la SGM y algunos casos de colonialismo. 
La discusión de Arendt y Fanon se supera a través de la búsqueda de la paz, entendiendo esta como un proceso constante de liberación que construya a su vez un espacio público que potencie las acciones políticas, tal y como lo hacen los Caracoles zapatistas.

\section{Conclusiones}

A lo largo de este capítulo se ha hecho un análisis de las estadísticas, acompañado de un relato de vida y la historia del EZLN como movimiento noviolento. Se ha utilizado la famosa discusión entre Hannah Arendt y Fratz Fanon entorno a la violencia, para superar lo que en un momento parece una contradicción, al tomar el zapatismo como un ejemplo de lucha noviolenta.

Hay tres elementos a destacar de este capítulo, el primero, la necesidad de incorporar una narración cualitativa sobre el modo de vida en Chiapas, al menos de manera superficial, para complementar la fría realidad de las estadísticas, al modo que se hizo en el primer capítulo con la situación actual de México. A este respecto, se puede concluir que la realidad chiapaneca es bastante compleja, pues no sólo es ejemplo perfecto de la colonización interna y todas consecuencias (racismo y clasismo principalmente) sino que es escenario de una nueva forma de relacionarse. La resistencia en Chiapas, muestra el carácter digno de las comunidades indígenas, pero también de la necesidad que muchos mestizos y campesinos tienen de encontrar nuevas bases para su actuar y pensar. De igual modo, es un lugar donde la convivencia entre nacionales y extranjeros conserva la jerarquía colonial y al mismo tiempo la transforma. Todo ello hace que la realidad sea compleja para analizar desde un ámbito puramente académico.

El segundo elemento a destacar en este capítulo es el prerrequisito que Hannah Arendt le pone al uso de la noviolencia, haciendo referencia directa a lo sucedido en los campos de 
concentración nazis de la segunda guerra mundial. Aquí la autora, muestra cómo a pesar de que la violencia jamás puede alcanzar objetivos políticos, sí que puede crear en casos excepcionales donde la injusticia es extrema, el espacio púbico necesario para que el uso de la noviolencia sea posible. Este espacio público debe, como mínimo, dar el reconocimiento de la existencia del otro, si no se logra este mínimo, es imposible cualquier estrategia noviolenta. Como se argumentó, en el caso del EZLN, esto se logró; la visibilización que lograron permitió que se diera a conocer su pensamiento, y que ellos pudieran seguir su camino hacia la autonomía.

Por último, es importante destacar cómo bajo los requisitos que Vicent Martínez Guzmán establece, el movimiento zapatista puede considerarse como un movimiento noviolento y capaz de crear una cultura de paz, aunque haya recurrido durante doce días a las armas. Lo anterior, al mostrar que con el levantamiento no se acabó la violencia originaria, sino que se creó el espacio público (y el reconocimiento) necesario para la lucha noviolenta. En las comunidades zapatistas hay un compromiso claro con la reconstrucción normativa de las instituciones, relatos, creencias, opciones ideológicas, metáforas, etc. que muestren las competencias originarias de los seres vivos para vivir en paz. Su propuesta apuesta por una reorganización de la forma de gobierno que excede al Estado Nacional y se compromete con la lucha para el reconocimiento de identidades colectivas que van más allá del pensamiento eurocéntrico dominante. 


\section{Capítulo V: Una propuesta de construcción de paz desde las resistencias indígenas: una}

mirada al pluriverso y la comunalidad.

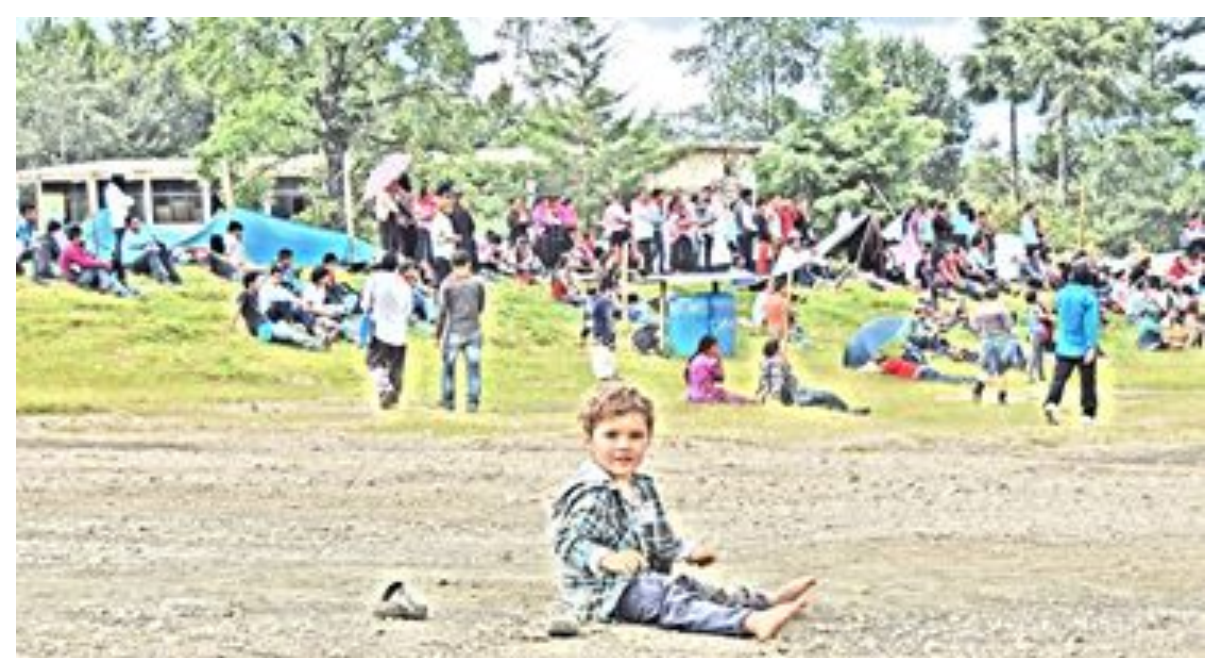

Si el poder es la categoría fundamental de toda política, de lo que se trata, en definitiva, es de proponer un paso trascendental: de la política moderna de dominación a una política de liberación (de toda pretensión de dominación)

Rafael Bautista

Para terminar con esta investigación, este capítulo pretender recoger la fundamentación ontológica de las resistencias indígenas, una propuesta que transforma por completo la cosmovisión bajo la cual el pensamiento europeo está fincado. Debo advertir que es quizá uno de los capítulos más complejos, pues su propuesta me atraviesa completamente, ya que mi formación está marcada por los cánones occidentales, es por eso que nuevamente mi puente de conexión entre la propuesta pluriversal y el pensamiento europeo será principalmente Hannah Arendt y la filosofía para la paz de Vicent Martínez Guzmán.

Ahora, la propuesta sobre la ontología relacional estará fundamentada principalmente en dos autores, Arturo Escobar y Mario Blaser, pensadores que no sólo proponen una transformación radical de la ontología del mundo universal hacia la ontología del mundo 
plural, sino que su propia ejecución los lleva a una transformación de la epistemología y por lo tanto de su modo de crear en la academía.

A este respecto, se utilizará también la propuesta de Boaventura de Sousa Santos que trabaja sobre la idea de que los movimientos sociales deben ser vistos como productores de conocimiento y no ya como objetos de estudio, para así mostrar el pensamiento zapatista como una propuesta teórica/práctica de construcción de paz que se puede seguir pero desde la retaguardia, es decir no desde la teorización sino desde el activismo.

Finalmente se hará una breve mención al concepto de comunalidad desde el pensamiento de Gustavo Esteva, Arturo Guerrero Osorio y Jaime Martínez Luna. Sin embargo, este apartado es quizá el que puede acarrear más problemas ya que el mismo concepto de comunalidad como palabra excede todo tipo de formulación académica, pero tal afirmación se explicará más adelante.

\section{El universo más allá de la modernidad}

Los estudios pluriversales surgen en las últimas décadas inspirados en el análisis crítico al desarrollo y las propuestas del postdesarrollo, también son consecuencia directa de la crisis ecológica mundial que busca nuevos esquemas para abordarla. Arturo Escobar con su hoy ya clásica obra La invención del tercer mundo: Construcción y deconstrucción del desarrollo (1996) y Mario Blaser con su propuesta sobre ontología política son algunos de los autores más relevantes de los estudios. El trabajo y las conversaciones que ambos han tenido se reflejan en el libro Sentipensar con la tierra. Nuevas lecturas sobre desarrollo, territorio y diferencia (2015), que se tomará como referencia primera para el desarrollo de este capítulo. 
Según Escobar los estudios pluriversales «surgen del afán de acompañar las luchas de aquellos mundos que buscan perseverar, en medio de las intensas arremetidas unimundistas de la globalización neoliberal.» (Escobar, 2015: 20). Además buscan «entender los múltiples proyectos basados en otros compromisos ontológicos y formas de mundificar la vida, y las muchas maneras como estas luchas debilitan el proyecto de mundo único y al mismo tiempo contribuyen a ampliar sus espacios de re-existencia» (Escobar 2015: 21).

Los estudios pluriversales son consecuencia directa del Mundo-Uno: «moderno/capitalista, secular, racional, y liberal con su insistencia en la ilusión del progreso y el desarrollo, en el consumo individual y la competitividad del mercado que se han convertido en la norma y medida del actuar humano.» (Escobar, 2015:21) Y en este sentido son una apuesta política también que esta intrínsecamente relacionada con las acciones y movimientos decoloniales.

La perspectiva desde la que se habla en los estudios pluriversales es la ontología política, de ahí que sea necesario hacer algunas puntualizaciones sobre tres conceptos principales: ontología, ontología política y práctica política ontológica, pues a través de éstos es posible comprender la propuesta de Escobar y Blaser, asi como la práctica de las comunidades zapatistas. De igual manera, se abordará el concepto de cosmopolítica en Blaser que ayuda no sólo a comprender el ideario zapatista, sino abre una puerta de comprensión original sobre la política de resistencia.

La ontología dentro de la filosofía es comprendida, tradicionalmente, como el estudio del ser y por lo tanto de lo real, incluso es posible entenderla como «nuestra forma de entender lo que significa que algo o alguien exista» (Winograd y Flores, 1986:30) La definición de ontología que usa Escobar es la de Blaser la cual consta de tres niveles: 
"el primero, ontología se refiere a aquellas premisas que los diversos grupos sociales mantienen sobre las entidades que realmente existen en el mundo. Así, por ejemplo, en la ontología moderna existen: "individuos" y "comunidades", "mente" y "cuerpo", como también: la "economía", el "mercado", el "capital", "árbol", "insecto", "especies" y, por supuesto, "mundo" — todos estos como constituidos en sí mismos, autosuficientes- Dentro de esta ontología, la vida está poblada por "individuos" que manipulan "objetos" en "el mundo" con mayor o menor eficacia. [...] El segundo consiste en la consideración de que las ontologías se enactúan a través de prácticas; es decir, no existen solamente como imaginarios, ideas o representaciones, sino que se despliegan en prácticas concretas. Estas prácticas crean verdaderos mundos — de aquí que a veces los conceptos de "mundo" y "ontología" se usen de forma equivalente-. El tercero, las ontologías se manifiestan en historias (o narrativas) que permiten entender con mayor facilidad, o encarnan, las premisas sobre qué tipo de entidades y relaciones conforman el mundo. Este último nivel está ampliamente corroborado por la literatura etnográfica sobre mitos y rituales de creación." (Escobar, 2015:95)

En resumen, se puede decir que la ontología por un lado define las entidades que existen en el mundo, por otro, estudia las prácticas concretas que se despliegan de las ideas o representaciones que enactúan ${ }^{127}$ el mundo y por último analiza las narrativas que muestran las relaciones entre entidades que conforman ese mundo.

Considero que la dimensión más importante a destacar es la segunda, donde se establece que las ontologías enactúan, pues ella transforma por completo la comprensión tradicional de ontología, y tiene que ver con la importancia de la enacción del mundo, es decir, con la construcción del mundo que se logra gracias a la relación de sus entidades. Esta afirmación elimina la concepción tradicional de la cultura como una perspectiva más del mundo tradicional, pero para ello es necesario abordar el concepto de ontología política.

De acuerdo también a Blaser, la ontología política tiene dos dimensiones:

\footnotetext{
${ }^{127}$ El verbo enactúar se utiliza dentro de los estudios pluriversales para mostrar la cocreación e interrelación de los mundos.
} 
Primero, a los procesos por los cuales se crean las entidades que constituyen un mundo particular; estos procesos, con frecuencia, conllevan negociaciones en campos de poder. Esta primera definición se refiere a dinámicas intra-mundos, por así decirlo; es decir, peculiares a una ontología dada. [...] [...] En segundo lugar, la ontología política es un campo de estudio que investiga dichas construcciones de mundo y negociaciones (al interior de un mundo particular); pero, por igual, los conflictos que surgen cuando los diferentes mundos luchan por mantener su propia existencia y perseverar, como parte del proceso de interactuar y entreverarse con otros mundos." (Blaser, 2009 en imprenta en Escobar, 2015:97)

La ontología política está enfocada por un lado al estudio de las relaciones intramundos, es decir las negociaciones e interacciones de las entidades que conforman ese mundo, pero no sólo se queda ahí, sino que avanza y estudia las relaciones e interacción que existen con otros mundos (inter-mundos), mostrando de esta manera que el carácter esencial de la ontología y la ontología política es el estudio de las relaciones y las consecuencias de éstas, es así que surge la práctica política ontológica. Ésta puede entenderse en un primer inicio como un concepto cercano a la Política cultural que buscaba poner de relieve tanto la dimensión política de la cultura como la dimensión cultural de la política. Sin embargo, y es aquí donde la transformación es radical frente al pensamiento europeo: lo que se comprendía hasta ahora como cultura hoy es ontología, es decir, se valida la construcción de un mundo distinto y ya no sólo de perspectiva diferente, sino una realidad diferente.

Esta afirmación asume varias cuestiones, por un lado, que la ontología se construye gracias a las prácticas de las entidades que conforman un mundo, pero a su vez y en forma de espiral esa ontología (ese mundo) me hace actuar de un modo específico. Además, esto asume que no hay cosa tal como UN mundo real objetivo al que puedo acceder de manera parcial, es decir no hay una naturaleza constituida por hechos irrefutables, sino que existen mundos construidos por las relaciones de las entidades que lo conforman. De tal suerte que lo que, dentro del pensamiento tradicional, que a partir de ahora se entenderá como la 
ontología dual, se concebía como una perspectiva más de aquella realidad objetiva, dentro de la ontología del pluriverso es la construcción de un mundo diferente más no separado, pues la prioridad, y aquí entra la práctica política ontológica, es la relación intra e inter mundos.

Escobar establece así que la pregunta más importante de la política ontológica es: ¿qué tipos de mundos se enactúan a través de qué conjuntos de práctica (con cuáles consecuencias para cuáles grupos particulares de humanos y no-humanos)? Esta propuesta busca una nueva forma de comprender la relación entre política y ontología, donde prima justamente LA RELACIÓN y es aquí donde se puede relacionar directamente con el pensamiento de Arendt y por lo tanto construir un puente más de entendimiento.

Para Hannah Arendt la vida activa es la vida que busca la inmortalidad mundana, la permanencia en el mundo de los seres humanos, en su cultura. La vida activa es aquélla que busca y encuentra su desarrollo en el mundo de las apariencias o en el mundo fenoménico, aquel mundo en el que se da la existencia. El ser humano encuentra su completo desarrollo en la vida activa, pues es aquí donde puede relacionarse; estar frente al otro; estar en movimiento y aparecer (Arendt: 2002).

La construcción del mundo se logra a partir del desarrollo de la vida activa, puesto que es un mundo fenoménico en el que el aparecer es indispensable. Por lo tanto, se puede concluir que la vida activa es la vida más perfecta a la que puede aspirar el ser humano.

Algunos podrían decir que esto ya existe en Aristóteles y su propuesta del zoon politikon, pero la originalidad de Arendt radica en el concepto de relación, pues para ella no es que el ser humano tenga en su naturaleza ser político, sino que naturalmente es un ser fenoménico, es decir, que aparece y para que pueda aparecer es necesario que haya un receptor. 
El mundo es la conjunción de apariencias que no pueden existir si no se le aparecen a algo y la política, entonces, es la relación entre el ser que aparece y el ser que percibe. La política es el entre que se crea con la aparición de los sujetos; la naturaleza social del hombre, el zoon politikon aristotélico se fundamenta en la relación de los sujetos, que no tiene que ver únicamente con la supresión de necesidades a través de la comunidad, sino con la relación de intereses comunes. Esto es lo mismo que para los autores de los estudios pluriversales, pues se comprende que el mundo es relacional, todo inter-existe; para Arendt porque todo aparece y para Escobar y Blaser porque toda relación enactúa (construye) un mundo.

Siguiendo con el pluriverso en Sentipensar con la Tierra. Nuevas lecturas sobre desarrolla, territorio y diferencia (2015) de Escobar además de explicar las definiciones que hasta ahora se han mencionado, hace una crítica a la ontología tradicional que considera dual, donde las similitudes con el pensamiento arendtiano son cada vez más grandes y hacen posible establecer un nexo con la filosofía para la paz de Vicent Martínez Guzmán, como se detallará.

En el libro la propuesta central, que es «invertir la evaluación usual del conocimiento: por un lado, hacer visibles y valorar los conocimientos otros de los movimientos sociales; y por el otro, al hacerlo, contribuir al debate sobre otras políticas rurales, sociales, ambientales y culturales posibles» (Escobar, 2015:15), surge de la intersección de dos problematizaciones: la primera, la problematización de las identidades "nacionales" que tuvo y tiene como resultado el surgimiento de voces, conocimientos, prácticas y estrategias políticas de organizaciones y movimientos sociales de corte étnico-territorial. La segunda, la problematización de la vida que tiene sus raíces en las discusiones sobre la crisis de la biodiversidad y la sustentabilidad de los años noventa. Ambas se han desarrollado casi a la par, dando cabida a multiplicidad de perspectivas para comprenderlas. Sin embargo, el autor 
aboga por comprenderlas como una intersección históricamente crucial. De manera burda se pueden comprender las dos problematizaciones y su relación a través de dos preguntas: la primera ¿cómo podemos defender (juntos) nuestro territorio? Y la segunda ¿cómo podemos sobrevivir (juntos) en este territorio?

De la primera problematización Escobar intenta mostrar cómo la defensa ha hecho posible la organización en torno a la tierra, que se reconfigura como territorio gracias a la recuperación de cultura y la movilización de sus habitantes para esa defensa, pero que esto más que una mera resistencia a los poderes del capital y el mercado, es una verdadera configuración de una ontología relacional que emerge para hacer frente a esa otra ontología dualista moderna del Mundo-Uno.

De igual manera, la primera problematización sienta las bases de la segunda problematización entorno a la vida, pues a pesar de que es una ontología basada en el territorio no está limitada a ellos, habla de los territorios, comprende que la relación entre los seres humanos y su territorio genera una forma de ser y hacer, no sólo de ver, es decir genera ontología y no sólo cosmovisión.

Esta perspectiva de las sociedades relacionales que presenta Escobar, sirve también para responder (de manera pluriversal) a preguntas entorno a la violencia a la que son sometidas las comunidades indígenas, afro o campesinas entre otras, pues se ve que la guerra no sólo es por la tierra, sino por el territorio que es sinónimo de mundo, por eso es una batalla contra ese mundo en el que caben muchos mundos. La guerra en la que estamos hoy, desde una perspectiva filosófica, es una guerra de la ontología dualista moderna contra la ontología relacional.

Ahora, por ontología dualista (OD) se entiende aquello que separa «lo humano y lo no-humano, la naturaleza y cultura, el individuo y comunidad, nosotros y ellos, mente y 
cuerpo, los secular de lo sagrado, razón y emoción, etc.)»(Escobar, 2014: 76). Es esta ontología la que se ha dado «el derecho de ser "el” Mundo (civilizado, libre y racional)» (Escobar, 2014: 76) y es más consolidarse como UN Mundo, que hoy llega a su máxima expresión con la llamada globalización neoliberal de corte capitalista e individualista. Es la ontología en la que se fundamenta gran parte del pensamiento europeo, la filosofía de conquista, parte importante dela filosofía occidental y el pensamiento colonial.

Esta ontología ha destrozado la base ontológica-territorial de muchos otros grupos sociales, principalmente aquellos en los que no primaban estas separaciones o construcciones binarias de la realidad, la mayoría en Latinoamérica.

La OD tiene cuatro principios fundamentales en los que desarrolla todo su actuar: la creencia en el individuo, en la economía, en lo real y en la ciencia, conceptos considerados como principios y por lo tanto desde la lógica moderna imposibles de cuestionarse, incluso se podría decir que para una mente moderna es absurdo hacerlo, imposible negar mi existencia como moderno, ¡se está cuestionando la base fundamental de la existencia del ser moderno: el "cogito ergo sum" de Descartes.

Es importante destacar que Escobar presenta los principios de la Ontología Dualista como creencias para «denotar el hecho de que no son la única forma de ser/pensar sobre estas dimensiones, sino que son formas históricamente específicas, "invenciones”, por así decirlo, de la ontología moderna» ${ }^{128}$ (Escobar 2015: 113) que nos ayudar a situar al mundo moderno como uno más dentro del pluriverso y no ya como El Mundo que todos por lo menos desean.

\footnotetext{
${ }^{128}$ Es justamente esta afirmación la que más adelante ayudará a comprender los nexos del pluriverso con la filosofía para la paz, pues las invenciones del mundo moderno, al considerarse como tales abren la puerta a que puedan ser transformadas, y las paces son nuestra capacidad de transformar lo que nos hacemos los unos a los otros.
} 
Ahora, sobre la creencia en el individuo, Escobar lo presenta como una de las invenciones más dañinas dentro de la tradición racionalista, pues se nos presenta (a los seres humanos) como «seres separados, autónomos dotados de "derechos" y de "libre voluntad"» (Escobar, 2015: 113). Sin embargo, los estudios etnográficos en muchas partes del mundo muestran cómo las personas son entidades relaciones, incluso el mismo pensamiento europeo lo establece así, tal es el caso del zoon politikón de Aristóteles o la relación en Arendt que se han usado en esta investigación. La creencia de considerarnos como entidades separadas encuentra de manera inmediata en la experiencia, su error, nuestro nacimiento lo pone en cuestión, sin la relación de nuestros padres sería imposible nuestra propia existencia.

Ya no es el pensamiento el que otorga o "valida" nuestra existencia tal como lo presentaba Descartes, es la relación de nuestros padres y la relación con nuestra madre la que la valida. Lo que se está diciendo es que no existe un pensamiento que fundamente la existencia de las entidades, sino que la existencia está validada con el otro. No hay un yo sin un tú y la relación de ambos es el fundamento de la existencia. Nuevamente para un individuo moderno esto es un gran shock, pero basta con mirar a nuestro alrededor, recordar los acompañamientos que algunos de nosotros hemos hecho para darnos cuenta que hay millones de personas que no piensan ni actúan así, que lo que se describe como una gran propuesta innovadora en el pensamiento, no es más que la simple vida cotidiana de millones de personas.

La creencia en lo real es quizá una de las más complejas de analizar, o por lo menos así ha sido para mí. Dentro de la tradición racionalista la evidencia de un mundo material que nos excede se ha traducido como la existencia de una "realidad objetiva" que existe por separado de nosotros, que pre-existe a las relaciones de las entidades que lo conforman. Esto tiene como consecuencia la separación binaria entre sujetos/objetos y naturaleza/cultura que 
provocan relaciones de dominación que enactúan un mundo donde la colaboración y el flujo con lo no-humano se vuelve prácticamente imposible. Además, esto en términos epistemológicos tiene gran repercusión, pues la creencia en lo real necesita de la creencia en la ciencia que estudia esa "realidad objetiva" separada de todas las entidades que conforman el mundo.

La creencia en la ciencia como lo presenta Escobar basándose en Boaventura Do Sousa Santos (2007) «ha creado una monocultura del saber, cuyo resultado ha sido la hegemonía del conocimiento moderno y la invisibilización y descalificación de toda otra forma de saber»(Escobar, 2015: 114). Generando así una herramienta de dominación, exclusión y violencia en los tres niveles. La ciencia aparece de esta manera durante la época colonial y se mantiene hasta nuestros días, tal como Castro Gómez hace notar en su libro La hybris del punto cero (2008) que se ha usado en el capítulo III de esta investigación.

Por último, la creencia es otro elemento interesantísimo de analizar pues se fundamenta en el complejo proceso civilizatorio en ascenso desde el siglo XVIII y, que por supuesto, tiene raíces en el proceso colonial iniciado en el siglo XVI, donde se da la invención de algo llamado "“economía” como esfera separada de la realidad y como dominio de pensamiento y acción vinculada con tora potente ficción: el mercado autorregulado» (Escobar, 2015:114)

Estas cuatro creencias, cuatro prácticas, constituyen esa ontología dualista marcada fuertemente por la tradición racionalista. Sin embargo, es posible que sea complejo para aquellas que hemos sido educadas bajo este marco no preguntar: ¿es verdad que la naturaleza y los humanos funcionamos así? Y la respuesta desde la ontología relacional es que tal pregunta no puede ser resulta sin meternos en los juegos de «verdad y poder (episteme) de la modernidad; más bien nos remite a una posición ético-política que no puede ser demostrada, 
sino vivida en sus implicaciones prácticas y políticas» (Escobar, 2015:109), como se verá en el trabajo desde la Filosofía para la Paz.

Ahora, sobre la ontología relacional Escobar apunta que hay dos elementos clave a considerar: el primero, «el territorio como condición de posibilidad» y segundo «las diversas lógicas comunales que con frecuencia las subyacen» (Escobar 2015: 103), el análisis del segundo no se desarrollará a detalle pues excede los límites de esta investigación, aunque se hará una aproximación a través del concepto de comunalidad.

Para el territorio, Escobar utiliza como el ejemplo la Ley 70 de las comunidades negras en Colombia, que según el autor está anclada en un entendimiento profundo de la vida (fundamentada en la relacionalidad);

[...] pone en funcionamiento una estrategia política de avanzada en el contexto regional y nacional en muchas áreas (por ejemplo, frente a los derechos de los grupos étnicos, la consulta previa, las actividades extractivas y el proceso de paz actual); evidencia una aguda conciencia de la coyuntura planetaria, cada vez más ineludible y amenazante, por la que atravesamos (cambio climático global y destrucción acelerada de la biodiversidad) y frente a la cual se imponen cambios radicales en el modelo de economía y desarrollo (que en América Latina algunos llaman "transiciones al post-extractivismo", y otros como "cambio de modelo civilizatorio"); y, manifiesta un sentido de utopía realista en relación con la gran multiplicidad de entramados humano-naturales que tendremos que seguir cultivando los humanos desde lugares específicos del planeta para promover las transiciones a "un mundo donde quepan muchos mundos". (Escobar, 2015:81)

Walter Porto Gonçalves establece las distinciones entre territorio, territorialización y territorialidad que permitirá comprender mejor la dinámica de la práctica política ontológica:

el territorio es una categoría densa [espessa, en el texto original en portugués] que presupone un espacio geográfico que es apropiado, y ese proceso de apropiación - territorialización - crea las condiciones para las identidades territorialidades - las cuales están inscritas en procesos, siendo por tanto dinámicas y cambiantes, materializando en cada momento un determinado orden, una determinada configuración territorial, una topología social (Porto Gonçalves, 2002:30). 
El territorio es por tanto material y simbólico al tiempo, biofísico y epistémico, pero más que todo es un proceso de apropiación socio-cultural de la naturaleza y de los ecosistemas que cada grupo social efectúa desde su "cosmovisión” u “ontología”. (Escobar, 2014: 91). A su vez esto nos permitirá reconfigurar el espacio geográfico liberal moderno por una geo-grafía, es decir por las nuevas grafías de la tierra que se van configurando y están en constante movimiento.

Es de suma importancia destacar que para Escobar, y otros autores en los que apoya su argumentación, como el antropólogo inglés Ignold (2000), el uso del concepto ontología en lugar de cultura, que es el que ha estado durante más tiempo en los debates, se debe a que este segundo concepto es limitado y no logra salir de la lógica de la modernidad, pues comprende como Uno el mundo natural, mientras la cultura son solo perspectivas para ver ese mundo natural objetivo que es estudiado por las ciencias exactas, relegando a un segundo nivel a la política como estudiosa de las perspectivas.

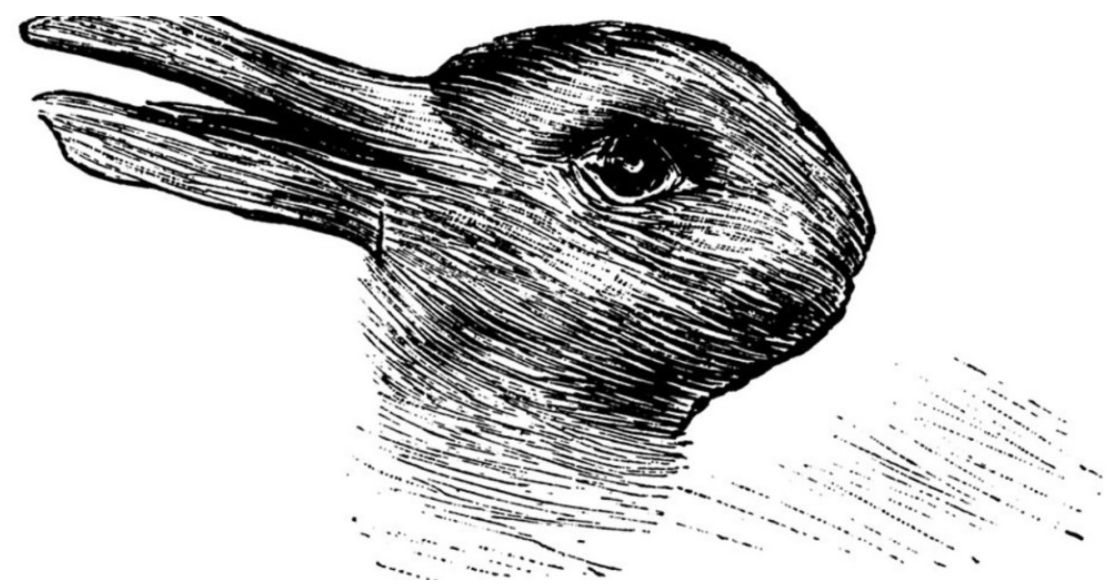

(Imagen tomada de Blaser, 2016: 557) 
Mario Blaser utiliza esta imagen para mostrar de manera simple cómo es que funciona el pluriverso en términos reales y su relación con el mundo material que excede el concepto de cultura y la razón por la que es necesario hablar de ontologías.

Por un lado, la imagen muestra un conejo mirando a la derecha y un ave mirando a la izquierda, la pregunta sería ¿qué es más real, el conejo o el ave? ¿Hay una realidad o dos? Y más aún ¿podría existir el pato sin el conejo? Las respuestas son complejas e intentaré darlas de manera simple. Por un lado, son tan reales el pato como el conejo, sin embargo no llegan a ser dos realidades, son más de una pero no llegan a dos, puesto que comparte un mismo espacio material que pone de relieve, no ya la verdad de su existencia, sino la relación entre ambas imágenes y así se contesta la tercera pregunta; no pueden existir, en esta imagen, en este mundo, el ave sin el conejo, una configuración distinta de la relación entre ambas produciría a su vez otra realidad, otro mundo y una nueva forma de existencia para ambas. Esto pone de manifiesto nuevamente que lo más relevante dentro del pluriverso es la enacción de los mundos y lo que de ella surge. En otras palabras, no hay verdad en la realidad ni búsqueda de ella en la filosofía, sino sentido y por lo tanto desde la filosofía para la paz hay posibilidad para pedir y dar razones sobre nuestro actuar tanto con lo humano como lo no humano.

Bajo esta mirada, la "verdad" de las ciencias modernas, europeas y seculares queda entredicho y se establecen sólo como una estrategia más de dominación y por lo tanto de violencia, Escobar lo define con mucha precisión:

Por un lado, [con la cultura] se afirma la unicidad de la realidad (solo existe Un Mundo natural); segundo, se postula la existencia de múltiples concepciones de este mundo, es decir, de "culturas" que "conocen" esta realidad única de diversas maneras (relativismo cultural); y tercero, toda la operación es legitimada por la existencia de una supra-racionalidad ("razón universal"), que solo el occidente posee en su grado más alto y que es la única garantía de verdad sobre esa realidad». De este modo, «la antropología se embarca en el estudio 
comparativo de visiones de mundo culturalmente específicas, mientras que la ciencia investiga el funcionamiento de la naturaleza» (Ingold, 2000, p. 15).

Hacer el cambio y comprender los estudios de la antropología, la sociología y la filosofía entre otras, desde la ontología política, abre las puertas a comprender la realidad pluriversal donde hay muchos mundos que se mueven, cambian y transforman de acuerdo a las prácticas de las entidades que lo conforman (no individuos). Esto constituye, a mi juicio, uno de los actos más revolucionarios dentro del pensamiento filosófico, pues se pone en cuestión uno de los principios fundamentales del pensamiento eurocentrado, la existencia de un mundo real objetivo. Y como Blaser apunta, «este cuestionamiento crea la posibilidad de todo un campo de ontología política como única salida para evitar ser capturados en la trampa epistémica de la visión dominante de la modernidad»(Blaser, 2010 en imprenta en Escobar, 2015:107)

Ahora, regresando a la relacionalidad, se comprende en la existencia misma de la realidad donde es fácil ver que nada (ninguna entidad) pre-existe a las relaciones que la constituyen por lo tanto todo está interconectado, interrelacionado, nada existe por separado. Pensemos en la paradoja tradicional sobre el origen de las cosas: ¿qué fue primero el huevo o la gallina? Bajo la ontología dualista la respuesta elige a uno de los dos como el origen, mientras que la ontología relacional nos abre la mente para tratar de ver todo lo que hay entre un huevo y una gallina, es decir, el origen de ambos es la relación de ambos, no hay huevo sin gallina, ni gallina sin huevo, nada pre-existe a las relaciones que lo constituyen ${ }^{129}$.

Asumiendo esto, se puede llegar a la política y la ética como temas centrales de la filosofía sin pasar, como sucede con Arendt, por una justificación de la vida activa, sino que

${ }^{129}$ El ejemplo es mío para mostrar la complejidad de comprender el origen como relación. 
se establece como el centro del pensamiento, ya que ahora somos lo que nos hacemos. De tal suerte que analizar el concepto de violencia y paz se vuelve tan antropológico como ontológico, y por supuesto político, cuestión que sin lugar a dudas tiene impacto directo en la gobernabilidad de un territorio y el espacio donde existe la filosofía para la paz.

\section{La filosofía para la paz desde la ontología relacional}

¿Qué es entonces la verdad? Una hueste de movimiento de metáforas, metonimias, antropomorfismos, en resumidas cuentas, una suma de relaciones humanas que han sido realzadas, extrapoladas y adornadas poética y retóricamente y que, después de un prolongado uso, un pueblo considera firmes, canónicas y vinculantes; las verdades son ilusiones de las que se han olvidado lo que son: metáforas que se han vuelto gastadas y sin fuerza sensible, monedas que han perdido su troquelado y no son ahora consideradas como monedas, sino como metal (Nietzsche, 1980, p. 10)

Gracias al giro ontológico que propone la ontología relacional considero que se puede desarrollar la filosofía para la paz de manera más efectiva. La crítica a la modernidad que se encuentra dentro de la fundamentación de Martínez Guzmán (2001) es profunda, pero sigue sin romper con el discurso hegemónico del eurocentrismo. Sin embargo, si se establece la ontología relacional como fundamento, dar y pedir razones de nuestras acciones se vuelve necesaria, y más aún, se abre el diálogo con conocimientos otros de manera fluida.

La cita que abre este apartado es una frase que el mismo Martínez Guzmán utiliza para iniciar su crítica a la modernidad y se enfoca principalmente en mostrar cómo la verdad no es otra cosa que las metáforas intuitivas que los seres humanos han creado de las cosas mismas. «Nadie dispone de la percepción correcta en una disputa de percepciones» (Martínez Guzmán, 2001: 85) y reafirma «hemos de asumir la capacidad fantástica del hombre como sujeto artísticamente creador», de esta manera, el autor intenta abrir la puerta hacia lo que en esta investigación se ha denominado ontología relacional, donde las metáforas e historias (la 
tercera dimensión de la ontología política) son las que condicionan la acción y que el error está en considerar esa creación humana como verdadera por encima de las demás.

El intelecto, del que los seres humanos nos sentimos tan orgullosos sólo tantea el dorso de las cosas, no su verdad. Se nos ha hecho creer que la verdad era la referencia adecuada a las cosas. En cambio, hemos sido los mismos seres humanos los que hemos inventado las maneras de designar a las cosas y después consideramos verdadero al hecho de que nuestras designaciones funcionen como las designaciones que hemos arbitrado que sean. (Martínez Guzmán, 2001: 84)

A partir de aquí, hacer una epistemología de la paz desde los estudios pluriversales supone, a mi juicio un avance en la filosofía para la paz, haciéndola más necesaria y al mismo tiempo más accesible, además de promover un camino innovador en la construcción de paz.

En el capítulo III se ha hecho una crítica a una esquematización propia del pensamiento de Vicent Martínez Guzmán que considero necesario ampliar, transformado la fundamentación kantiana de su propuesta con la ontología pluriversal.

Los manuales de historia de la filosofía occidental apuntan a la Grecia clásica y a los siglos VI y V antes de Cristo como el momento de aparición de la conciencia de la capacidad de los seres humanos de dar razones de lo que sucede en la naturaleza -razón teórica-, pero sobre todo, de la capacidad de dar razones y de exigirnos razones uno a otros de las normas que rigen nuestra conducta -razón práctica. Según mi interpretación, con este descubrimiento de lo que llamamos la filosofía heredada de los griegos, la especie humana ha de asumir la responsabilidad y el compromiso derivados del descubrimiento de la autonomía de la racionalidad. (Martínez Guzmán, 2001:17)

Asumir al pensamiento occidental como descubridor de la racionalidad humana no sólo es un error en términos históricos, sino que es un error en términos éticos, pues justamente otorgarle a la razón, y no a la relación, la capacidad de dar y pedir razones de nuestras acciones vuelve a poner de manifiesto una cierta superioridad de la racionalidad. Justamente esta superioridad es la que establece en la epistemología una jerarquización del saber, además de seguir asumiendo a la realidad como separada y desconectada de nosotros. La añorada 
búsqueda del compromiso y responsabilidad queda confinada a la buena voluntad de la razón y no a la existencia misma del ser en la pluralidad.

Como ya había escrito, la epistemología del pensamiento occidental, tal y como se ve desde la ontología de Immanuel Kant, que a mi juicio puede ser considerado como uno de los máximos representantes de la ontología dual por su añoranza de sistematizar la filosofía al modo de las matemáticas, se atribuye el descubrimiento del deseo de emancipación como acción necesaria de la razón. En su texto ¿Qué es la Ilustración? (1979) Kant busca la emancipación y la transformación del poder político como una acción congruente con el ejercicio de la razón, el problema es que la razón de Kant es una razón desconectada, individual y dominante, además de que asume los valores del Estado prusiano como inherentes a la naturaleza y por lo tanto accesibles a la razón. Su sistematización y especialmente el sapere aude es ejemplo perfecto de la ontología dual como una herramienta de dominación, pensar por ti mismo es otorgarle a la razón individual un carácter central en la conformación del mundo, haciendo imposible el diálogo con todas aquellas visiones que no se adecuen a esta visión.

Fundamentar la acción ética comprometida y responsable, tal y como busca Martínez Guzmán en la filosofía para la paz, en el desarrollo de aquella razón individual limita enormemente el diálogo y requiere necesariamente de establecer valores éticos que pueden o no ser compartidos y que muchas veces caen en una solidaridad jerarquizada como cuando se habla de "saberes" y no de conocimiento. La razón kantiana no puede ser el fundamento de relaciones capaces de construir la paz en el más amplio sentido de la palabra, eso sólo puede comenzar a gestarse si desde el origen se comprende que somos relación y movimiento, no razón deductiva. La misma crítica de Martínez Guzman a la modernidad y la superioridad del intelecto con su afán de verdad contiene la semilla de lo que hasta ahora 
he dicho, sin embargo, en este autor hay una visible tensión entre su formación dentro del pensamiento eurocéntrico que busca la universalidad, y lo que su búsqueda de las paces le ofrece, que se acerca mucho más al pluriverso.

Otra crítica es el tipo de filosofía que se quiere hacer desde la filosofía para la paz, pues nuevamente quiere dotarla de un carácter universal que sea igual para todos los seres que habitan el mundo, sobre todo el punto tres y cuatro.

La reconstrucción de la filosofía deber ser:

- Crítica: para que nos permita ver los engaños de la comunicación

- Constructiva: interdisciplinar para ampliar el horizonte de análisis

- Teórica: para encontrar vías para una descripción universal

- Trascendental: al modo kantiano.

Bajo la ontología relacional la única vía de construcción epistemológica radica en análisis de las relaciones que conforman el mundo que se desea analizar, por lo tanto, más que teoría, la filosofía desde la filosofía para la paz tiene que ser política y estar íntimamente ligada a los movimientos sociales, así como a las diversas formas de manifestación del poder.

En este esquema es interesante recordar la propuesta de Boaventura de Sousa Santos:

Las teorías adecuadas a la rebelión son las teoría de retaguardia, las teorías que acompañan la práctica revoltosa para facilitar los intercambios de experiencias y la densificación de su sentido, para ampliar las señales las señales emergentes que dan fuerza a la lucha y hace creíbles los esfuerzos y los riesgos, para criticar la novedad que se disfraza de rutina y la rutina que se disfraza de novedad, para ayudar a los que caminan más despacio y evitar que se pierdan y que su andar los encamine hacia la contrarrevolución. (Boaventura de Sousa Santos, 2015:21)

La cita de Sousa Santos es riquísima pues muestra un camino para que el trabajo académico y la teorización no caiga en su desconexión de la realidad, sino que sea fiel y crítico acompañante de los movimientos para así ver, en primera línea, los mundos que se van entrelazando. La filosofía para la paz debe centrar su quehacer en la práctica política 
ontológica, es decir en la observación y análisis de las diversas relaciones que emergen de la interacción intra e intermundos del pluriverso.

La transformación que supone el uso de la ontología relacional (estudios pluriversales) afecta sin lugar a dudas el concepto de trascendentalidad kantiano que recoge el pensamiento de Martínez Guzmán, pues ya no hay necesidad de acercarse al noúmeno, alejarse de las limitaciones del pensamiento para acercarse al conocimiento verdadero, pues ya no hay conocimiento verdadero, hay relación, movimiento interacción y constante transformación, que además asume la imposibilidad de quitarnos la circunstancia al pensar.

Dentro de la propuesta de Martínez Guzmán hay una clara recuperación de Kant y podemos destacar tres puntos:

- El principio filosófico kantiano sobre la necesidad del uso de la razón práctica.

- Comprender la paz como el ejercicio de la racionalidad práctica de Kant.

- Comprender la paz perpetua no como estado al que llegar sino como una forma de dirimir los conflictos, de esta manera nuestra paz se transforma en paces.

Es interesante ver cómo en la misma recuperación que Martínez Guzmán hace de Kant intenta desvincularse del ejercicio de la razón pura, como si intuyera que ahí se encontraba gran parte de sus problemas y que era imposible tomar su visión ontológica como fundamentación de la filosofía para la paz.

La racionalidad práctica emerge entonces, quizá vista desde el propio Kant, como el fundamento de la posibilidad de construir juntos una realidad diferente, sólo que el uso de la razón pura como fundamento último era necesario en la construcción de un sistema universalizante. Es interesante ver cómo muchos de los pensadores occidentales clásicos se daban cuenta de la importancia de la relación por encima de la sustancia en el análisis de la realidad, pero les era imposible dejar de buscar la esencia fuera de ella. 
Ahora, considero necesario releer la esquematización sobre la Filosofía para la paz que he propuesta en el capítulo III pero tomando como fundamento la ontología relacional y se verá que no sólo encaja mejor en términos teóricos, sino que abre la puerta a una interpretación innovadora del quehacer filosófico y el compromiso de éste ante los mundos del pluriverso.

La Filosofía para la paz ${ }^{130}$ :

15. Comprende la necesaria reconstrucción y reconfiguración de la filosofía, renunciando primero al orgullo epistemológico que pretende un pensamiento universal y, segundo, al orgullo etnocéntrico europeo, para transformarlos respectivamente en compromiso y responsabilidad. Establece como marco teórico, para llevar a cabo esta reconfiguración, la cosmología social occidental, que bajo esta relectura se presenta ya no como el paradigma de verdad sino una ontología más dentro del pluriverso y que comparte bases fundamentales con lo que hasta ahora se ha definido como ontología relacional.

16. Elimina principios y paradigmas filosóficos: establece que el objeto de la filosofía no será ya la sustancia (ser) sino la relación y en este sentido pasa de la heteronomía a la autonomía (fincar razones que nos responsabilicen). Filosofar será, en este marco, la capacidad de razonar; dar y pedirnos cuentas de nuestras acciones. Aquí no sólo se comprender mejor la propuesta, sino que gracias a la ontología relacional se presenta como evidente.

17. Establece que razonamos para encontrar unos mínimos éticos, unos ideales regulativos que nos permitan criticar nuestras acciones. Que lo hacemos a través del análisis de nuestros discursos, para hacer una reconstrucción racional de la comunicación. Y lo hacemos porque intentamos comprender el sentido del ser humano. Si se asume que nuestras relaciones construyen y transforman los mundos, la búsqueda de mínimos está dada dentro del mismo cuestionamiento sobre nuestras acciones, nunca antes la política, la ética y la ontología estaban tan intrínsecamente unidas.

18. Se seguirá usando la división kantiana entre razón práctica y razón teórica para:

a. Reconocer las razones de la naturaleza: comprender la realidad como aparece a nuestro entendimiento.

b. Reconocer las razones de nuestras acciones: para comprender el sentido de nuestras acciones y responsabilizarnos de ellas.

19. Define a la filosofía como: «una reconstrucción normativa de las competencias de los seres humanos para hacer las paces, con atención vigilante a las razones y sentimientos que se expresan desde las diferentes investigaciones para la paz.» (Martínez Guzmán, 2001:24)

20. Establece que la filosofía como metodología es una «autocrítica hacia los desarrollos unilaterales de la racionalidad, como lo es hacia su occidentalidad,

${ }^{130}$ He eliminado de esta esquematización los puntos críticos pues líneas arriba ya se han analizado. 
usando elementos de denuncia de la relación entre racionalidad y poder como Foucault, deconstruyendo y reivindicando las diferencias y los márgenes como Derrida, reconociendo las limitaciones contextuales de la razón situada como Rorty.» (Martínez Guzmán, 2001:24)

21. La filosofía se comprende como universalidad comunicativa, como capacidad de comunicación al estilo de Habermas. Sin embargo, el diálogo intercultural que se propone intentar priorizar la comprensión intercultural de la realidad y, más aún la comprensión pluriversal.

22. La filosofía se comprende a su vez como actitud performativa, como paso a una perspectiva autorreferencial reflexiva y transcendental, esto quiere decir que es debe ser crítica, abierta y en movimiento, no lineal y sistemática. Tal y como propone Boaventura con las teorías de retaguardia.

23. Los usos de la razón práctica (al modo kantiano, es decir la razón del actuar) se dividen en tres y cada uno tendrá dos usos dentro de la propuesta de Martínez Guzmán:

a. Estratégico, responde a dos preguntas. Su origen está en la filosofía y su resultado es la poética (del logos a la praxis)

i. ¿Qué quiero?

ii. ¿Cuál es la mejor estrategia para alcanzar lo que quiero?

b. Ético (costumbre): responda a una pregunta y otorga tres lentes. Su origen esté la capacidad crítica y su resultado es la performatividad

i. ¿Por qué quiero lo que quiero?

1. Contexto

2. Situación (al modo existencial de Beauvoir)

3. Circunstancia

c. Moral: que responde a dos peguntas. Su origen está en la educación y su resultado es la democracia participativa.

i. ¿Afecta lo que quiero a los demás?

ii. ¿Cómo hago que lo que quiero sea justo?

Estos usos responden a una interpretación de la propuesta ética de Kant, asumiendo, también su parte más peligrosa: «si todos podrían querer que en mi situación cada uno actuara según las mismas máximas», pero que bajo la ontología relacional adquiere un matiz que lo transforma, pues actuar es parte de esa espiral que construye mundos y los transforma. Ya la pregunta no es si tenemos las mismas máximas, sino que consecuencias nos creamos con nuestro actuar.

24. La filosofía, recogiendo lo anterior es ahora una herramienta de los Estudios para la paz, ya que a través de la teoría crítica de la occidentalidad está obligada a un diálogo intercultural con las teorías de la democracia, la educación para la adquisición del punto de vista moral. Así se establecerán dos principios fundamentales para el quehacer filosófico de la paz:

a. Nueva definición de persona como sujetos de actos de comunicación en el marco de un reconocimiento universal de los derechos de interlocución

b. El sentido de la responsabilidad solidaria manifestada en las razones que damos al comunicarnos y los compromisos que al hablar 
asumimos como los seres humanos, para superar el sentido de la solidaridad emotiva; la caridad.

25. Ya que la filosofía se establece en gran medida como metodología será una reconstrucción racional constante de la comunicación que se aplicará a los cuatro ámbitos principales de los estudios de paz:

a. Johan Galtung y su teoría de las violencias y la paz imperfecta de Francisco Muñoz.

b. Sistema-mundo de Immanuel Wallenstein

c. Códigos de Paz de Dorothy V. Jones

d. Concepto de seguridad en la Guerra Fría y años posteriores.

Es así que se puede concluir que la paz, o mejor dicho la filosofía para hacer las paces, esta fincada en la posibilidad de un diálogo intercultural, constante y permanente, en donde la construcción de argumentos se dé de manera intersubjetiva, y la forma de decirlos sea empática. Donde se comprende la concepción de bien común como búsqueda de convivencia activamente armónica y se comprenda la capacidad de construcción y transformación de los mundos en el pluriverso que tienen nuestras relaciones.

\section{La comunalidad una propuesta de construcción de paz}

La palabra sin acción es vacía. La acción sin palabra es ciega. La palabra y la acción fuera del espíritu de la comunidad son la muerte. Pensamiento tradición Nasa

Dentro de ese pluriverso existe un mundo, el indígena, que presenta un ser/hacer completamente distinto de lo que se ha construido en Occidente ${ }^{131}$, ese mundo está fundamentado en la ontología relacional, pero en la experiencia cotidiana aparece, a mi juicio, su gran complejidad, pues aparece como un mundo en resistencia frente al olvido, la muerte y la violencia, que se ha enfrentado durante siglos a ese otro mundo que quiere

\footnotetext{
131 Por Occidente hago referencia a la construcción del mundo dual donde el capitalismo y la colonización son elementos fundantes de la espiral de relaciones que venimos construyendo en lo que Boaventura De Sousa Santos llama el Norte Global.
} 
desaparecerlo y que para muchas personas hoy, es nuestro motor de inspiración, aunque estemos lejos aún de entender sus verdaderas implicaciones; ese es el mundo de la comunalidad.

La comunalidad es la palabra mediante el cual los teóricos (de retaguardia) Florentino Díaz, indígena mixe y Jaime Martínez Luna (2003), indígena zapoteco, presentaron la vida y lucha en sus comunidades a finales de los setenta. En principio y como palabra, tal como propone Gustavo Esteva (2014) les salió de manera natural y se correspondía directamente con la vida cotidiana en sus comunidades, incluso cuando la usaban entre ellos, no requerían explicación alguna, el problema de la comunalidad como palabra (como enunciación), surgió cuando alguien que la escuchó no comprendió plenamente a lo que se refería.

Así surgió la comunalidad como término para buscar un terreno común con aquellos que necesitaban una explicación. Según Esteva, Díaz y Martínez Luna los primeros intentos no se lograron bien, puesto que «se trata de la contradicción existencial que inevitablemente experimentaban al tratar de convertir su notable hallazgo en algo contrario a su naturaleza». Esteva es tajante al decir que «como palabra, la comunalidad no es definible... todo intento de definición implicaría una reducción al plano abstracto y lógico, que puede ser útil para diversos propósitos, pero no es pertinente ni aceptable para abordar la palabra» (2014:177). Sin embargo, como término apunta que es posible su comprensión siempre y cuando el «respaldo del término no contamine su disfrute gozoso de palabra, que late al margen de la costra científica.» (2014:178). Así, presenta el trabajo de Arturo Guerrero y sus teorizaciones alrededor de la comunalidad como un camino imprescindible para adentrase en este concepto.

Es importante destacar que el trabajo de Martínez Luna entorno a la comunalidad desde su descubrimiento, a finales de los años setenta hasta hoy, suponen una de las bases fundamentales para profundizar sobre el tema. Sin embargo, considero ahora en esta breve 
introducción al concepto quedarnos solamente con una de sus aproximaciones:

Somos Comunalidad, lo opuesto a la individualidad, somos territorio comunal, no propiedad privada; somos compartencia, no competencia; somos politeísmo, no monoteísmo. Somos intercambio, no negocio; diversi- dad, no igualdad, aunque a nombre de la igualdad también se nos oprima. Somos interdependientes, no libres. Tenemos autoridades, no monarcas. (Martínez Luna, 2015: 17)

La cita abre la puerta para ver las dinámicas que dan forma a la comunalidad, pero tal y como propone Gustavo Esteva (2013) y Arturo Guerrero, debe quedar claro que ésta como mundo (palabra) se vive y ya (Guerrero, 2015: 113), no cabe ninguna teorización o explicación pues es experiencia cotidiana en algunas regiones del mundo, especialmente desde donde ambos autores escriben, la Sierra Juárez de Oaxaca. Mantener esa visión ha permitido que el carácter original e innovador de la palabra no se pierda.

Ahora, la comunalidad como relato es término y es una reflexión desde ese mundo que se vive y que puede ser puente entre lo comunal y la sociedad económica. Guerrero propone una metáfora para comprenderla:

El río corre. Contra una raíz del añoso árbol, un tronco o una piedra, choca su corriente y se forma un remolino, una espiral: la imagen de la Vida. Tal es la metáfora y la idea de lo complejo de Edgar Morin (2009) que deseamos adecuar libremente aquí. El fluir del río y los accidentes de la rivera generan al remolino. Pero el remolino logra su propia dinámica interna, distinta a la del río en general. Tiene existencia propia, un orden "adentro", relativamente estable, aunque moldeado por la corriente de "afuera". Sin embargo, no podemos separar al remolino del río. Vemos a la comunalidad como una espiral en la corriente del capitalismo, un modo localizado de construir la modernidad (Guerrero 2013: 42)

La propuesta de Guerrero y Luna establecen que la comunalidad aparece en el mundo como efecto de resistencia frente a la estructura que los ha oprimido, pero la emergencia de este mundo tiene propias dinámicas y movimientos al interior que van modificando así también su forma de relacionarse con el exterior, con ese afuera. Una espiral parece ser una forma acertada de reconocer dichos movimientos, pues muestra la tensión constante entre los 
límites de uno y otro. Justamente la adecuación resultante de esta tensión es el Nosotros Comunal.

El uso del Nosotros jamás ha sido tan adecuado, pues se establece como un nombre de la comunalidad y viceversa, ya que al surgir como reflexión al interior de las comunidades entorno a su propia experiencia, lucha y existencia, es intercambiable, es más preciso y adecuado que otros términos que han sido dados desde ese afuera como "cultura" o "identidad étnica" entre otros.

Además, esta enunciación de la vida cotidiana, aparece como resistencia también desde la narrativa hegemónica, proponiendo términos que encajan realmente con su realidad, pero es importante mostrar que la forma de enunciación se presenta también como un puente de entendimiento; enunciar el Nosotros comunitario exige, por un lado, el reconocimiento de los otros a los que aparece, y pide ese mismo reconocimiento que otorga desde la horizontalidad y el encuentro de las diferencias. Es claro que también al enunciar se puede traicionar lo vivido, es por eso que es necesario mantener la visión de que dicha enunciación solo puede darnos una imagen de la vida comunal, pero no nos puede decir qué es. Establece una relación de constante asombro, como si fuera un diálogo, pero que está en constante movimiento y cambio:

Para Arturo Guerrero, la paradoja comunal consiste en «conservarse cambiando, cambiar para permanecer y perdurar; adecuación primordial entre conservar y crear; renovación interminable de lo que no cambia». Es cierto: la mejor de las tradiciones de las comunidades indias es la tradición de cambiar la tradición de manera tradicional. Por eso siguen siendo quienes son, adaptándose a las más 
diversas circunstancias. Y Arturo concluye: En este carácter paradójico de la comunalidad reside sin duda el arte de vivir comunal (...) En la comunalidad, al habitar se le da existencia a lo que nos da existencia, realizamos lo que nos da realidad" (2005: 321 y 326). Por eso aprender a escuchar la palabra "comunalidad, sentipensarla, puede ser fuente primordial de inspiración para las tareas de hoy. Eso debería tratar de recoger, así sea indirectamente, el término comunalidad. (Esteva, 2015: 185)

La comunalidad aparece en 3 dimensiones que se ha construido en su relación con el exterior y a través de las cuales se configuran los movimientos en su interior. Estos tres son la Raíz, el acuerdo y el ejercicio. De manera rápida, la raíz se concibe como aquello que sostiene y nutre el mundo comunal, aquello que lo dota de sentido y que desde afuera se comprende comúnmente como mito; en ese horizonte en el que la gente orienta su vida encontramos la relación esencial entre la Madre Tierra / Territorio. Por otro lado, el acuerdo es ese campo de madurez de la comunidad donde se establecen las reglas decididas por todos, es la emergencia de la raíz como ley propia. Por último, el ejercicio es la realización natural de las personas y los seres en un Nosotros, es el espacio donde surge el reconocimiento, el intercambio y adecuación (Guerrero, 2013 y 2015).

Esta breve introducción a la comunalidad permite, aunque de manera limitada, hacer una aproximación a la importancia que tiene desde la filosofía para la paz y específicamente desde la añoranza y esperanza de la construcción de paz en escenarios violentos. Para ello es interesante recuperar también la propuesta de Raquel Aguilar Gutiérrez, donde establece una distinción entre "entramados comunitarios" a «la multiplicidad de mundos de la vida que pueblan y generan el mundo bajo pautas diversas de respeto, colaboración, dignidad, carió y 
reciprocidad, no plenamente sujetos a las lógicas de la acumulación, aunque agredidos y muchas veces agobiados por ellos.» (2012, p.3).

Dentro de estos entramados, como interpreta Escobar (2015), emergen como respuesta pacífica a la violencia, las luchas se ven en términos de auto-organización enfocada en la construcción de formas de poder no estatales, las cuales se manifiestan como micro gobiernos barriales o anti poderes dispersos; es decir, una territorialidad alternativa a la del Estado (Mamani, 2005, 2006; Zibechi, 2006). Son tipos de lucha que no aspiran a tomar el poder; sino a reorganizar la sociedad sobre la base de las autonomías locales y regionales, y que se caracterizan por la activación de relaciones sociales y formas de organización no capitalistas y no liberales. Se trata de «organizarse como los poderes de una sociedad otra» (Zibechi, 2006, p. 75 en Escobar, 2015: 65).

Así, la comunalidad vista desde el zapatismo se presenta como la construcción de una realidad donde las paces son fundamento de su existencia, son ejercicio que se realiza en cada acción, donde se excede la capacidad comunicativa como fundamento de la posibilidad de construir la paz, pues la misma existencia en la horizontalidad y el ejercicio permanente de relaciones no subordinadas ayudan a la consolidación de un mundo otro, donde caben muchos mundos. Todos se entre tocan, se enactúan, se reconfiguran dejándonos inmersos en un pluriverso donde la paz no sólo es posible y realizable, sino que como la comunalidad, se vive y ya.

\section{Conclusiones}

El último capítulo recoge la propuesta ontológica que emerge de la lucha de las comunidades indígenas; una teorización que además de poner en cuestión los principios fundamentales del pensamiento europeo propone un quehacer filosófico y académico distinto. 
Los estudios del pluriverso donde se enmarca el estudio de la ontología relacional frente a la del Mundo Uno surgen tanto de la crítica al desarrollo como la defensa de los territorios en diversas regiones del mundo, especialmente en Latinoamérica.

A modo de conclusión se puede decir que el giro ontológico que proponen estos estudios busca, por un lado, la recuperación del conocimiento no hegemónico, así como una fundamentación donde las relaciones de poder puedan transformarse desde los cimientos. Evidencia que la naturaleza no es un cúmulo de hechos irrefutables, sino que es una entidad más, afectada por las relaciones que mantiene con las otras entidades de su mundo, eliminando de esta manera la relación jerárquica entre sujetos y objetos y la construcción de binarios en la que está fundamentada la ontología del Mundo Uno.

El Mundo Uno es la manera en la que los estudios pluriversales presentan el mundo racionalista eurocéntrico y que domina, hasta nuestros días, los discursos políticos, científicos y éticos. Es un mundo totalizante que se impone frente a otros mundos con categoría de verdad y realidad, pero de la que carece incluso bajo sus propios principios, tal como lo muestran los cambios constantes de leyes científicas.

Inspirados en la crítica de los estudios postcoloniales y cómo influyeron en los estudios críticos al desarrollo, se presenta la ontología dual del Mundo Uno, como un mundo en el que prima la dominación y se tiene la razón del hombre (racionalidad masculina patriarcal) como centro. Se privilegia la individualidad por encima de la comunidad, la ciencia como garante de todo conocimiento y por ende se legitima la existencia de UNA realidad y finalmente se naturaliza la economía. Estas creencias provocan que las relaciones que enactúan este mundo construyan escenarios de dominación y violencia desmedido, como los proyectos extractivistas que se llevan a cabo principalmente en las comunidades indígenas. 
Frente a este mundo aparece el mundo de las ontologías relacionales, aquél donde configuran vínculos entre lo humano y lo no humano y que buscan la sostenibilidad por encima de las ganancias y donde la búsqueda de la verdad se abandona por la búsqueda del sentido en comunidad. Así aparece la propuesta ontológica política de la comunalidad que es, por un lado, la enunciación de la vida cotidiana de las comunidades en lucha frente a la ontología dual y, por otro, la vida que sólo se puede vivir en esas regiones y que es inefable desde la perspectiva académica.

Por último, en este capítulo se ha propuesto cómo fundamentar la filosofía para la paz ya no en Kant, sino en los estudios pluriversales y especialmente en la ontología relacional. Ello permite avanzar en una propuesta de construcción de paces no sólo más inclusiva, sino que supera la universalidad en la que la propuesta de Kant está fundamentada. 


\section{GENERAL CONCLUSIONS}

Throughout the five chapters this research has shown the importance of transforming the Western paradgimas of philosophy in order to search for the foundations of peace building in Mexico.

This way has made me analyze in the first chapter an overview of Mexico based on the statistics, the life stories, as well as a historiographic analysis in which emerge the six paradigms of violence that can help understand the scenario of violence and decadence that the country is living today.

One of the main elements to be highlighted in this chapter is the relationship between Spanish colonization and the neo-colonization of internal colonialism, as well as the war between relational ontology and the dual ontology that is beginning to be seen, although it is analyzed in detail until the final chapter.

It is worth remembering that the common elements that have stood out between the colonial period and the consolidation of the Mexican Nation-State are the -cides, those paradigms of violence in which the construction of the country is based: genocide, ecocide, culturicide, feminicide and deicide. There is one more that is not mentioned in detail in the first chapter because it crosses the other five but in chapter III, it is described in depth: the epistemicide.

These paradigms show that it was through massacres how the Mexican society was configured, making each -cide a principle in the way of acting and therefore building a world rooted in duality. It is pertinent to review each of these paradigms:

1. Epistemicide: it was the elimination of all knowledge outside the European scientific method where any kind of wisdom that was not objective and therefore generated a devastating split in knowledge was relegated: the division between mind and body, and between thought and 
senses. Wisdom was depersonalized and turned into technique, not knowledge. The project of modern reason arrived in Mexico through the criollos who imposed it as a tool of domination, based on the concept of race but which was consolidated in the country thanks to the project of progress and development after the revolution.

2. Culturicide: it was the elimination of life forms prior to the colonial era: forms of relationship and worlds of action, causing that for the human beings of our society, the traditions and ways of acting of the community lost their meaning. The indigenous world view vanished from the horizon of prosperity, relegated to a world of superstition and knowledge.

3. Feminicide: patriarchy came to our continent with colonization, a patriarchy that has meant, and unfortunately continues to do so, the death of thousands of women all over the planet, women who are conceived as objects of domination, like everything that does not fit in the schemes of dual ontology. The representation of patriarchy in the exploitation and domination of indigenous women is clear, that is why the voice that rises with Zapatismo in 1994 acquires a feminine tone as a symbol of resistance and therefore the desires of its death become paradigm to continue the domination.

4. Ecocide: it was the way to stop conceiving nature as an active subject and transform it into an object of domination. Death was erected over life, a paradigm was constructed that put our very existence at risk. Ecocide represents the rupture and dissociation of the human being from himself.

5. Genocide: during the conquest, genocide was not only a historical event, but the first paradigm of violence under which the entire "new society" of Mexico would be based. From 1521, women, nature, people, all became objects of domination; life ceased to be an end in itself to become the means for accumulation.

6. Deicide: the religiosity and belief of the Mexican people is marked by a double guilt, on the one hand the guilt of the sin of Christianity and on the other the guilt of not understanding life under the designs of a single god. When they killed the indigenous gods, they killed a 
way of relating them to the world, leaving in their place a void that is sometimes filled with guilt and another with ambition: detachment and despair.

These six paradigms have been presented in this research as the foundations of Mexican society that allow us to understand the social dynamics, and even more the structural and cultural violence in the country.

Also in the first chapter there was a historical tour of the hand also of the official statistics and two life stories that allow deepening on the conditions of the country, but have also been presented as a proposal for peace building from the academic field to work constantly in an interdisciplinary way.

In the second chapter the basic concepts on which this investigation rests were analyzed: peace, violence and politics.

From the elements to be highlighted in the analysis of the concepts we can observe that, if peace is studied only from violence, it is granted an ontological status that is strongly damaging to the construction of peace, since it is no longer considered an accident. However, according to Hannah Arendt (1984) it is necessary to grant that ontological status to evil (injustice and violence) if it is to be understood and minimized in society.

Second it is observed that peace is a process and therefore it can not have a closed definition, it is a power of conflict, which is also a process, which is constructed through tools such as intersubjective dialogue.

Third, it was established that peace can not be guaranteed by power, as presented in the European State-Nation vision, since it is about the relationship between individuals and the capacities that emerge from this encounter, in this way peace is used in this research as the process of dialogue that arises from the encounter between human beings and that privileges harmony, empathy and intersubjectivity. 
On the other hand, two interesting characteristics stand out in the analysis of violence. On the one hand, as Arendt asks, the need for violence to have an ontological status that gives meaning to its existence and this status is granted by the Arendtian conception of evil (injustice and violence). In this way all the irrational elements are removed to conceive it as a way of doing something. Thus, its next characteristic arises, and it is that violence is always instrumental, accidental, it depends on others to exist and on who does it directly, it depends on power understood as domination.

In addition, it has been argued that violence appears in the world in three ways: directly, structurally and culturally. Of these three, the most dangerous, because it is the foundation of the other two, is cultural violence, since that is where the paradigms identified in the first chapter rest.

Finally, the concept of politics within Arendtian thought has been quickly analyzed to show two important issues: first, the historical moment in which she discovers the great transformation of politics, which is the 16th century with the play The Prince of Machiavelli, the same century of the conquest of America and therefore of the expansion of the model of domination in the whole world, as already argued in the first chapter. And second, politics is the place where ethics appears, where it is possible to talk about peace, and this lays the foundation for building the bridge of understanding between decolonial thinking (specifically the ontological turn of studies of the pluriverse) and the Western thinking.

It is in the third chapter where the currents of thought that underlie research are deeply analyzed: decolonial thinking and philosophy for peace, and in turn the currents that have influenced it (philosophy of liberation, dependency theory, development studies), with the intention of building bridges of understanding between both that allow understanding the ontological and political proposal of the indigenous resistances of the Mexican southeast. 
On the one hand, it was pointed out how decolonial thinking has great differences with postcolonial thought both in the form and in the background, from the geographical situation that identifies both currents of thought; decolonial thinking speaks from a Latin American reality while postcolonial thought develops more in what is known as "East", and although this difference is not exclusive or limiting, it does reflect important differences. Secondly, it was identified how postcolonial thought emerges directly from French poststructuralist thought and therefore speaks from the construction of hegemonic discourses of domination (which encompasses all regions, not just the East).

In the third place, it was clarified how in spite of the differences between the two currents of thought, both are necessary for a better understanding of the realities in the pluriversal ontology, although for this investigation priority was given to decolonial thinking, for its marked work activist and his closeness to the resistance in Mexico.

Another of the outstanding elements of decolonial thinking is the work of the group Modernity / Coloniality / Decoloniality where authors such as Walter Mignolo, Aníbal Quijano, Arturo Escobar and others can be found.

This group was taken as the most important academic representation of decolonial thinking as part of a new framework of interpretation that will be known as the de-colonial turn, which conceives the indignation before the colonial horror as an origin, besides understanding modernity as a point of historical inflection where the thought of resistance emerges. Likewise, it tries to go through history, analyze politics and ethics, not from the dominant discourses and the European reality, but from the vanquished, from the dominated, from the nobody.

Finally, on decolonial thinking, it was explained how it has roots in two important studies of the twentieth century, the theory of dependency and development studies. Thanks 
to these, it has a clear approach to the reality of Latin America and the great challenges it has faced in economic and neo-colonization matters in recent decades.

The third chapter also analyzed the philosophy for peace, proposed by Vicent Martínez Guzmán, in whom rests the framework of interpretation of peace of my work. The way that led its author to the construction of this current of thought was explained, however, the only and Eurocentric Western ontology in which it is framed was established as limiting. Especially the foundations were criticized by Kant and Habermas who conceive modernity as an unfinished project, but who continue to put European values at the center of rationality. It is in the fifth chapter that a proposal of foundation is made that exceeds the principles of Kantian philosophy.

In this chapter both decoloniality and the philosophy for peace seem somewhat remote and in some scenarios as antagonistic currents, however, thanks to the epistemological turn of Martínez Guzmán and the similarities with the decolonial turn, both seek the construction of a new world, fair and with diverse cosmologies. Thanks to this intention in both and to the phenomenology in the thought of Hannah Arendt in dialogue with Enrique Dussel, I propose the foundation for a bridge of understanding between both that will allow the understanding of the thought of indigenous resistances.

Arendt's proposal to stop focusing metaphysics on the Aristotelian substance or the Kantian noumenon, closely following the phenomenology of Husserl, and changing it by the relationship, allows, on the one hand, to understand that the world is not only what precedes us, but it makes sense thanks to our relationships, and on the other hand, these relationships are what will shape the reality we live, therefore, if we change our way of relating, we change the world. 
On the other hand, Dussel's concept of proxemia, that sees how the relationship is not only constitutive of the world, but is also constitutive of our own existence as it is original, opena the way to understand the community as the path of existence of human beings.

Both phenomenology and proxemia in Dussel's Philosophy of Liberation are the pillars of this bridge of understanding between philosophy for peace (Western thought) and decolonial thinking and both can thus understand the ontological proposal of the pluriverse and the political life of communality that is analyzed in the fifth chapter of this investigation.

In the fourth chapter an analysis of the statistics has been made, accompanied by a life story and the history of the EZLN as a nonviolent movement. The famous discussion between Hannah Arendt and Frantz Fanon about violence has been used.

There are three important elements of this chapter, the first, the need to incorporate a qualitative narrative about the way of life in Chiapas, at least superficially, to complement the cold reality of statistics, as it was done in the first chapter with the current situation in Mexico. In this regard, it can be concluded that Chiapas's reality is quite complex, since it is not only a perfect example of internal colonization and all consequences (racism and classism mainly) but it is the scene of a new way of relating.

The resistance in Chiapas shows the dignity of the indigenous communities, but also the need that many mestizos and peasants have to find new bases for their actions and thinking. In the same way, it is a place where coexistence between nationals and foreigners preserves the colonial hierarchy and at the same time transforms it. All this makes reality complex to analyze from a purely academic field.

The second element to be highlighted in this chapter is the prerequisite that Hannah Arendt puts to the use of nonviolence, making direct reference to what happened in the Nazi concentration camps of World War II. Here the author shows how, despite the fact that 
violence can never achieve political objectives, it can create, in exceptional cases where injustice is extreme, the public space necessary for the use of nonviolence to be possible. This public space must, at least, give recognition of the existence of the other, if this minimum is achieved, any nonviolent strategy is impossible. As it was argued, in the case of the EZLN, that recognition was achieved; the visibility they achieved allowed their thinking to be known, and they could continue on their path towards autonomy.

Finally, it is important to point out that under the requirements that Vicent Martínez Guzmán establishes, the Zapatista movement can be considered as a nonviolent movement capable of creating a culture of peace, even though it has resorted to weapons for twelve days. The foregoing shows that the uprising did not put an end to the original violence, but created the space necessary for nonviolent struggle. That within their actions there is a clear commitment to the normative reconstruction of institutions, stories, beliefs, ideological options, metaphors, etc. that show the original competences of living beings to live in peace. That his proposal bets for a reorganization of the form of government that exceeds the National State and is committed to the struggle for the recognition of collective identities that go beyond the dominant Eurocentric thinking.

The last chapter includes the ontological proposal that emerges from the struggle in indigenous communities; a theorization that, in addition to questioning the fundamental principles of European thought, proposes a different philosophical and academic task.

The studies of the pluriverse, where the study of relational ontology is compared to that of World One, arises both from the critique of development and the defense of territories in various regions of the world, especially in Latin America.

By way of conclusion we can say that the ontological turn proposed by these studies seeks the recovery of non-hegemonic knowledge, as well as a foundation where power 
relations can be transformed from the foundations. It shows that nature is not an accumulation of irrefutable facts, but that it is one more entity, affected by the relations it maintains with the other entities of its world, eliminating in this way the hierarchical relationship between subjects and objects and the construction of binaries on which is based the ontology of World One.

The World One is the way in which pluriversal studies present the Eurocentric rationalist world and that dominates, up to our days, political, scientific and ethical discourses. It is a totalizing world that imposes itself against other worlds with a category of truth and reality, but of which it lacks even under its own principles, as shown by the constant changes of scientific laws.

Inspired by the critique of postcolonial studies and how they influenced developmentcritical studies, the dual ontology of the One World is presented, as a world in which domination prevails and man is the reason (patriarchal masculine rationality) as the center. Individuality is privileged over community, science as guarantor of all knowledge and therefore the existence of ONE reality is legitimized and finally the economy is naturalized. These beliefs cause the relationships that enact this world to build scenarios of domination and excessive violence as extractive projects that are carried out mainly in indigenous communities.

In front of this world, the world of relational ontologies appears, where relationships between the human and the non-human are formed and which seek sustainability over profits and where the search for truth is abandoned by the search for meaning in community. This is how the political ontological proposal of communality appears, which is the enunciation of the daily life of the communities in struggle, against the dual ontology and the life that can only be lived in those regions and that is ineffable from the academic perspective. 
Finally, in this chapter it has been proposed how to base the philosophy for peace not in Kant, but on the pluriversal studies and especially in the relational ontology which allows to advance in a proposal of construction of peace not only more inclusive, but overcomes the universality that still feels that it is based on Kant.

In summary, this thesis presents three questions as a peacebuilding proposal: the first, the necessary interdisciplinary analysis of conflicts, addressing a historical framework, a theoretical one and another necessarily experiential and qualitative (life story), in this way it is possible to base the analysis in the relationships of the actors (entities) involved. The second issue is closely related to the Zapatista proposal and has to do with the creation of "a world where many worlds fit", that is, through pluriversal studies (in the epistemological field) to work on showing the different relationships between worlds that exist and how they affect in this sense the politics and life of the beings that inhabit it. The third question refers to the construction of community in different worlds, however, there are scenarios where the community is not viable since the individualistic conformation of society is so ingrained that it practically makes its development impossible.

In this scenario is the Mexican society, based on the paradigms of violence that have been detected in the historiographical analysis, which make it practically impossible to transform them into communality. However, it is important to emphasize that in societies that are submerged in violence, it is possible to establish cooperation and collaboration, and, therefore, it is possible to build a community, which, although it remains rooted in the belief of the individual, opens a crack in the World One.

In this sense, the history of Zapatismo offers the opportunity to see how it is possible to leave scenarios of domination without the permanent use of violence, but also the importance of time and commitment in the consolidation of community and autonomy. 
In addition, it shows the non-hegemonic education based on three pillars: recognition, dialogue (collective reflection) and active listening are the basic elements that the Zapatistas have used especially in the last five years of work.

Thus, this thesis establishes as a proposal for the construction of peace, based on the ontological turn and the political-communal experience of Zapatismo, the elimination of individual as the center of societies, the scientific as the scale to measure knowledge, the real as a tool of hierarchy, as well as the imposition of a way of being, doing and thinking. In addition, I propose the relational ontology aimed at communality as the way to build plural societies where peace appears and is practiced every day. From the philosophical point of view, I likewise propose pluriversal studies as a methodology that would help to take away the universalist character that classical philosophy has had up to our days and in this sense I approach the proposal of philosophy with children that understands it as a transformation tool.

Following this path and as future lines of research, I intend to enter the world of nonhegemonic education where art and collective reflection are prioritized, to the way in which Zapatismo approaches science and art in its annual festivals CompARTE y ConCIENCIAS, asking: are we paceworkers capable of laying the foundations of a community for peace through art? 


\section{Bilbliografía}

ARISTÓteles (2000): Metafísica, México, UNAM

Abaggnano, nicola, et al (2007): Diccionario de Filosofia, México, Fondo de Cultura Económica.

ARENDT, HANNAH (2013) [1963]: Sobre la Revolución Madrid, Alianza Editorial.

○ (2011) [1970]: Sobre la violencia, Madrid, Alianza Editorial.

○ (2006) Diccionario filosófico, Barcelona, España, Herder

○ (2005) [1958] La condición humana, Barcelona, España, PAIDOS

○ (2002) [1951]: Los orígenes del totalitarismo, Tomo III, Madrid, España TAURUS.

- (2002b) [1978\}: La vida del espíritu, Barcelona, España, PAIDOS.

○ (2000) [1963] Eichmann en Jerusalén: un estudio sobre la banalidad del mal, Barcelona, LUMEN.

$>$ Ávila, Alfredo y Luis JaUREGUi, (2014): «La disolución de la monarquía hispánica y el proceso de independencia» en Velázquez García, Erik...[et.al] 2014: Nueva historia general de México, México, El Colegio de México.

$>$ Aspe Armella, Virginia (2016): «Sobre violencia, cultura y reconciliación en México», No. 12, México, Open Insight,

> Bautista, Rafael (2011): ¿Qué significa mandar obedeciendo? México, Rebelión.

Beolegui, Carlos (2003): Historia del pensamiento filosófico latinoamericano. Una búsqueda incesante de la identidad Bilbao, Universidad de Deusto. 
Blaser Mario, JuAn Ricardo Aparicio (2015): «La ciudad letrada y la insurrección de saberes subyugados en América Latina» en Leyva, Xochitl, Camila Parcal, Axel Köhler coord 2015, 104-134, Tomo I.

D Castro Gómez, Santiago (2008): La hybris del punto cero, Venezuela, Fundación Editorial El Perro y la rana.

Cortina, Adela (2010): Justicia cordial, Madrid, Mínima Trotta.

$>$ Cardoso h, Fernando y Enzzo Faletto, (1968): Dependencia y desarrollo en América Latína, Buenos Aires, CEPAL.

> Descartes, Rene (2001) [1637]: Meditaciones, México, Porrúa,

$>$ De las Casas, BARTOlomé (2004) [1594]: Brevísima relación de la destrucción de las Indias, Madrid, Bilbioteca Edaf.

$>$ De Sousa Santos, Boaventura (2015): «Prólogo» en Leyva, Xochitl, Camila Parcal, Axel Köhler coord 2015, 12-21, Tomo I.

$>$ Dussel, EnriQue (2008): Filosofia de la liberación, México, Fondo de Cultura Económica.

○ (2007): Política de la Liberación. Historia mundial y crítica, España, Trotta.

$>$ Echenique March, Felipe I. y García Cue, Alberto (2009): Miguel Hidalgo y Costilla. Documentos de su vida: 1750-1813, México, Instituto Nacional de Antropología e Historia.

> Escobar, ARturo (2015): Sentipensar con la tierra. Nuevas lecturas sobre desarrollo, territorio y diferencia. Chiapas, Ediciones Cideci. Unitierra.Chiapas.

$>$ Esteva, Gustavo (2016): «Para sentipensar la comunidalidad», Bajo el volcán año 15, número 23, septiembre febrero 2016. 
FERnANDO, Galindo (2004: Mundo común y politica: el espacio de la acción en Hannah Arendt, México DF, UNAM.

> Frantz, FAnON (1961): Los condenados de la tierra. Buenos Aires, Taxalaparta.

Fraustro, Salvador (coord.) (2016): Los doce mexicanos más pobres. El lado B de la lista de millonarios., OXFAM, México, Planeta.

> Galtung, Johan (1998), Tras la violencia, 3R: reconstrucción, reconciliación, resolución. Afrontando los efectos visibles e invisibles de la guerra y la violencia. Guernika, Guernika Gogoratuz.

$>$ Galeano, EduARdo (1989): El libro de los abrazos, Uruguay, Siglo XXI.

> GARCÍA LEÓN, ANTONiO (1985): Resistencia y utopia: memorial de agravios y crónicas de revueltas y profecias acaecidas en la Provincia de Chiapas durante los últimos quinientos años de su historia, México, Ediciones Era.

> GARCÍA MARTínez; BernARdo (2014): «Los años de expansión», en Velázquez García, Erik...[et.al] 2014: Nueva historia general de México, México, El Colegio de México.

> González Casanova, Pablo (1969): La democracia en México, México, ERA.

○ (1979a): Imperialismo y liberación. Una introducción a la historin contemporánea de América Ldtina. México: Siglo XXI Editores.

○ (1979b): Sociologia de la explotación. México: Siglo XXI Editores, 1979b.

○ (2003): «Colonialismo interno. Una redefinición» [en línea]. Revistn Rebeldzd (2003). Disponible en: <wwwrevistarebeldia.org/O12/ out06.html.Rebeldía>.

Gilly, Adolfo, ET AL., (1995), Discusión sobre la historia, México, Taurus.

$>$ Guitierrez Chong, Natividad (2010): «Los pueblos indígenas en los nacionalismos de Independencia y liberación: el colonialismo interno revisitado» en 
María Luisa Rodríguez-Sala... [et al.] Independencia y revolución: contribuciones en torno a su conmemoración, 117-150, México: UNAM, Instituto de Investigaciones Sociales.

> Herceg Santos, José (2011): «Filosofía de (para) la Conquista. Eurocentrismo y colonialismo en la disputa por el Nuevo Mundo», Atenea, [en linea] (503), pp.165186. Disponible en: https://www.redalyc.org/articulo.oa?id=32819393009

> Hernández, Esquivel (2015): Desigualdad extrema en México, México. OXFAM IGNOLD, TIM (2000): The perception of enviroment, Londres, Routledge.

JimeneZ-Bautista, Francisco (2012): «Conocer para comprender la violencia: origen, causas y realidad», Convergencia. Revista de Ciencias Sociales, vol. 19, núm. 58, Universidad Autónoma del Estado de México, México

KAnt, ImannUel (2001): Crítica de la razón práctica, Madrid, España, Alianza.

> Latour, Bruno (2005): Reassembling the Social: An Introduction to ActorNetwork-Theory, Oxford, Oxford University Press.

Lederach, John Paul (2007): La imaginación Moral. El Arte y el Alma de la Construcción de la Paz, Bilbao, Gernika Gogoratuz.

- (2000): El abecé de la paz y los conflictos. Educación para la paz, Catarata, Madrid.

- (1997): Building Peace: sustainable reconciliation in divided societies, Washington, DC.

> Leyva, Xochitl (2015): «La obra que camina» en Leyva, Xochitl, Camila Parcal, Axel Köhler coord 2015, Prácticas Otras de conocimiento. Entre crisis, entre Guerras, 9-15, Tomo III, San Cristobal de las Casas, Cooperativa Editorial Retos. 
MARTínez GuZMÁn, Vicent (2001), Filosofía para hacer las paces, Barcelona, Icaria.

- (2005), Podemos Hacer las Paces. Reflexiones éticas tras el 11-S y el 11-M, Bilbao: Desclée de Brouwer

Maldonado Torres, Nelson (2008): La descolonización y el giro des- colonial. Tabula Rasa [online]. n.9 [cited 2012-12-21], pp. 61-72.

> Mignolo, Walter (2008): La opción de-colonial: desprendimiento y apertura. Un manifiesto y un caso de estudio. Tabula Rasa [online] no. 8, pp 243 - 281.

$>$ Mora, Mariana (2008): La descolonización de la política, EUA, University of Texas at Austin.

○ (2015): «The Politics of Justice: Zapatista Autonomy at the Margins of the Neoliberal Mexican State», Latin American and Caribbean Ethnic Studies, vol. 10, issue 1 (2015) pp. 87-106 Published by Routledge

$>$ Muller, JeAn-Marie (2006): La no-violencia como filosofía y como estrategia. Barcelona, Hogar del Libro.

> Muñoz Ramírez, Gloria (2003): EZLN: 20 y 10, el fuego y la palabra, México, Rebeldía-LaJornada.

$>$ NAlda, EnRIQUe (2014): «El clásico en el México antiguo» en Velázquez García, Erik...[et.al] 2014: Nueva historia general de México, México, El Colegio de México.

$>$ Negrete Rovira, Miguel del Castillo (2017): La distribución y desigualdad de los activos financieros y no financieros en México, México, CEPAL 
OMAR, Sidi (2006): Los estudios Post-coloniales: Hacia un nuevo proyecto para la crítica y la transformación cultural, Tesis de doctorado, Castellón, Universitat Jaume I

> PAtch, Robert W. (2003). «La rebelión de Jacinto Canek en Yucatán: una nueva interpretación». Desacatos, (13), 46-59. [Versión en línea: 26 de noviembre de 2018 http://www.scielo.org.mx/scielo.php?script=sci arttext\&pid=S1607050X2003000300004\&lng=es\&tlng=es.]

QuiJano, A. (2000). Colonialidad del poder, eurocentrismo y América Latina. En E. Lander (Ed.), La colonialidad del saber, eurocentrismo y Ciencias Sociales (pp. 201246). Caracas: ediciones Faces, UCU.

QuiJanO, A. (2005). El "movimiento indígena" y las cuestiones pendientes en América Latina. Revista Tareas, (119), 31-62.

$>$ Reale, Giovanni y Dario Antiseri (2007): Historia de la Filosofia I, Bogotá, Colombia, San Pablo

Tortosa, José MARÍA (2000): «Guerras por la identidad: de la diferencia a la violencia», en Aguirre, M. y otros (eds.) (2000): Globalización y Sistema Internacional. Anuario CIP 2000, Barcelona, Icaria, 99-112.

SAID, E. W. (1978): Orientalism, London, Penguin Books

> Salazar Bondy. Antonio (1968): ¿Existe una filosofía de nuestra América?, México, Siglo XXI.

Saez de Heredia Alzate, Ramón, (2000): Resolución del conflicto. Programa para Bachillerato y Ed. Secundaria, Tomos I y II, Bilbao, Ediciones Mensajero. 
Schopling, GeOrge (2001): «Ethnic and civic nationalism (Hans Kohn's typology)». En Enycl'opaediaofNationalirm, editada por Athena S. Leoussi. Londres: New Brunswick/Transaction Publishers.

> Shiva, VAdana (1995): Abrazar la vida: mujer, ecología y supervivencia, España, Horas y horas.

Spivak, Gayatri (1993): «Can the Subaltern Speak?» en P. Williams y L. Chrisman (eds.), Colonial Discourse and Post-Colonial Theory, Hemel Hempstead: Harvester Wheatsheaf.

$>$ Stavenhaguen, Rodolfo (1968). «Clases, coloniaiismo y aculturación. Ensayo sobre un sistema de relaciones interétnicas en Mesoamérica». Cuadernos del Seminako Integrnhón Social Guatemalteca 19, cuarta serie.

- (1973) Las clases sonales en las sociedades agrarias, 5ª ed. México: Siglo XXI Editores.

VÁzQuez Vidal, Miriam Arely (2013): El origen de la violencia: un estudio sobre el poder como consenso y el poder como dominación. Universitat Jaume I, España-

○ (2011): El origen del mal: un estudio sobre los gobiernos totalitarios. Universidad Panamericana. México

VelázQuez García, ERIK (2014): «Los habitantes más antiguos del actual territorio mexicano» en Velázquez García, Erik...[et.al] 2014: Nueva historia general de México, México, El Colegio de México.

VILloro, Luis (2014) [1987]: Los grandes momentos del indigenismo en México, México, Fondo de Cultura Económica.

○ 1978: «Filosofía y dominación», No. 12, México, Nexos. 
$>$ Young-Bouhl, Elisabeth (2006): Why Arendt Matters, EUA, Yale University Press

$>$ Zagal, Héctor y Sergio Aguilar Álvarez, ZAGAL, (1996): Límites de la argumentación ética en Aristóteles, México DF, Publicaciones Cruz.

Z Zavala, Silvio (1947): La Filosofía Política en la Conquista de América. México. Fondo de Cultura Económica.

\section{Páginas web:}

CONEVAL: Consejo Nacional de Evaluación de la Política de Desarrollo Social Comunicado de prensa del número 09 (con base en la información proporcionada por el Instituto Nacional de Estadística y Geografía sobre la evolución de la pobreza de 2010 - 2016 el 30 de agosto de 2017 en la Ciudad de México.

> Enlace Zapatista: http://enlacezapatista.ezln.org.mx/ (Consulta 20 de agosto de 2018).

$>$ Índice de Paz Global (Global Peace Index) Institute for Economics and Peace, Centre for Peace and Conflict Studies, Universidad de Sydney, [versión en línea: https://www.datosmacro.com/demografia/indice-paz-global (31 de diciembre de 2017)]

$>$ Real Academia Española (2001). Diccionario de la lengua española (22 ed.) Consultado en http://www.rae.es/rae.html 